\title{
IUCN
}

\section{Oil palm and biodiversity}

A situation analysis by the IUCN Oil Palm Task Force Meijaard, E., Garcia-Ulloa, J., Sheil, D., Wich, S.A., Carlson, K.M., Juffe-Bignoli, D., and Brooks, T.M.

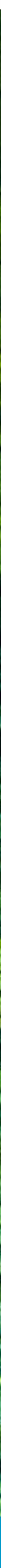




\section{About IUCN}

IUCN is a membership Union uniquely composed of both government and civil society organisations. It provides public, private and non-governmental organisations with the knowledge and tools that enable human progress, economic development and nature conservation to take place together.

Created in 1948, IUCN is now the world's largest and most diverse environmental network, harnessing the knowledge, resources and reach of more than 1,300 Member organisations and some 10,000 experts. It is a leading provider of conservation data, assessments and analysis. Its broad membership enables IUCN to fill the role of incubator and trusted repository of best practices, tools and international standards.

IUCN provides a neutral space in which diverse stakeholders including governments, NGOs, scientists, businesses, local communities, indigenous peoples organisations and others can work together to forge and implement solutions to environmental challenges and achieve sustainable development.

Working with many partners and supporters, IUCN implements a large and diverse portfolio of conservation projects worldwide. Combining the latest science with the traditional knowledge of local communities, these projects work to reverse habitat loss, restore ecosystems and improve people's well-being.

www.iucn.org

https://twitter.com/IUCN/

\section{About IUCN Oil Palm Task force}

The IUCN Oil Palm Task Force (OPTF) aims to inform the debate on the sustainability and responsible management of palm oil and give guidance to the IUCN about its policies and strategies that affect or are affected by palm oil. We aim to make use of the IUCN's extensive knowledge networks on biodiversity and environmental issues, social, economic and cultural issues, and policy to comprehensively guide thinking on the complex issues of agro-industrial and smallholder oil palm in the world's tropical regions.

Our objectives in the period of 2017-2020 are to:

1. Conduct a situation analysis to provide a more comprehensive understanding of the reality of oil palm sustainability, and what could be done to improve it; and 2. Act as an authoritative advisory body on oil palm and how this relates to global sustainability objectives, and an intermediary between the oil palm industry, the IUCN network, and the other stakeholders in oil palm discussions.

The Oil Palm Task Force was formally established in 2017.

https://www.iucn-optf.org/ 


\section{Oil palm and biodiversity}

A situation analysis by the IUCN Oil Palm Task Force Meijaard, E., Garcia-Ulloa, J., Sheil, D., Wich, S.A., Carlson, K.M., Juffe-Bignoli, D., and Brooks, T.M. 
The designation of geographical entities in this book, and the presentation of the material, do not imply the expression of any opinion whatsoever on the part of IUCN concerning the legal status of any country, territory, or area, or of its authorities, or concerning the delimitation of its frontiers or boundaries.

The views expressed in this publication do not necessarily reflect those of IUCN.

This publication has been made possible in part by funding from IUCN project "Global Commons: Solutions for a Crowded Planet", funded by the Global Environment Facility.

Published by: $\quad$ IUCN, Gland, Switzerland

Copyright: 2018 IUCN, International Union for Conservation of Nature and Natural Resources Reproduction of this publication for educational or other non-commercial purposes is authorised without prior written permission from the copyright holder provided the source is fully acknowledged.

Reproduction of this publication for resale or other commercial purposes is prohibited without prior written permission of the copyright holder.

Citation: Meijaard, E., Garcia-Ulloa, J., Sheil, D., Wich, S.A., Carlson, K.M., Juffe-Bignoli, D., and Brooks, T.M. (eds.) (2018). Oil palm and biodiversity. A situation analysis by the IUCN Oil Palm Task Force. IUCN Oil Palm Task Force Gland, Switzerland: IUCN. xiii + 116pp.

ISBN:

978-2-8317-1910-8 (PDF)

978-2-8317-1911-5 (print version)

DOI:

https://doi.org/10.2305/IUCN.CH.2018.11.en

Cover photo: $\quad$ An aerial view of an oil-palm plantation. 2seven9/Shutterstock.com

Creative direction, design, and layout: Nadine Zamira Syarief, Abiyasa Adiguna Legawa, Dwita Alfiani Prawesti

Available from: $\quad$ IUCN (International Union for Conservation of Nature)

Science and Economic Knowledge

Rue Mauverney 28

1196 Gland

Switzerland

Tel +41229990000

Fax +41229990002

Erik.MEIJAARD@ssc.iucn.org

www.iucn.org/resources/publications

Text printed on 100gsm silk with the cover on 300gsm silk. All materials are FSC Mix 70\%. 


\section{Table of contents}

Foreword

Executive summary vii

Contributors $\quad$ X

Acknowledgements $\quad$ xi

List with tables, figures, boxes $\quad$ xii

1. Introduction 1

1.1 The IUCN Oil Palm Task Force 3

1.2 Scope of the situation analysis 3

1.3 Oil palm, some facts and figures $\quad 4$

1.3.1 What is oil palm?

1.3.2 Where is oil palm currently grown?

1.3.3 How is oil palm grown and what happens to palm oil? $\quad 8$

1.4 Oil palm and international agreements 16

2. Oil palm impacts on biodiversity 18

2.1 Deforestation and oil palm expansion $\quad 20$

2.2 Impacts on species $\quad 23$

$\begin{array}{ll}2.3 \text { Biodiversity values in smallholder oil palm plantations } & 29\end{array}$

2.4 What are the less-studied ecosystem impacts of palm oil? 30

2.4.1 Greenhouse gas emission from oil palm development 31

2.4.2 Land clearing with fire and resulting smoke and haze 32

2.4.3 Local climate impacts 32

2.4.4 Volatile organic compounds from oil palm 33

2.4.5 Water quality in and downstream from oil palm 33

2.4.6 Changes in soil quality following oil palm development 34

2.4.7 Spill-over of oil palm pests

2.4.8 Invasive aspects of oil palm cultivation 34

2.5 How does oil palm compare with other major impacts to biodiversity? 36

2.6 What are the knowledge gaps? 41

3. Environmental governance to mitigate oil palm impacts to biodiversity 42

3.1 Leading conservation strategies 44

3.2 The mitigation hierarchy 45

3.3 Environmental governance initiatives that aim to address conservation concerns 46

3.3.1 Certification standards $\quad 46$

3.3.2 Corporate commitments to no deforestation 48

$\begin{array}{ll}\text { 3.3.3 Regulatory requirements } & 50\end{array}$

3.3.4 Jurisdictional and landscape approaches

3.4 Comparing environmental governance initiatives $\quad 54$

3.4.1 Conservation scope 54

3.4.2 Complementarity between environmental governance initiatives 58

3.5 Are environmental governance initiatives effective? 60

3.5.1 What are the impacts of environmental governance initiatives on biodiversity conservation? 60

3.5.2 Unintended consequences of initiatives and pledges 64

3.5.3 Challenges to implementation $\quad 65$

$\begin{array}{ll}3.6 \text { Knowledge gaps } & 67\end{array}$ 
4. The future of oil palm 68

4.1 What is the future demand for palm oil?

4.2 What is the potential impact of oil palm expansion in forest frontiers?

4.2.1 Increasing yield 71

4.2.2 Oil palm expansion and its potential impacts on biodiversity

4.2.3 Oil palm expansion into savanna and shrubland 75

$\begin{array}{ll}4.3 \text { Growth of the oil palm sector in Africa } & 77\end{array}$

4.4 Growth of the oil palm sector in the Americas 80

4.5 What are the knowledge gaps? 81

5. Conclusion $\quad 82$

$\begin{array}{lc}\text { References } & 86\end{array}$

Appendix 1. The IUCN Oil Palm Task Force 104

Appendix 2. Global mapping industrial-scale oil palm plantations 105

Appendix 3. How much global deforestation is really due to palm oil? 107

Appendix 4. Snake species that benefit from oil palm 113

Appendix 5. Current practices to mitigate impacts to biodiversity?

Appendix 6. Expansion into frontiers - a theoretical model of impacts to biodiversity? 115 


\section{Foreword}

Palm oil is a highly controversial issue. Many conservation practitioners, scientists, and members of the public consider it one of the greatest threats to tropical biodiversity. Many others, especially palm oil producers, governments, and communities that grow the crop, rely upon this palm for its high yields and financial returns. Consequently, there are different viewpoints about the interaction between sustainable land use and oil palm cultivation.

Ultimately answers about oil palm sustainability require value judgements, but these need to be underpinned by evidence. This report provides objective, and science-based evidence to support better guidance for the palm oil industry, and for the organizations and governments that develop policies and standards for palm oil.

This report offers novel datasets and insights. It presents the first comprehensive map of all globally planted industrial-scale oil palm, and reviews deforestation statistics in relation to oil palm development. An overview of current sustainability policies and initiatives indicates the extent to which these have managed to reduce impacts of oil palm development on biodiversity. Based on these assessments, the report considers what the future of palm oil could look like and what this could mean for global conservation efforts.

One common thread runs through this report, which is that there is strong evidence that palm oil is here to stay. Given a certain global demand for vegetable oils, and the fact that the oil palm produces these oils more effectively than any other crop, there appears to be no straightforward way to phase out palm oil without incurring potentially more significant environmental and social impacts elsewhere from compensatory expansion of alternative oil crops

The report highlights a number of remaining knowledge gaps, related to socio-economic, cultural and financial impacts and provides a series of recommendations for further research in these areas. These gaps will need to be addressed before we can provide a full assessment of best practices towards improving the broader sustainability context of palm oil.

This assessment is an important step forward, one that we hope will guide palm oil producing companies and investors, governments, nongovernmental organisations, and the public towards decisions that generate improved outcomes for life on Earth.

Inger Andersen

Director General IUCN

Prof. Jon Paul Rodríguez

Commission Chair of SSC

Angela Andrade

Commission Chair of CEM

Kristen Walker-Painemilla

Commission Chair of CEESP 


\section{Executive summary}

This report has been written by the IUCN Oil Palm Task Force in response to IUCN Resolution WCC2016-Res-061-EN requesting "a situation analysis of the implications for biodiversity conservation from the expansion of oil palm, and to review and define best practices in the industry". The Situation

\section{Analysis primarily focuses on oil palm in the context of biodiversity conservation based} on literature published before 31 January 2018, and aims to provide a constructive pathway to addressing sustainability challenges in the palm oil industry. A draft version of this report was reviewed by 43 external reviewers from non-governmental organizations, academic institutions and people working in the palm oil industry, who provided some 600 comments that were then incorporated into a revised version.

This report does not assess the social and economic implications of palm oil production and expansion but will refer to these when they are likely to have an impact on biodiversity conservation. Through identification of key knowledge gaps, the Situation Analysis will also provide direction to the Oil Palm Task Force in terms of seeking to address these knowledge gaps in the remainder of the 2017-2020 Quadrennium.

\section{Chapter 1 Introduction}

Chapter 1 provides a brief summary of the palm oil production processes, where palm oil is produced and the different scales of production, from smallholders to industrial-scale operators. Based on a new global analysis, an updated map of global oil palm plantings is presented. As of October 2017, the total planted area of industrial-scale oil palm is estimated at 18.7 million hectares, but in addition to this, large areas of smallholder oil palm exist, which cannot currently be reliably mapped at a global scale. In some countries, smallholder plantings are estimated to constitute up to $94 \%$ of the total plantings, so the total area of planted oil palm is significantly larger than the 18.7 million hectares presented here. Chapter 1 finally discusses how the issue of oil palm sustainability relates to international agreements such as the Convention on Biological Diversity and the Sustainable Development Goals.

\section{Chapter 2 Oil palm impacts on biodiversity}

Chapter 2 reviews the past impacts of oil palm development on biodiversity. Oil palm has been locally responsible for high deforestation rates. As much as $50 \%$ of all deforestation on the island of Borneo between 2005 and 2015 was driven by oil palm development. The current review indicated that in both Central America and West Africa between 1972 and 2015, oil palm made up 2-3\% of forest loss. Where oil palm replaces tropical forest, the negative impact on biodiversity is significant. Conversion for oil palm has played a major role in the decline in species such as orangutans. However, some species, such as various pigs and snakes can, benefit from the presence of oil palm. Because oil palm is a long-lived crop, in mixed landscapes of oil palm and forests, older oil palm plantings can play some role in maintaining ecological connectivity between populations of forest species. This chapter briefly reviews other impacts of oil palm development, including emission of greenhouse gases, the association with land burning and regional haze, local climate change, water quality issues, and pest spill-over effects. We conclude that, as one of the larger drivers of deforestation (behind cattle ranging, and local and subsistence agriculture), oil palm development has significant negative impacts on global biodiversity. Given the growing global demand for vegetable oils, and the fact that oil palm produces much more oil per area unit than other oil crops, a shift from palm oil to other oil crops, does not guarantee a net positive outcome for biodiversity. 


\section{Chapter 3 Environmental governance to mitigate oil palm impacts to biodiversity}

Chapter 3 describes current governance initiatives that aim to address impacts of oil palm development on biodiversity. These range widely from government regulations to voluntary actions. The most common strategy used by these initiatives is to avoid the conversion of forests and other areas identified as important for biodiversity. Much effort has gone into developing tools to define and identify these areas, with the High Conservation Value and High Carbon Stock frameworks being the most recognized. There is at present limited evidence of the conservation effectiveness of these initiatives and tools, with few robust studies having analysed this. Those that have, indicate that these initiatives have few additional benefits compared to businessas-usual, although this may be due to the difficulty of assessing long-term and interacting effects in a rapidly evolving governance landscape. There is, however, high complementarity between current initiatives, given that they have different scopes, are aimed to be implemented at different scales, and target different stakeholders. Nevertheless, they lack harmonization (in particular between government and voluntary policies) and their implementation is limited by the low demand for more sustainable palm oil, difficulties in produce traceability, and the lack of robust monitoring, reporting and verification processes. Chapter 3 also discusses the potential impacts of banning palm oil, which may result in negative unintended consequences and undermine conservation efforts in these landscapes.

\section{Chapter 4 The future of oil palm}

Chapter $\mathbf{4}$ examines the future of oil palm. As the demand for vegetable oil grows, the demand for palm oil is projected to increase too. Higher palm oil production can be achieved through increasing yields in existing production areas and through the expansion of the cultivated areas. Despite being the highest yielding oil crop per unit area, there is a large range of yields across palm oil producers worldwide. Closing this yield gaps through improved management, practices and plant material, is a real opportunity to increase total production and reduce conversion of natural ecosystems. Yet, such a strategy might also incentivize further oil palm expansion by increasing the competitiveness and opportunity costs of this commodity and, as such, its potential benefits or impacts to biodiversity are unclear. Future increases in oil palm areas remain at the centre of the sustainability debate in the sector. Much of the concern originates from the significant overlap between areas with biophysical potential for oil palm cultivation and areas of high biodiversity values, in particular in tropical Africa and America, which are thought to be the next frontier for this crop. Yet, under current conditions a widespread expansion of palm oil is unlikely. In Africa, this is because of a lack of infrastructure, uncertainty in land tenure, and low yields linked to sub-optimal biophysical conditions. While in the Americas expansion will likely be limited by low yields, high production costs, high investments costs (including land purchase), and weak demand from national markets. Opportunities for low impact expansion on biodiversity exist in countries with large areas of degraded land, such as the extensive low productivity pastures of Colombia and Brazil, although careful planning is needed to avoid negative impacts to natural grassland ecosystems in some of these countries.

\section{Chapter 5 Conclusion}

The evidence presented in this report clearly indicates that oil palm development at the expense of tropical forest reduces the diversity and abundance of most native species. From a biodiversity perspective further expansion of oil palm into native forests should be prevented. This can be achieved through demand-side policies (e.g., the new European Union policies on the use of palm oil for biofuel) or supplyside policies (e.g., strengthening environmental governance to protect forests and other ecosystems in producer countries). Further study is needed on how this can be done optimally so that not only environmental and biodiversity objectives are achieved but also social and economic ones. 


\section{Key knowledge gaps and areas of further research}

To fulfil the global demand for vegetable oils, wise decisions need to be made about the crops that are best at producing these oils, and how to minimize minimalize their social and environmental impacts. This requires an understanding of: 1. the areas where different crops could be grown; 2. the use of different oils for different purposes (e.g., biofuel, food, cosmetics etc.); 3. the way crop prices relate to each other; 4. how, for each of these crops, the societal benefits of expanding them compare with the costs; and 5. knowledge on who benefits and who loses as a result of different options. We also need to better understand the constraints on oil palm expansion to allow for more accurate forecasting of future biodiversity impacts. The most significant remaining knowledge gaps that require further research, are:

- The socio-cultural and economic impacts of oil palm development and how these vary temporally and spatially compared to environmental and biodiversity impacts;

- Spatial distribution of all vegetable oil crops and how this could change with genetic improvements (e.g., greater environmental tolerance) and analysis of how different oils can replace each other;
- Modelling of past oil palm expansion using spatial data in addition to biophysical and socio-economic data (e.g., infrastructure, labour availability, political stability, presence of competing crops) to better understand what the key constraints are to expansion, and thus to more accurately model future expansion;

- Study of the impacts of large-scale oil palm expansion in relation to local climate and water regimes, and how these impacts affect vegetation and other ecosystems;

- Study of the costs and benefits for oil palm growers of optimal biodiversity management (e.g., maintaining and effectively protecting forest set asides, prohibiting hunting and collecting of wild species), and the extent to which this can improve biodiversity outcomes;

- Study on how species survive in and move across oil palm landscapes (connectivity studies); and

- Study to characterize the biodiversity value of traditional oil palm production systems and on the feasibility, efficiency and productivity of small scale oil production systems (micromills), and the conservation benefits of such systems. 


\section{Contributors}

\section{Editors}

Meijaard, E. (Chair, IUCN Oil Palm Task Force), Garcia-Ulloa, J. (Institute for Terrestrial Ecosystems, Department of Environmental Systems Science, ETH Zurich), Sheil, D. (Faculty of Environmental Sciences and Natural Resource Management, Norwegian University of Life Sciences), Wich, S.A. (Liverpool John Moores University), Carlson, K.M. (University of Hawai'i at Mānoa), Juffe-Bignoli, D. (The Biodiversity Consultancy), and Brooks, T.M. (IUCN).

\section{Chapter authors}

\section{Chapter 1. Introduction}

Meijaard, E., Lee, J.S.H. (Nanyang Technological University of Singapore), Hance, J. (Independent journalist), Sheil, D., Gaveau, D. (CIFOR), Colchester, M. (Forest Peoples Programme), Macfarlane, N. (IUCN) and Brooks, T.M.

\section{Chapter 2. Oil palm impacts on biodiversity}

Sheil, D., Wich, S. A., Ancrenaz, M. (HUTAN), Gaveau, D., Carlson, K.M., Furumo, P. (University of Puerto Rico at Rio Piedras), Hoffmann, R. (IUCN SSC), and Meijaard, E.

Chapter 3. Environmental governance to mitigate oil palm impacts to biodiversity Garcia-Ulloa, J., Carlson, K.M., Rosenbarger, A. (World Resources Institute), Furumo, P., Struebig, M. (Durrell Institute of Conservation and Ecology [DICE], University of Kent), Slade, E. (University of Oxford), Gaveau, D., Delabre, I. (Zoological Society of London), van den Hombergh, H. (IUCN-Dutch National Committee), Hance, J. and Meijaard, E.

\section{Chapter 4. The future of oil palm}

Wich, S.A., Delabre, I., Koh, L.P. (University of Adelaide), Ancrenaz, M., Meunier, Q. (Olam International Ltd. in Gabon), Gaveau, D., Carlson, K.M., and Meijaard, E.

\section{Chapter 5. Conclusion}

Meijaard, E., Sheil, D., Garcia-Ulloa, J., Wich, S.A., Carlson, K.M., Juffe-Bignoli, D., and Brooks, T.M. 


\section{Acknowledgements}

The development of this situation analysis was supported by the IUCN project "Global Commons: Solutions for a Crowded Planet", funded by the Global Environment Facility.

We thank Rossana Merizalde for logistical support. We also thank Katarina Dian and Giannis Xirogiannis for their help in facilitating the Situation Analysis workshops, Conrad Savy, Darrel Webber, Paul Hartman, Max Hougton, Rob McWilliam, Christopher Stewart, Tom Clements, Ginny Ng and Mike Hoffmann for their help in conceptualizing the approach for developing the Situation Analysis. The development of the initial concept notes and convening process for this situation analysis was supported and funded by the Foundation Mercator Switzerland and the Zurich-Basel Plant Science Centre.

The following people have contributed to the content of the report: Molly Hennekam, Ramesh Raja Segaran, Laura Whyte, and Tasya Sarira; Edward Pollard and Malcolm Starkey (The Biodiversity Consultancy); the IUCN/SSC Bear Specialist Group; R.J. Blakemore, and Daniel Natusch (IUCN SSC Boa and Python Specialist Group); Charlotte Z. Smith (University of Hawaii).
The following individuals and respective institutions provided peer review comments: Catherine Barton, Elizabeth Bennett, Barbara Bramble, Doris Cellarius, Philippe Charrier, Elizabeth Clarke, Marcus Colchester, Izabela Delabre, Oliver Wearn, Tom Maddox, Chris Carbone, Ellen Dierenfeld, Stefano Doglio, David Ganz, Carolina Garcia, Dave Garshelis, Kwai Hin Han, Anna Heath, Richard Jakob-Hoff, Andrew Kittle, Katharina Lapin, Stanislav Lhota, Katie Major, Břeněk Michálek, Jim Moore, Ginny $\mathrm{Ng}$, Charlotte Opal, Ben Phalan, Matthias Rinke, Denis Ruysschaert, Tomas Satak, Mike Senior, Ellen Brown, Melissa Thomas, Pavel Tomsik, Paulina Villalpando, Mojmír Vlasin, Gretchen Walters and Martin Zordan.

We also thank Rona Dennis for proof reading the report. 


\section{List with tables, figures, boxes}

\section{List of tables}

Table 1. Contribution of palm oil exports to country's Gross Domestic Production (GDP). 6

Table 2. Different definitions of industrial palm oil across the world. 13

Table 3. Bear use of oil-producing crops and ramifications. 40

Table 4. Projected number of threatened species and the extent of their ranges that could be affected by potential future oil palm expansion.

Table 5. List of IUCN Oil Palm Task Force members as of January 2018.

Table 6. Estimated planted industrial-scale oil palm (in hectares) for 24 countries according to the FAO and according satellite analysis.

Table 7. Search terms used in literature search.

Table 8. Articles used in study.

Table 9. Global and regional deforestation from oil palm expansion.

Table 10. Southeast Asian snake species that thrive in oil palm plantations, their IUCN Red List status, major prey items, and utilisation for the leather industry.

\section{List of figures}

Figure 1. An oil palm plantation in Indonesian Borneo, showing palms in the foreground, the palm oil mill in the middle ground and a forested national park in the background. (@) Douglas Sheil)

Figure 2. A day in your life with palm oil.

Figure 3. Map of planted oil palm globally according to satellite analysis reviewed and conducted in the current analysis.

Figure 4. The palm oil story.

Figure 5. The palm oil supply chain.

Figure 6. Palm oil yields in major producing countries.

Figure 7. Smallholder oil palm plantation in Aceh, Sumatra. (๑ Janice Lee)

Figure 8. Proportion of the area of smallholder and large landholder concessions in selected countries.

Figure 9. Oil palm labourers in Riau weighing fresh fruit bunches after harvesting them from a smallholder oil palm plantation. (๑) Janice Lee)

Figure 10. Oil palm's role in deforestation.

Figure 11. The expanding area (7.8 Mha) of industrial oil palm plantations in six time periods from 1973 to 2015 with vegetation cover of the land just before observed conversion to oil-palm.

Figure 12. The Tripa peat swamp area, a former rich wildlife habitat, clear cut, burnt and drained. (๑) lan Singleton)

Figure 13. Number of threatened species affected by the highest level of the threat classification schemes as recorded in the IUCN Red List of Threatened Species.

Figure 14. Number of threatened speciesaffected by different types of threats from agriculture and aquaculture as recorded in the IUCN Red List of Threatened Species.

Figure 15. The impacts of converting primary rainforest into an oil palm plantation on the abundance and species richness of different taxa.

Figure 16. Bearded Pigs are an important source of food for many, including these nomadic Penan people of central Borneo. (@ David Hiser)

Figure 17. Orangutan in a forest set-aside in an oil palm plantation in West Kalimantan. (๑ Nardiyono)

Figure 18. Dried python skins in Central Kalimantan, Indonesia. (๑) Daniel Natusch)

Figure 19. Blood Pythons collected from nearby oil palm plantations in north Sumatra, Indonesia. (๑) Daniel Natusch)

Figure 20. Fruiting bodies of Lichenomphalia sp. are commonly encountered in peat swamp forest, but are absent in oil palm cultivation areas. (๑ Sabiha Salim)

Figure 21. Oil palm plantations have a predominantly negative net effect on ecosystem functions when compared to primary and secondary rainforest.

Figure 22. Varanus salvator macromaculatus, Uncle Tan's Wildlife Camp, Sungai Kinabatangan, Sabah, Malaysia. (๑) Bernard Dupont)

Figure 23. Major threats for terrestrial mammals and birds, separated by the mechanism of the threat (habitat loss or direct mortality).

Figure 24. Estimate of proportion of total area of land-use change associated with various proximate drivers of deforestation, and absolute net forest area change associated with proximate drivers of deforestation. 2000-2010. 
Figure 25. Soundscape examples for different land uses.

Figure 26. Percentages of total land areas used for vegetable oil production by different crops and the relative contribution to total oil production from each of these crops.

Figure 27. Fat male Malayan Sun Bear, known to use oil palm areas, being radio-collared in Sabah. (@ Andrew Hearn)

Figure 28. Vegetation stratification considered by the High Carbon Stock Approach.

Figure 29. The mitigation hierarchy for managing biodiversity risk.

Figure 30. Number of companies with and without commitments by commodity.

Figure 31. Proportion of companies with sustainability pledges that commit to address different aspects of biodiversity conservation

Figure 32. Land illegally occupied by independent farmers in concessions and in State Forest.

Figure 33. A riparian reserve in an oil palm landscape in Sabah, Malaysia.

Figure 34. Schematic representation of selected interactions between different sustainability tools and initiatives in the oil palm industry.

Figure 35. Roundtable on Sustainable Palm Oil Certification-certified area by region in 2017.

Figure 36. Zero deforestation performance by commodity.

Figure 37. Forest set asides in an oil palm plantation in West Kalimantan. (@ Douglas Sheil)

Figure 38. Possible unintended consequences of different oil palm development trajectories, and thus the initiatives and policies that shape these trajectories.

Figure 39. Palm oil. World population growth and demand for edible vegetable oil.

Figure 40. Greenhouse emissions are plotted against overall environmental impacts of 29 transport fuels, scaled relative to gasoline.

Figure 41. New oil palm varieties such as this Australia-grown variety produce increasingly high yields, up to 10,500 kilograms of oil per hectare.

Figure 42. Map of tropical regions of America, Africa and Asia-Pacific, showing biophysical suitability areas for oil palm (class 'Good' and above), Key Biodiversity Areas and biodiversity hotspots.

Figure 43. A) Overlay map of concentration of threatened vertebrates and oil palm suitability in Colombia.

B) Concentration of threatened vertebrates and lands legally line for oil palm development.

C) Oil palm suitability and lands legally excluded for oil palm development.

Figure 44. Theoretical potential for oil palm plantations in Central Africa.

Figure 45. Africa: harvesting of fresh fruit bunches.

Figure 46. Increase in oil palm harvested area in Africa, the Americas and Asia, between 1960 and 2020.

Figure 47. Percent of oil palm expansion into forest from 1972 to 2015 across regions and research investigations.

Figure 48. Percent of deforestation from oil palm from 1972 to 2015 across regions and research investigations.

\section{List of boxes}

Box 1. What is sustainability?

Box 2. Is it palm oil or oil palm? Actually, it's both.

Box 3. Who are the palm oil smallholders in Indonesia?

Box 4. The social dynamics of biodiversity loss and conservation in oil palm landscapes

Box 5. Oil palm and the Aichi Targets

Box 6. Oil palm the biggest driver of deforestation in Borneo since 2005

Box 7. Rotten palm oil; the Tripa case

Box 8. Pigs in plantations

Box 9. Is palm oil the biggest killer of orangutans?

Box 10. Look before you leap, for snakes among sweet flowers do creep...

Box 11. Climate change

Box 12. Earthworm depletion under palm oil plantations in Malaysia, and a possible remedy

Box 13. Scavengers become settlers of oil palm plantations

Box 14. The sounds of biodiversity in Colombian oil palm and other land covers

Box 15. Bears and oil crops

Box 16. Identifying areas of conservation importance: High Conservation Value and High Carbon Stock

Box 17. The issue of stranded assets

Box 18. The messy reality of oil palm development: the Riau puzzle

Box 19. The importance of protected riparian areas for biodiversity and ecosystem services

Box 20. Do undeveloped patches in oil palm plantations support biodiversity conservation?

Box 21. Land sparing, land sharing or something in between?

Box 22. Oil palm will not be grown everywhere where it can grow

Box 23. When savannas matter more than carbon 


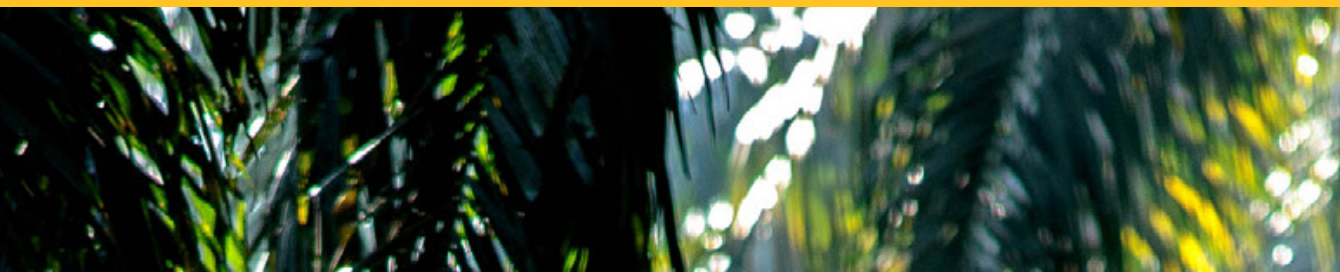

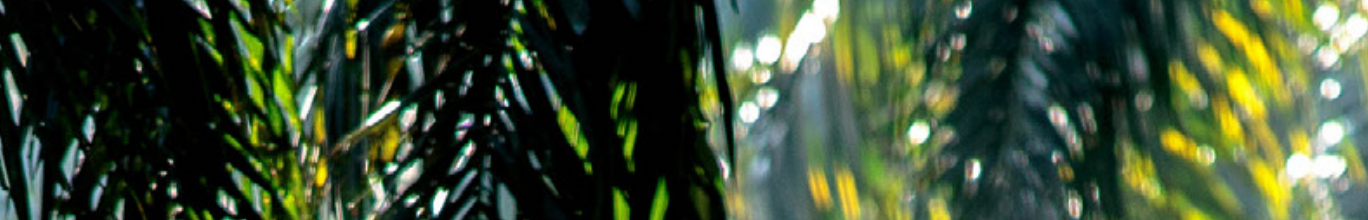
(4) $16 \div$ and

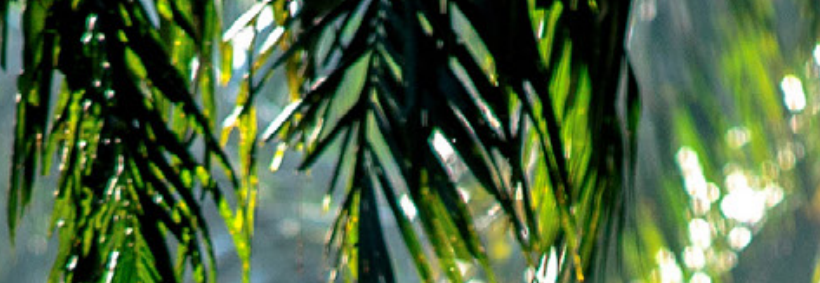

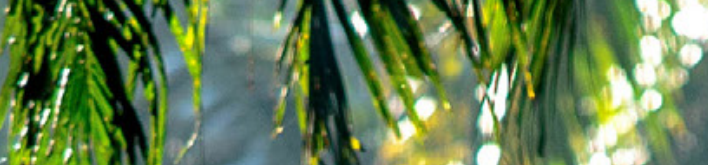

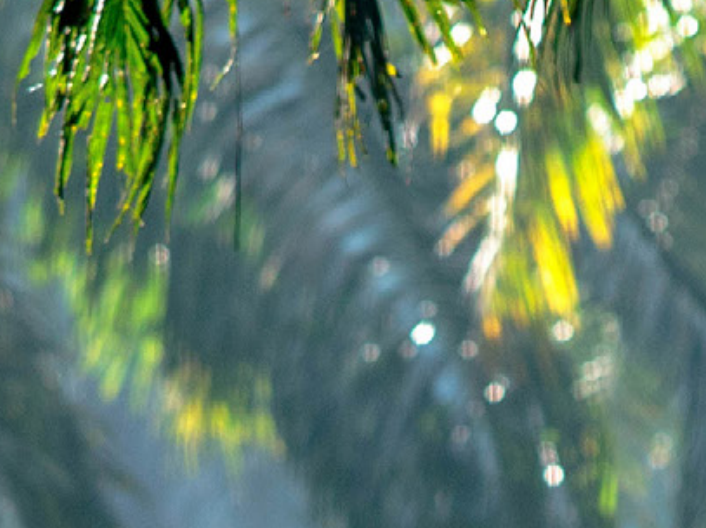

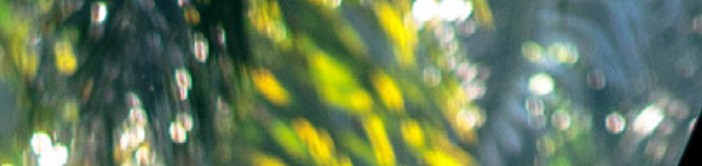
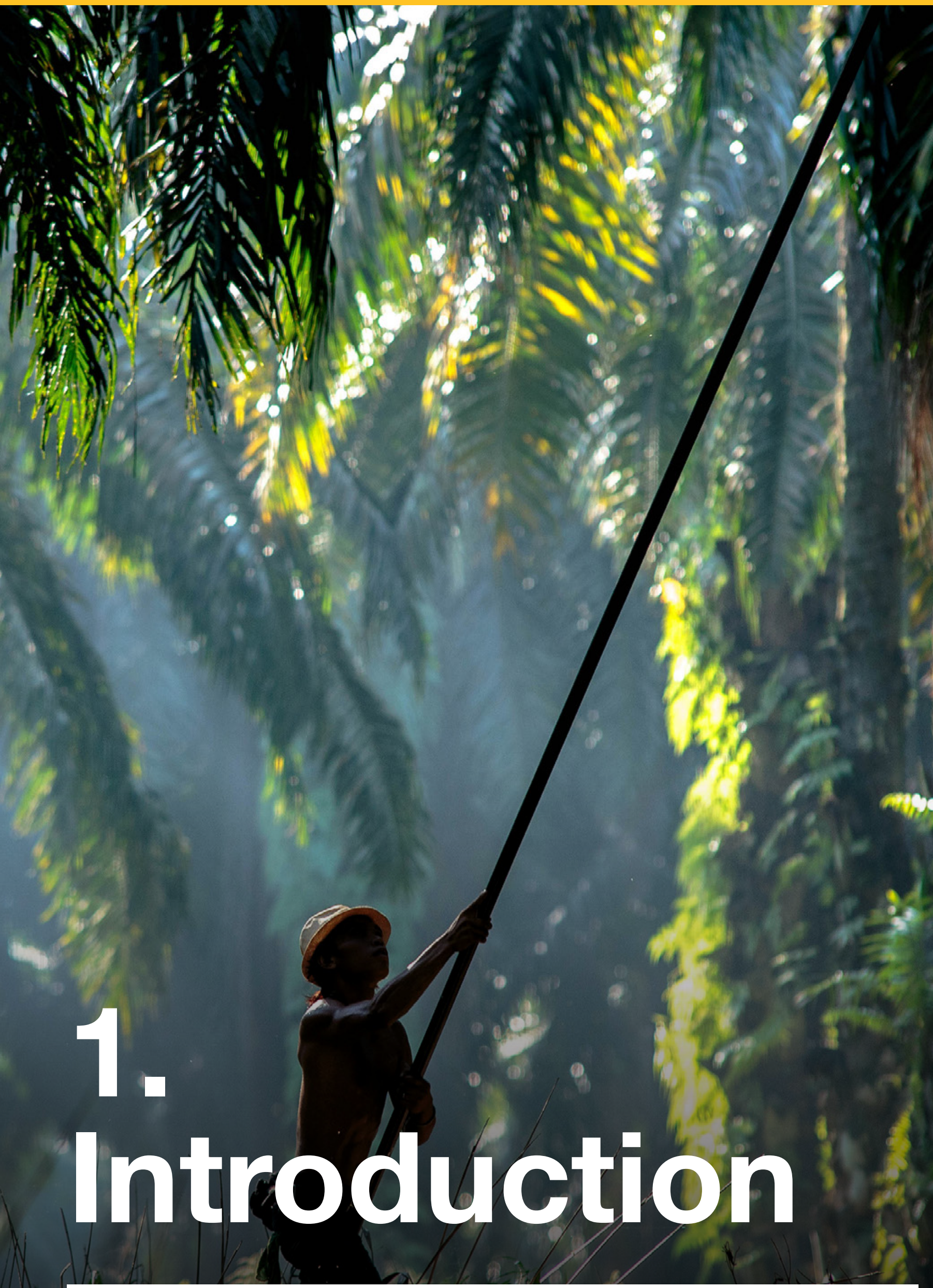
- Oil palm is established as an important oil crop globally.

- With 18.7 million hectares of planted industrial-scale oil palm in 2017, this is the 3rd largest oil crop in terms of planted area behind soy and rapeseed. Because of its high yields, oil palm produces about 35\% of all vegetable oil on less than $10 \%$ of the land allocated to oil crops.

- Oil palm has a large smallholder sector, with in some countries up to 94\% of the oil palm land allocated to smallholders. The distinction between smallholders and large landholders and industrial-scale palm oil producers, is not always clear.

- Expansion of oil palm, without accounting for biodiversity, is not compatible with international biodiversity policies. 


\subsection{The IUCN Oil Palm Task Force}

The IUCN Oil Palm Task Force (OPTF) was established to implement the IUCN Resolution 61: 'Mitigating the impacts of oil palm expansion and operations on biodiversity' adopted at the IUCN World Conservation Congress in Hawai' $i$, in September 2016. The Resolution requested key deliverables for the Task Force, "building upon existing studies focused on the impacts of palm oil expansion and operations on biodiversity, landuse planning and best practices". A description of the Task Force structure, members, and goals is available in Appendix 1.

Using the latest research and scientific information, the Oil Palm Task Force will give guidance to the IUCN and others about policies and strategies which affect or are affected by palm oil. Making use of IUCN's extensive knowledge networks on biodiversity and environmental issues, social, economic and cultural issues, and policy, the group also seeks to comprehensively guide thinking on the complex issues of agro-industrial and smallholder oil palm in the world's tropical regions.

\subsection{Scope of the situation analysis}

This report has been written by the IUCN Oil Palm Task Force in response to the IUCN resolution WCC2016-Res-061-EN requesting "a situation analysis of the implications for biodiversity conservation from the expansion of oil palm, and to review and define best practices in the industry".

Following this mandate, this Situation Analysis primarily focuses on oil palm in the context of biodiversity conservation, and aims to provide a more constructive pathway to addressing biodiversity challenges in the palm oil industry. This report does not assess the social and economic implications of palm oil production and expansion but will refer to these when they are likely to have an impact on biodiversity conservation.
Section 1 of the report introduces the crop and the biodiversity policy context. The subsequent sections of the report are structured around three temporal stages: past, present and future.

- The past: What have the impacts of oil palm been on biodiversity?

- The present: What is being done about these impacts, what initiatives exist, and what have they achieved?

- The future: What development scenarios exist for oil palm and what could be done to change the course of the palm oil industry towards a more sustainable future? (Box 1)

\section{Box 1.}

\section{What is sustainability?}

\begin{abstract}
Sustainability can be a perplexing term: what is sustained, how is it sustained and how can we be certain it can be sustained in the long-term? The concept of sustainability means different things to different people. For many production systems the concept of sustainability was once focused on maintaining yield at some level in perpetuity. But this relatively simple concept has long been crowded out by additional social, economic and environmental concerns and requirements. In biological conservation we generally seek to conserve and sustain some or all aspects of a regional biota. If the habitat necessary to achieve this is being replaced with some production system it can be viewed as misleading to call the system sustainable (even if the environmental impacts are minimised). This is why many conservationists are uncomfortable to call any intensive farming systems "sustainable". Here we use the terms "sustainability" and "sustainable" with care, unless the use is in official name (e.g., Roundtable on Sustainable Palm Oil), or in a specific context, such as "unsustainable hunting".
\end{abstract}

The Situation Analysis is a priority output of the IUCN Oil Palm Task Force. The results and recommendations from the study, along with the other operative clauses of Resolution 61, will serve as a road map for the priorities and strategies of the Task Force for the remainder of the 2017-2020 IUCN Quadrennium. 
It is intended that this report will serve as an evidence-base to inform decision-makers on oil palm, to assist land-use planners in avoiding and mitigating the negative impacts of oil palm expansion, to guide the industry and smallholders in the implementation of best practices to improve their environmental performance, and to support non-governmental organisations and consumers in encouraging such practices. Throughout this report, we also aim to highlight complex implications that often surround simplified messages, such as going "palm-oil free".

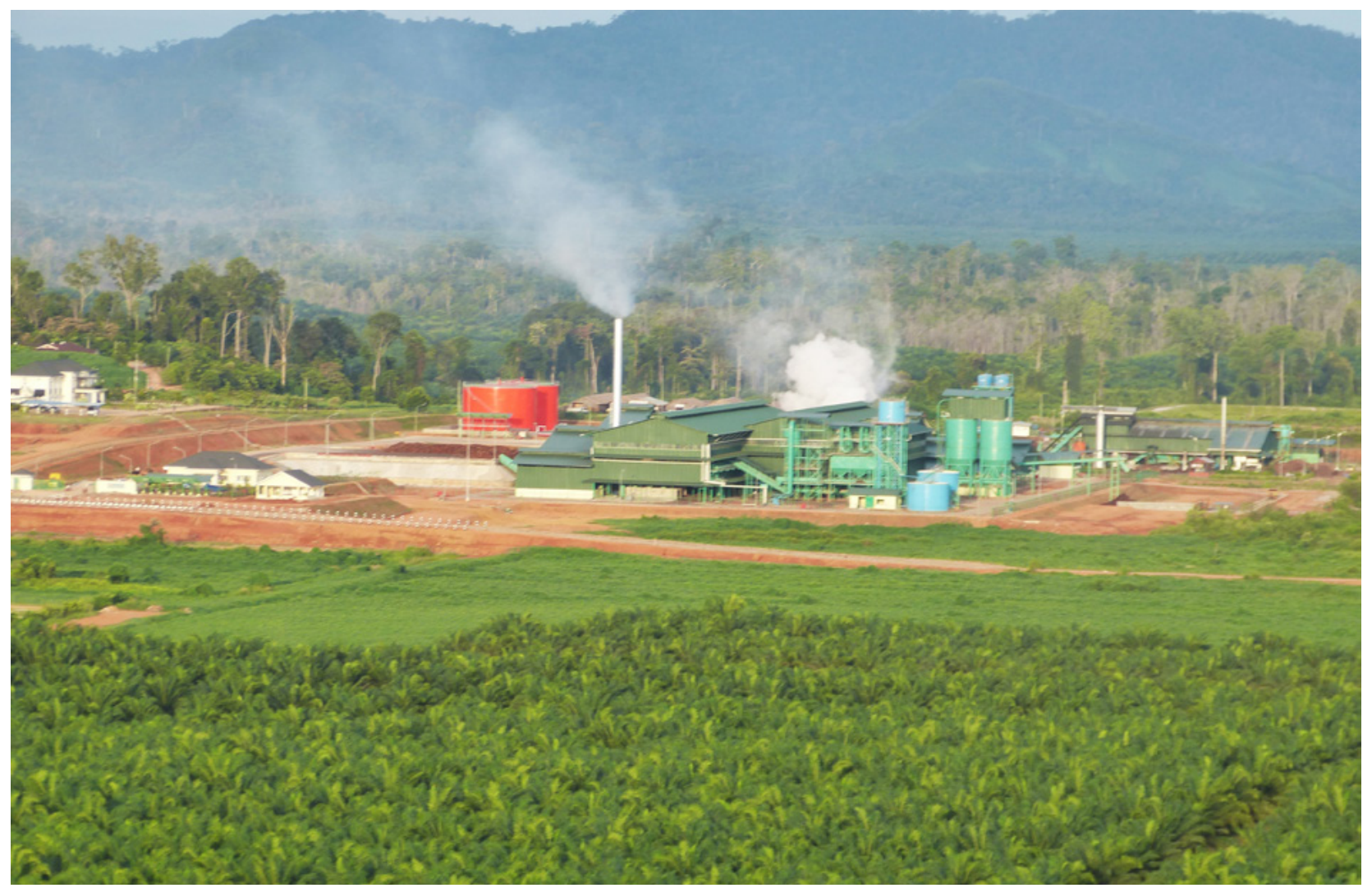

Figure 1. An oil palm plantation in Indonesian Borneo, showing palms in the foreground, the palm oil mill in the middle ground and a forested national park in the background. (@ Douglas Sheil)

\subsection{Oil palm, some facts and figures}

\subsubsection{What is oil palm?}

Palm oil is derived from the oil palm tree (Box 2). Its scientific name is Elaeis guineensis Jacq. which loosely translated means Oil of Guinea. The species is listed on The IUCN Red List of Threatened Species (widely recognized as the most comprehensive, objective global approach for evaluating the conservation status of plant and animal species) as of Least Concern (1). The African oil palm has an American relative Elaeis oleifera (Kunth) Cortés which is usually called "American oil palm". The American palm is seldom planted, though hybrids between the two species are widely used in parts of South and Central America.

As its name suggests, the oil palm is endemic to Africa, and for thousands of years, people there have cultivated oil palm in different small-scale setting and used palm oil in various ways. Since the early 1990s, and in some places the 1970s - with the rise of processed foods and increased consumerism - palm oil has been turned into a global commodity (2).

Today, oil palms cover landscapes from Borneo to Colombia. It is considered an invasive species in some countries, including the USA, Madagascar and in some dry areas of the Pacific and in remnants of Atlantic Forest in Brazil (3). Palm oil and its derivatives can now be found in everything from cosmetics to 


\section{A Day in Your Life with Palm Oil}

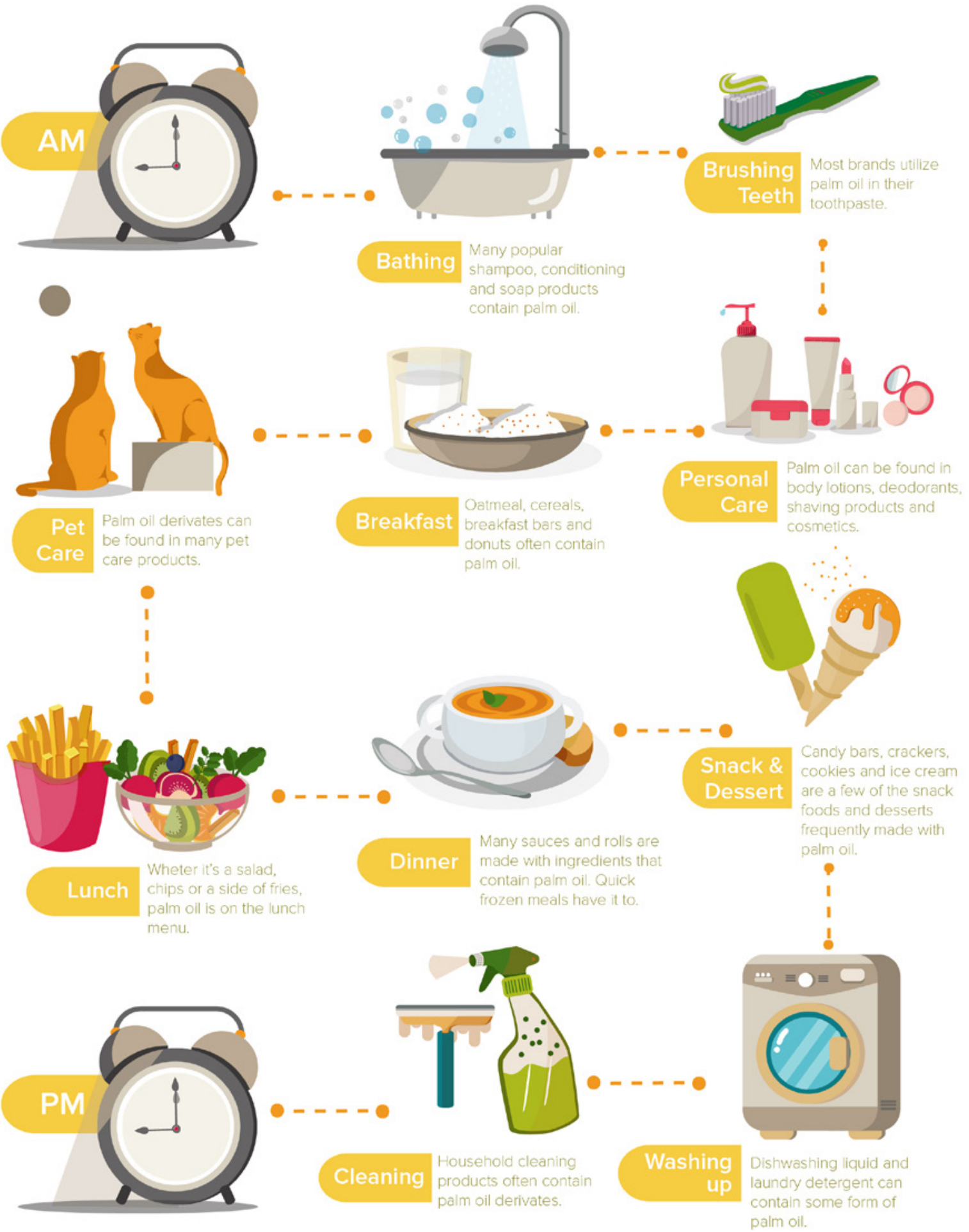

Figure 2. A Day in Your Life with Palm Oil, based on a design by Philadelphia Zoo. 
frozen pizzas (Figure 2). It has become a popular commodity because of its high yield - surpassing the yields of other vegetable oils such as soy, canola, olive, sunflower and rapeseed several times over - combined with its relatively low production costs. In 1980, the world produced four-and-a-half million tonnes of palm oil. In 2014, the world produced nearly 70 million tonnes, 15 times as much.

Box 2.

\section{Is it palm oil or oil palm? Actually, it's both.}

\begin{abstract}
Oil palm refers to the trees that produce fruits from which oil is harvested. Palm oil - flipping it - refers to the oil that is produced from the fruit harvested in these plantations. Palm oil is the oil used in soap, noodles, a plethora of other foods and consumer goods, and diesel (Figure 2). We therefore use palm oil in reference to the product and oil palm in reference to the trees.
\end{abstract}

Still, as the debate over the commodity has grown, references to "oil palm" have largely dropped off in the media and in the public debate. Oil palm, today, is a term used mostly by the industry and scientists - not so much by NGOs, journalists, or the assistant in your grocery. Palm oil looks to have won - and become the norm for most references to either the crop, the industry or the plant itself.

\subsubsection{Where is oil palm currently grown?}

Oil palm is a tropical plant species. It needs high rainfall, adequate solar radiation of $16-17 \mathrm{GJ} / \mathrm{m}^{2}$ per day, and high humidity to maximize photosynthetic capacity (4), and grows best and produces most fruit in areas with mean maximum temperature of 30 $32^{\circ} \mathrm{C}$ and mean minimum of $21-24^{\circ} \mathrm{C}$ (5). Its Asian growing area stretches in a band $\mathrm{ca}$. the equator roughly from around $12^{\circ} \mathrm{N}$ to $12^{\circ} \mathrm{S}$. In Africa, the crop is mostly planted north of $4^{\circ} \mathrm{S}$, although exceptions exist as far south as $13^{\circ} \mathrm{S}$ (Zampalm in Zambia) and even $18^{\circ} \mathrm{S}$ (La Palmeraie de Melville in Madagascar), while in the Americas it reaches as far north as $16^{\circ} \mathrm{N}$ into southern Mexico and Guatemala. Where its growth is particularly dependent on the length of the dry season, with plantings close to the subtropics, such as those in Myanmar, suffering from water stress (6).

Oil palm is grown in some 43 countries (http:// theoilpalm.org/about/), but the biggest plantings are in Indonesia and Malaysia. The new map presented here (Figure 3), indicates that, respectively, the two countries occupy 6,033,868 hectares (32\%) and $11,129,434$ hectares $(60 \%)$ of the total planted area of some 18.7 million hectares of industrial-scale oil palm currently planted around the world. This estimate excludes many independent smallholder plantings, described below (i.e., those not included in a collaborative scheme setting with an industrialscale producer), which are more difficult to map at a global scale, because of their heterogenous nature.

Table 1. Contribution of palm oil exports to country's Gross Domestic Production $(G D P)(7,8)$.

\begin{tabular}{lll}
\hline Country & GDP (million current US\$, 2016) & Exported value (millions US\$, 2016) \\
\hline Indonesia & 932,448 & 14,365 \\
Malaysia & 296,359 & 9,064 \\
Colombia & 282,357 & 245,5 \\
Guatemala & 68,175 & 283 \\
Ecuador & 98,010 & 228 \\
Honduras & 21,364 & 230 \\
Papua New Guinea & 20,003 & 507 \\
Costa Rica & 58,109 & 101.5 \\
\hline
\end{tabular}




\section{South-East Asia}

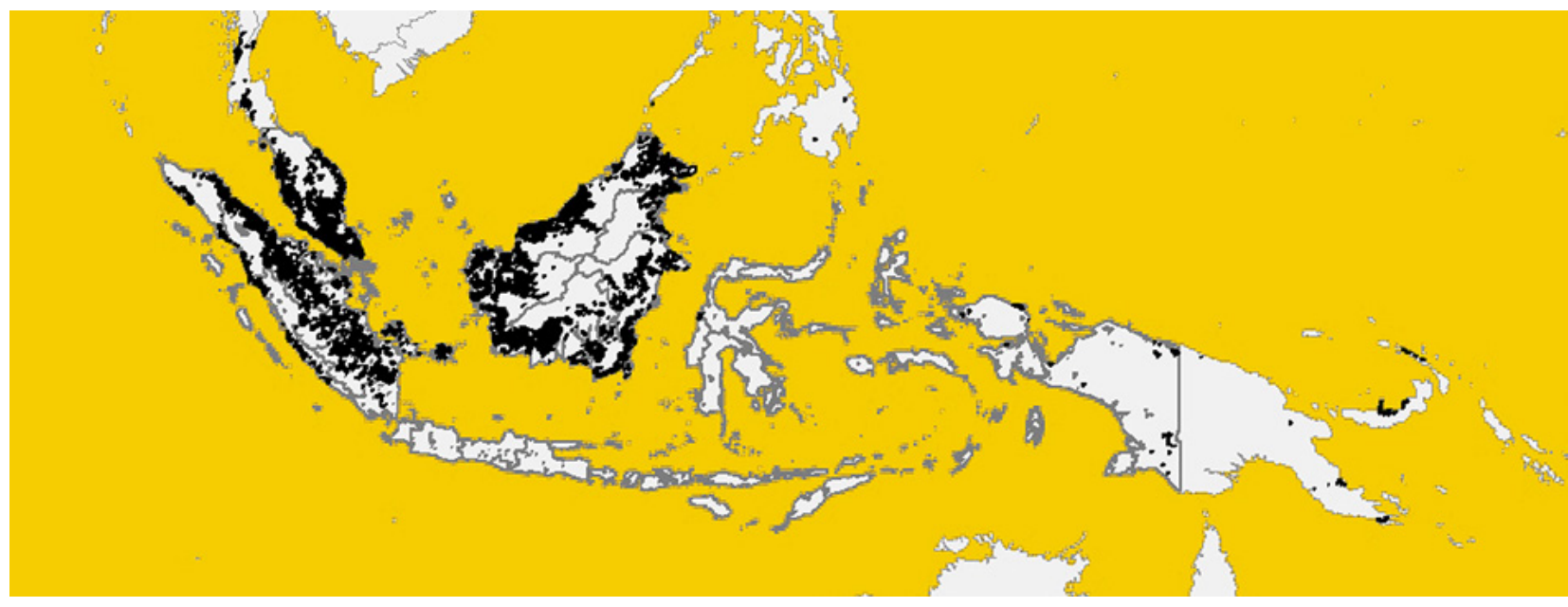

\section{Central \& South America}

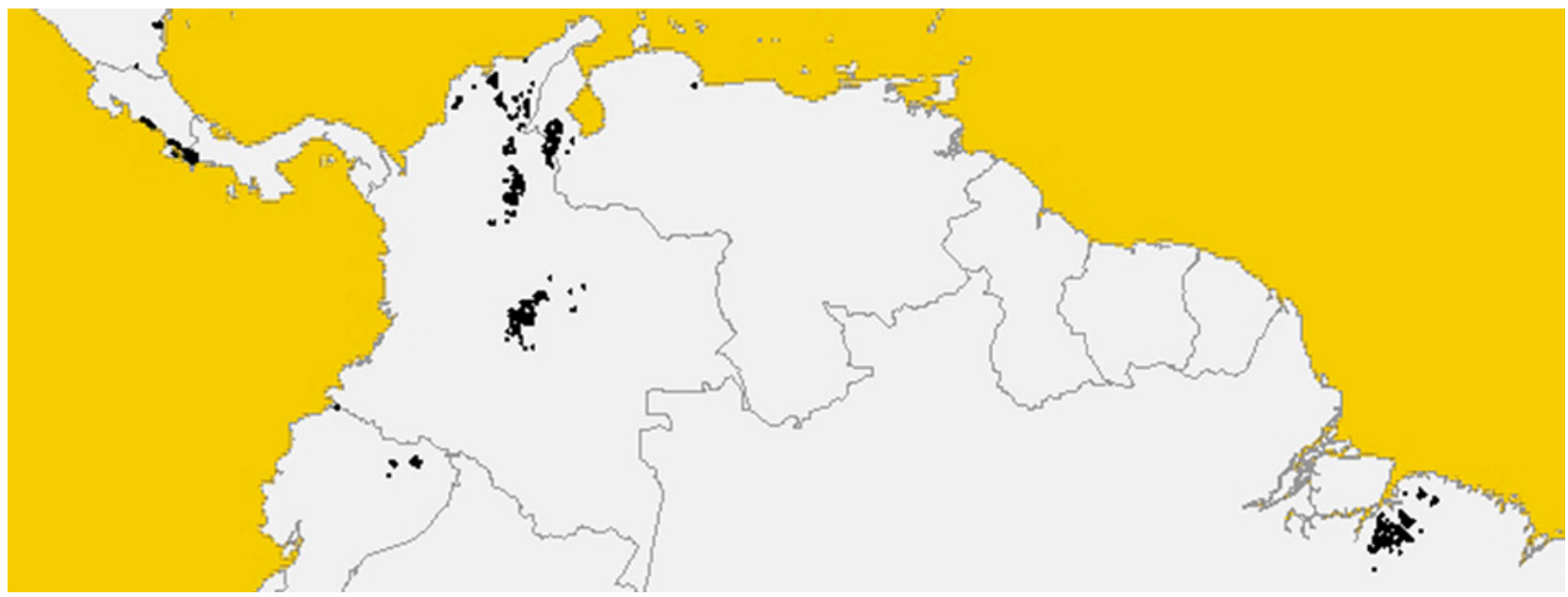

\section{West \& Central Africa}

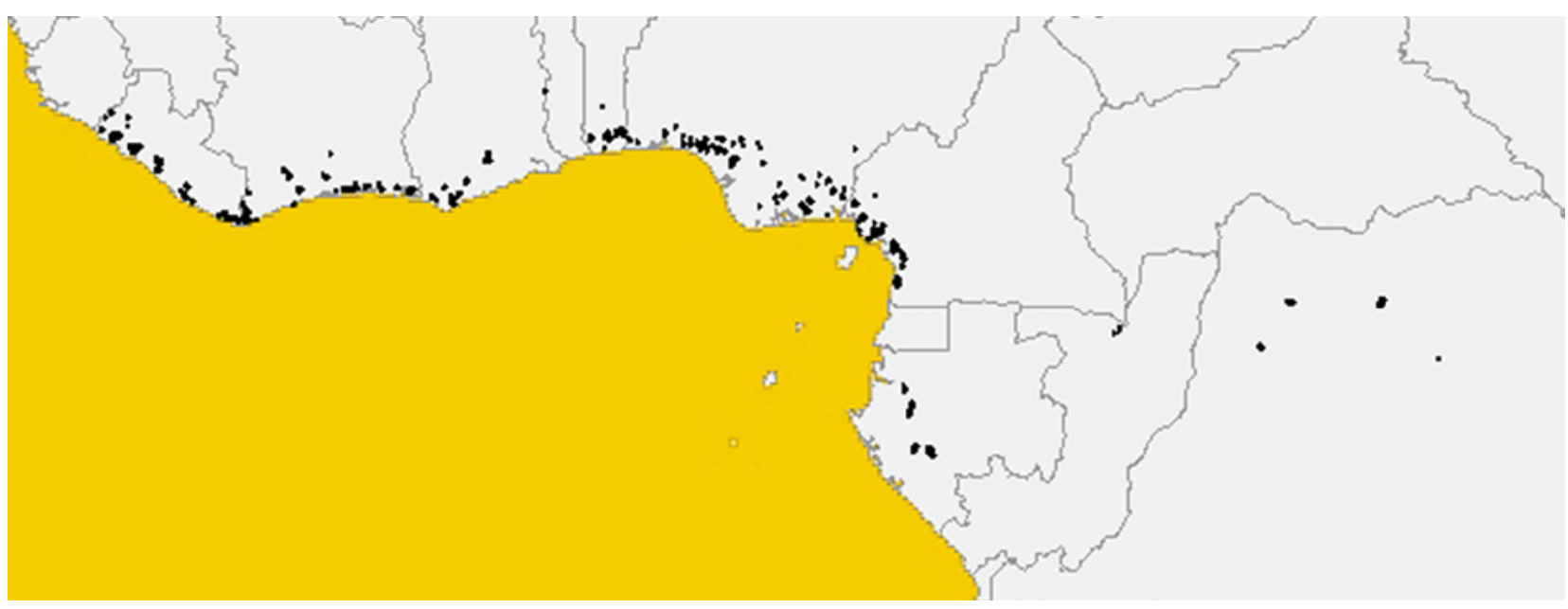

Figure 3. Map of planted oil palm globally according to satellite analysis reviewed and conducted in the current analysis (LANDSAT and MODIS, see Appendix 2). This map represents the planted area of large-scale/industrial oil palm. It lacks information on smallholder oil palm, and on semi-wild plantations, estimated by us to cover 4 Mha in West Africa. 
Other countries with planted significant areas of oil palm include Nigeria, Columbia, Brazil and Papua New Guinea, but none come close to the areas planted in Indonesia and Malaysia. Some small producing countries include Vanuatu, Gabon and the Solomon Islands, where palm oil production may play a relatively large economic role (Table 1).

\subsubsection{How is oil palm grown and what happens to palm oil?}

\section{Oil palm production cycle}

At around three years after planting, the oil palm tree begins to bear fruit and reaches a phase of peak production about 10 years after planting (9). Oil palm fruit development requires pollination. The most commonly used species for this is the African oil palm weevil (Elaeidobius kamerunicus). After this species was introduced to South-East Asia in the 1980s, palm oil yields increased by as much as 53\% because of more effective pollination (10), although since then there have been reports of reduced pollination effectiveness and declining yields (10). The life cycle of an oil palm plantation is about 25 years, after which the tree becomes too tall, manual harvesting more difficult, and yields decrease (11). The plantation is subsequently cut down and left to lie fallow before a new cycle of replanting begins. It is then replaced by a new planting. Oil palm is a relatively high-yielding and labour-intensive oil crop compared to other oil crops (Figure 4).

The cultivation of oil palm is done mostly as a monocrop for commercial purposes, except in Africa where it is part of an agroforest system (11). Palms are normally planted some 7.5 to $10 \mathrm{~m}$ apart, allowing the individual palm crowns to grow without overlapping each other and thus maximizing light and photosynthesis.

The greenfield investment costs for establishing an oil palm plantation and a mill are approximately
USD10,000/ha $(9,12)$. This investment typically receives a positive cash flow five to six years later. The production of oil palm is labour-intensive because harvesting is largely manual. The minimum labour requirement for an oil palm plantation is about one labourer for every 8-12 ha (9). High labour requirements make oil palm an important livelihood option in regions where wages are low and labour is abundant (9) This can have an unintended effect of reducing labour for local food production in nearby areas with labour shortages (13). Also, the high labour needs generates labour in-migration from lower income countries and regions, and local competition for jobs $(14,15)$.

Fresh fruit bunches are the raw products from the oil palm tree and are typically harvested every 10-14 days from a mature oil palm plantation (11). These fresh fruit bunches must reach the mill within 24 hours after harvesting to ensure optimal quality of the oil (9), although cases have been reported of oil spending up to 5 days on the road before arriving at the mill (16). After this the fruits are pressed and the kernels crushed, and the oil extracted from both the flesh of the fruit, producing the orange-coloured crude palm oil, and the seed of the fruit, producing the paler palm kernel oil.

Palm oil is high in palmitic fatty acid and almost $75 \%$ of world production goes into food products, particularly cooking oil and processed oils and fats (e.g., margarine). Palm kernel oil is high in lauric fatty acids and is used mostly for soap and industrial purposes, as well as processed foods (9) (Figure 2). There are commercially available alternatives to palm oil but they tend to be economically infeasible for the scale at which palm oil is being used for food and industrial purposes (17). A potential substitute may come in the form of the yeast, Metschnikowia pulcherrima, which is used as a biological control agent in the South African wine industry and is able to produce oil with a similar lipid profile to palm oil $(18,19)$. 


\section{The Palm Oil Story}

The most widely used vegetable in the world

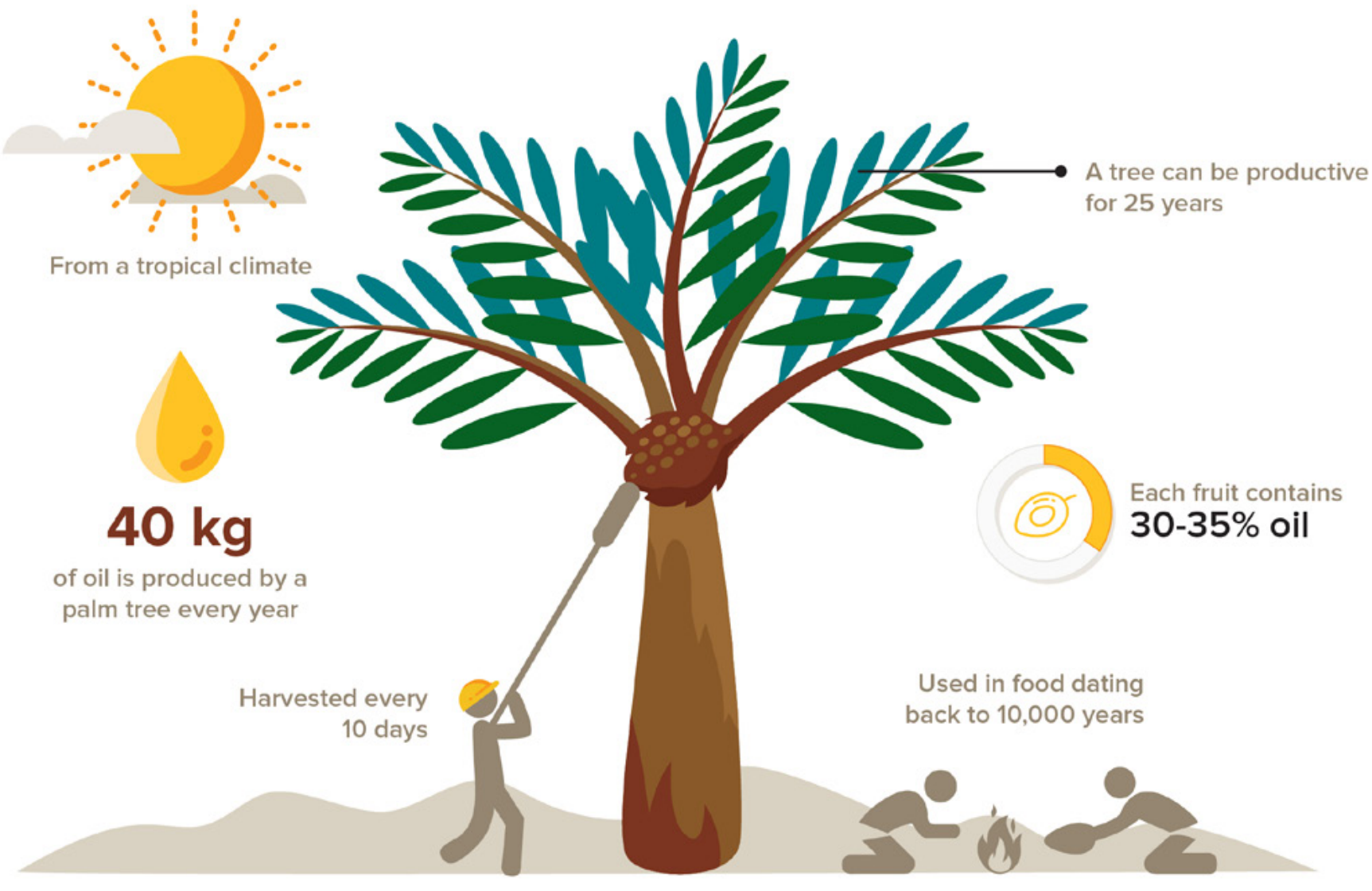

\section{Land-use efficiency}

Economic contribution

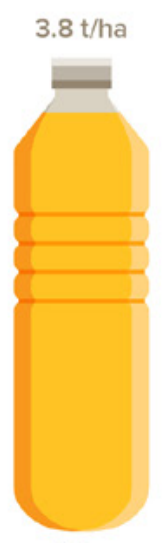

Palm

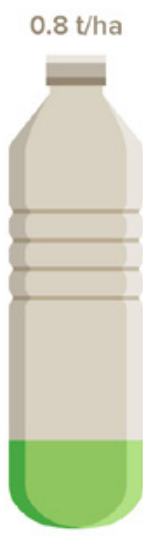

Rape

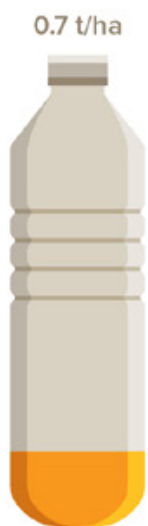

Sunflower

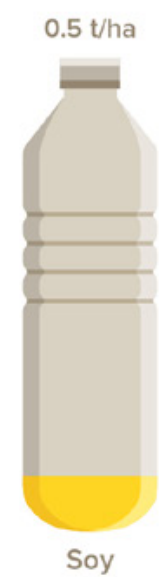

-tonnes/hectare
Palm oil creates jobs:

1 worker per 8 ha

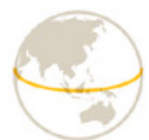

Grows best around the equator

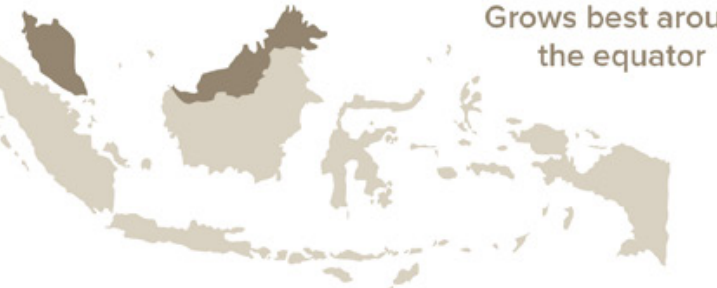

Indonesia \& Malaysia provide

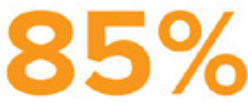

of the world production

Figure 4. The Palm Oil Story based on an infographic by the European Palm Oil Alliance. 


\section{Palm Oil Supply Chain}

NOTE : Volumes in this infographic are averages.

There is a lot of variation in processing, transport capacity and ingredient use

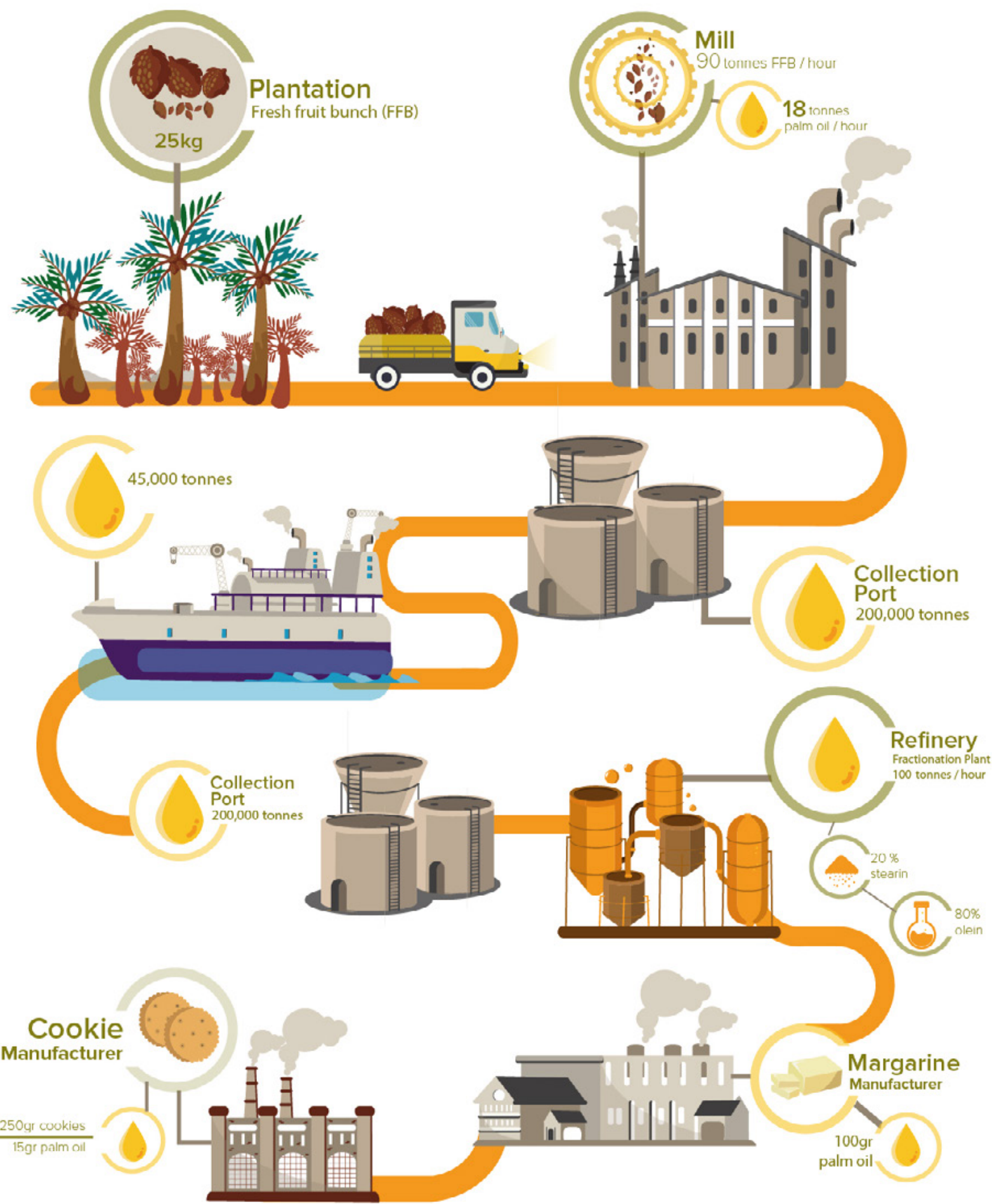

Figure 5. The palm oil supply chain. Adapted from an infographic by RSPO.

\section{Oil palm yield and trade}

Among the world's vegetable oil crops, oil palm is the most productive with a current global average yield of
3.5-4.0 tonnes of palm oil per hectare and a genetic yield potential of 11-18 tonnes of fresh fruit bunches per hectare (20). Palm oil yields vary greatly from, for example, smallholder producers in Cameroon 
producing 1 tonne of oil per hectare (21), to industrial-scale producers in Malaysia and Indonesia who produce around 4 tonnes of oil per hectare (22) (Figure 6). This is also because the tree planting densities in some agricultural settings is much lower than in other. Despite the variation, palm oil yields are well above good rapeseed oil yields in Europe and soybean oil yields in Brazil which are 1.8 tonnes of oil per hectare and 0.6-ᄀ0.8 tonnes of oil per hectare respectively (9). Yields of oil palm plantations vary among countries and production systems (e.g., industrial vs smallholder plantations) and are reliant on a range of factors related to the climate, quality of seedlings, soil fertility and agricultural practices (e.g., use of inputs, frequency and timing of harvesting fresh fruit bunches) (11) (Figure 6).

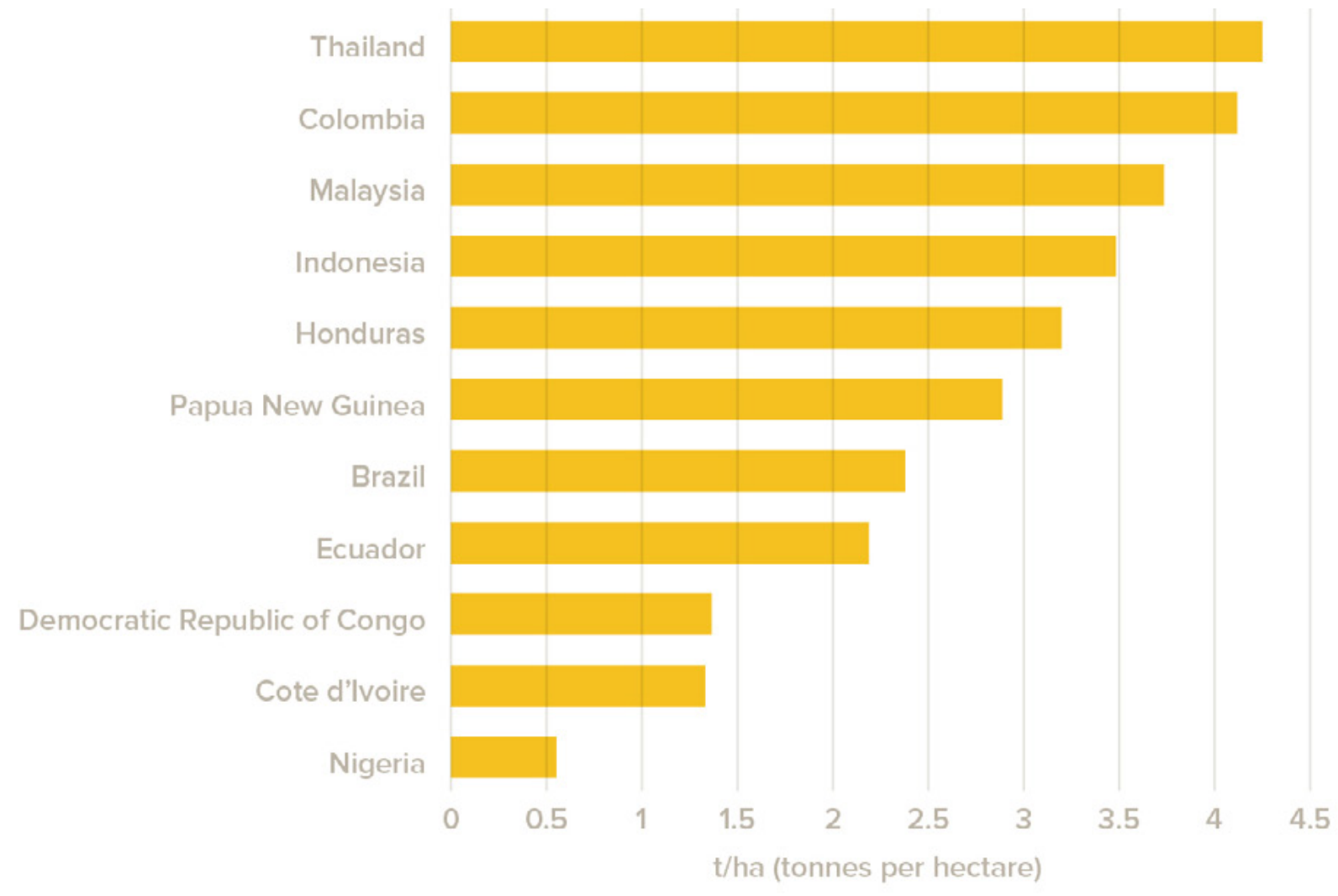

Figure 6. Palm oil yields in major producing countries from FAOSTAT for 2013 showing the major variation in palm oil yields between countries (2).

Malaysia and Indonesia are world leaders in palm oil trade, together providing $85 \%$ of the global supply of $62 \mathrm{Mt}$ in 2016 (23). This is followed by Thailand, Colombia, and Nigeria. The bulk of palm oil produced in these countries is destined for export especially to the European Union, China, India, United States, Japan and Pakistan. In West and Central Africa palm oil is used more for domestic consumption than for export (9), while also in Colombia 83\% of locally produced palm oil is retained for consumption and biofuel (24). Indonesia is both a major exporter (ranked first) and also a major consumer (ranked second) of palm oil in the world (9). In terms of palm oil imports, India ranks first at 9.2 Mt, followed by the
European Union (6.5 Mt), China (4.9 Mt), Pakistan (3 Mt), and the United States of America (1.4 Mt) (23).

\section{Oil palm production systems across the world}

Many people are familiar with the image of oil palm plantations as being rows and rows of monoculture oil palm trees planted over vast areas (Figure 1). While this is often the correct picture, a wide range of palm oil production systems exists, varying from one country to another. 


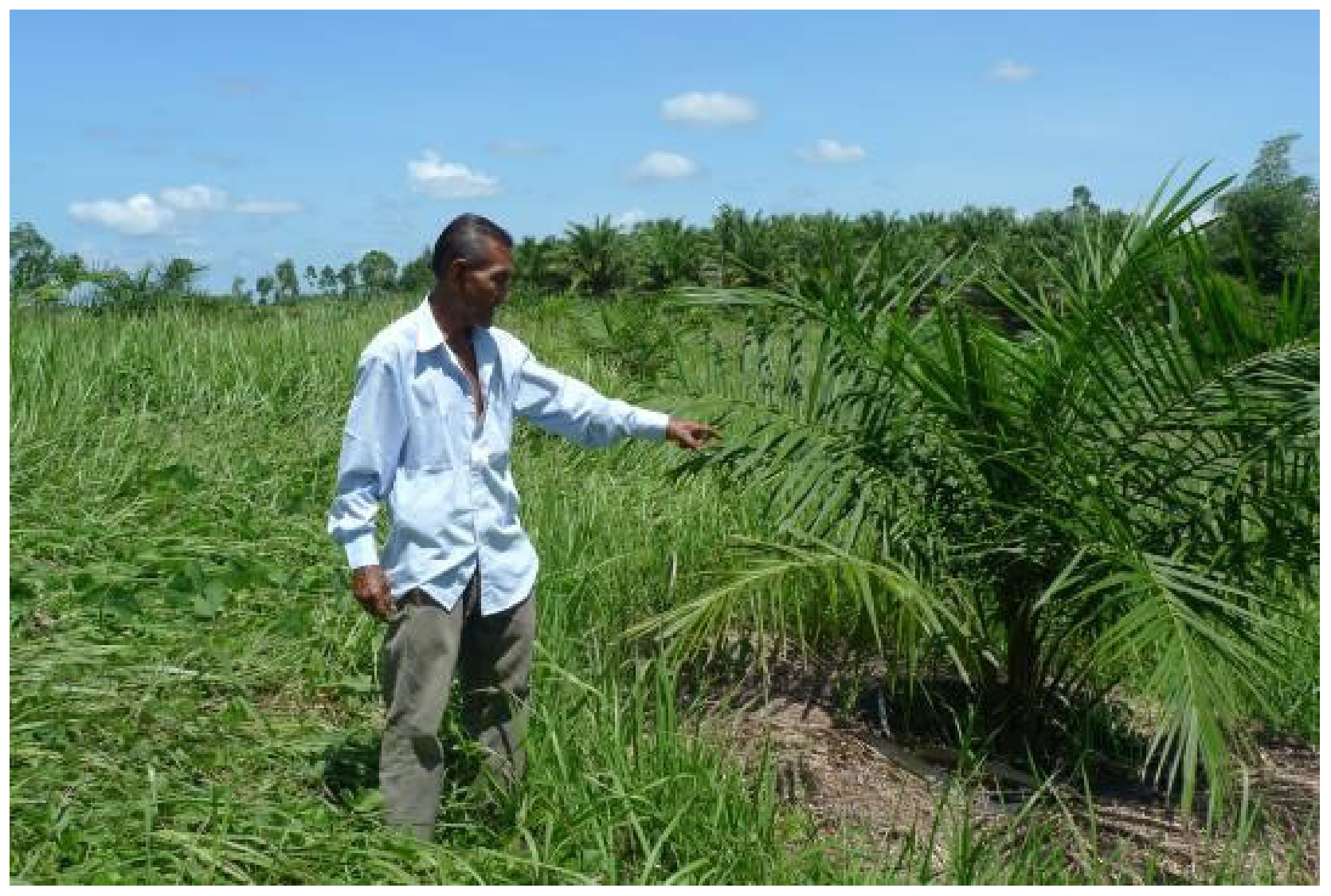

Figure 7. Smallholder oil palm plantation in Aceh, Sumatra. (C Janice Lee)

Oil palm plantations can be categorised into four broad types:

- Industrial plantations, which are usually managed by a company, possess their own palm oil mill, and occupy thousands of hectares.

- Medium-scale operators, often develop plantations like smallholders and operate medium to large plantations (generally greater than 25 hectares in Indonesia, but up to several thousand hectares) without formal company status (25).

- Smallholder plantations, (Figure 7) which are typically run as family farms, rely on other actors for processing their fresh fruit bunches, and occupy smaller areas, typically less than 50 ha as defined by the Roundtable on Sustainable Palm Oil (26). Smallholders can operate independently or collaborate in a company scheme (27). Land distribution between the smallholder and company varies from companies owning 100\% of the land to smallholders owning $100 \%$ of the land and companies assisting farmers with financing and technical support; and (27).

- Smallholder plantations in agroforestry settings who harvest semi-wild plantations of oil palm. This category is large in central African countries and the oil produced is mainly for local consumption (28).

While these 'industrial' and 'smallholder' categories are useful as a summary distinction, there are substantial differences in the definition of these categories, as well as their relative significance, among countries (Table 2), and even greater variation in the typology of 'smallholder' production systems. Understanding the variation in oil palm production systems, especially within the 'smallholder' category, is an emerging topic of enquiry as it has implications for understanding and addressing small-scale drivers of land use and land cover change (e.g., deforestation, burning) $(25,29,30)$. For example, differences among smallholders are crucial in developing frameworks for sustainability certification standards and criteria (31). 
Table 2. Different definitions of industrial palm oil across the world.

\begin{tabular}{|c|c|c|c|}
\hline Country/Region & Industrial plantations & Smallholder plantations & References \\
\hline Indonesia & $\begin{array}{l}\text { A minimum extent of } 6,000 \text { ha is } \\
\text { required for a mill to be developed but } \\
\text { plantations can be as large as } 20,000 \\
\text { ha. }\end{array}$ & $\begin{array}{l}\text { Oil palm plantations which are } \\
\text { less than } 25 \text { ha are considered } \\
\text { smallholdings in Indonesia. }\end{array}$ & (32) \\
\hline Malaysia & $\begin{array}{l}\text { Large-scale private commercial } \\
\text { plantations can range from } 40 \text { ha to } \\
\text { more than } 100,000 \text { ha in Peninsular } \\
\text { Malaysia, Sarawak and Sabah. In } \\
\text { Sarawak, state-mediated private } \\
\text { company plantations require a } \\
\text { minimum size of } 5,000 \text { ha. }\end{array}$ & $\begin{array}{l}\text { Smallholder oil palm plantations in } \\
\text { Peninsular Malaysia are generally } \\
\text { less than } 4 \text { ha and typically support } \\
\text { mixed-age stands, where oil palm is } \\
\text { intercropped with other commercial } \\
\text { plants (e.g., bananas, cassavas, coffee } \\
\text { or indigenous fruit trees). }\end{array}$ & $(33,34)$ \\
\hline Papua New Guinea & $\begin{array}{l}\text { The reported size of industrial estates } \\
\text { ranges from } 5,600 \text { to } 23,900 \text { ha. }\end{array}$ & $\begin{array}{l}\text { The average size of smallholdings } \\
\text { ranges from } 2 \text { to } 4 \text { ha. }\end{array}$ & (35) \\
\hline Ghana & $\begin{array}{l}\text { Industrial monoculture estates are } \\
\text { usually at least } 40 \text { ha in size but have } \\
\text { been reported to reach a size of } 6,500 \\
\text { ha. }\end{array}$ & $\begin{array}{l}\text { Smallholder plantations range from } 0.5 \\
\text { to } 5 \text { ha. }\end{array}$ & $(36-38)$ \\
\hline Cameroon & $\begin{array}{l}\text { Oil palm estates above } 100 \text { ha are } \\
\text { described as 'agro-industrial estates'. }\end{array}$ & $\begin{array}{l}\text { The reported average size of } \\
\text { smallholdings ranges from } 8 \text { to } 40 \text { ha. }\end{array}$ & $(9,35,39)$ \\
\hline South \& Latin America & $\begin{array}{l}\text { Remote sensing studies classify oil } \\
\text { palm plantations greater than } 50 \text { ha as } \\
\text { 'industrial, medium-large-scale oil palm } \\
\text { plantations'. }\end{array}$ & $\begin{array}{l}\text { Smallholder oil palm plantations vary in } \\
\text { size: Ecuador (<50 ha), Colombia (8-12 } \\
\text { ha), Honduras (<10 ha), Brazil (2-10 } \\
\text { ha), Guatemala ( } 2 \text { ha). }\end{array}$ & $(24,40,41)$ \\
\hline
\end{tabular}

Small-scale oil palm plantations across the tropics vary in size, some displaying characteristics of small and medium enterprises or companies (30, 35). Understanding the typology of 'smallholder' producers is important considering their contribution to oil palm planted areas around the world (see Figure 8 and case study below "Who are the palm oil smallholders in Indonesia?") and because they produce around $40 \%$ of global palm oil (42).

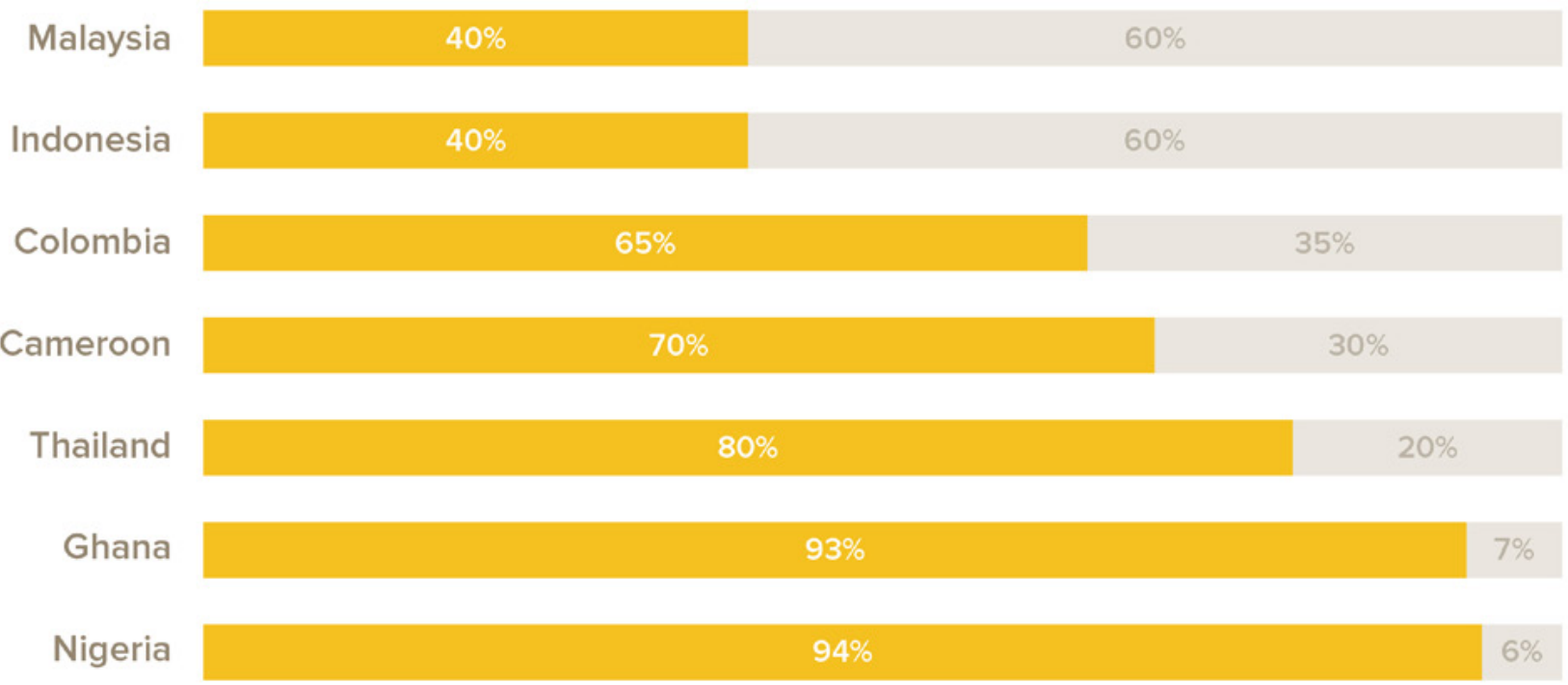

Figure 8. Proportion of the area of smallholder and large landholder concessions in selected countries (9, 21, 43-46). 


\section{Box 3.}

\section{Who are the palm oil smallholders in Indonesia?}

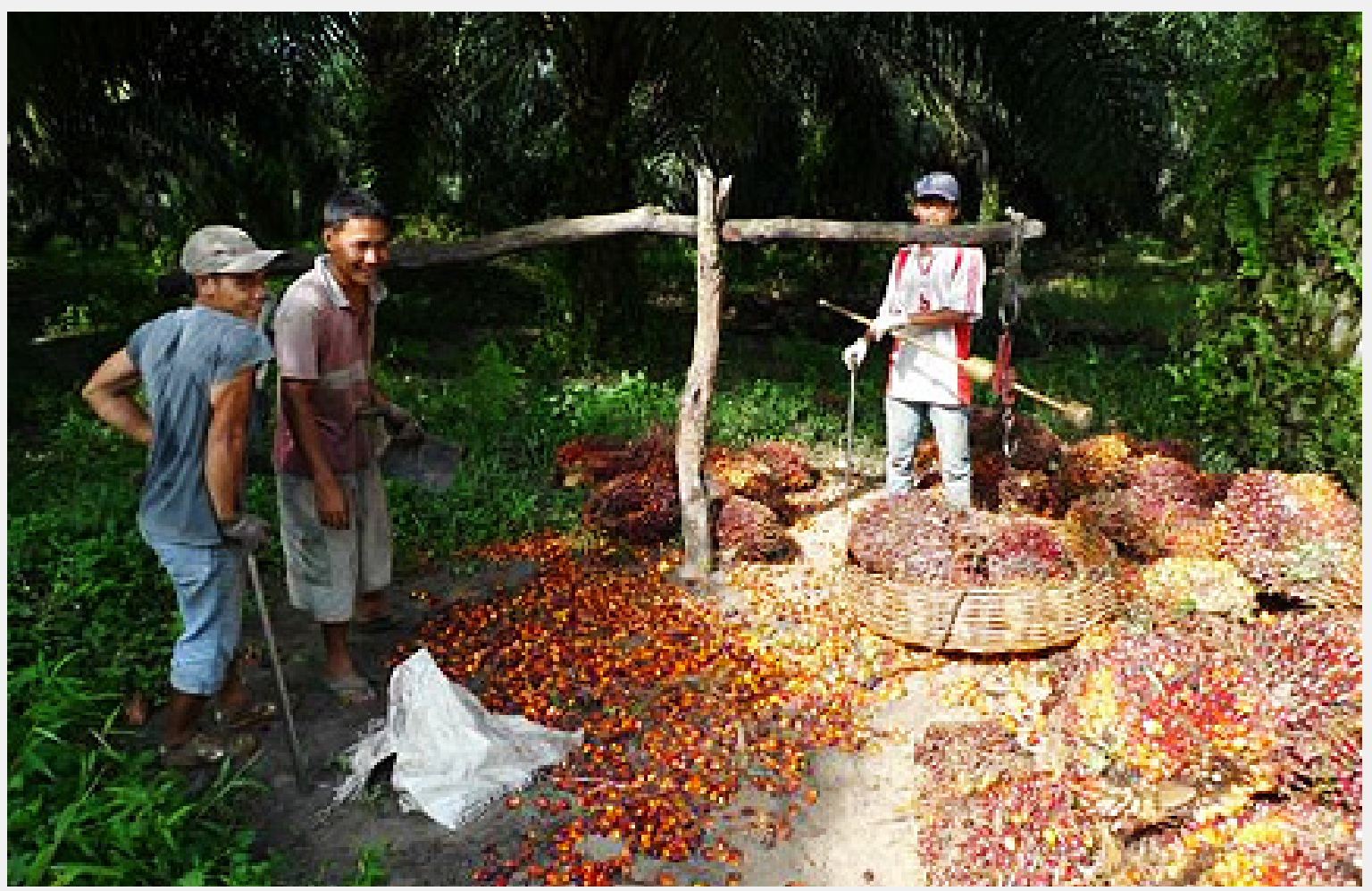

Figure 9. Oil palm labourers in Riau weighing fresh fruit bunches after harvesting them from a smallholder oil palm plantation. (C) Janice Lee)

To qualify as a 'smallholder farmer' in Indonesia, according to the government, farms must be less than 25 hectares, above which an agricultural business license is needed (49). In reality though, Indonesian smallholders are incredibly diverse. Because they manage about $40 \%$ of all Indonesian plantations by area, they are a vital but little-studied part of the palm oil story $(46,47)$. Little research exists on who these different growers are, and, important in the context of the current study, what impact they are having on biodiversity.

Some growers manage their plantations independently and are free to choose where they sell their fruit. Such smallscale "independent" smallholders are typically connected to an agent who purchases their fruit and sells them to neighbouring mills. On the other hand, company-managed growers rely on a specific company to manage or co-manage their plantations. Such farmers are contractually bound to sell their fruit to that company's oil mill $(27,47)$. These smallholders are labelled "plasma" or "scheme" smallholders by the government and the research community.

Some accounts suggest a new and emerging group of "elite" "smallholder" oil palm growers who have sufficient capital to establish larger oil palm plantations $(50,51)$. These growers can avoid licensing rules by registering their plantation areas under separate names and keeping each plantation below the 25 hectare limit. These growers can be viewed as "landlords" and may play an important role in the future of oil palm expansion and its impact.

Some of the "landlord" type growers own multiple plots of land and tend to reside in the same area as their plantations. Other growers who own an average plot size of around 50 hectares sometimes reside in a different district to their plantations. In some ways, these growers operate more like companies rather than smallholders. Both types of growers are more likely to be located on land classified in Indonesia as 'state forestland', which is typically not accessible to individual farmers, indicating that these actors have sought to claim new land not legally available for oil palm development.

In landscapes with a range of different types of oil palm growers with different licensing responsibilities, it can be difficult to assign responsibility for deforestation and fires given unclear land tenure and overlapping claims (25). 
Studies have segregated palm oil producers based on the size of their plantations, whether they are locals or migrants, and the presence and nature of any financial assistance $(27,30,39,47)$. The average size of an oil palm smallholding ranges from 2-4 ha in Papua New Guinea (35), 5-10 ha in Peru (40), 8-40 ha in Cameroon (39), while smallholder oil palm plantations in Peninsular Malaysia are generally less than 4 ha each and typically support mixed-age stands where oil palms are intercropped with other commercial plants (e.g., bananas, cassavas, coffee, or indigenous fruit trees) (34). Increasingly, there are reports of medium to large-scale oil palm plantations across all three continents, which are often owned by urban investors and operate under legal frameworks for smallholders. Such producers own 20-200 ha of oil palm plantations in Colombia (9), 10-200 ha in Cameroon (48), 10-1,200 ha in Indonesia (30, 47), and 309-7,128 ha in Papua New Guinea (35).

The variation in producer groups across palm-oil producing countries is a consequence of the history, development policies, and political economy of the country, province, state or district (Box 4). An understanding of the range of oil palm production models is crucial to evaluating the positive and negative impacts of oil palm development in each country.

Box 4.

\section{The social dynamics of biodiversity loss and conservation in oil palm landscapes}

The links between social dynamics and biodiversity are complex and vary a great deal from place to place and through time. Deforestation often (52-55) accelerates when indigenous peoples' and local communities' land rights are not protected, although there are exceptions $(56,57)$. Conversely conservation goals are more likely to be achieved where communities' rights are respected (58-60), although evidence for this is mostly based on selected case studies rather than counterfactual thinking and objective impact evaluation (61).

Agrarian reforms, which - instead of redistributing farmlands - target forests as an 'escape valve' to lessen rural dissent about landlessness, may benefit people but may also lead to rapid forest loss $(62,63)$. Land tenure regimes and land governance systems which effectively protect local peoples' rights are therefore widely recognised as essential to responsible forest management and commodity production as well as conservation, and are also ethically appropriate (64).

In the palm oil sector, the links between tenure insecurity and accelerated deforestation are well documented, for example, the lack of secure rights for forest peoples opens up forested areas to investors seeking to establish plantations (65, 66). When the customary lands of communities are taken over without consent or compensation ('land grabs') then pressure on remaining forests intensifies (67). Ensuing land conflicts impose high costs on companies and communities alike and paralyse land governance, thereby disrupting both plantations and conservation efforts (68-71).

Field studies show that company efforts to protect conservation set-asides in accordance with voluntary standards - such as the Roundtable on Sustainable Palm Oil, the High Conservation Value system and the High Carbon Stock approach - run into problems: when land tenure laws prevent company set asides yet do not respect community rights $(72,73)$; when management and monitoring is weak and fails to include local people (74); when inadequate lands are set aside for local livelihoods causing people to occupy conservation areas for lack of alternatives $(72,75)$ and; when companies exclude forested areas from their concessions yet communities are offered no incentives to look after these areas (76). Voluntary standards now require 'integrated conservation and land use plans' based on respect for customary rights and the free, prior and informed consent of communities, in order to overcome these deficiencies ( 77 , 78).

The direct links between weaknesses in land governance, including corruption and collusion over obtaining oil palm development permits, are well established in the academic literature on forest management (79) and extensively documented in the grey literature on oil palm (80). 


\subsection{Oil palm and international agreements}

Ongoing and projected oil palm expansion has substantial implications for existing international sustainability strategies, goals, and targets agreed by all nations. Countries that have committed to these policy frameworks can use them to develop and implement national policies to support sustainable palm oil production and reduce impacts on biodiversity.

\section{The Convention on Biological Diversity}

One-hundred and ninety-six countries, including all oil palm producing nations, are parties to the Convention on Biological Diversity (CBD) (81). They are committed to the Strategic Plan for Biodiversity 2011-2020, which has a mission to "take effective and urgent action to halt the loss of biodiversity (82). Thus, in cases where oil palm production causes the loss of biodiversity, for example in driving deforestation (see Section 2.1), countries are committed to implementing responses (see Section 3.3) to prevent this loss. The Strategic Plan for Biodiversity 2011-2020 encompasses 20 specific Aichi Targets. Many of these are directly relevant to oil palm production and consumption (Box 5).

The current Strategic Plan for Biodiversity expires in 2020, and consideration of the implications of oil palm for biodiversity conservation provides insight into how governments might want to formulate targets within a new strategic plan. For example, it would be valuable to consider incorporation of a target for avoiding unsustainable hunting of terrestrial species - a key issue in oil palm landscapes (Section 2.2) - given that the current strategic plan only targets sustainable harvest of aquatic species (Aichi Target 6).

\section{The Sustainable Development Goals}

In 2015, the world's governments also adopted the 2030 Agenda for Sustainable Development incorporating 17 Sustainable Development Goals (SDGs). Goal 15, to safeguard life on land, is the most directly relevant SDG to the implications of oil palm for biodiversity conservation. However, nearly all of the Sustainable Development Goals are relevant to palm oil sustainability in one way or another: other particularly notable goals are those for ending poverty (Goal 1), clean water (Goal 6), economic activity (Goal 8), responsible production and consumption (Goal 12), climate action (Goal 13), and stable governance (Goal 16).

Two characteristics of the Sustainable Development Goals are crucial for the relationship between oil palm and biodiversity conservation: they are universal (they apply equally to all countries) and they are indivisible and of equal value. Their universality commits governments to action on oil palm and biodiversity conservation in consuming as well as producing nations. Their indivisibility commits governments to prioritise the biodiversity and other environmental implications of oil palm at the same level as social and economic aspects.

\section{Climate change and desertification related conventions}

Besides the CBD, there are other 'Rio Conventions' that establish intergovernmental targets of direct relevance to oil palm and biodiversity conservation. Overall, 196 countries are Parties to The United Nations Convention to Combat Desertification, and its 2018-2030 Strategic Framework provides a global commitment to achieve "Land Degradation Neutrality". Similarly, the United Nations Framework Convention on Climate Change, to which 197 countries are Parties, agreed to the Paris Agreement of 2015 , to limit climate change to less than $2^{\circ} \mathrm{C}$ above pre-industrial levels. The establishment of oil palm plantations on ecologically degraded lands could advance both commitments, but they would be compromised if oil palm is allowed to drive deforestation, forest degradation and peat land loss (83). 
Box 5.

\section{Oil palm and the Aichi Targets (82)}

At least 11 of the 20 Aichi Targets are directly relevant to oil palm and biodiversity conservation:

Target 2 requires integration of biodiversity values into development and poverty reduction strategies and planning processes. Such national and regional planning across landscape levels is essential for avoiding leakage in preventing oil palm impacts on biodiversity.

Target 3 calls for reform of incentives and subsidies harmful to biodiversity, and application of positive ones. Incentives reform is a clear measure available to countries in ensuring sustainability of palm oil.

Target 4 requires sustainable production and consumption, and Target 7 demands sustainable management of agriculture. Options for ensuring oil palm sustainability are available to producer countries. Tools to strengthen sustainable consumption are also available for consumer countries.

Target 5 requires that rates of deforestation and other natural habitat loss are halved. The degree to which oil palm causes deforestation is highly variable over space and time (see section 2.1), but where it is a driver, natural forest conversion for oil palm production must clearly be reduced to achieve this target.

Target 8 demands the reduction of pollution to levels not harmful to biodiversity. The impacts of the use of pesticides, fertilisers, and palm oil mill effluents in oil palm plantations are poorly known and so an important research priority.

Target 11 calls for equitable management of protected areas and other effective area-based conservation measures. Well- managed protected areas and set-aside areas are important in ensuring that oil palm does not cause biodiversity loss. A target of $17 \%$ of land protected increases pressure on land for other uses.

Target 12 requires the recovery of threatened species. Oil palm-driven deforestation should be avoided, especially in areas holding threatened species and species found nowhere else. However, oil palm plantations can also provide a beneficial habitat for some species, especially if hunting is controlled, and in comparison, to degraded lands and other agriculture (see section 2.2).

Target 13 seeks to maintain the genetic diversity of domesticated species; retaining the genetic diversity of oil palm will be essential if the crop is to expand into new lands as projected under current scenarios (see section 4).

Target 19 calls for closing knowledge gaps regarding biodiversity. Many issues regarding the implications of oil palm for biodiversity conservation remain poorly known, and research on these is a priority.

Target 20 requires the mobilisation of finances to implement the Strategic Plan for Biodiversity 2011-2020 from all sources. A number of such sources are available for addressing the implications of oil palm, including through the Global Environment Facility and Green Climate Fund, international financial instruments, overseas development assistance, incentive mechanisms, and private sector investment. 


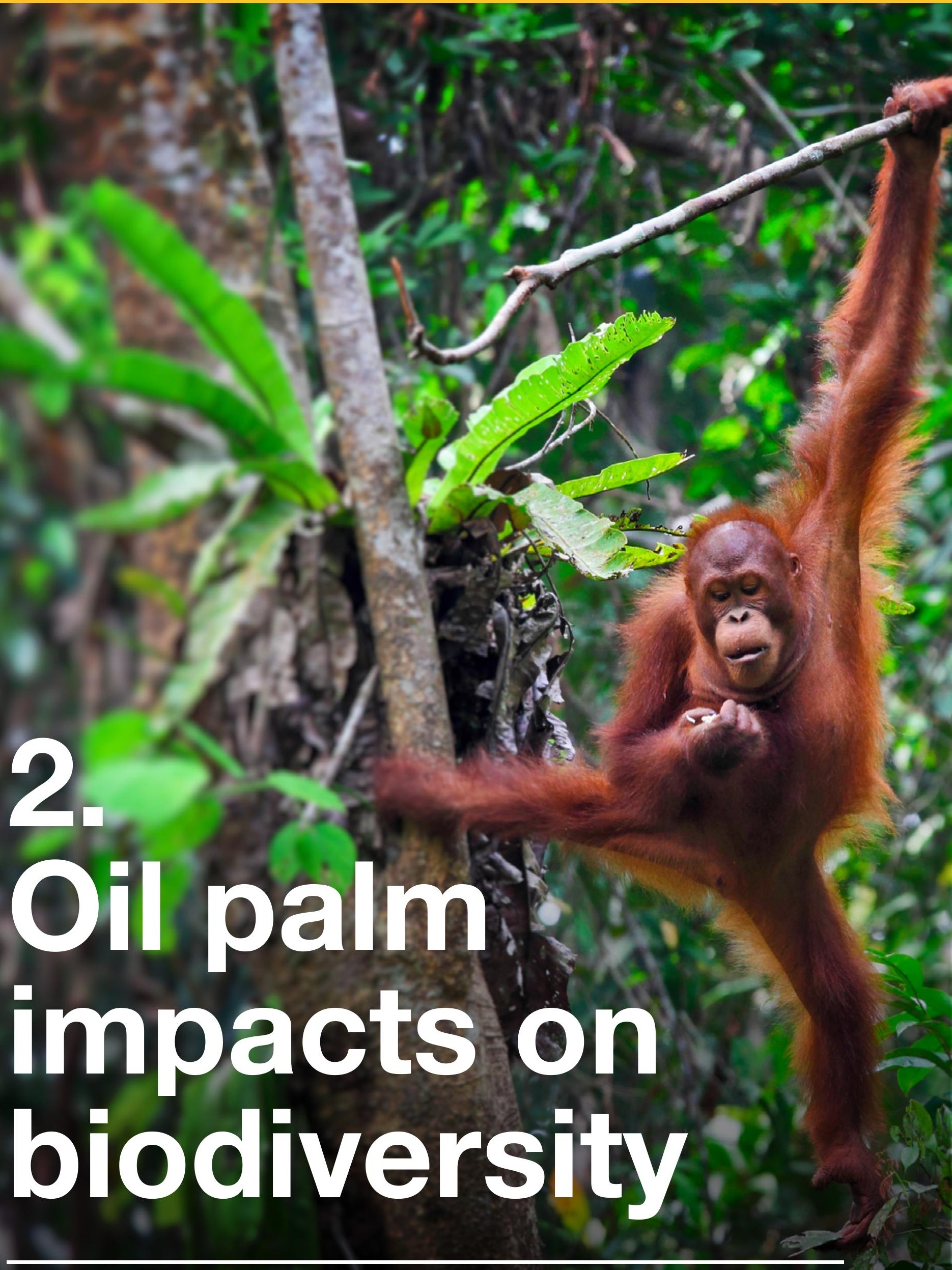


- Habitat loss caused by deforestation and fire prior to oil palm development is the main direct impact on biodiversity. Globally oil palm development causes less than $0.5 \%$ of all deforestation, but in parts of the tropics this can be much higher, e.g. up to 50\%.

- Ecologically and structurally oil palm plantations are much less diverse than tropical rainforests and species diversity therefore declines significantly once forests are converted to oil palm.

- Some studies indicate higher ecological and species diversity in smallholder plantations compared to industrial-scale ones, but conservation benefits of smallholder plantations are likely to be limited because of their lower yields and thus greater land needs.

- Human-wildlife conflict often increases following the establishment of oil palm, with species like orangutans and tigers being displaced when forests are cleared for oil palm, causing conflict with people living around the plantations.

- Other indirect impacts of oil palm on biodiversity include greenhouse gas emission related to deforestation and peat-drainage, the use of fire in land clearing and resulting smoke-haze, downstream water quality and freshwater species diversity, invasive species associated with oil palm, pest-spillover effects, and secondary impacts of hunting.

- Some species, primarily ecological generalists, such as pigs and certain snakes, benefit from the presence of oil palm because of high availability of food items like oil seeds and rodents, such as rats and squirrels. 
The impacts of palm oil production on biodiversity are well documented (84-87) and highly publicised. They include habitat loss and degradation (e.g. of natural forests and peatlands), declines in species populations (e.g. orangutans being the most wellknown and cited species), and other less obvious impacts such as indirect (e.g. induced in-migration and road building) and cumulative (i.e. landscape effects in combination with other land-use changes) impacts. However, many of these impacts have not always been put into context (e.g., comparison with other crops), or their complexity fully acknowledged.

\subsection{Deforestation and oil palm expansion}

The contribution of oil palm development to deforestation depends on the definition of forest, and the geographic and temporal scope of analysis. This study reviewed the available information (see Appendix 3) and found great variability, both geographically and over time in both the absolute (area) and relative (proportion of a country or region) of deforestation due to oil palm planting. One study suggests that between 2000 and 2013, just 0.2\% of global deforestation in what they term "Intact Forest Landscape" area was converted to oil palm (88) (Figure 10). In the tropics, a more relevant region because this is where oil palm grows, oil palmdriven deforestation rates have been much higher. In Malaysia, for example, oil palm development accounted for $47 \%$ of deforestation from 1972 to 2015 (Figure 10). In Indonesia, the world's leading palm oil producer, around $16 \%$ of forest loss was directly linked to the commodity over the same period (Figure 10). The pattern is similar if one looks at deforestation patterns on the island of Borneo (Box 6). One study in Nigeria suggested that oil palm made up just $3 \%$ of forest loss in the early 2000 s (89). Estimates of oil palm's contribution to total forest loss in Central and South America, as well as the remainder of West Africa, are unavailable.

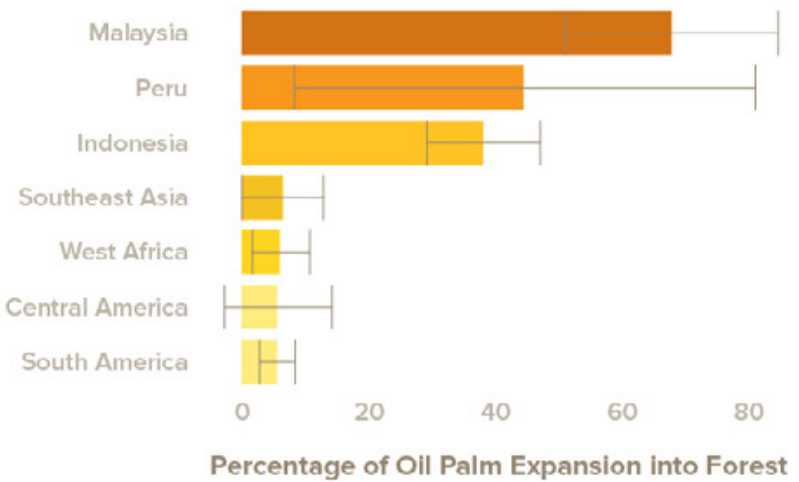

Figure 10. Oil palm's role in deforestation. The figure on the left depicts the contribution of oil palm to overall deforestation, while the figure on the right shows the percentage of all oil palm expansion that cleared forest. Southeast Asia (SE Asia) excludes Indonesia and Malaysia, while South America excludes Peru. Bars indicate the standard deviation of the sample mean weighted by study area.

Not all oil palm development results in the loss of tropical forests. Across the tropics, this study found that about half of oil palm development between 1972 and 2015 expanded into forested lands, the other half replaced croplands, pasturelands, shrublands, and other land uses. This ranges from $68 \%$ expansion into forests in Malaysia and $44 \%$ in the Peruvian Amazon, to just 5-6\% in Central America, South America excluding Peru, and West Africa (Figure 10). To what extent oil palm expansion causes indirect land use change, i.e., the displacement of pasture and other crops into forest lands that would otherwise not have expanded there, remains poorly known.

Only a few studies have tracked the contribution of smallholder oil palm expansion to tropical forest loss. Future research is needed to understand the role of smallholder oil palm farmers, who produce around $40 \%$ of global palm oil (90), in forest cover loss. 
Box 6.

\section{Oil palm the biggest driver of deforestation in Borneo since 2005}

Borneo is the world's largest palm oil producing region, with 8.3 Mha of industrial oil palm plantations as of year 2016 (see also (91) to view maps interactively) (92). In Malaysian Borneo, palm oil is the largest destroyer of species-rich rain forests. Between 1973 and 2015, industrial oil palm accounted for $57-60 \%$ of all deforestation in that region (92). But the case is more complex in Indonesian Borneo. Long before oil palm came on the scene, Indonesian Borneo suffered large-scale forest loss and degradation due to timber extraction and burning. This cleared land allowed some industrial plantations, such as oil palm, to be developed without additional forest loss.

Deforestation rates linked with oil palm developments have been particularly marked in Borneo since 2005, the year that marks the beginning of Indonesia's palm oil production boom (92) (Figure 11). From 2001 to 2016, forest area loss averaged 350,000 ha annually (93). Between 2005 and 2015, industrial oil palm plantations became the primary driver of deforestation in Borneo, accounting for $50 \%$ (2.1 Mha) of Borneo's old-growth forest area loss (4.2 Mha) (92). Oil-palm driven deforestation has been more severe in Malaysian Borneo than in Indonesian Borneo, the latter being where more plantations have been established on ecologically degraded non-forested lands than at the expense of forests (92).

Unknowns remain: for example, this research was only able to track industrial-sized palm oil concessions, leaving small growers out. Experts believe smallholders may be linked to a significant amount of deforestation - but more research is needed.
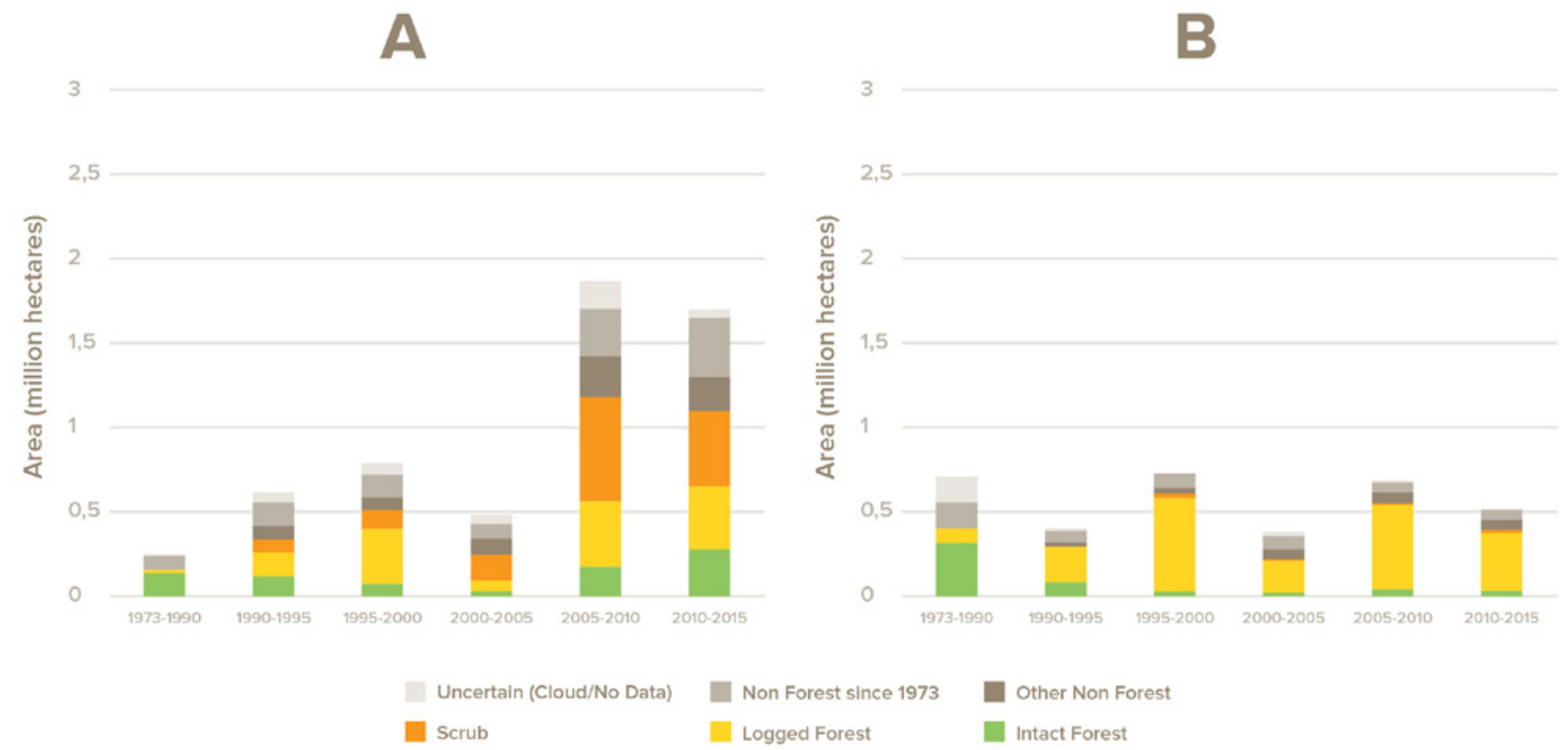

Figure 11. The expanding area (7.8 Mha) of industrial oil palm plantations in six time periods from 1973 to 2015 with vegetation cover of the land just before observed conversion to oil-palm in Indonesian Borneo (A), and Malaysian Borneo (B). 
Box 7.

\section{Rotten palm oil; the Tripa case}

In the late 1980s, the Tripa swamp forests on the Indonesian island of Sumatra, covered more than 60,000 hectares and were home to more than 3,000 Sumatran orangutans and countless other species. (94). Through the 1990s, several oil palm companies cleared forests and drained peatlands to make way for oil palm. In 1998, the Ministry of Forestry reclassified wildlife-rich Tripa from state forest land to land for other use, officially opening Tripa up to agriculture $(95,96)$.

In the early 1990s, the government granted concessions to several palm oil companies. They cleared large parts of the forest, drained the peat, and planted palms (Figure 12). Ten years later, half of the Tripa swamp forest had been converted to monoculture plantations (94). While the civil war in Aceh led to a reduction in oil palm expansion in Tripa, in the mid-2000s the district governments started granting concessions to oil palm companies, despite official statements that forests in the region were protected as part of the vast Leuser Ecosystem (94).

In 2011, a consortium of local NGOs filed a lawsuit against PT Kallista Alam, one company operating inside no deforestation zone, which had been recently classified by the Indonesian Primary Forest and Peatland Moratorium issued by the President. Despite this injunction, in March 2012, companies set more than 90 fires to clear land within their illegal boundaries, burning forest and leaving lasting environmental damage (94). Eight months later, the Indonesian Ministry of Environment filed a new charge against these companies. In January 2014, the district court ordered PT Kallista Alam to pay fines of about \$27 million for illegal clearance of 1,000 hectares of protected forest. However, by 2016, these fines remained unpaid, despite a ruling by the Supreme Court of Indonesia. (97).

The clearing of the Tripa peatswamp forests by rogue palm oil companies was halted due to three main factors. First, researchers had precise, accurate and verifiable data to document the environmental infractions. Second, a consortium of actors, including NGOs and local community members, decided to work together for a shared goal. And finally, and most importantly, the government took action. If not for these factors, there would potentially be zero forest or orangutans left in Tripa (98). But it also shows that some oil palm companies are willing to flout the rules, especially in remote areas where government supervision and monitoring is difficult.

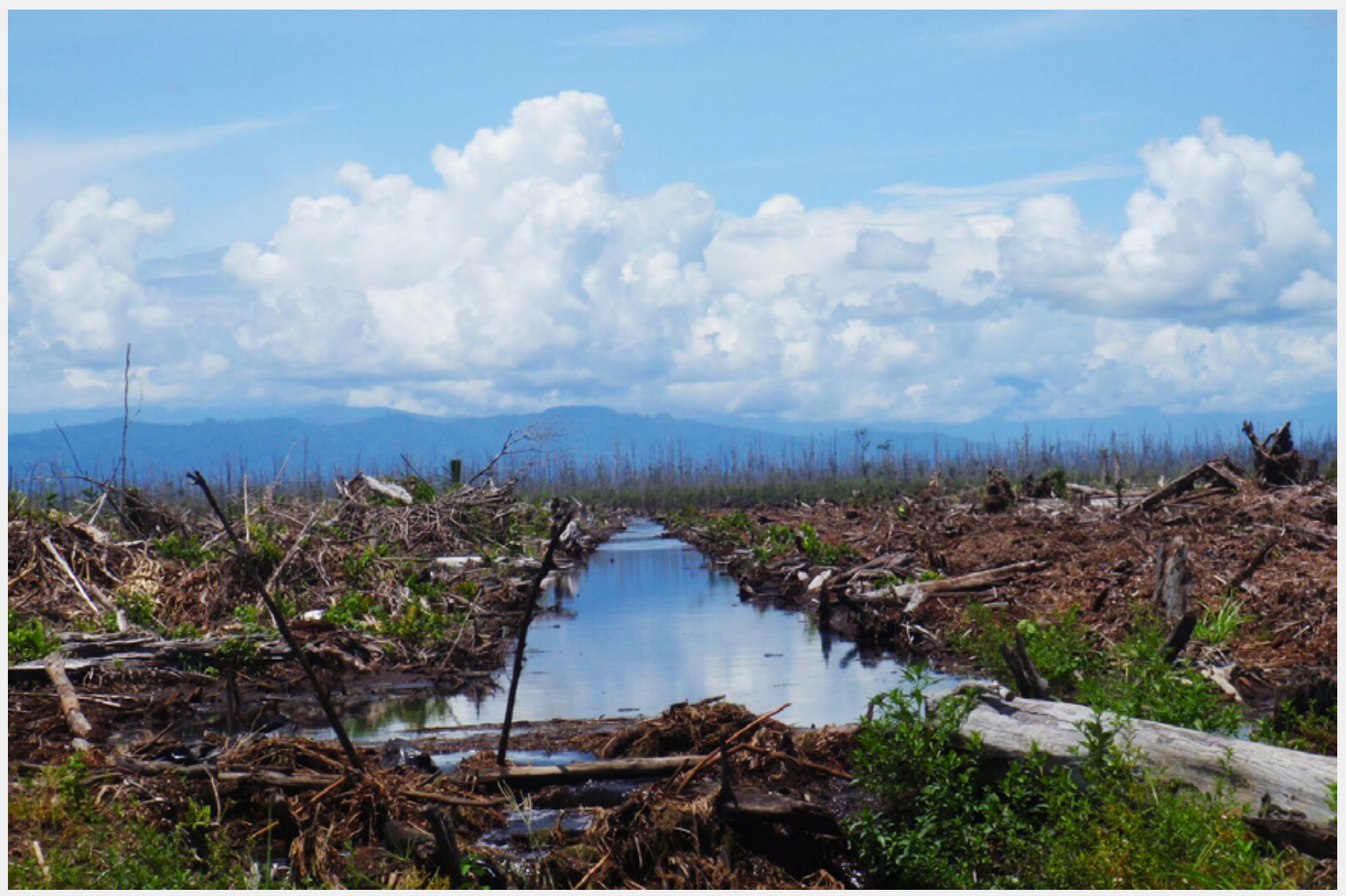

Figure 12. The Tripa peat swamp area, a former rich wildlife habitat, clear cut, burnt and drained. (@ lan Singleton) 


\subsection{Impacts on species}

Globally, agriculture and aquaculture rank as the most common threat to species listed on the IUCN Red List of Threatened Species (under Red List Categories \& Criteria version 3.1.) as Critically Endangered, Endangered or Vulnerable, above biological resource use (hunting and trapping, gathering plants, logging and fishing) and natural system modification (fire, fire suppression, dams and water management) (Figure 13). A total of 9,251 of these species are threatened by agriculture and aquaculture. Within this category, most species are threatened by smallholder farming categories followed by agro-industry farming and shifting agriculture in annual and perennial non-timber crops (Figure 14). The IUCN Red List categories, however, do not specifically list oil palm agriculture as a threat. A more in-depth search with key words "palm oil" or "palm plantation" or "oil palm" within Threats text boxes for the species assessments revealed that globally 405 species have oil palm mentioned in these texts. Of these, 193 are listed as Critically Endangered, Endangered or Vulnerable.

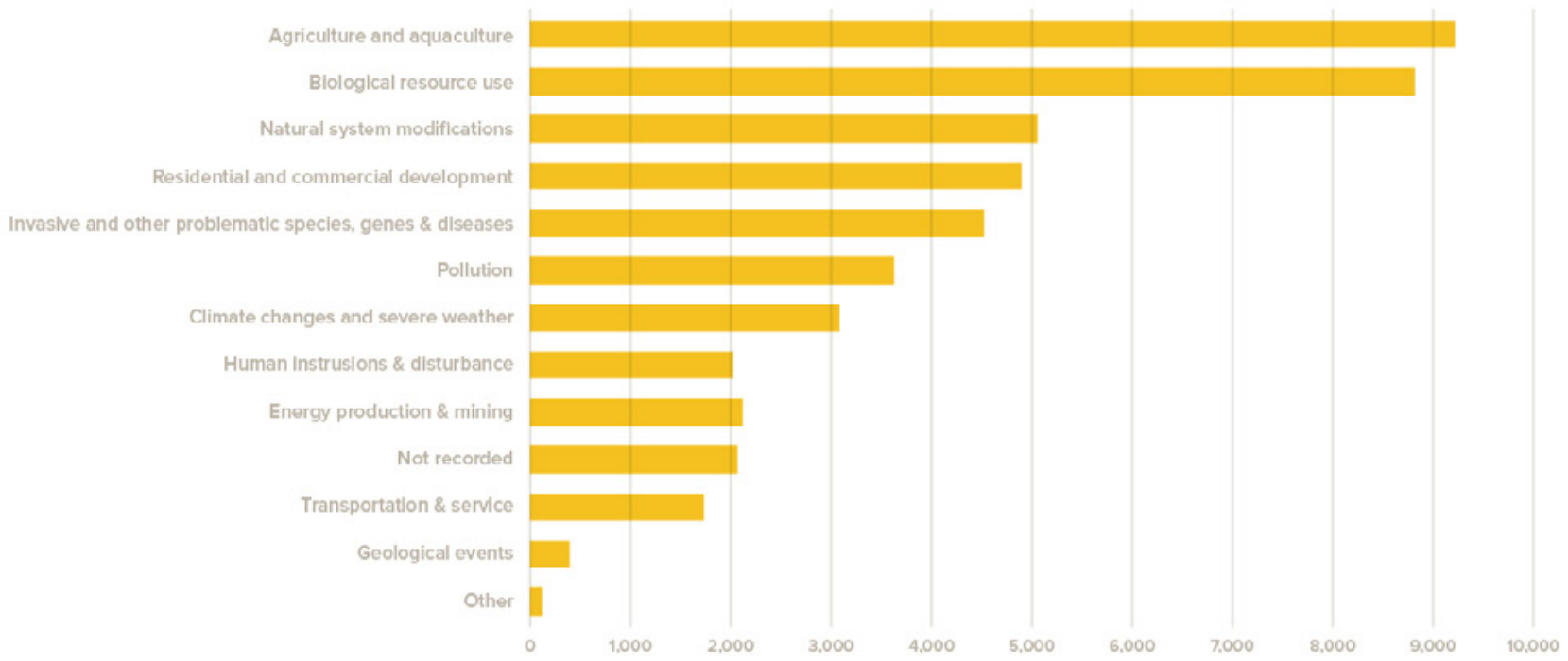

Figure 13. Number of threatened species (only Critically Endangered, Endangered and Vulnerable species) affected by the highest level of the threat classification schemes as recorded in the IUCN Red List of Threatened Species, accessed in December 2017.

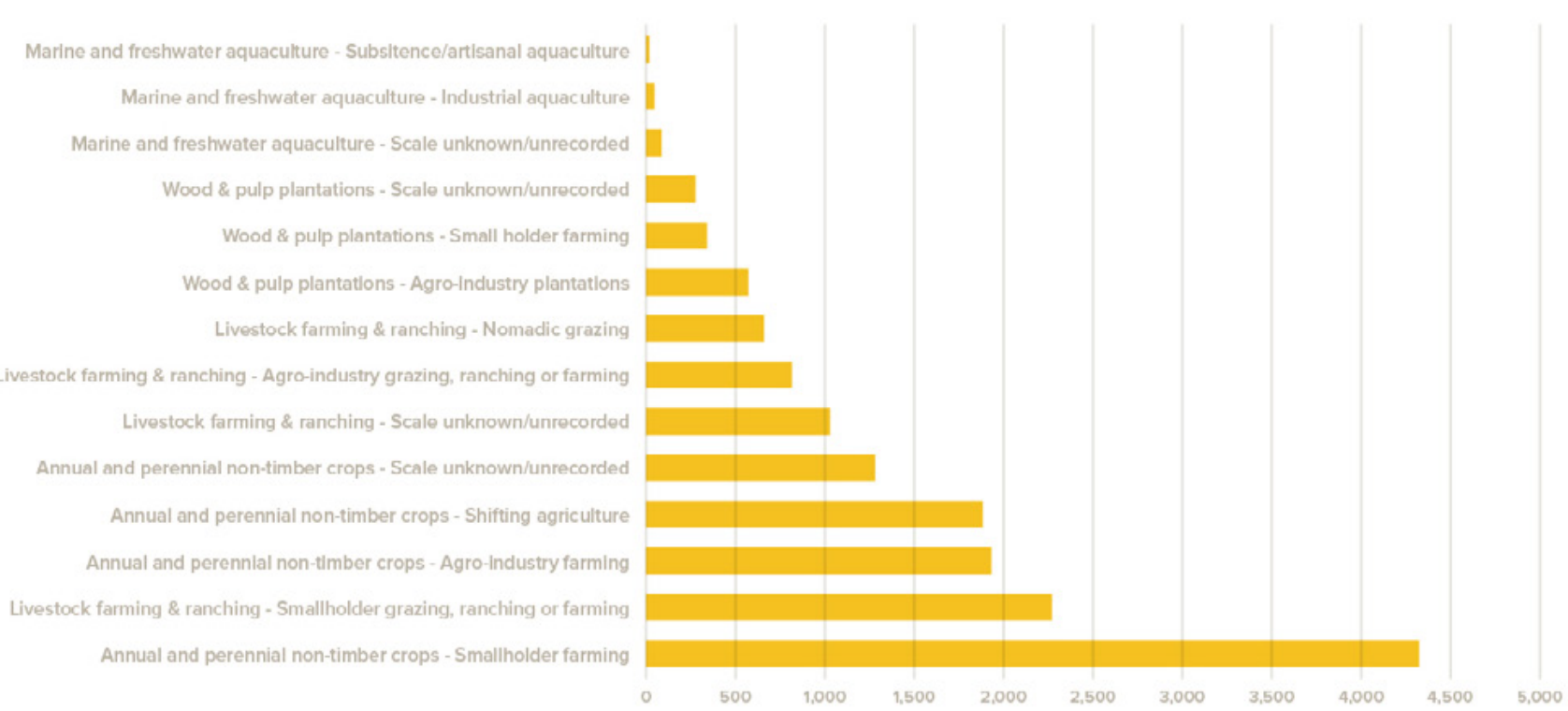

Figure 14. Number of threatened species (only Critically Endangered, Endangered and Vulnerable species) affected by different types of threats from agriculture and aquaculture as recorded in the IUCN Red List of Threatened Species accessed in December 2017. 
Evidence shows that palm oil production has had substantial negative impact on most species, mainly through the clearing of natural forests on mineral and peat soils (which also requires drainage) to make way for plantations (84-87). Other reported impacts include run-off of fertilizer and pesticides (99), which likely affects freshwater biodiversity. Indirect impacts also include poaching and trapping of birds, mammals and snakes in plantations.

Severely affected species include orangutans (see case study below), gibbons (100), tigers (101), and forest specialist species, such as muscicapine (Old World) flycatchers (102). Tree and other plant diversity is severely reduced with some planted areas showing more than 99\% less tree diversity than natural forests (103). Oil palm plantations also contain fewer animal species $(103,104)$ with studies showing a reduction in mammal diversity of $65-90 \%$ $(105,106)$. Most species groups decline in both richness and abundance (103, 107-109) (Figure 15), with IUCN Red-listed mammals declining by $85 \%$ (110), although there are some exceptions (87). Generally, the simple ecological structure of oil palm favors generalist species such as pigs (Box 8) and some mammalian carnivores such as the leopard cat Prionailurus bengalensis and Malay Civet Viverra tangalunga (110), while forest-dependent species, such as arboreal, fruit-eating gibbons, rarely manage to survive in monocultural stands of oil palm (87, 103). Oil palm also displaces certain forest species, which generates conflicts with people in the oil palm landscapes over agricultural crops, as well as conflict-killings. This has been well demonstrated for orangutans $(111,112)$ (Box 9), as well as tigers (113), elephants (114) and rhinos (113). Over the last four decades, species have slid towards extinction twice as fast in Indonesia as in any other country (115), at least in part as a result of forest conversion for oil palm production.

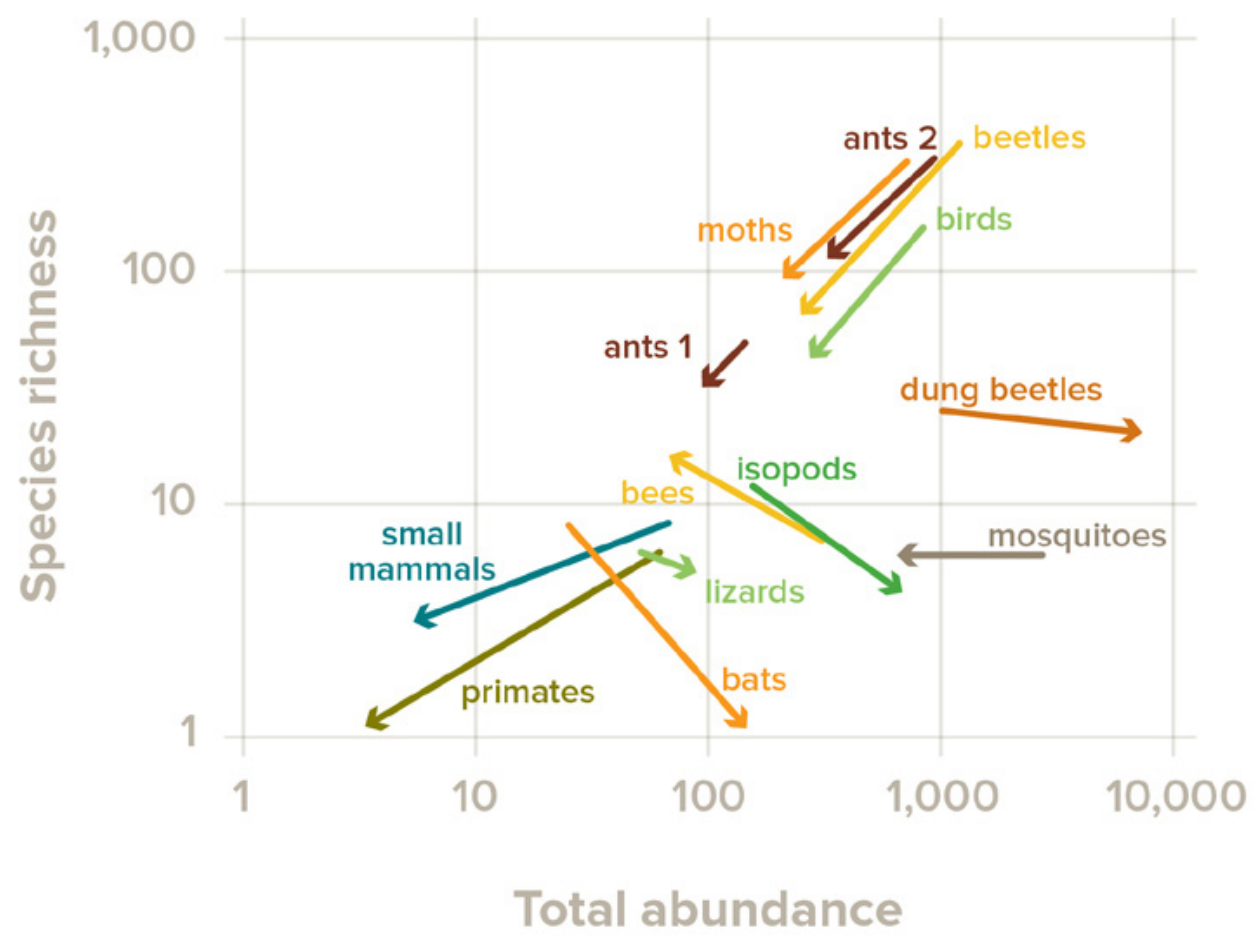

Figure 15. The impacts of converting primary rainforest into an oil palm plantation on the abundance and species richness of different taxa. Arrow tails denote primary forest communities and arrow heads oil palm communities (103). 
Box 8.

\section{Pigs in plantations}

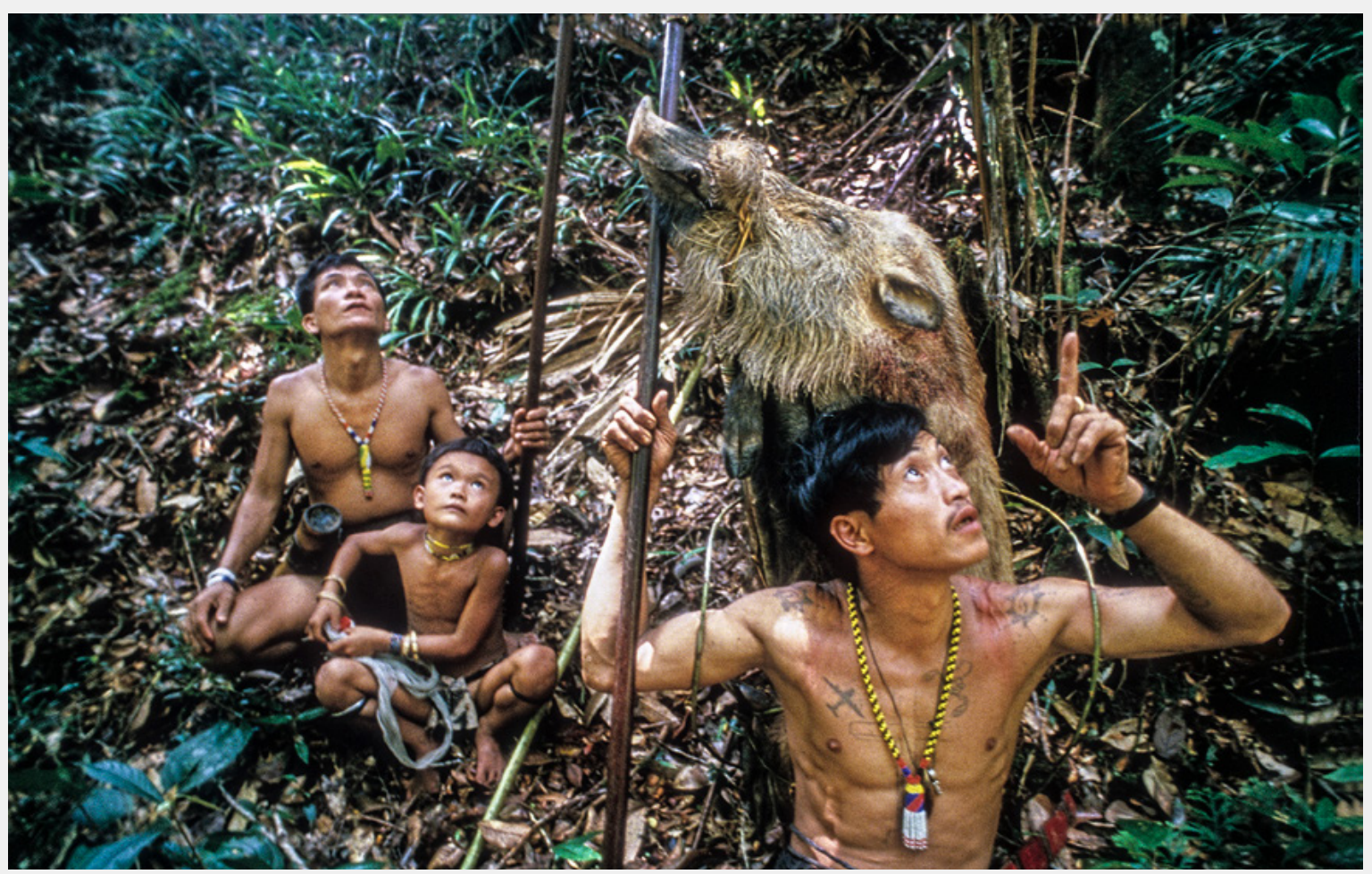

Figure 16. Bearded Pigs are an important source of food for many, including these nomadic Penan people of central Borneo. (C) David Hiser)

Pigs are an important protein source to many forestdwelling people (116) (Figure 16). For example, the striking looking Bearded Pig (Sus barbatus), named because of its remarkable beard, has significant cultural and economic importance for rural communities on Borneo, Sumatra and the Malay Peninsula, where it has been hunted for thousands of years for food (117).

Until relatively recently, the Bearded Pig was widespread and fairly common across the Malay Peninsula (118). A long and narrow strip of land sitting at the southernmost point of the Asian mainland, this commodity-rich region produces tin, rubber, timber, coconut and palm oils, pineapples and bananas. To sustain such high levels of agricultural production, large-scale logging and deforestation has made way for the planting of vast swathes of land, and palm oil plantations have proliferated.

As oil palm plantations expand, the clearance of natural forest habitat (often coupled with unsustainable hunting) has triggered the serious decline of many species including the Bearded Pig, although another species of pig, the Wild Boar (Sus scrofa) was thriving (119). Where previously commonly found in Peninsular Malaysia, Bearded Pigs suffered a drastic drop in numbers and, at the turn of the 21st Century, were thought to have possibly disappeared altogether.

That was until 2015, when, during a survey of the east coast of the Malay Peninsula, direct observations revealed the existence of the pigs in oil palm plantations (120). Faced with being killed by plantation workers, as a pest or for a meal, why do pigs take this risk? Largely, it would seem, to feed opportunistically on the fallen palm fruits - a dependable and easily available resource in an otherwise ecologically simplified habitat. It is unlikely that these plantations provide a safe haven as they can be freely hunted. For example, one hunting study site in Borneo found that the local abundance of Bearded Pigs was $91 \%$ lower in oil palm compared to surrounding forest (110).
Given the commonly monocultural nature of oil palm cultivation, the simple, one canopy layer structure of plantations, the almost complete absence of leaf litter, the lack of understory vegetation and woody debris, and the more open canopy, it is hardly surprising that the species diversity of oil palm 
concessions is lower than that of natural forests. A different but also important comparison is that between the biodiversity impacts of oil palm and other oil-producing crops, such as soy, maize, rapeseed, sunflower, coconut, and ground nut, or with agricultural and silvicultural crops in general (121). Some work towards this is being undertaken (see case study below). Another relevant comparison is between monocultural and polycultural oil palm, with the latter showing significantly elevated levels of bird diversity (122), but lower abundances (123). Related to this is the discussion on land sharing and sparing in oil palm (124, 125), i.e., whether palm oil production from high-yielding oil palms in landscapes dedicated to palm oil production has less impact on biodiversity than palm oil produced in mixed landscapes of oil palm agroforestry. We describe key findings from this debate in Chapter 4.

Another important issue to consider is the role that oil palm plantations play in multifunctional landscapes (more towards the land sharing side of the sparingsharing continuum). Because oil palm plantations sit in landscapes with other land uses they can function as areas that animals can use as they move between forest patches, as has, for instance, been found for Bornean orangutans (126). This dispersal through multifunctional landscapes remains poorly understood: which species move through, how far do they move, do they need forested corridors or do they move through the actual oil palm stands, and do small patches of forest in plantations facilitate dispersal?

Box 9.

\section{Is palm oil the biggest killer of orangutans?}

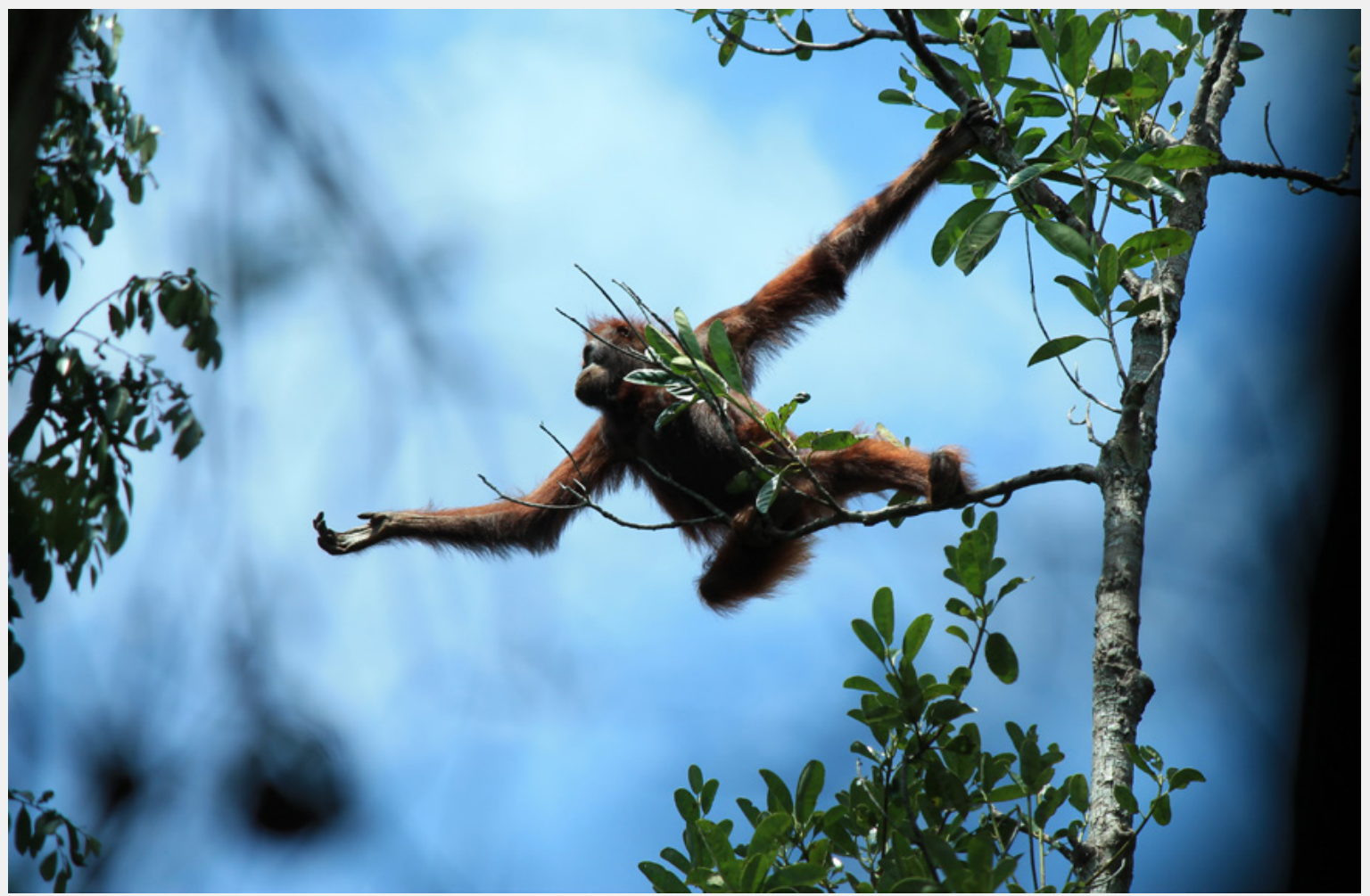

Figure 17. Orangutan in a forest set-aside in an oil palm plantation in West Kalimantan. (C) Nardiyono)

All three orangutan species are assessed as Critically Endangered on the IUCN Red List, predominantly because of habitat loss and hunting (127-129), and the numbers of Bornean orangutan (Figure 17) have declined by $25 \%$ during the past decade alone (130). Given these declines, we must compare the various threats to orangutans to improve conservation strategies (131-133). 
Recent evidence shows that hunting has been the primary driving force killing off local Bornean orangutan populations over the last 200 years $(134,135)$. Researchers have estimated that every year between 1,500-2,500 Bornean orangutans are killed, half of them shot during humanorangutan conflicts, which often are around expanding agriculture, while the other half is killed for meat $(111,134)$. Hunting is also a major threat for the newly described Tapanuli orangutan $(131,136)$.

Because a very large part of the low-lying areas of Borneo was occupied by orangutans in the past (137), it is fair to assume that the development of oil palm plantations across the lowlands resulted in a significant reduction in orangutan numbers. However, the decline of orangutans on Borneo started well before the onset of palm oil development in the 1970s $(135,138)$, and the deforestation story is also more complex than often presented. Between 2000 and 2010 , oil palm caused $22.8 \%$ of deforestation in Kalimantan (Indonesian Borneo) compared to 8.8\% resulting from timber plantations for production of pulp and paper, but in Sumatra things were the reverse with oil palm causing $9.3 \%$ of deforestation and timber plantations responsible for $25.3 \%$ (139).

Thus, although oil palm expansion is certainly a threat to orangutans (140), pulp and paper plantations, fire-induced deforestation, small-scale agriculture and especially hunting are main threats as well. Some 10,000 orangutans are currently found in areas on Borneo allocated to oil palm (140) and better management practices are urgently required to ensure these orangutans are not displaced or killed in the process of oil palm development.
In 2010, approximately 22\% of the orangutan's range in Borneo fell within protected areas, 29\% in logging concessions, and $19 \%$ within palm oil concessions that have not yet been converted (132). Currently, about 10,000 orangutans are found in undeveloped forest areas within oil palm concessions held by companies that have not been certified by the Roundtable on Sustainable Palm Oil (140). Companies holding these licenses can legally clear these forests, as long as they do not kill protected species, such as orangutans in the process. Suitable conservation solutions require engagement with the oil palm sector, unless government decides to withdraw plantation licenses (141). These types of situations where oil palm (and other) companies are operating in wildlife habitat will become increasingly common. This requires that we assess the role that companies can play in conservation management (133).

For orangutans this may not be too difficult. Although oil palm does not provide viable orangutan habitat, orangutans are capable of persisting to some extent in palm oil landscapesas long as some natural forest with connectivity is maintained. Increasingly, researchers have seen orangutans nesting in palms, feeding on fruits or dispersing through oil palm areas (126). This does not mean that oil palm is a viable orangutan habitat. Forest areas have to be set aside and actively managed to ensure long-term survival of orangutans and other species. We know this is possible. At least one plantation in West Kalimantan currently manages 150 orangutans in their landscape (142) where these animals are relatively safe. The challenge now is to step it up from one to one thousand plantations that also overlap with orangutan habitats.

\section{Box 10.}

\section{Look before you leap, for snakes among sweet flowers do creep...}

Most people spend their lives trying to avoid snakes. But in many parts of Southeast Asia, densities of several snake species have increased thanks to the rapid expansion of oil palm plantations. In most ecosystems, snake densities are strongly linked to the abundance of prey - more prey for snakes equals more snakes $(143,144)$. In naturally forested areas, prey abundance is limited by forest productivity, and by competition with other animals for limited resources. However, in oil palm plantations, tightly packed rows of palm trees provide an almost-limitless supply of energy-packed fruits (palm kernels).
Common to many highly nutritious agricultural crops is the increasing density of animals that feast upon them (145, 146). The chief beneficiaries of oil palm's expansion in Southeast Asia are several species of rodents that are often associated with humans (e.g., the Malaysian Field Rat Rattus tiomanicus, the Malaysian House Rat Rattus rattus diardii and the Rice-field Rat Rattus argentiventer). These particular species can sometimes reach extraordinarily high population densities in oil palm plantations (> 400 individuals/ha; 147 , 148) and cause immense damage to oil palm crops and to their profitability (148). As the density of rats increases, so do 


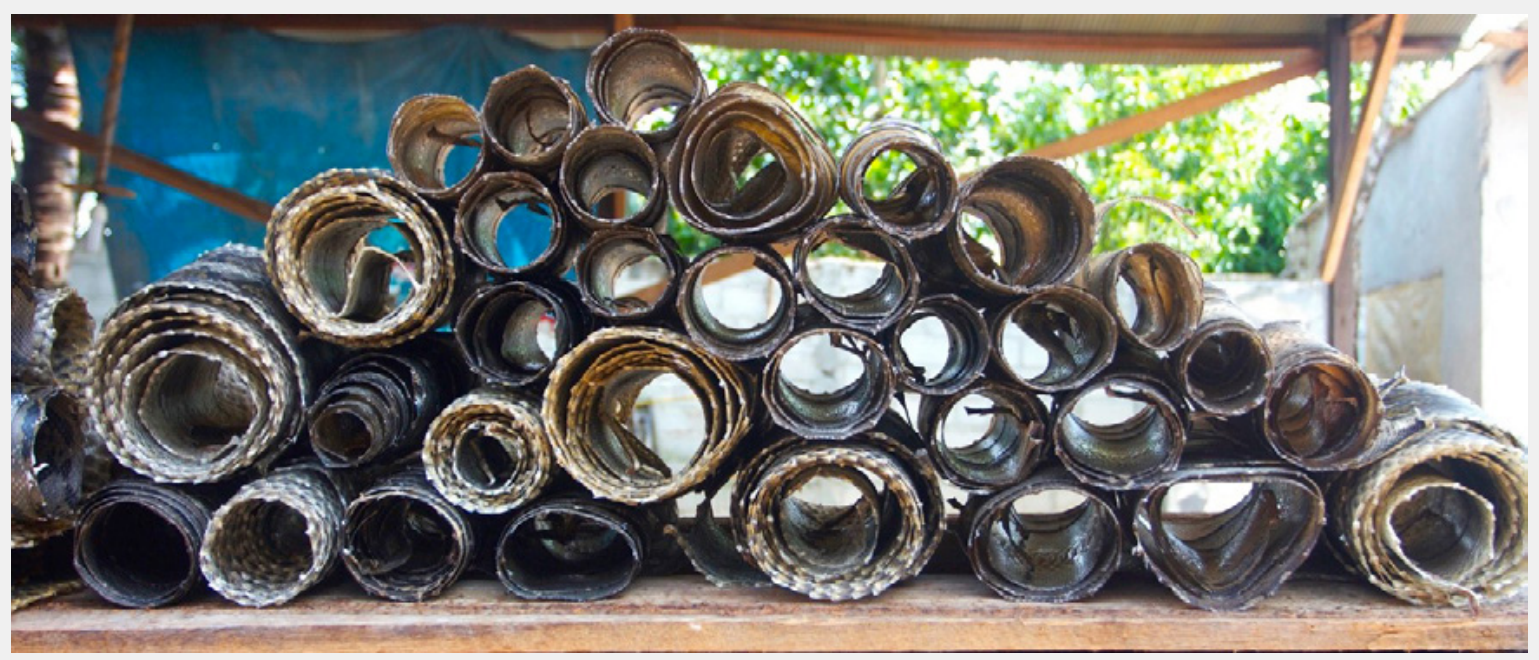

Figure 18. Dried python skins in Central Kalimantan, Indonesia. Several species of Southeast Asian snakes are utilised for their skins, which enter the global trade in exotic leather. (C Daniel Natusch)

the snakes that feed upon them (see Table 10 in Appendix 4).

For at least eight Asian snake species there is evidence that they thrive in oil palm plantations, and appear to have increased their densities in response to increased prey abundance (Table 1, Appendix). These snakes share several biological traits: many are habitat generalists (they do not require complex primary forest for survival); they all possess life-history traits that allow them to promptly respond to a food surplus (they grow and mature rapidly, and are highly fecund); and, most importantly, they all feed on rodents.

Intriguingly, this increase in abundance has improved the ability of local people to sustainably harvest snakes, which in turn improves their capacity to generate income from their natural resources. Each year, hundreds of thousands of tropical snakes are harvested from the wild to meet domestic and international demand for exotic leathers largely for the European fashion market (Figure 18). Snake harvests have been ongoing in Southeast Asia for decades and research on some species suggests that such off-take can be sustainable $(149,150)$. This is perhaps facilitated by the same traits that allow those snakes to thrive in oil palm plantations.

The majority of snakes harvested for trade are opportunistically captured in oil palm plantations by workers going about their daily activities $(150,151)$. Snake skin traders in Sumatra, Indonesia, report that Blood Pythons Python brongersmai are far more common now than before the expansion of oil palm 20 to 30 years ago (Fig. 3 in 151). This same phenomenon is true in other parts of the world, where densities of some snakes are higher in oil palm plantations than nearby forested areas, e.g., Africa (152) and South America (153).

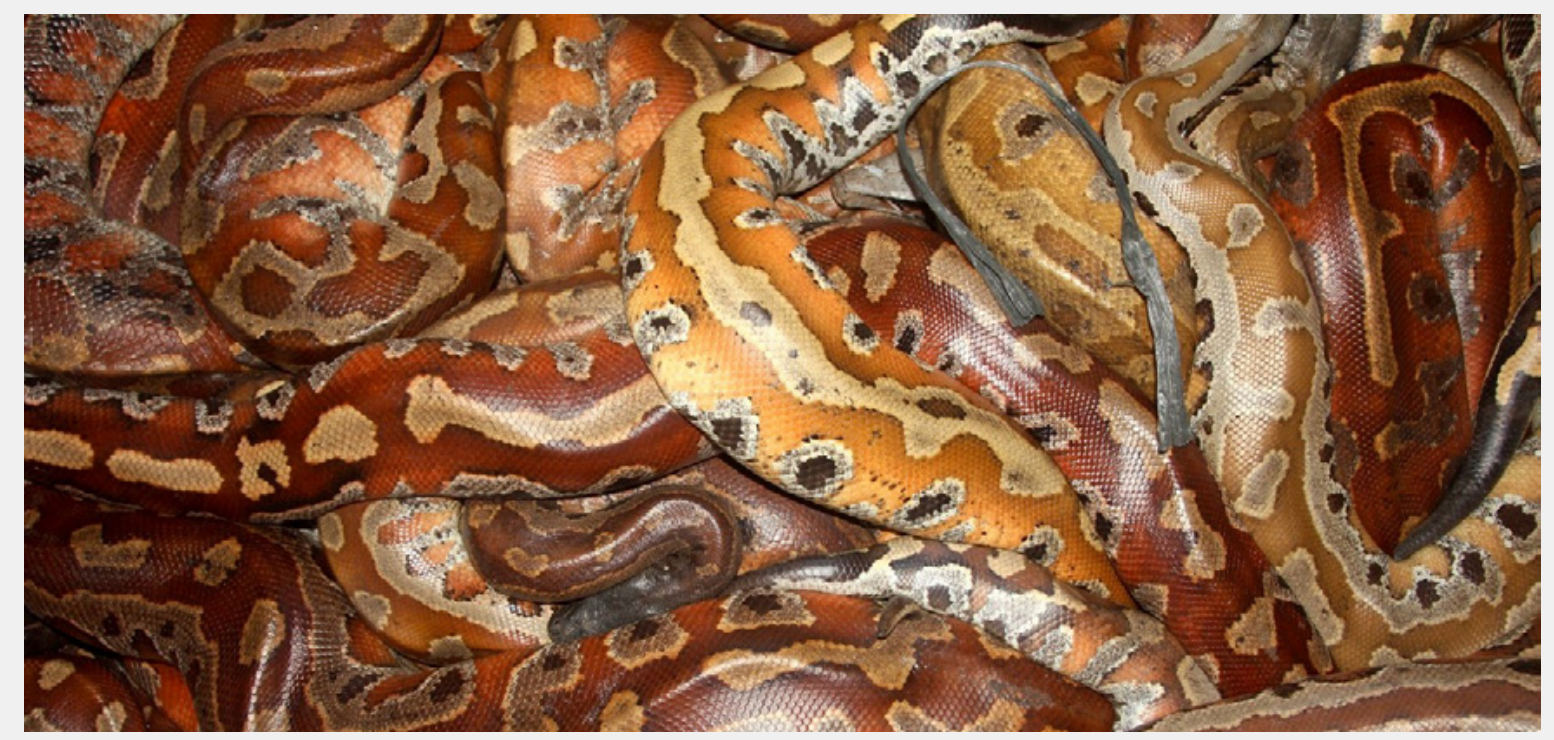

Figure 19. Blood Pythons collected from nearby oil palm plantations in north Sumatra, Indonesia. (C Daniel Natusch) 
So, surprisingly, expansion of oil palm has triggered two unintended benefits. Firstly, an increased prey-base and higher abundance of snakes undoubtedly improves the resilience of the populations of some snakes to harvesting. And secondly, the higher abundance of snakes available for harvesting enhances the income earning potential of local people relying on this trade - and hence their livelihoods (e.g., 37\% of Indonesians live on \$US3/day or less and oil palm workers earn between US\$ 1 and 7 per day; one python can be worth \$US30, see 154, 155).

The net impact of oil palm is the result of a complex interplay between rodents, snakes, local people, and the loss of ecosystem services provided by the natural forests that palm plantations have replaced. For example, despite increases in snake abundance favouring snake hunters, those gains must be offset by the economic costs of removing a natural biological control. Plantation owners suffer enormous economic losses due to rodent damage to palm fruits (148) and removal of rodent-eating snakes for trade presumably increases those losses. Indeed, some plantation owners have recognised the role snakes play in regulating rodent populations and do not permit hunting on their estates (156, 157).

For biodiversity more broadly, despite oil palm expansion benefitting a handful of snake species, populations of many others have suffered. Southeast Asia is home to more than 400 species of snake, yet only eight (2\%) are so far known to thrive in oil palm plantations (Figure 19). Others occupy specialised niches that are unavailable outside the natural forests that oil palm plantations have replaced and have likely been extirpated from large areas of their former range.

\subsection{Biodiversity values in smallholder oil palm plantations}

Oil palm plantations have lower biodiversity levels compared to natural forests (104) but are there differences between different types of oil palm production systems such as smallholder and industrial oil palm plantations? This remains poorly studied compared to the large number of studies comparing biodiversity in industrial plantations and forest, although some studies have been conducted in Peninsular Malaysia $(34,158)$ and another study in southwest Ghana and northern India also included small-scale oil palm agroforestry (125). One study on bird diversity between industrial oil palm plantations and smallholdings showed that plantation estates and smallholdings supported similar bird assemblages, with smallholdings supporting slightly higher levels of bird species richness (34). Bird abundance and functional diversity were also slightly higher in oil palm smallholdings compared to large plantations (34). Higher levels of bird species richness in smallholdings could be attributed to higher measures of landscape heterogeneity around oil palm smallholdings (158), or the use of cattle grazing (159). Importantly though, when assessed at a species by species basis, both the smallholdings and large plantations exclude forest specialist species and mosaic farmlands are a poor compromise for forest (125). A study of mammals showed that

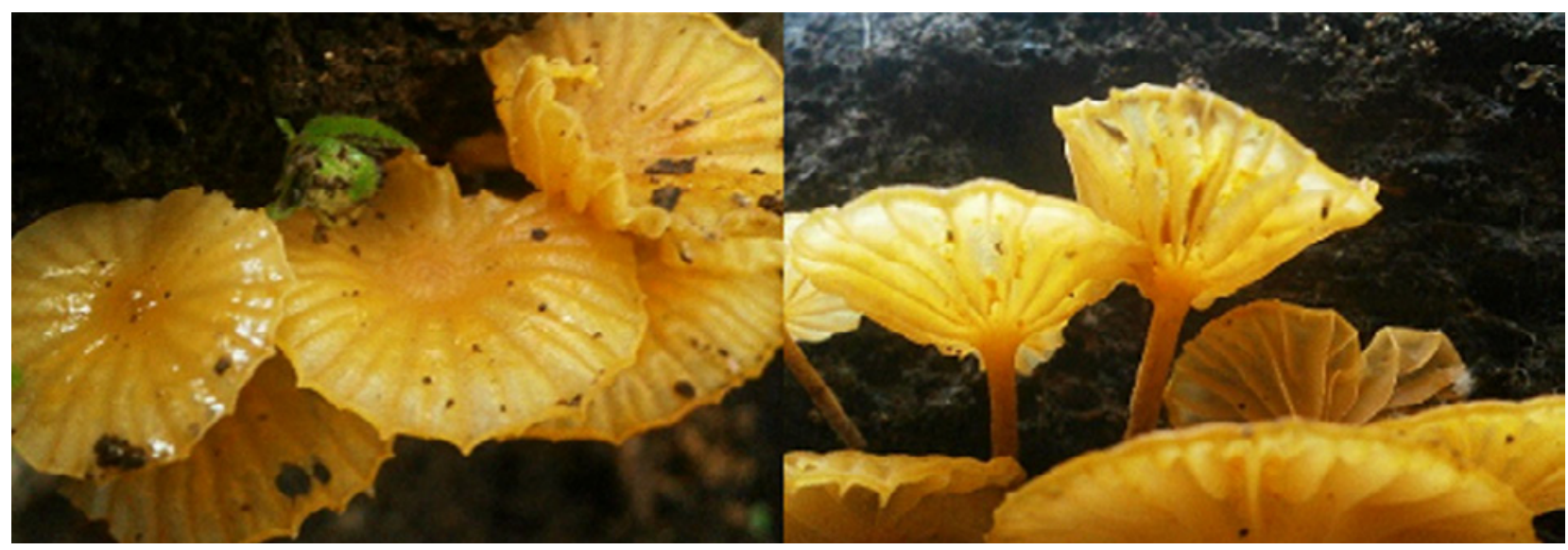

Figure 20. Fruiting bodies of Lichenomphalia sp. are commonly encountered in peat swamp forest, but are absent in oil palm cultivation areas (161). (@ Sabiha Salim) 
more carnivorous and herbivorous species were reported in smallholdings than plantation estates, most probably again as a response to greater habitat heterogeneity in smallholdings, while the size of patches of remnant rainforest were important factors influencing the richness of mammal species in oil palm landscapes (160). Nevertheless, both oil palm smallholdings and industrial estates had lower biodiversity levels than logged peat swamp forests (34). Illegal hunting and poaching were observed more frequently in smallholder oil palm plantations compared to industrial plantations (158). Macrofungal diversity (Figure 20) among large scale oil palm plantations, monoculture smallholdings (i.e., planted only with oil palm) and polyculture smallholdings (i.e., oil palm intercropped with other commercial crops such as banana, coconut, and tapioca) showed no significant differences among these production systems (161).
Thus, preliminary research from Peninsular Malaysia shows slightly higher levels of biodiversity in oil palm smallholdings, but this is likely context specific and so should not be generalized to other oil palm dominated landscapes in the tropics. Some smallholdings, for example, may be under more hunting pressure than well-managed large-scale plantations.

\subsection{What are the less- studied ecosystem impacts of pallm oil?}

Most environmental effects of palm oil remain poorly characterised, including those related to greenhouse gases, water issues, and the spread of pests. Most of the studies on the impact of oil palm

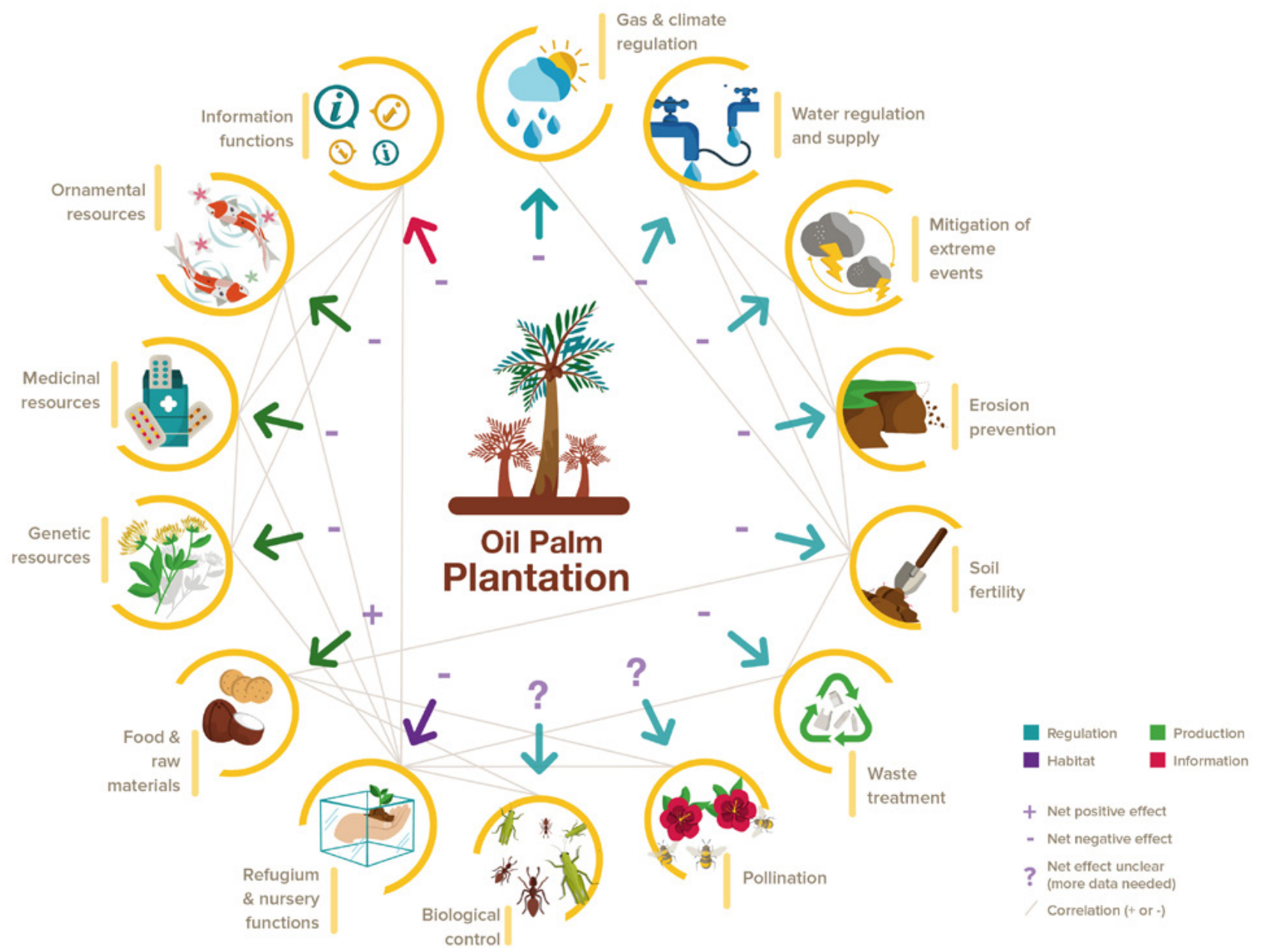

Figure 21. Oil palm plantations have a predominantly negative net effect on ecosystem functions when compared to primary and secondary rainforest. Net effects do not imply that all effects on a given ecosystem function are positive or negative, but that the majority or most-dominant effects are in the given direction. Estimates of net effect direction and correlation are qualitative and are based on the synthesis of literature presented in (163). 
development have looked at the direct impacts, e.g., deforestation, while indirect and cumulative impacts remain poorly known. Downstream water pollution from oil palm fertilizer, pesticides and other chemicals and their impact on human health, aquatic species and fisheries are little studied. The displacement effect of oil palm development, which pushes other activities, such as smallholder agriculture or hunting, elsewhere, similarly remains poorly known. Also, the links between palm oil production, the production of other oil crops, global demand, and global biodiversity impacts require further study (162). Here we highlight several other topics of potential importance with regard to oil palm impacts (Figure 21), which are, so far, poorly understood.

\subsubsection{Greenhouse gas emission from oil palm development}

Atmospheric greenhouse gases absorb and reemit radiant heat thus influencing global temperature. Clearing land, planting and managing oil palm and processing oil-palm products and wastes, can all influence the concentration of atmospheric greenhouse gases and thus contribute to climate change and associated threats to the world's biota (Box 11). The most influential greenhouse gases in Earth's atmosphere are water vapour, carbon dioxide, methane and nitrous oxide - all of which can be influenced by the production of palm oil. We know the most about carbon dioxide.

The concentration of carbon dioxide in the atmosphere is $410 \mathrm{ppm}$ (parts per million, March 4,2018 ) - to find equivalent concentrations to the current period we have to look back two and a half million years. Carbon dioxide concentrations continue to rise with projections suggesting a $0.5 \%$ annual growth through the 21 st century.

In addition to its role as a greenhouse gas, increasing atmospheric carbon dioxide impacts water bodies leading, among other things, to acidification of the world's oceans (164). Studies show that aquatic organisms differ in sensitivity but the anticipated impacts are "generally large and negative" (165). Summary assessments, examining a broad range of evidence, have concluded that given current carbon dioxide emission trends "most marine organisms evaluated will have very high risk of impacts by 2100 and many by 2050" (166). There is concern that these changes will cause extinctions and marine biologists note that ocean acidification contributed to past mass extinctions (e.g., 167).

Clearing forests leads to the emission of carbon dioxide. Particularly large amounts are released when peat soils are drained during the land clearing and preparation phase, leading to decomposition or burning $(168,169)$. Though palm oil plantations can maintain high rates of carbon uptake and their oil can potentially replace fossil fuels, it would take decades, to compensate for the carbon released when forests are cleared and peatlands drained. However, in the long-term, if palm oil directly replaces fossil fuels, it is theoretically possible to achieve carbon neutrality and even negative emissions as long as fossil fuels play a minimal, if any, role in the plantation's fertilization, processing and transport etc. For example, Danielsen et al. (84) estimated that "it would take between 75 and 93 years for the carbon emissions saved through use of biofuel to compensate for the carbon lost through forest conversion, depending on how the forest was cleared. If the original habitat was peatland, carbon balance would take more than 600 years. Conversely, planting oil palms on grasslands would lead to a net removal of carbon within 10 years." Such outcomes depend on management choices explaining why palm oil is viewed as "both the best and the worst known source of biofuel from a global C[arbon] balance perspective" (170). The potential to achieve carbon positive outcomes in the longerterm is substantially greater than for other oil-crops that replace forest as, despite its longer maturation phase, oil palm requires an order of magnitude less land to produce equivalent amounts of biofuel. One estimate in Thailand, assuming that production was sourced from existing plantations concluded that palm oil biodiesel could leads to a $46-73 \%$ reduction in greenhouse gas emissions compared to fossil fuelbased diesel (171). Nonetheless, major uncertainties remain, these include the dynamics of soil carbon under oil palm and how these vary with conditions 
and management practices, and the emissions associated with processing (170).

Oil palm plantations have been observed to release nitrous oxide into the atmosphere (172). Nitrous oxide is a long-lived and potent greenhouse gas with a global warming potential estimated at 265-298 times greater than carbon dioxide and is estimated to be $19 \%$ more abundant in the atmosphere now than in pre-industrial times (173). It accounts for around $6 \%$ of total anthropogenic radiative forcing with soil management including tillage and fertilizer application being the main sources. The addition of fertilizer can accelerate the mineralization of soil organic matter leading to emissions of both carbon dioxide and nitrous oxide. An oil palm plantation trial on peatlands in Sumatra found that nitrous oxide emission rates were 5-10 times those in natural peatland forests and were "exponentially" boosted by fertiliser (urea) treatment (174). Studies on mineral soils show that emissions vary considerably depending on how they are managed (175).

Oil palm plantations, and the production of palm oil, can be significant sources of methane (176). Methane is the second most important driver of the atmospheric greenhouse effect and is 72 times more potent over a 20-year period and is associated with various additional (generally less well understood) impacts on atmospheric properties including stratospheric water vapour, ozone, sulphate aerosol and lifetimes of various other atmospheric compounds. Methane has more than doubled since pre-industrial time with some projections predicting a further doubling by 2100 (173). Methane is formed during anaerobic decomposition and is generally associated with anoxic waters and liquid waste-this is why the anaerobic ponds used to treat palm oil mill effluent and waterbodies within and around palm plantations are the main sources. If mill effluent is not suitably treated to minimise methane generation and release, it can be a significant source of atmospheric methane. With methane collection, emissions may be much reduced and the methane collected can be used to produce energy. One recent study estimated that capturing waste methane "biogas" and using it to generate electricity can reduce the greenhouse gas emissions of biodiesel production from palm oil by about one third (177).

There has been relatively little research on what determines the emissions of methane and nitrous oxide from oil palm landscapes. We were unable to find any studies that looked at the impact of smallholder practices on greenhouse gas emissions.

\subsubsection{Land clearing with fire and resulting smoke and haze}

Some palm oil growers burn their land to clear it (25). These fires, especially when they occur on peat, can produce a considerable amount of smoke and toxic compounds with negative impacts on people and wildlife. Indeed, smoke from such fires likely contribute to various respiratory problems and many premature deaths (178). Smoke-induced haze events related to tropical fires, and especially those in peat lands, are suggested to have had various impacts on other species as well as including reduced production, pollination and even the cross-species transfer of zoonotic diseases (179). Few of these impacts have been well-studied, but one evaluation of bird song in Singapore during the 2015 haze event reported a major decline during the haze event of bird song and only a partial recovery over the subsequent four months - suggesting that bird populations suffered from the persistent haze (180).

\subsubsection{Local climate impacts}

Palm oil plantations tend to be hotter, drier and brighter than forests due to the less dense canopy of plantations. For example, one study found that oil palm plantations are up to $6.5^{\circ} \mathrm{C}$ warmer during the warmest time of the day when compared to intact old-growth forest and that mean daily peak soil temperature, vapour pressure deficit and specific humidity were greater in oil palm (181).

Forest loss and land-use change more generally also impact the local and regional climate though the details remain debated (182-185). For example, the increased temperatures and reduced rainfall 
recorded over Borneo since the mid-1970s, appears to be related to the declining forest cover on the island, and the changes are greater in areas where the losses are greater (186). Nonetheless confidently attributing some proportion of such changes to oil palm cultivation, while plausible, is beyond our current understanding.

\subsubsection{Volatile organic compounds from oil palm}

Vegetation, particularly forests, release a rich and complex mixture of volatile organic compounds into the atmosphere (187). The behaviour and wider influence of these compounds has made them a major source of uncertainty in climate models (188). They also influence air quality.

Forest loss generally reduces the emissions of volatile organic compounds but oil palms are significant emitters of such compounds. One study in Malaysia estimated that the oil palm plantations emitted about seven times more isoprene per unit area than the forests they replaced (189). Isoprene is believed to influence the atmospheric properties that control the condensation of water vapour, thus influencing cloud cover and rainfall (188). Isoprene contributes to a process that involves the generation of hydroxyl radicals which promotes smog and ozone in a polluted environment $(190,191)$. Thus, we can predict that oil palm plantations will exacerbate air pollution in the vicinity of industrial centres with wider consequences for people and the environment. Given the recognised negative implications for human health there are likely serious implications for many other species. There is some evidence that emissions of other organic compounds are higher in oil palm plantations than in forest (e.g., estragole and toluene, 192), although the overall picture seems to be that these emissions, and differences, are relatively minor compared to isoprene (193). The implications of all these changes remains speculative and largely unexplored.

Box 11.

\section{Climate change}

Our planet's biota is threatened by the magnitude and rate of predicated climate change (194). Researchers already attribute local extinctions to climate change $(195,196)$. The Earth has warmed by an estimated $0.74{ }^{\circ} \mathrm{C}$ in the last 100 years, and may increase by another $1.5^{\circ} \mathrm{C}$ to $4.5^{\circ} \mathrm{C}$ this century (197) leading to the warmest global climate in over two million years (198). Rainfall patterns are also changing though the trends are uncertain $(199,200)$.

Predicted temperature changes will push many species beyond their current tolerance levels if they stay where they are (201). Many species appear unlikely to move to suitable elevations or latitudes quickly enough $(202,203)$. Conservationists have identified few practical interventions to maintain species in a rapidly warming climate and various summaries and overviews have concluded that mass extinctions may be imminent (196, 204-206) and even the most common species appear at risk (207).

Climate change does not operate in isolation. Extinction risks will often be accentuated by the interaction with habitat loss and fragmentation, hunting and other factors $(208,209)$.

\subsubsection{Water quality in and downstream from oil palm}

Plantations increase run-off and siltation due to reduced ground cover and earth moving. Drainage of acid sulphate soils can lead to the release of high acidity water. Drainage also leads to lowering of ground water, and a change in the seasonal rhythms

of this water, potentially impacting neighbouring forests and other habitats. Streams flowing through plantations and other cleared areas are warmer, shallower, have more sand and reduced abundance of species such as dragonflies $(210,211)$, although flood-control channels can serve as habitat for some water birds in oil palm areas (212). 
Fertilizers, pesticides, and other chemicals all influence local drainage and impact water quality and aquatic habitats. The effluent from most modern mills is generally minimized as much as possible, but release into local rivers has been known to cause severe impacts on aquatic ecosystems (213). It is also generally believed that the release of nutrients and silt from palm oil and other land developments will negatively impact aquatic habitats nearbyincluding fisheries and coral reefs (214).

\subsubsection{Changes in soil quality following oil palm development}

The impact of fertilization and empty fruit bunch recycling on chemical and physical soil properties is well documented. Less attention has been paid to the impacts on soil biological properties, i.e. soil biodiversity (215). Soil biota directly contribute to the regulation and long-term maintenance of several ecosystem functions and services including primary production, carbon sequestration and nitrogen turnover (216). Results of recent studies on the impact of empty fruit bunch application on soil properties (217), showed higher macrofaunal (especially higher densities of earthworms (Box 12), millipedes and nematodes) and soil organic carbon content (218).

Box 12.

\section{Earthworm depletion under palm oil plantations in Malaysia, and a possible remedy}

\begin{abstract}
Surveys of several palm oil plantations in Malaysia (219) revealed low numbers of only one exotic earthworm of mean 14.8 worms per $\mathrm{m}^{2}$ (range $0-42$ per $\mathrm{m}^{2}$ ). Depletion is similar at 29 other agricultural sites with just two exotics of 15.6 worms per $m^{2}$ (220). In comparison, four undisturbed lowland rainforests of Sabah and Sarawak had mean 50.6 worms per $\mathrm{m}^{2}$ (range 15-103 per $\mathrm{m}^{2}$ ) and expected species richness in the order of 4 to 14 natives $(221,222)$. Thus, the earthworm population decline under intensive agriculture is -70.8 to $-100 \%$ and the native biodiversity loss is complete.
\end{abstract}

The only species reported under palm oil (219), was cosmopolitan South American Pontoscolex corethrurus.
This ubiquitous interloper often dominates tropical soils in various states of degradation $(223,224)$. The disappearance of native earthworms and the low abundance of exotics are indicative of an ecologically degraded soil-ecosystem and presage extinction of local species, as is reported from Indonesia (225).

A partial remedy (226) is suggested by recycling palm-oil mill wastes via vermi-composts using Eudrilus eugeniae, another exotic from Africa (227). Alternatively, conversion to fully organic palm oil production may increase biodiversity without compromising yield, as for rice and sugarcane crops in the Philippines (223).

\subsubsection{Spill-over of oil palm pests}

Palm oil plantations support various pests including rodents like the Malaysian House Rat (Rattus rattus diardii), beetles like the Asiatic Rhinoceros Beetle (Oryctes rhinoceros) and the Red Palm Weevil (Rhynchophorus ferrugineus) $(228,229)$. These organisms likely have a range of local effects, both positive and negative, including attracting other predatory species (such as snakes, owls, Leopard Cats and pigs) that may impact neighbouring

habitats. Some of these organisms are not specialists of oil palm but will feed on and potentially influence the population dynamics of other species. Palm oil also appears to support high densities of some scavenging species (Box 13).

\subsubsection{Invasive aspects of oil palm cultivation}

Oil palm is now considered a potentially invasive 


\section{Box 13. \\ Scavengers become settlers of oil palm plantations}

Scavengers play a prominent role in maintaining the healthy functioning of ecosystems. They "clean-up" the environment by seeking out dead or decaying organic matter, helping to reduce the spread of disease as well as recycling essential nutrients - an integral ecosystem service. Due to their flexible feeding preferences, scavengers are typically adaptable and opportunistic. But, as landscapes rapidly change to high intensity agricultural use, are forest scavengers robust enough to adapt to significant human and habitat disturbance?

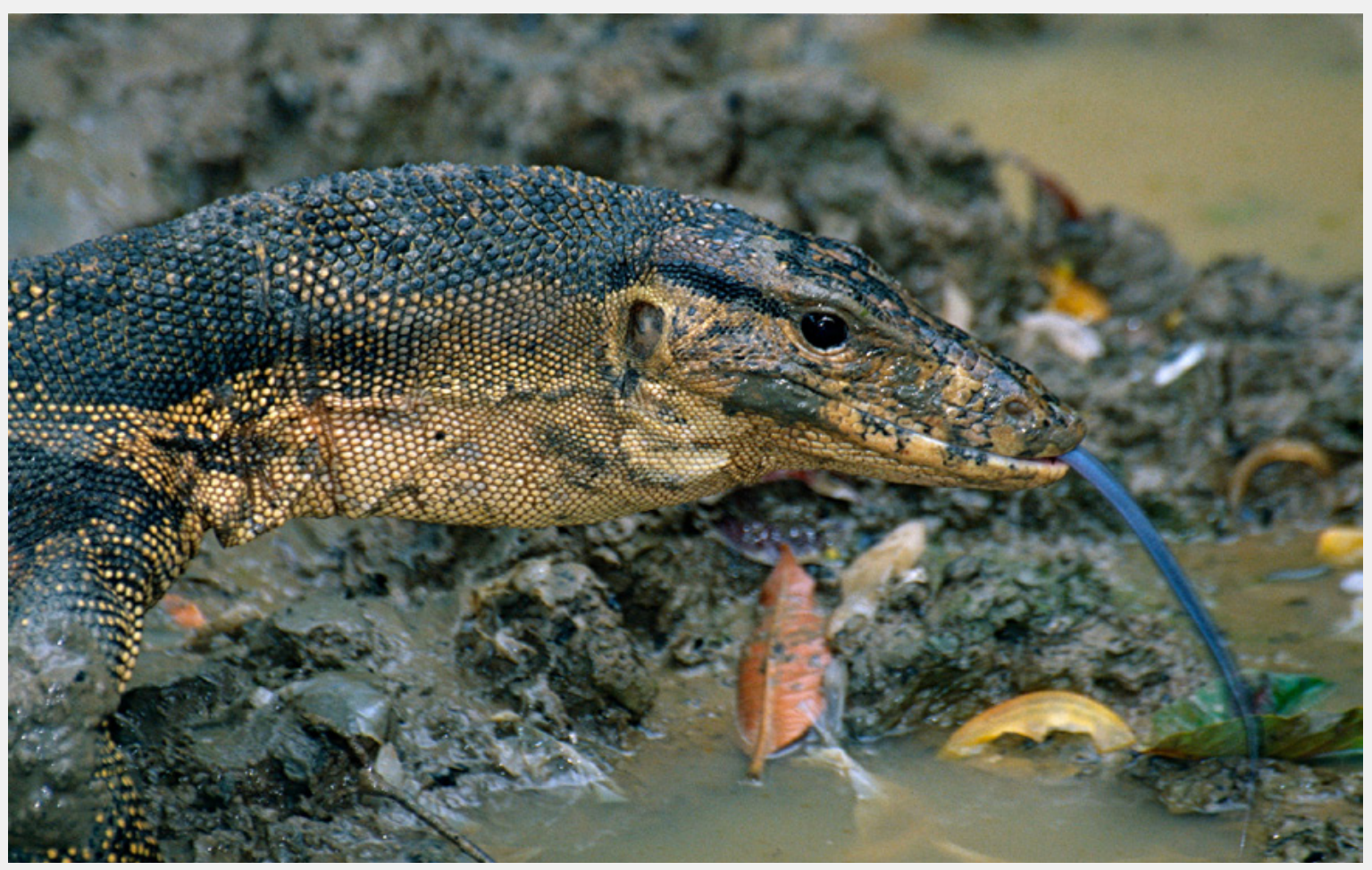

Figure 22. Varanus salvator macromaculatus, Uncle Tan's Wildlife Camp, Sungai Kinabatangan, Sabah, Malaysia. (C) Bernard Dupont)

For the giant lizards of Borneo, the answer appears to be yes. As oil palm plantations advance across the island and natural forest habitat is lost, forest species such as orangutans are suffering. The Southeast Asian Water Monitor (Varanus salvator macromaculatus) (Figure 22), however, is appearing to thrive in the plantations in the North-East Malaysian state of Sabah (236), and numbers increase with increasing levels of disturbance i.e., high land use intensity areas.

The Southeast Asian Water Monitor's generalist diet (eating practically anything) enables it to tolerate the ecological conditions of oil palm - because where there are humans there is food - in the form of refuse, domestic animals and agricultural products. Not only do the water monitors benefit from this readily available food source, but also from the reduced presence of other mammalian scavengers that are unable to tolerate the pressures of anthropogenic landscapes.

Interestingly, the water monitors in the plantation surveyed were also found to be in good health, as reflected in their large body size and good body condition (236). This is despite higher numbers (typically males) being drawn into favourable areas and competing with one another. This triggers territorial battles resulting in high energy expenditure and the increased density of individuals potentially risks greater parasite loads, thus reducing overall fitness levels.

Currently, for this particular scavenger, it would seem that oil palm plantations can be exploited to sustain healthy populations. Whether this persists in the long-term is likely dependent on the resilience of this species, particularly as the natural forests of Borneo continue to be at the mercy of economic incentives derived from a booming oil palm industry. 
species in remnants of the Atlantic Forest in Bahia State, Brazil (230) and on several islands in the Pacific, where it is considered a High Risk invasive species (231). Oil palm is also often associated with a number of other crops that can be nonnative, depending on where the oil palm is grown. This includes cover crops and nitrogen fixing green fertilizers such as Mucuna bracteata DC. ex Kurz, Axonopus compressus P. Beauv., Calopogonium caeruleum (Benth.) Hemsl., and Centrosema pubescens Benth. (232), the African Oil Palm Weevil (Elaeidobius kamerunicus), which is introduced as a pollinator of oil palm $(233,234)$, and species such as Barn Owls (Tyto alba), which does not naturally occur on Borneo, Sulawesi and in Papua, but is often introduced into plantations there to control rodent pests $(229,235)$.

\subsection{How does oil palm compare with other major impacts to biodiversity?}

Agriculture and overexploitation of natural resources are the largest threats to threatened species (Figure 23). Timber harvest, developments for residential and commercial housing, energy production and mining, and transport and service corridors, hunting, and invasive species follow on their heels $(237,238)$.

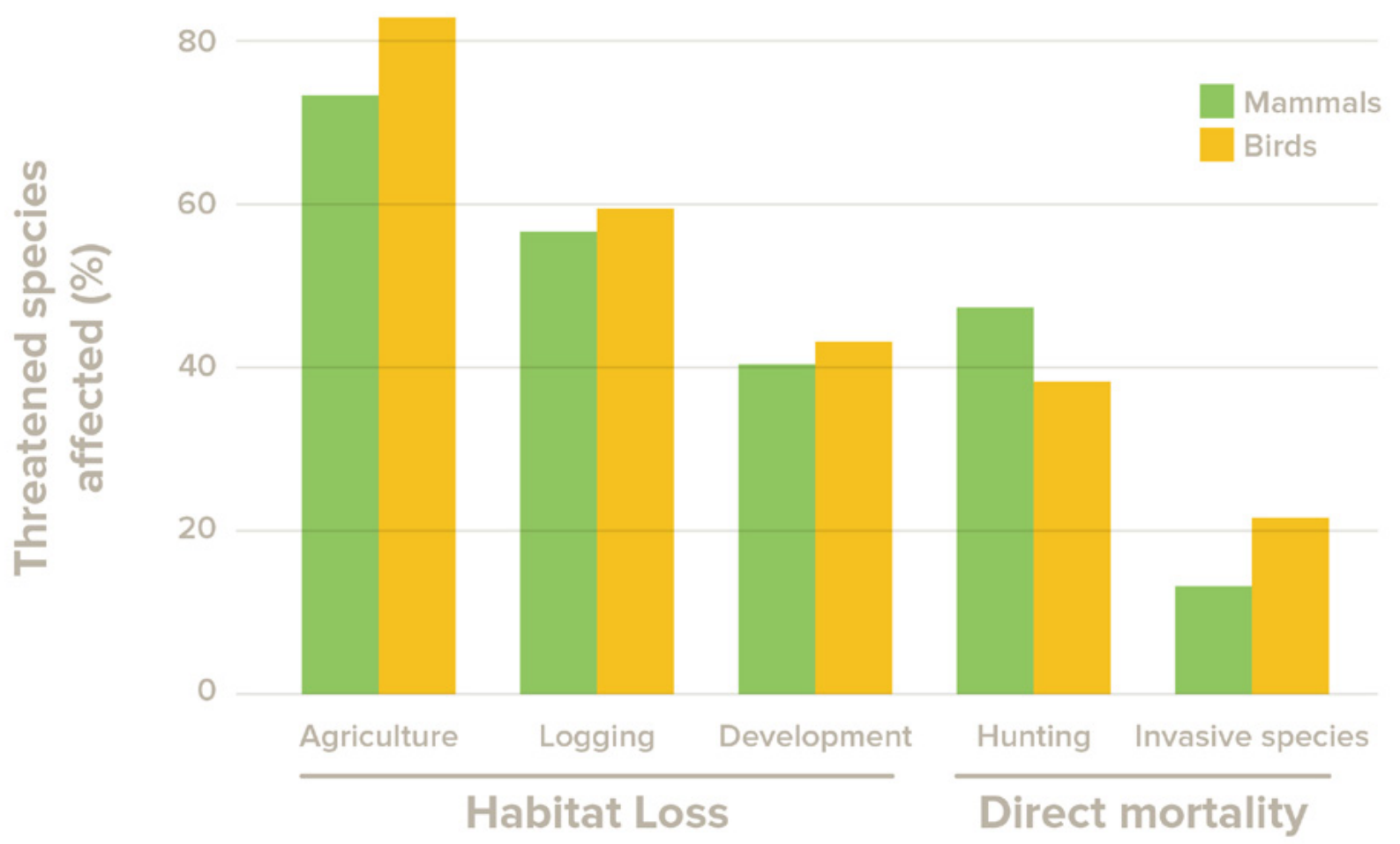

Figure 23. Major threats for terrestrial mammals and birds, separated by the mechanism of the threat (habitat loss or direct mortality). Categories are aggregations of various stresses and threats, as defined by the IUCN (237).

While the oil palm industry certainly impacts biodiversity negatively, it is far from being the only driver of global biodiversity loss through agriculturedriven deforestation. The impact of oil palm therefore needs to be considered in relation to other drivers of deforestation and oil palm's negative impacts on biodiversity should be compared with those of other agricultural systems (for an example of such a comparison, see Box 14 below). A global scale analysis of deforestation in developing countries indicates that in Africa and Asia, local and subsistence agriculture is a larger driver of deforestation than commercial, industrial-scale agriculture (239) (Figure 24), but in Latin America commercial agriculture is a larger driver. It is difficult to compare the biodiversity impacts of oil palm to other agricultural systems directly, but it is clear that other agriculture also comes at high costs to biodiversity. For example, in the Amazon, one hundred and fifty million hectares has been lost and around $80 \%$ of this was due to cattle ranching (240). Although oil palm plantations are biodiversity-poor, 
cattle pastures contain even less biodiversity (Box 14): research has shown that palm oil plantations house around $50 \%$ more species of ants and dung beetles and $67 \%$ more reptiles and amphibians than cattle pasture (241).

Another major crop, soy, also has a large negative impact on biodiversity (242), supporting an impoverished bird diversity compared to natural ecosystems in Brazil and Argentina (243, 244). Much of the soy production in Brazil has replaced the high-biodiversity Cerrado grasslands, home to many species found nowhere else (162), despite the Soy Moratorium $(245,246)$. More recently the soy boom is pushing small-scale farmers and herders from already-deforested areas into still standing forest, leading to more deforestation in the Amazon $(247,248)$, but also into the Cerrado (249) and wetlands such as the Pantanal (250).

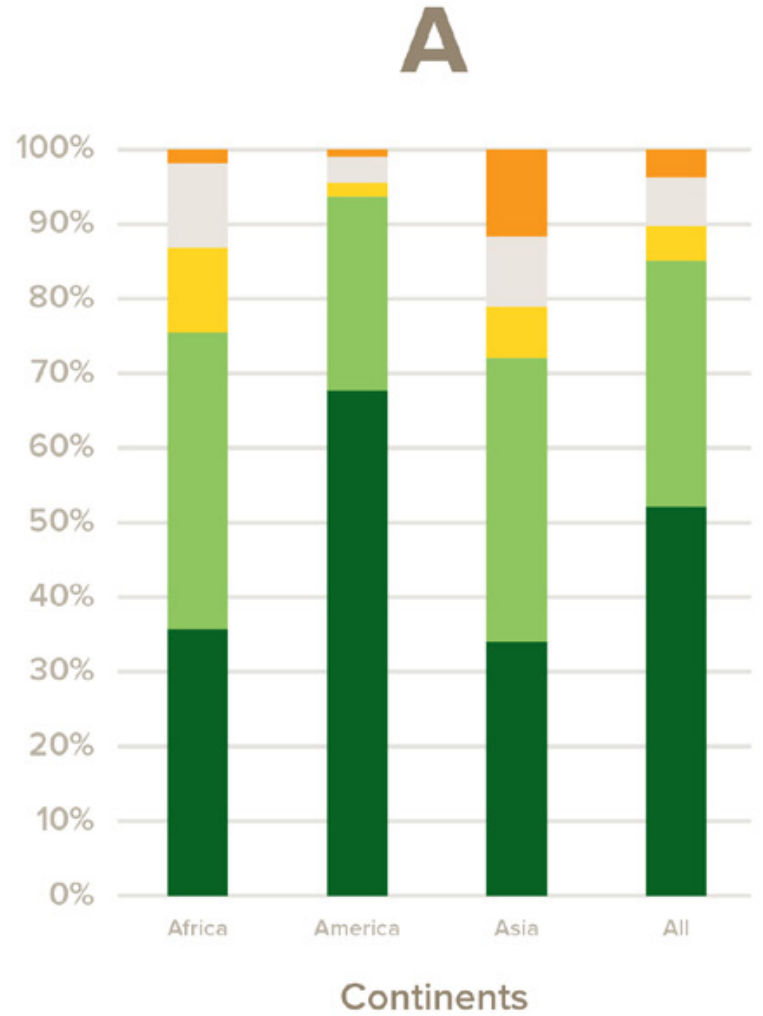

Urban expansion Infrastructure
Rubber is another important crop in Southeast Asia where $97 \%$ of global rubber is produced, mainly in monoculture plantations (251). Rubber grown as a monoculture has a similar negative impact on bird species richness as oil palm in both Indonesia and Thailand $(252,253)$, although for some other species groups rubber might be richer than oil palm (85). Given that small-scale agriculture is such a large driver of deforestation as well it is important to determine whether this drives lower biodiversity losses as a mix of trees and crops (agroforestry) than as a monoculture. Generally, it seems that agroforestry maintains higher levels of biodiversity than monocultures $(254,255)$, although this would still exclude most forest specialist species that are often the target of conservation efforts (256). Thus, even though oil palm plantations lead to extremely high biodiversity losses, this is a common feature for many agriculture systems (162).

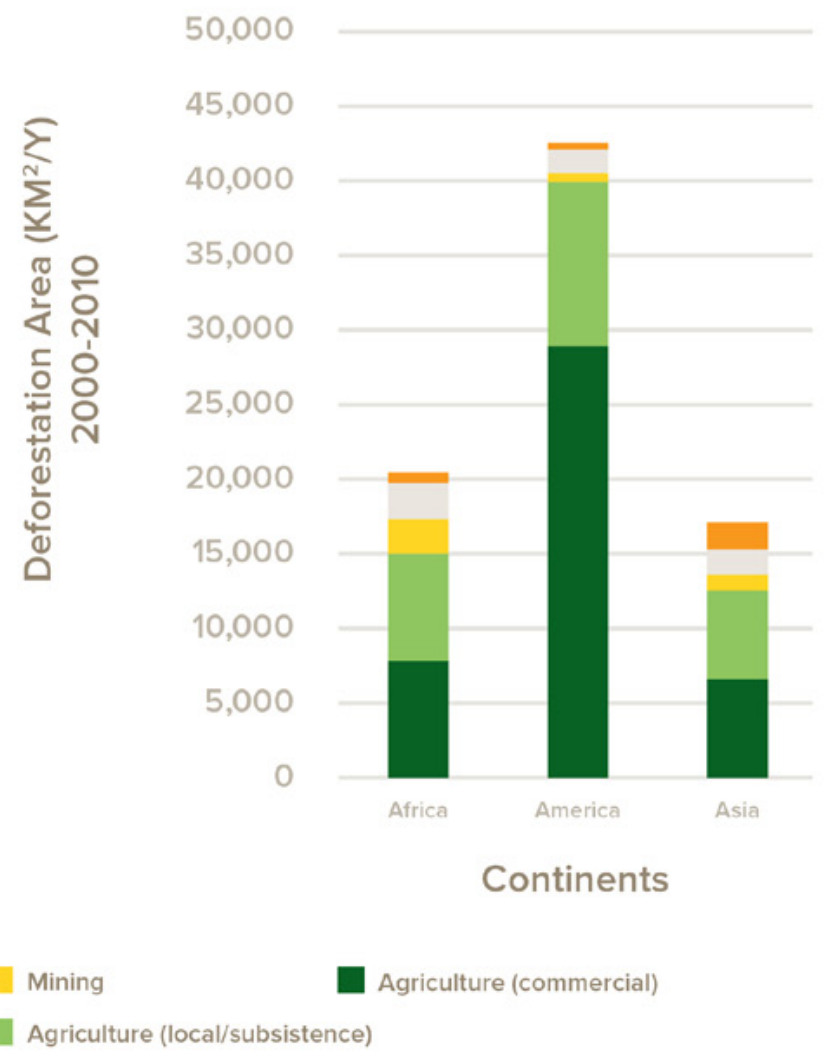

Figure 24. Estimate of (A) proportion of total area of land-use change associated with various proximate drivers of deforestation, and (B) absolute net forest area change associated with proximate drivers of deforestation 2000-2010 (257). 


\section{Box 14}

\section{The sounds of biodiversity in Colombian oil palm and other land covers}

Growth of the oil palm sector in the Latin America \& Caribbean region has largely taken a different direction compared to South-East Asia. With the exception of deforestation in Peru and other sub-national production zones (e.g. northern Guatemala), most of the recent oil palm expansion in the Latin America an Caribbean region has replaced previously degraded lands (24). In Colombia, the leading palm oil producer in the region and fourth largest producer worldwide, major oil palm production zones have emerged in areas with a long history of developments. Extensive cattle pastures characterize these landscapes, and other monoculture commodity crops such as banana, rice, and rubber. In this context, oil palm may provide better habitat for local biodiversity compared to the other production systems it replaces.
Researchers from the University of Puerto Rico use acoustics to understand these land use transitions and their implications for biodiversity in in Peru, Costa Rica and Puerto Rico (258). Acoustics characterize the species community present in oil palm landscapes by using soundscapesbased on daily cycles of acoustic activity (Figure 25). They provide an indicator of avian, amphibian, mammalian, and insect biodiversity. Soundscapes are primarily shaped by the continuous calls of insects and frogs during the dark hours. Birds contribute less to the overall soundscape as they are usually active for shorter periods of time throughout the day, particularly at dawn and dusk.

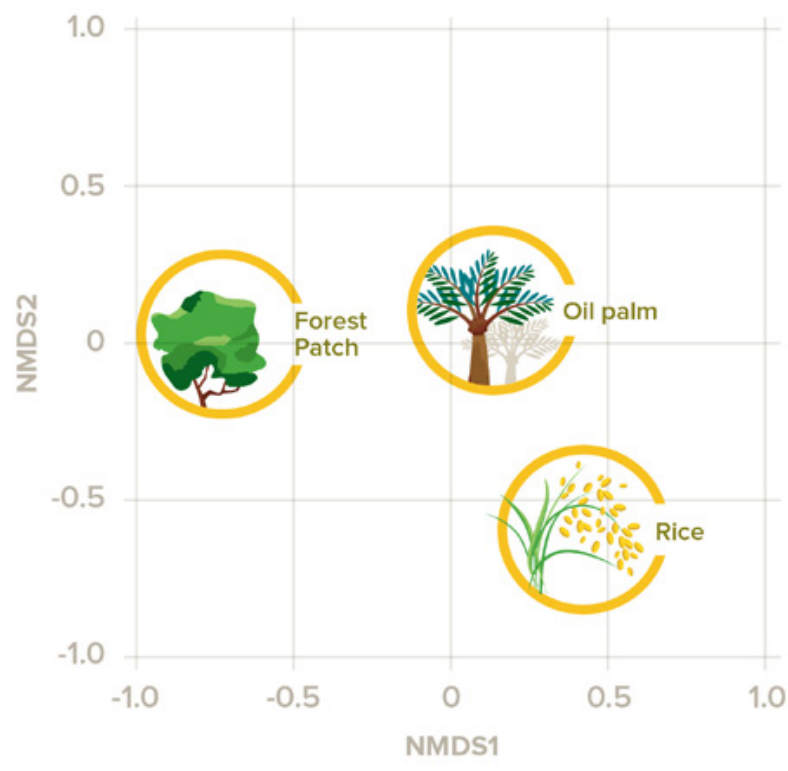

\section{Forest Patch}

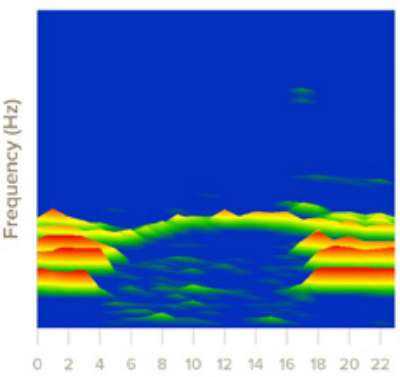

Hour
Oil Palm

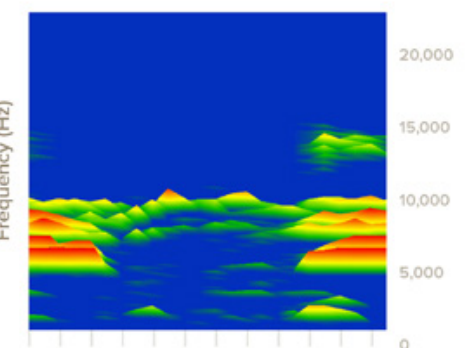

$\begin{array}{llllllllllll}0 & 2 & 4 & 6 & 8 & 10 & 12 & 14 & 16 & 18 & 20 & 22\end{array}$ Hour
Rice

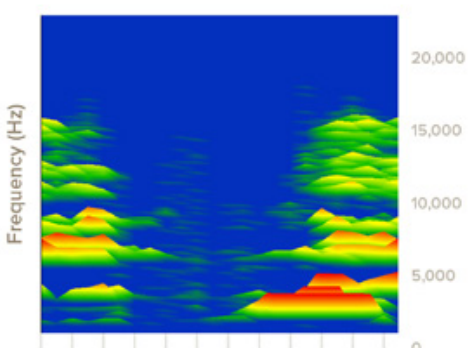

$\begin{array}{llllllllllll}0 & 2 & 4 & 6 & 8 & 10 & 12 & 14 & 16 & 18 & 20 & 22\end{array}$

Hour

Figure 25. Soundscape examples for different land uses. 
Analyses indicate that oil palm may provide better habitat for forest species than pastures, banana, and rice areas. This is likely due to the longer-lived nature of perennial oil palm plantations ( $\sim 30$ years) compared to more temporary or seasonal crops, and the formation of a closed canopy of up to $20 \mathrm{~m}$ when fully grown, including trunk epiphytes and understory growth that provide additional microhabitats. While oil palm will not provide suitable habitat for many forest dwelling species, the analyses suggest it will pose neutral losses in biodiversity when replacing other production systems in Colombia, perhaps providing a better matrix for species movement between natural areas.

\section{Box 15.}

\section{Bears and oil crops}

Six of the eight species of bears are known to forage on vegetable oil crops (Table 3). All of these are forestdependent species, normally feeding on small fruits and insects. Agricultural crops are often more concentrated than natural foods, so bears exploiting these foods may gain weight faster than bears subsisting entirely on a natural diet. This could be beneficial to bears: an increase in weight may translate directly to increased reproduction. On the other hand, all species feeding on oil crops suffer from increased human-caused mortality. Recognizing the risks of encountering people, bears tend to feed on crops mainly at night, or when natural foods are in short supply. Crop fields, though, do not provide adequate cover or shade, and bears may suffer nutritional deficiencies on a diet solely made up of oil crops.

Recent studies have found that some Malayan Sun Bears (Helarctos malayanus) living adjacent to oil palm plantations do venture into the plantation from the forest edge to consume palm fruits. Camera trap photos of bears living near oil palm, and actual weights of such bears, reveal that some individuals are indeed fatter than bears living wholly on forest foods (Figure 27). This may indicate that the oil palm fruits are fostering the weight gain, and this may in turn enhance their reproduction. Surprisingly, Malayan Sun Bears seem not to damage palm oil plantations because they mainly take fruits on the ground (some of which might not have been harvested anyway). This may mean that Malayan Sun Bears are not targeted as a pest species for retaliation - that is, unless those bears are thought to damage oil palm trees.

This does not necessarily mean plantations are good for Malayan Sun Bears overall (262), with one study finding that abundance was $92 \%$ lower in plantations compared to nearby forest (110). Whatever benefits some individual bears might gain by consuming fruits in the plantations are likely overcome by the large-scale loss of forested habitat on which bears depend along with a heightened vulnerability to incidental killing from snares set for other species, and hunters seeking bears for commercial use. In fact, oil palm plantations may function as a classical "attractive population sink": a rich food source which attracts bears and may lead to their death. Even if they are not retaliated against as pests, plantations increase access to people which provides more opportunities to hunt wildlife.
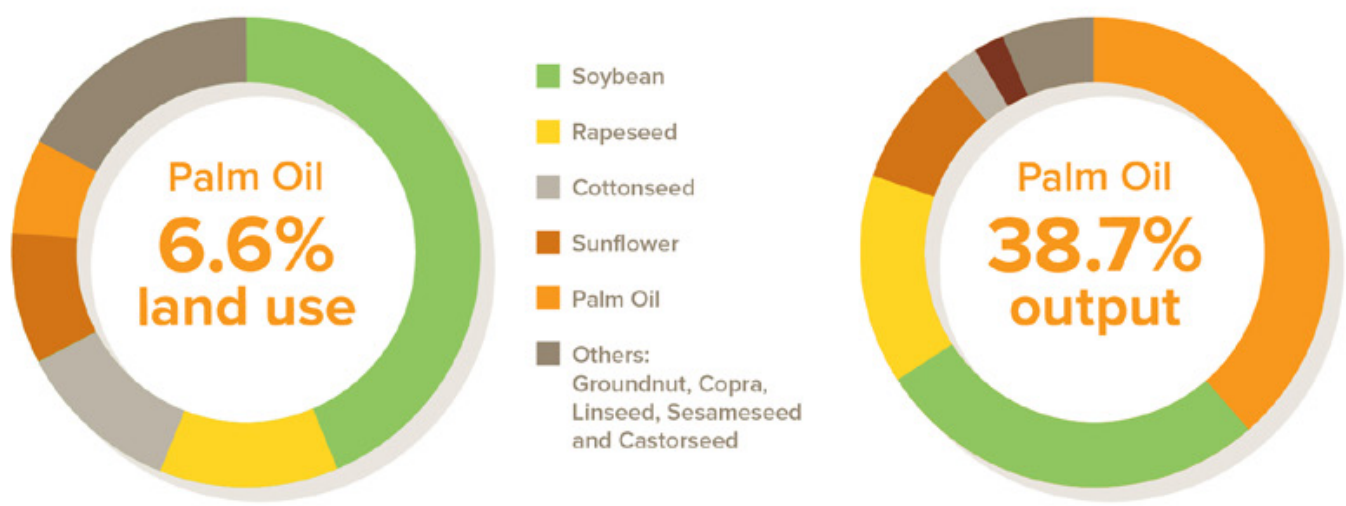

Palm Oil \& Palm Kernel Oil

Soybean

Rapeseed

Sunflower

Cottonseed

Groundnut

Others

Figure 26. Percentages of total land areas used for vegetable oil production by different crops (left) and the relative contribution to total oil production from each of these crops (right) (260). 
Table 3. Bear use of oil-producing crops and ramifications. $R L=$ Red List Category. LC - Least Concern; VU - Vulnerable. N/A: not available in range of species.

\begin{tabular}{|c|c|c|c|c|c|c|c|c|}
\hline \multirow[t]{2}{*}{ Species } & \multirow[t]{2}{*}{$\mathbf{R L}$} & \multicolumn{5}{|c|}{ Feed on crop } & \multirow{2}{*}{$\begin{array}{l}\text { Significant } \\
\text { weight gain } \\
\text { from feeding } \\
\text { on crops }\end{array}$} & \multirow{2}{*}{$\begin{array}{l}\text { Increased } \\
\text { reproduction } \\
\text { from feeding } \\
\text { on crops }^{1}\end{array}$} \\
\hline & & Maize & Soy & Sunflower & Peanut & Palm oil & & \\
\hline American black bear & LC & YES & Rarely & YES & Occasionally & $\mathrm{N} / \mathrm{A}$ & YES & YES \\
\hline Brown bear & LC & YES & Rarely & YES & NO & N/A & $\mathrm{YES}^{2}$ & Likely² \\
\hline Andean bear & $\mathrm{VU}$ & YES & $\mathrm{N} / \mathrm{A}$ & $N / A$ & N/A & $\mathrm{N} / \mathrm{A}$ & Likely & Likely \\
\hline Asiatic black bear & $\mathrm{VU}$ & YES & NO & $N / A$ & NO & NO & Likely & Likely \\
\hline Sloth bear & $\mathrm{VU}$ & Occasionally & NO & Occasionally & YES & Rarely & Unknown & Unkown \\
\hline Malayan Sun bear & VU & YES & $\mathrm{N} / \mathrm{A}$ & $\mathrm{N} / \mathrm{A}$ & NO & YES $^{3}$ & $\mathrm{YES}^{4}$ & Unknown \\
\hline
\end{tabular}

\section{Notes to Table:}

${ }^{1}$ Killed to protect the crop or simply because of increased exposure to hunters.

${ }^{2}$ In parts of Europe, bears are provided corn in feeders to supplement their natural diet to increase weight gain and reproduction

${ }^{3}$ Only crop not significantly damaged or depleted by bear feeding because bears eat the cut or fallen fruits.

${ }^{4}$ Tentative conclusion: small sample size.

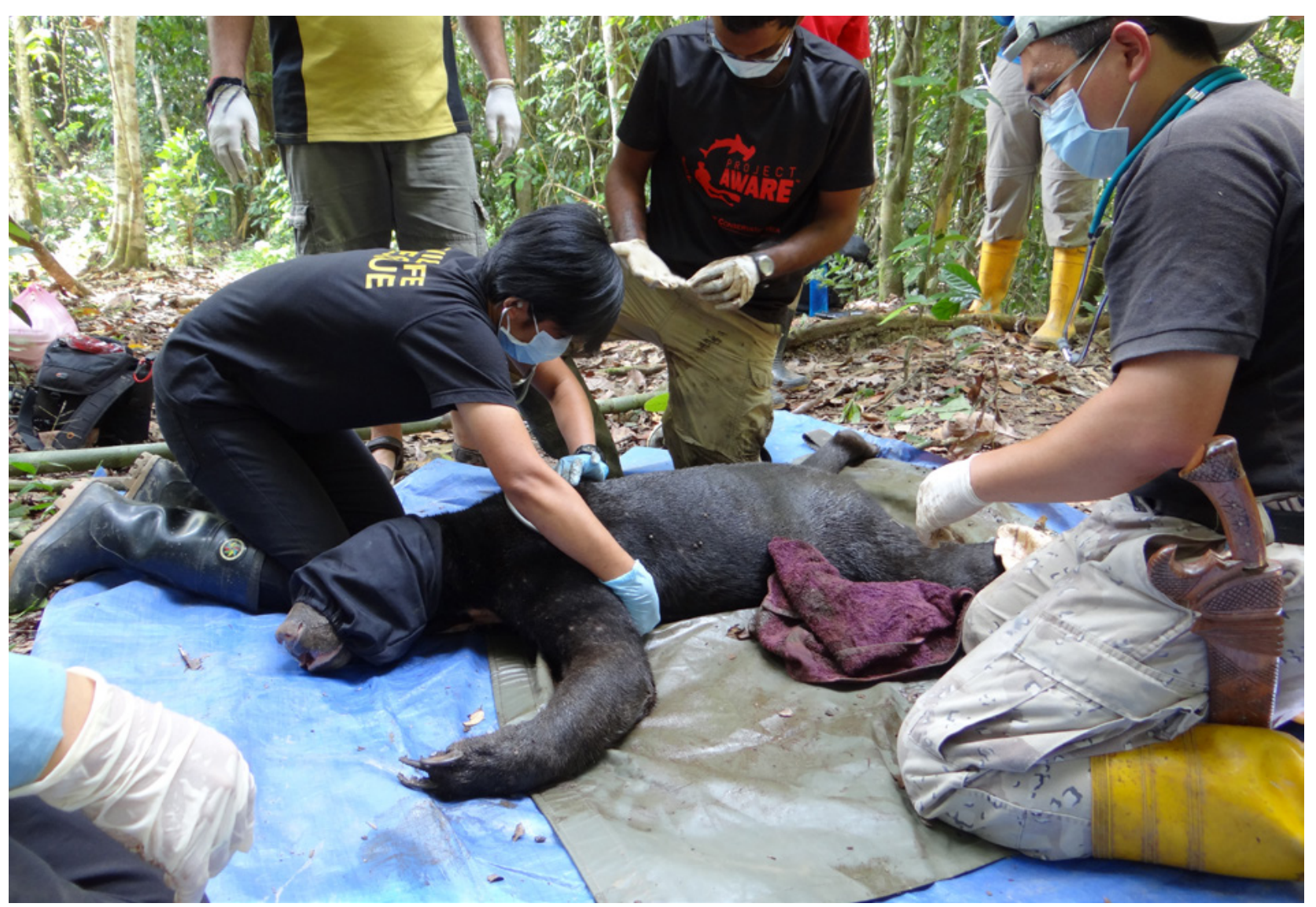

Figure 27. Fat male Malayan Sun Bear, known to use oil palm areas, being radio-collared in Sabah. Few Malayan Sun Bears have been radio-collared, and fewer still near oil palm plantations, so it is unknown how much they rely on the oil palm fruits for food. Many of the bears living near plantations, though, have been observed with injuries from wire snares. (C Andrew Hearn) 
No vegetable oil crops are without impacts on biodiversity and simply shifting from palm oil to, for example, soy-derived oil, would have repercussions on biodiversity (162). Oil palm has 6-10 times higher oil yields than other vegetable oil crops (259). It uses some $6 \%$ of the total area used to grow vegetable oils, but according to research in 2012 and FAO 2014 data (2) it produced over a third of the world's vegetable oil (Figure 26). Soy required $40 \%$ of the area to produce just $22 \%$ of global vegetable oils (260) - although we note that soy also produces other products besides oil. Nevertheless, if we replaced palm oil with other oilseed crops, we would need to significantly increase the global area used for production of other vegetable oils (261) with potentially large negative biodiversity impacts (121).

\subsection{What are the knowledge gaps?}

To fulfil a global demand for vegetable oils, wise decisions need to be made about the crops that are best at producing these oils, with minimal social and environmental impacts. This requires an understanding of: the potential areas where different crops could be grown; the use of different oils for different purposes (e.g., biofuel, food, cosmetics etc.); the way crop prices relate to each other; how, for each of these crops, the benefits of expanding them weigh up to the costs; and knowledge on who benefits and who loses. These are complex issues. Further research is crucial to ensure we can make environmentally and socially optimal decisions on the production of vegetable oils. Specifically, the following studies would help inform this optimization process:

- An analysis of the socio-cultural and economic impacts of oil palm development and how these vary temporally and spatially compared to environmental and biodiversity impacts;

- Mapping of all vegetable oil crops and analysis of how different oils can replace each other and result in deforestation and biodiversity loss;

- Study of the range of contexts under which people grow oil palm and better understanding of what "smallholder" means, and how this relates to biodiversity impacts. This could also include distinguishing where profit motives versus livelihood can be differentiated;

- $\quad$ Practical trials on the extent to which polycultural oil palm (intermixed with other crops or tree species) can improve environmental and biodiversity outcomes while maintaining yields; an example is a recent study on trunk epiphytes in oil palm, which, if not removed, increase species richness, maintains yields, and saves companies money (263);

- Study of the costs and benefits for oil palm growers of optimal biodiversity management (e.g., maintaining and effectively protecting forest set asides, prohibiting hunting and collecting of wild species), and the extent to which this can improve biodiversity outcomes. Especially, the issue of hunting and collecting of wildlife in oil palm plantations requires further study;

- Study of the impacts of large-scale oil palm expansion to local climate and water regimes, and how these impacts affect vegetation and other ecosystems;

- $\quad$ Studies on how native and non-native species move across oil palm landscapes (connectivity studies), unsustainable hunting and collecting can be effectively controlled, and what landscape elements are cost-effective means to improve the ecological integrity of landscapes; and

- $\quad$ Studies on plantation management processes that retain less visible and less often surveyed biodiversity (e.g., aquatic and soil diversity, invertebrate pollinators etc.). 


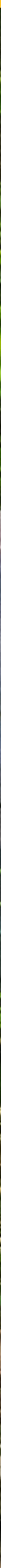


- The leading approach to mitigating impacts on biodiversity is to avoid converting forest and other important areas for conservation.

- Over the past two decades, a large range of environmental governance initiatives have emerged to address sustainability in the industry. These include voluntary certification and corporate commitments, state led regulations and hybrid landscape approaches. There is high complementarity between these initiatives, and together they cover a broad conservation scope and stakeholders.

- The most recognized tools applied to identify forest and other areas for conservation are the High Conservation Value approach and more recently the High Carbon Stock approach. These tools are used by producers aiming to meet the requirements of certification and their voluntary commitments, and more recently applied at regional and national scales.

- There is at present still limited evidence of the effectiveness of sustainability initiatives in the industry. Available evidence is clouded by a lack of clarity whether failures are due to deficiencies in the initiatives themselves, or due to problems in their implementation. 
Given the known and potential impacts of oil palm development for biodiversity, what is currently being done to manage them? This chapter provides an overview of the leading strategies and initiatives that the private sector and government institutions are using to avoid and minimise impacts to biodiversity. It also reviews the current level of understanding on the scope and effectiveness of these initiatives, and presents an overview of the challenges ahead in the search for conservation solutions in oil palm producing landscapes.

\subsection{Leading conservation strategies}

The main strategy for mitigating biodiversity impacts from oil palm cultivation has been to address the loss of natural forest and peat lands. Avoidance or protection of these areas has been the focus of environmental governance initiatives, including regulatory policies, corporate commitments and certification standards. These initiatives apply tools to identify and manage sensitive areas of conservation importance (Box 16). In addition, many initiatives include auditing, traceability, transparency and monitoring mechanisms to realize conservation outcomes.

Sustainability initiatives in the industry have been mostly reactionary to the proximate causes of biodiversity loss from land use changes (e.g., fire, land clearing) during oil palm expansion. Less effort has been dedicated to changing the underlying causes (e.g., increasing demand for edible oil, political economies of land acquisition), perhaps

\section{Box 16.}

\section{Identifying areas of conservation importance: High Conservation Value and High Carbon Stock}

Several sustainability initiatives in the industry have focused on placing safeguards to protect areas of conservation importance. Characterizing and identifying these areas is technically challenging and often controversial, and various tools have been proposed and continuously developed to address this issue. Two leading tools are the High Conservation Value approach and the High Carbon Stock Approach, which have been formally adopted within international certification standards and by companies with voluntary pledges in the oil palm sector. Other initiatives have focused on the development of guidelines for the identification of degraded areas (e.g., 265) and the mapping of vulnerable habitats such as forested peatlands (e.g. Indonesia's licensing moratorium on peatlands (266)).

The High Conservation Value approach is an ongoing process of identifying, managing and monitoring biological, ecological, social or cultural values that are of outstanding significance or critical importance at the national, regional or global level. These values are grouped in six main categories (267) and the approach focuses on providing a framework to identify and manage them throughout the lifecycle of an oil palm plantation.

The High Carbon Stock approach is a methodology designed to distinguish forest areas that should be protected from ecologically degraded lands that may be developed (77). The approach currently proposes vegetation types and structures as criteria to determine the suitability of an area for conversion to oil palm. Open land and scrub are judged acceptable for development from an ecological standpoint, low-, medium- and high-density forests should be set aside as High Carbon Stock forests, and young regenerating forests may either be converted or preserved depending on patch size and connectivity characteristics (Figure 28). High Carbon Stock forests can contain high mammal diversity and abundance, at least when hunting is minimal $(110,268)$. This approach requires concurrent implementation of the High Conservation Value framework.

The High Conservation Value approach (and by extension the High Conservation Stock approach) uses field and secondary data on concentration of biodiversity, vulnerability of species, and habitat distribution and coverage. As such, the successful implementation and articulation of both approaches depend on the continuous production, revision and availability of conservation assessments (e.g. identification of key biodiversity areas, global and national red list assessments for species and ecosystems, designation of Ramsar areas, etc.). Application of the new Key Biodiversity 
Areas standard (270) could strengthen the scientific credibility and transparency of the High Conservation Value identification process (271).

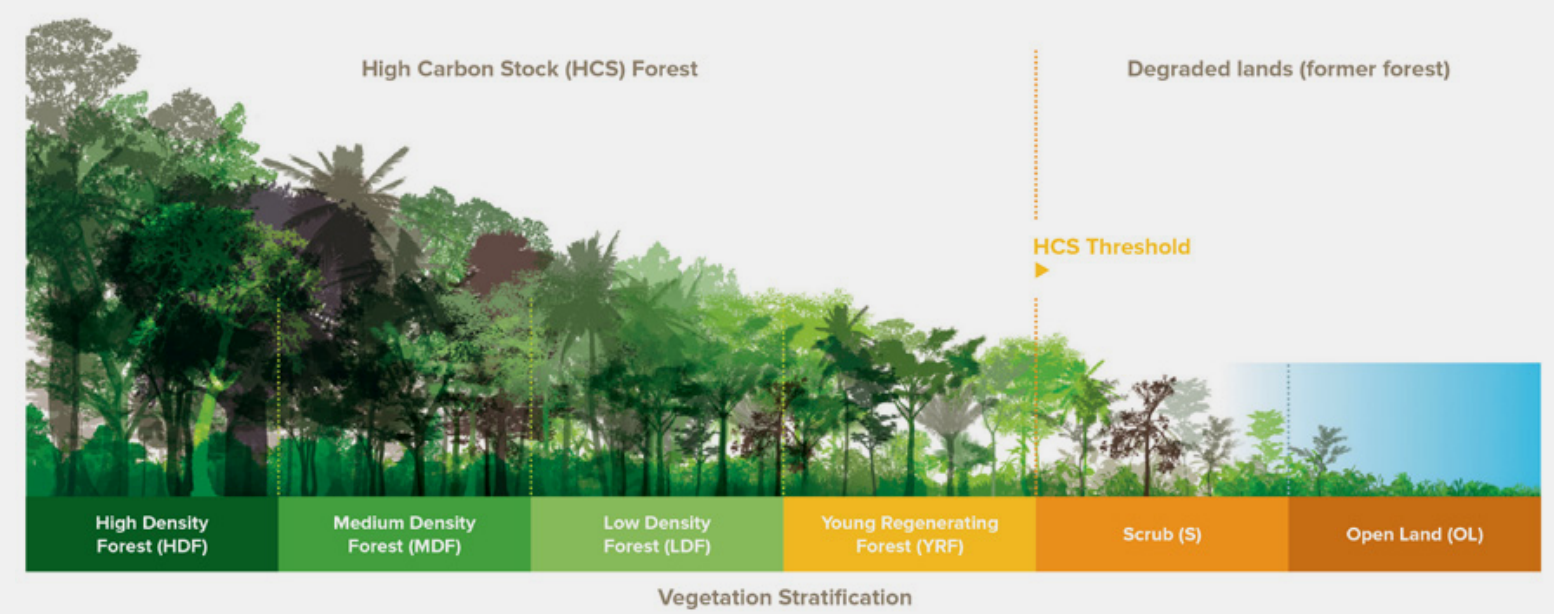

Figure 28. Vegetation stratification considered by the High Carbon Stock Approach (269). Adapted from HCS Approach Steering Group.

because these are more difficult to influence and often operate at regional to global scales. Trends of shifting diets, increasing global wealth, and urbanization mean that demand for edible oil will continue to increase in the foreseeable future.

Because oil palm is a highly efficient crop already embedded within national and global economies, eliminating production of this crop to alleviate impacts is impractical; therefore, a more realistic focus is to shift consumption demands toward more sustainable sources.

\subsection{The mitigation hierarchy}

Environmental impact assessments commonly require application of impact mitigation measures for any project or development, including oil palm, which will have environmental and social impacts. The mitigation hierarchy (Figure 29) is a sequence of steps taken throughout a project's lifecycle starting with avoidance of impacts, minimization of inevitable impacts, on-site restoration and finally compensation or biodiversity offsets if required (272, 273). Compensation means compensating for the impact by replacing or providing substitute resources or environments. Specifically, in terms of biodiversity, compensation involves measures to recompense, make good or pay damages for loss of biodiversity caused by a project. Sometimes 'compensation' is synonymous with 'offset', but compensation is contrasted with a biodiversity offset in that a biodiversity offset is generally considered as a no net loss (or net gain) conservation outcome (273). Governments, companies, banks and civil society are placing more emphasis on the rigorous application of the mitigation hierarchy to avoid, minimize and compensate for project impacts on biodiversity.

The adequacy of application of the mitigation hierarchy, such as rehabilitation, restoration and compensation measures, is currently understudied in the context of rapid and widespread expansion of oil palm cultivation. Thus, these approaches are yet to be fully incorporated within environmental governance initiatives in the industry, even though they have been used for specific cases (e.g., the Roundtable on Sustainable Palm Oil's Remediation and Compensation Procedure, 274).

The mitigation hierarchy for managing biodiversity risk could provide a useful framework for the articulation of these strategies with the existing approaches in the sector. The mitigation hierarchy has not been widely applied in an oil palm context, 
where most sustainability requirements are based on regulation, corporate biodiversity standards and sustainability standards. As will be discussed below, these requirements are influenced by changing global demand patterns towards more responsibly produced palm oil.

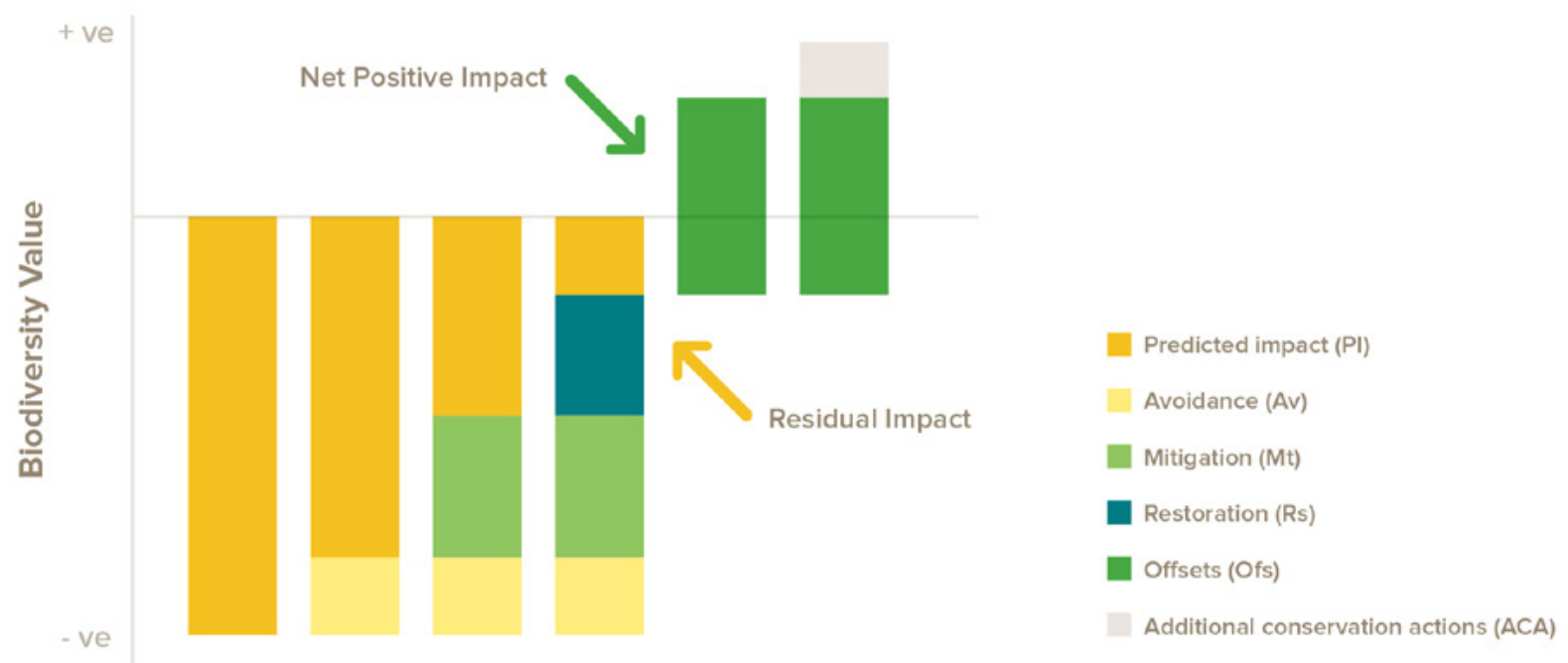

Elements of NPI

Figure 29. The mitigation hierarchy for managing biodiversity risk (272).

\subsection{Environmental governance initiatives that aim to address conservation concerns}

Multiple environmental governance initiatives have emerged in the last two decades with the aim of minimizing social and environmental impacts throughout the palm oil supply chain. Their focus has not solely been on biodiversity conservation, but cover other sensitive issues such as greenhouse gas emissions, agronomic practices, fire control, labour rights, gender equality, land tenure rights, and indigenous peoples rights. Addressing these complex and numerous issues has resulted in a wide range of initiatives ranging from voluntary certification standards (e.g. Roundtable on Sustainable Palm Oil) and voluntary pledges by individual companies (e.g. zero-deforestation commitments), to national policies regulating land allocation in oil palm production (e.g., Indonesia's Forest Licensing Moratorium) and international commitments by governments (e.g., Amsterdam Declaration). Although these initiatives are largely implemented on the ground by the private sector and governments, they have been continuously developed with the participation of non- governmental organizations, including environmental and community and workers' rights groups, who have also played an important role in scrutinizing their implementation. Here, we briefly describe these initiatives.

\subsubsection{Certification standards}

Certification of more sustainable production is a leading environmental governance initiative in the palm oil sector. It aims to engage stakeholders in the supply chain, in particular producers and mills, in the implementation of standards that set a minimum level of best practices for the industry. Certified producers may receive premium prices or secure access to particular markets.

Roundtable on Sustainable Palm Oil. In 2017, about $19-20 \%$ of all global palm oil production was certified by the Roundtable on Sustainable Palm Oil (275). The inception of the roundtable in 2004 was the starting point for companies in the palm oil sector to embrace the concept of sustainability in a voluntary way. Since then, the standard has seen slow but consistent progress in terms of uptake. The Roundtable itself has experienced dramatic 
growth in terms of membership, which as of 2017 consisted of around 3200 downstream stakeholders (i.e., processors, traders, retailers, and supply chain associates) and 175 oil palm growers. This significant participation by downstream stakeholders implies a strong demand for, or at least interest in, more sustainable palm oil. Yet, the limited number of growers that are members of the Roundtable on Sustainable Palm Oil suggests that certified palm oil demand is not mainstream but rather is limited to a niche market.

Conservation concerns are addressed by the Roundtable on Sustainable Palm Oil through its requirement to implement environmental impact assessments, identify and manage High Conservation Value areas (Box 16), avoid clearing primary forest, protect riparian buffers, avoid fires and control pollution. For instance, certification is only granted when new plantings since 2005 have not replaced primary forest or High Conservation Value areas. However, by following the Roundtable on Sustainable Palm Oil's Remediation and Compensation Procedure, producers are able to certify units for which no HCV assessments were undertaken. To ensure compliance, the Roundtable on Sustainable Palm Oil uses a third-party verification and certification system conducted by independent and accredited certification bodies. After certification, growers are audited annually for compliance and are required to undergo re-certification every five years. The Roundtable on Sustainable Palm Oil also has in place an open complaints system regarding breaches of specific statuses by its members.

In recent years, the Roundtable on Sustainable Palm Oil has developed specific initiatives to respond to new developments in the sectors and specific concerns by consumers. This is the case of the Roundtable on Sustainable Palm Oil - Renewable Energy Directive (RSPO-RED) scheme, which allows palm oil producers and processors to comply with the EU Renewable Energy Directive requirements. RSPO-Next and the Palm Oil Innovation Group are other initiatives that aim to certify members that exceed the requirements of the Roundtable on Sustainable Palm Oil Principles and Criteria through voluntary policies or innovative actions. Furthermore, in 2017, the Roundtable on Sustainable Palm Oil initiated a process to incorporate the High Carbon Stock approach (Box 16) within its principles and criteria framework (276).

Other certification systems. The Roundtable on Sustainable Palm Oil is the most widely used global standard, but it is not the only one. Other global certification standards used by the oil palm sector are the International Sustainability and Carbon Certification, the Rainforest Alliance Sustainable Agricultural Standard, the Sustainable Agriculture Network, the Roundtable on Sustainable Biomaterials, and the SET - Applied Sustainability scheme. Here we provide details on two of the most prominent certification schemes used in the industry.

Oil palm growers selling to the European biofuels market have pursued International Sustainability and Carbon Certification (ISCC) (277). This certification scheme has been developed for a large range of industries, including feedstocks and raw materials used in the global food, energy and manufacturing sectors. International Sustainability and Carbon Certification requires companies to demonstrate the production and sourcing of sustainable and deforestation-free raw materials. Under this scheme, oil palm growers are not allowed to establish plantations in areas of high levels of carbon stocks (note this is unrelated to the High Carbon Stock approach described in Box 16) and High Conservation Value areas (as defined in Box 16). In 2016, 22 million tons of fresh fruit bunches were produced by International Sustainability and Carbon Certification companies (278).

The Rainforest Alliance Sustainable Agricultural Standard certifies producers that comply with a set of economic, social and environmental principles and is considered one of the most stringent certification standards for biodiversity protection. The Rainforest Alliance addresses biodiversity conservation through safeguards towards the protection of all natural ecosystems, High Conservation Value areas (as defined in Box 16), the maintenance of natural vegetation and protection of wildlife. Currently, less 
than 100,000 hectares of oil palm have been certified by the Rainforest Alliance (279).

\subsubsection{Corporate commitments to no deforestation}

\section{Companies' commitments to no deforestation.}

In the last decade, the palm oil sector has seen a growing trend in individual corporate commitments to "no deforestation", from actors across the supply chain. These pledges have emerged in large part as a response to international civil society campaigns (e.g., 280), demanding that companies in the agricultural and forestry sectors go beyond certification standards, such as the Roundtable on Sustainable Palm Oil certification. These pledges are in many cases part of larger voluntary sustainability policies that address not only environmental concerns but also social issues.

Many of the main producers and buyers of palm oil now have "no deforestation" pledges in place.

A 2017 cross-commodity survey (281) found that companies in the oil palm sector have the highest proportion of no-deforestation commitments across four commodity supply chains strongly linked to global deforestation (Figure 30). Although the majority of these commitments have been made by the retailer and manufacturer stakeholders in the supply chain (281), the largest palm oil producers in the world have also joined such pledges. Currently, 41 of the 50 palm oil companies with the largest market capitalization and land areas have committed to address deforestation, while 29 of these companies have also committed to implementing zerodeforestation policies (282) (Figure 31).

Some corporate commitments address conservation concerns not only through "no deforestation" pledges, but also explicitly commit to conserve biodiversity (Figure 31). Of the 50 companies included in the study shown in Figure 31, the majority commits to using the High Conservation Value approach as one of their main tools to address conservation within the planning and production phase of plantations. The more recent High Carbon Stock approach has also been taken up by $44 \%$ of these companies. In general, companies express

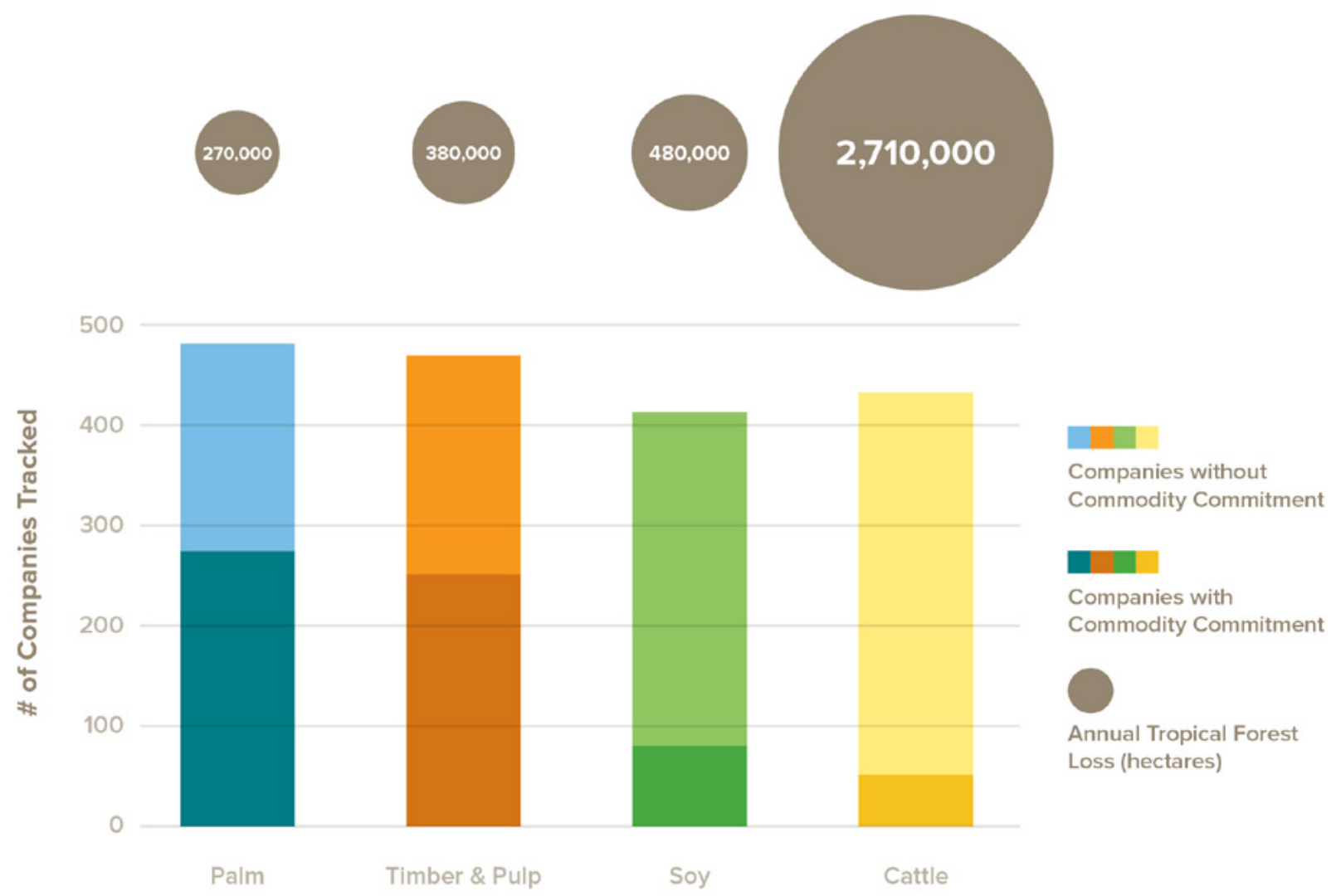

Figure 30. Number of companies with and without commitments by commodity (283). 
open commitments to address deforestation and conservation of biodiversity and High Conservation Value areas, but are less explicit in applying these commitments to smallholders and independent suppliers (Figure 31).

Some companies are beginning to commit to corporate sustainability beyond zero-deforestation, in ways that resemble in-house certifications (284). Nestle, for example, has stipulated a set of minimum, non-negotiable standards in its supplier code of conduct. These standards include equitable social conditions for workers, occupational health and safety, and waste minimization that reinforce the Roundtable on Sustainable Palm Oil Principles and Criteria (285).

Companies with "no deforestation" commitments are in a powerful position to drive behavioural change upstream in the supply chain. Buyer demands are thought to serve as a leverage point to mobilize sustainability practices of less visible producers such as non-certified small-to medium-sized companies and smallholders with insufficient incentives or capacity to prioritize conservation. The rather low level of implementation and tracking of such commitments suggests, however, that they are still far from fulfilling this potential (16). Nevertheless, these corporate commitments to "no deforestation" could have significant impacts on curbing deforestation by the biggest players in the industry. In Indonesia, for instance, it is estimated that these commitments could reduce up to $47 \%$ of cumulated deforestation by 2030 under certain policy scenarios (286).

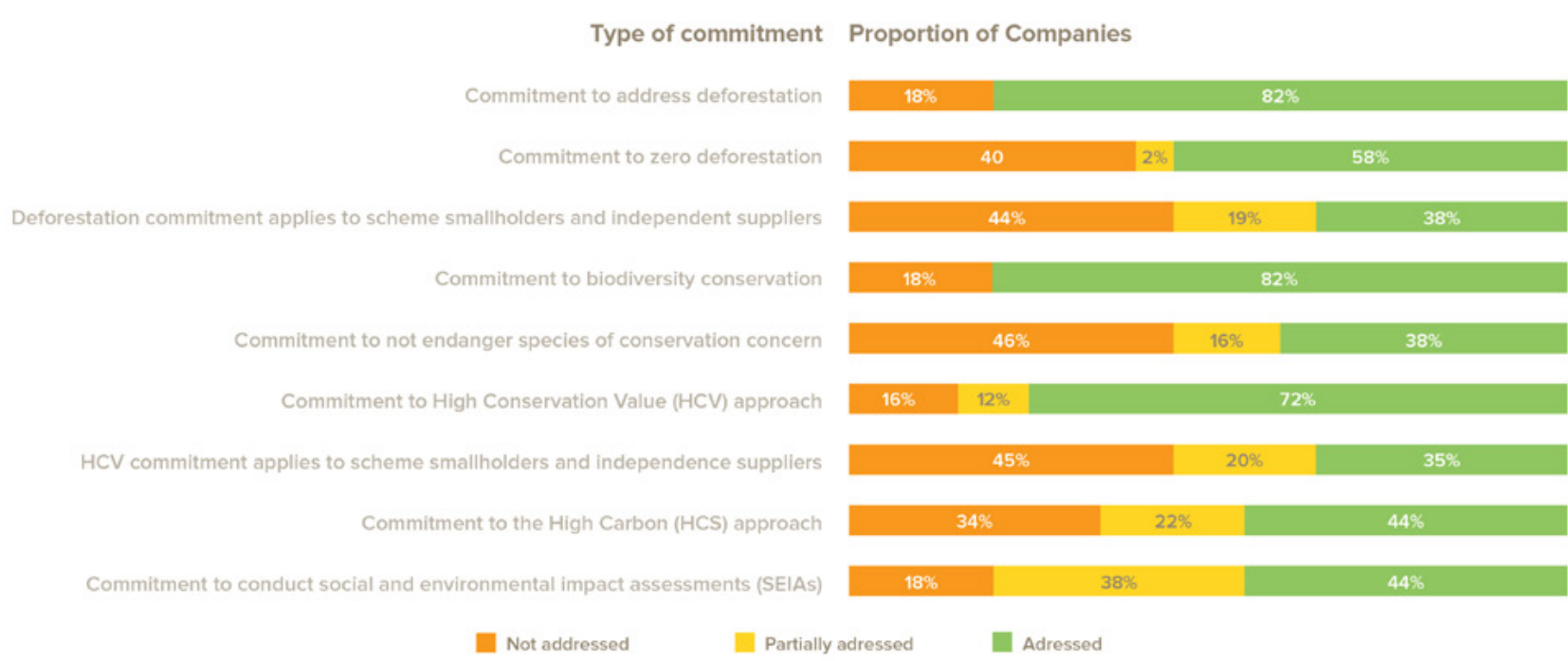

Figure 31. Proportion of companies with sustainability pledges that commit to address different aspects of biodiversity conservation. Green: Explicit commitment, Yellow: Partial commitment, Orange: No explicit commitment. Data taken from SPOTT database (287).

\section{Box 17.}

\section{The issue of stranded assets}

One of the perverse outcomes of no deforestation pledges are 'stranded assets'. Stranded assets are assets that have suffered from unanticipated or premature write downs, devaluations or conversion to liabilities. A recent study showed that 6.1 million ha of forests and peatland are "stranded assets" on the balance sheet of Indonesian palm oil companies as they cannot viably be developed (288). Twenty-nine percent of Indonesia's leased-out landbank cannot be developed without violating buyers' No Deforestation, No Peatland, No Exploitation (NPDE) policies, and with $10 \%$ of Indonesia's total land area having been leased out for oil palm concessions (288), this means that significant land areas do neither fulfil their full economic objectives nor do they benefit environmental protection because these stranded assets are rarely managed for conservation objectives. 


\subsubsection{Regulatory requirements}

\section{Policies of governments where palm oil is}

grown. Governments of producing countries have also reacted to international debates on oil palm and deforestation. In Brazil, for example, the National Plan for the Production and Use of Biodiesel and the Brazilian Forest Code, are among several regulatory documents that refer to the sustainable development of oil palm (289, 290). In Indonesia, where most of the growth in production has occurred in the last 20 years, two important sets of national policies have been created to manage impacts: a deforestation moratorium and a national mandatory certification scheme. The Indonesian moratorium on issuance of forest utilization licences, issued in 2011, addresses environmental concerns about oil palm development by prohibiting the allocation of new oil palm leases in "primary forests" and "peatland areas". In the same year, the Ministry of Agriculture initiated the Indonesian Sustainable Palm Oil certification system (ISPO) (291). This initiative aims to increase the competitiveness of Indonesian palm oil products in the global market by addressing environmental and social issues and ensuring compliance with Indonesian laws and regulations (292). The Indonesian Sustainable Palm Oil criteria addresses conservation concerns through the restriction of forest clearance within protected areas or areas under the 2011 deforestation moratorium. Forests outside these areas can be cleared as long as growers have met the legal requirements to do so (292). For instance, "conversion forests" within the forest estate can be cleared, as long as growers have obtained the required permits from the Ministry of Forestry. The Indonesian Sustainable Palm Oil criteria also require protection of riparian forests (to control erosion processes) and peatland areas (with $>3 \mathrm{~m}$ depth), and contain provisions against the conversion of areas of conservation importance. Yet, the criteria do not provide clear definitions and frameworks to identify these areas $(292,293)$.

In Malaysia, the Malaysian Sustainable Palm Oil system (MSPO) (294) aims for all palm oil producers within the country to comply with the federal and state laws. The system was introduced in 2012 by the federal government and will become mandatory for all producers by the end of 2019 (295). The Malaysian Sustainable Palm Oil system is based on seven principles, which includes the protection of the environment, natural resources, biodiversity and ecosystem services and guidelines for the development of new plantations. The Malaysian Sustainable Palm Oil requires producers to comply with national legislation including completion of Environmental Impact Assessments and Socioenvironmental Impact Assessments. New plantations are required to avoid planting on land with high biodiversity value, however, this is allowed if it is carried out in compliance with national or subnational legislation. As of November 2017, 4,004 hectares of independent smallholder lands and 293,714 hectares of plantation and organized smallholders had been certified under the MSPO system, $67 \%$ of which were in the states of Sarawak and Sabah (296).

\section{Policies of governments that import palm oil.} Governments that use but do not produce palm oil have set aspirational goals for and restrictions on palm oil imports and purchases. Several importing governments have made political commitments related to oil palm's perceived sustainability. Most of these policies occur in the Global North, especially Europe, where a growing number of consumers consider palm oil to be environmentally unsustainable. For example, a recent study conducted in France suggested that consumers' willingness to pay for products containing palm oil declined after they received information about the environmental impacts of oil palm (297). In contrast, while India and China together consumed around $23 \%$ of total palm oil supply in 2015 (23), demand for sustainable palm oil in Asia remains extremely low, despite recent uptake of Roundtable on Sustainable Palm Oil certification in China $(298,299)$. Most prominent among government aspirational commitments is the non-binding Amsterdam Declaration that supports a fully sustainable palm oil supply chain (i.e., imports meet Roundtable on Sustainable Palm Oil standards, at minimum) by 2020 (300). In mid-2018, the Declaration had been signed by six countries in Europe. Individual nations have also considered policies restricting palm oil 
imports due to sustainability concerns. For instance, in 2016, France proposed to levy an extra tax on palm oil imports to encourage sustainable production of vegetable oils, but this tax was scrapped due to legality concerns (301).

Other restrictions on palm oil imports apply only to palm oil used as a biofuel. In 2017, around $27 \%$ of palm oil production was used for industrial purposes including as biodiesel (23), often to satisfy government-mandated biofuel targets. Some governments have renewable fuels programs linked to climate change mitigation that require biofuels to meet certain benchmarks in terms of how much they reduce greenhouse gas emissions relative to fossil fuels. These benchmarks typically consider both direct and indirect land use change emissions from biofuels. Direct emissions are emissions from clearing land for biofuels production (302). Where biofuel feedstocks are grown on lands previously used to produce food, feed, or materials, indirect land use change-where displaced demand for food, feed, or materials leads to land use change elsewhere -- is a major concern (303).

In the United States, the Renewable Fuel Standard requires that biomass-based diesel meets a lifecycle greenhouse gas emissions reduction of 20\% (304). The United States Environmental Protection Agency analysis indicated that palm oil biofuels do not meet this minimum threshold needed to qualify as renewable fuel (305). However, since certain biofuel production facilities have been grandfathered into the program, some palm oil is used to satisfy Renewable Fuel Standard mandates (306). Europe's Renewable Energy Directive (RED) requires that the European Union fulfil 20\% of its energy needs by 2020 with renewable sources of fuel. Qualifying biofuel feedstocks cannot have not been sourced from land with high biodiversity value, high carbon stock, or drained peatlands, which addresses concerns regarding direct impacts of biofuel demand on biodiversity (307). Yet, evidence suggests that indirect land use change induced by demand for palm oil as a biofuel may be substantial. A 2015 study that modelled land-based emissions under several biofuel mix scenarios in Europe found that across all conventional feedstocks considered, oil palm had the greatest emissions intensity (emissions per megajoule of biofuel consumed) (308). Oil palm's intensity was 1.5 times that of soybean, the second most emissions intensive feedstock, and was largely driven by carbon dioxide emissions from drainage of peatlands in Southeast Asia for oil palm development. In response to this study and others like it, ongoing revisions to the Renewable Energy Directive are likely to reduce the role that palm oil and other crop-based biofuels play in biofuels targets. This may include phasing palm oil-based biodiesel out of Renewable Energy Directive transport targets by 2021 (309). Some governments also restrict their own palm oil purchases. For instance, in 2017, Norway passed a law that bans public use and procurement of palm oil for biofuel (310).

Exporting countries including Indonesia and Malaysia have objected to these bans, arguing that they discriminate against palm oil and ignore other biofuels such as soybean that also drive tropical deforestation (311). Others argue that such bans may be counter-productive. Imposition of blanket restriction on palm oil imports provides no incentives for conservation-friendly practices, but instead treats all palm oil as equal (312). For instance, oil palm expansion in Latin America has largely occurred onto already cleared lands on non-peat soils, such as pasturelands (24). Nevertheless, even use of "sustainable" palm oil as a biofuel is likely to induce indirect land use change and associated impacts on biodiversity and climate.

If importing government commitments, import restrictions, and procurement policies reduce demand for palm oil, this could have unintended consequences for global biodiversity. Most studies agree that changes in demand for palm oil will affect global land markets $(121,308,313)$. Specifically, due to the relatively high degree of substitutability across edible oils, reduction in demand for palm oil could lead to expansion of other oil crops such as rapeseed, sunflower, and soybean (314). Since oil palm produces more oil per area than other major oil crops (315), such substitution would likely drive a net increase in global cropland area (121). Yet, these 
effects differ greatly across models and depend on assumptions about the elasticity of demand, future yield increases, and several other factors (316). Therefore, the effects of import restrictions on biodiversity are highly uncertain and depend on which crops expand (e.g., rapeseed or soybean) and where expansion occurs (e.g., into tropical forests or temperate grasslands).

\subsubsection{Jurisdictional and landscape approaches}

Recent pledges by stakeholders, changes in governance in the sector, and calls for crosscommodity approaches and commitments have generated considerable attention to the use of landscape and jurisdictional approaches to sustainability. Jurisdictional approaches are subnational programmes that aim to realize sustainability goals across an entire administrative region, such as a province or district (317). Although still in their early days, these approaches are actively discussed within existing platforms such as the Roundtable on Sustainable Palm Oil. Landscapes approaches, on the other hand, are less well-defined, but can be understood as approaches that address the inter-connected social, environmental, economic and political challenges at landscape scales through integrated solutions (318). Both types of approaches, can provide a framework to articulate sustainability initiatives across sectors (including oil palm), mitigation strategies for climate change (e.g., reducing emissions from forest degradation and deforestation) and social objectives (poverty alleviation, economic development) in a particular region (319). Their benefits include reduced costs of monitoring deforestation, low-risk for longterm investment, increased legal compliance, and conflict resolution between companies and local communities. Biodiversity conservation could also be enhanced because larger areas of habitats and ecosystems would be protected, reducing risks of leakage and non-permanence (317).

Some of the first pioneer jurisdictional programmes in the oil palm sector are being set up on the island of Borneo. There, the Malaysian state of Sabah and the
Indonesian district of Seruyan (Central Kalimantan) have committed to produce certified palm oil across their entire jurisdiction by 2025. Achieving this ambitious vision will require an adaptive process centred around a shared vision and objective, a strong multi-stakeholder governance structure, mechanisms for broad public participation and accountability, champions in the different stakeholder groups, the design of a monitoring system to report and verify the on-the-ground deliverables and the creation of an enabling environment including policies, incentives for investment and fair sharing of costs and benefits $(317,320)$.

Beyond Asia, similar public-private initiatives have been established through the Tropical Forest Alliance 2020 in the oil palm sectors of Africa and Latin America, on regional and national levels, respectively (321). Gabon, for example, is preparing a national approach to palm oil as part of its national land use plan, for which recommendations on land allocation to agriculture are being developed alongside conservation, timber production and other land uses. In Colombia, a national-scale jurisdictional approach has materialized around a zero-deforestation initiative signed in December 2017 by the national government, oil palm growers, national and multinational processors/traders, the national federation of oil palm growers (Fedepalma), the national federation of biofuel producers (Fedebiocombustibles), and civil society and non-profit groups (e.g. WWF, Proforest) (322). Additionally, the Orinoquia Sustainable Integrated Landscape initiative is a regional jurisdictional effort put forth by the Colombian government to ensure low-carbon, biodiversity friendly development in Colombia's last agriculture frontier and the country's largest palm oil production zone (see section 4.2.3 of this document) (323).

Challenges still lie ahead for the long-term effectiveness and implementation of jurisdictional approaches. One of the major critiques is a lack of agreement on which standards should be put in place and how they will be achieved (324). Because jurisdictional approaches aim to consolidate input from more actors across sectors, they are inherently more complex and may be prone to lack of alignment 
that arises at the intersect between top-down and bottom-up models. Furthermore, the success of these initiatives rests firmly with regional or national political will, especially regarding enforcement

(317). This could complicate the application of a jurisdictional approach to emerging oil palm frontiers, where land tenure is often poorly defined and geographical remoteness hampers monitoring and enforcement efforts (Box 18). Key is determining the right scale of these initiatives to ensure effective governance and stakeholder follow-through. Whether the jurisdictional approach lives up to expectations, it will at least be successful in opening dialogue among the varied stakeholders that are active in oil palm landscapes, helping to create more inclusive national standards and regulatory frameworks.

Box 18.

The messy reality of oil palm development: the Riau puzzle

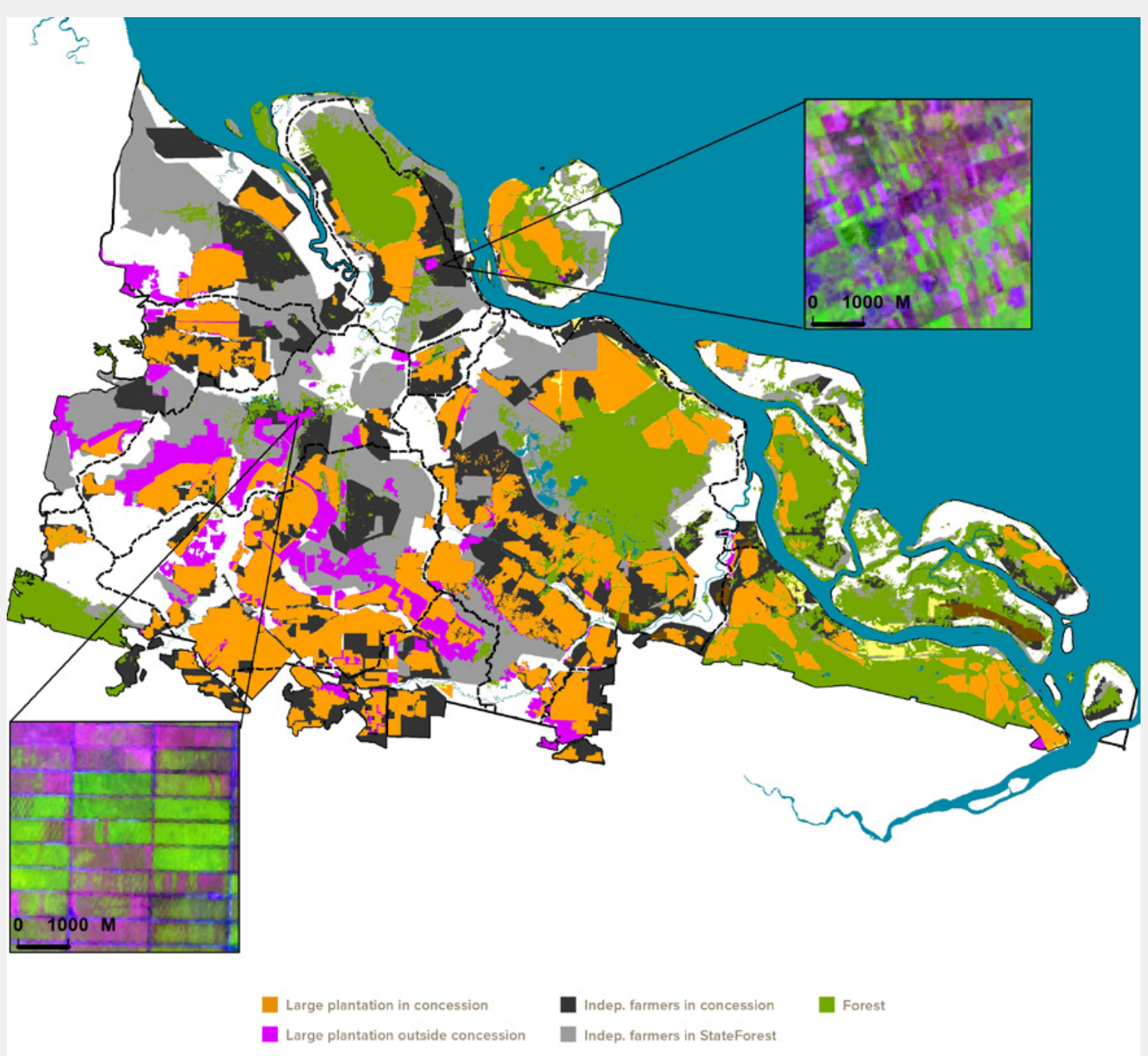

Figure 32. Land illegally occupied by independent farmers in concessions (black) and in State Forest (grey). The inset in a Landsat snapshot reveals clusters of land parcels with irregular shapes, varying sizes, and directions in a pulpwood concession. This spatial pattern characterizes lands occupied by independent farmers (either already planted or under development). Land illegally planted by oil palm companies outside concessions (purple). The small inset reveals regular gridlike land parcels outside concessions. This spatial pattern characterizes lands occupied by companies (either already planted or under development). 
Mitigating the impacts of palm oil development hinges in part on transparency around land ownership, one component of the highly complex and variable local governance of palm oil. A good example can be found in the Indonesian province of Riau, a major palm oil producing area that accounts for nearly 2.5 million hectares or $23 \%$ of Indonesia's total mature oil palm acreage (325). Here, about 50\% of the total oil palm area is managed by smallholders. Not only are oil palm lands in Riau managed by multiple actors, but landholdings are not always registered with the government. In a 4.1 Mha study region of northern Riau (Figure 32), oil palm and pulp and paper concessions managed by private companies span 1.8 Mha, while the smallholder planted oil palm area totals 0.7 Mha. Nearly half of the total planted oil palm area lacks official land ownership records, according to the National Land Registration Agency (BPN). The situation is even worse on peatlands, where $57 \%$ of planted areas lacked official papers. This is in line with overall Riau statistics in which only $15 \%$ of all agricultural land parcels have a national-level registration and $26 \%$ of all oil palm plantation were only registered at the village level (325).

Although small independent farmers cannot legally occupy land in concessions (i.e., land managed by private companies), their presence - evidenced by small land parcels of irregular shape, size, and direction apparent from satellite imagery - was detected in 98\% of the 163 pulp and oil palm plantation concessions present in the study area, such that 0.26 Mha appear to be occupied by small and medium-sized independent oil palm farmers (Figure 32).

Companies are also growing oil palm outside of government registered concessions. Over 28\% (185,598 ha) of the total large-scale oil palm area developed in the study region occurred immediately outside of legal concession boundaries, based on the presence of grid-like land parcels detected on LANDSAT satellite imagery (Figure 32). Recent reports on the implementation of zero deforestation commitments in Riau and other provinces found that large companies continue to rely on considerable quantities of raw materials to fill the demand of their downstream facilities from uncontrolled or uncertified third-party sources (16), and most likely from illegal sources. As such, many of these companies continue to be involved in disappearance of the last remaining natural forests in critical biodiversity areas like the Tesso Nilo landscape in the Riau Province (16).

Despite overlapping claims, large areas in these landscapes have been cleared of forest but remain undeveloped. About 2.17 million ha of forest (or $75 \%$ of 1990 forest area) were cleared between 1990 and 2016. Industrial oil palm plantation development comprised only a third of this deforestation.

By 2016, about 54\% (2.2 Mha) of the study region was a mosaic of smallholder oil palm and unused lands covered in shrubs and ferns. Almost half (1 Mha) of these non-forested lands occurred on organic peatland soils that are vulnerable to fire. Unused lands comprised 61\% (0.24 Mha) of burned area in 2013-2014. During the 2015 haze crisis, Indonesian army troops sent to battle fires lacked the capacity and manpower to control fires in these vast areas. A combination of a lack of official status regarding landholdings, and vast unclaimed or uncultivated lands, reduce participation in controlling fires. To control fires, restore peatlands, and reduce deforestation in Riau, the provincial government must recognize the many stakeholders, their motivations, and their land management practices (326).

\subsection{Comparing environmental governance initiatives}

At first glance, the range of sustainability initiatives in the oil palm sector appears to be large and overwhelming, and seemingly in competition with each other. Here, we review the stated scope and complementarity of these initiatives with respect to biodiversity conservation, recognizing that a more systematic and comprehensive analysis to fully understand these aspects is needed.

\subsubsection{Conservation scope}

Conversion of primary forests. An analysis of current sustainability initiatives in the palm oil sector reveals that their main conservation focus is avoiding forest loss within planned oil palm plantations (277). The majority of these initiatives contain explicit safeguards to protect primary forests. The Roundtable on Sustainable Palm Oil, for instance, only certifies new plantations that have not replaced any primary forests that existed before 2005, while the International Sustainability and 
Carbon Certification standard uses similar provisions but with a 2008 cut-off date. Other initiatives, such as the Indonesian Forest Licensing Moratorium, are less restrictive in the protection of these habitats. Although recognized as a big step toward addressing deforestation in Indonesia, the licensing moratorium only includes selected primary forest areas and peatlands in the country but does little to ensure these areas are appropriately managed and protected (327).

Conversion of secondary forests. Initiatives differ in their treatment of "secondary forests" that recently regrew, or that have been heavily logged. These differences are underlined by the difficulties of defining and identifying these areas (i.e., lack of agreement on how to define forest degradation, see 328), and the different interpretations on the costeffectiveness of conserving these forests $(329,330)$. Some initiatives explicitly protect secondary forests in most cases (e.g., the High Carbon Stocks approach allows only the conversion of scrub or open land areas), while others only protect these habitats if they are identified as being of conservation importance (e.g., the High Conservation Value approach). Other initiatives do not have any explicit provisions to define in what cases the conservation or clearing of these forests is desirable (e.g., Indonesian Sustainable Palm Oil). Addressing the conversion of secondary forests is an important issue due to the progressive long-term deforestation and degradation of forests, and the multiple pathways of commodity crops observed in many tropical areas (331) (e.g. premeditated and continuous degradation of forested areas that leads to an eventual conversion to other uses including palm oil). Governance initiatives that include cut-off dates for deforestation may be able to address this issue, by requiring new plantations to be established in areas that were deforested before a specific date (e.g. 2005 in the Roundtable on Sustainable Oil Palm).
Loss of ecosystem services. Most of the initiatives in the industry have not only focused on providing protection based on assessments of the successional state of a forest (i.e. whether it is primary or secondary), but also used ecosystem services criteria to identify areas of conservation importance. In particular, many initiatives provide guidance towards the protection of peatland and riparian forests (Box 19), because of the carbon storage, soil protection, and water regulation services they provide. As with secondary and primary forests, much of the controversy in regard to these interventions derive from the lack of agreement on definitions used to identify sensitive peatland and riparian forests. The Indonesian Sustainable Palm Oil regulation, for instance, provides protection to peatland areas with a peat depth higher than $3 \mathrm{~m}$, while some corporate commitments pledge to avoid development in soils that contain $65 \%$ or more of organic matter regardless of depth (332). The principles and criteria of the Roundtable on Sustainable Palm Oil require producers to avoid development on fragile soils and in peatland areas, but they do not provide clear guidelines for their identification in the 2013 Principles and Criteria. The protection of peatland areas in Indonesia received an important boost from the national government, when it introduced a moratorium on new licenses in the vast majority of peatland areas in the archipelago in 2011 (327). Definitions on the appropriate width of riparian areas to protect water related services also vary across initiatives. However, from a biodiversity perspective, wider riparian areas may yield better conservation outcomes as recent evidence suggests (Box 19). Besides the focus on services related to carbon, water and soil process, the High Conservation Value Approach is the only instrument that includes specific guidelines for the protection of areas that provide other important ecosystem services in local and regional contexts. 
Box 19.

\section{The importance of protected riparian areas for biodiversity and ecosystem services}

Where riparian reserve guidelines exist they are often vague and highly variable between countries and administrative regions. For example, whilst Indonesia stipulates that rivers $<30 \mathrm{~m}$ wide should have reserves of $50 \mathrm{~m}$ on each bank, and larger rivers need a $100 \mathrm{~m}$ reserve, neighbouring Malaysia has different requirements depending on the size of the river, the land-use context and the state. Brazil has recently changed its riparian policies to be more lenient to agribusiness, and guidelines are notably absent or poorly defined in some countries, particularly the emerging agricultural markets of Central Africa and mainland Asia.

Recently, the Roundtable on Sustainable Palm Oil updated its Principles and Criteria to include protection, management, and restoration of riparian areas $(333,334)$. Guidance includes both the protection of existing native, typically forested vegetation alongside waterways as riparian reserves, but also the restoration of degraded and previously planted areas. Scientific experiments are underway in Sumatra to test the best way to do this (335). Nevertheless, it is important to note that most studies to date have worked with short term datasets, and the long-term value of riparian reserves for wildlife, hydrology, and other ecosystem services is largely unknown.

Around a third of research on riparian reserves has focussed on hydrology. Protected riparian vegetation helps regulate rainfall and run-off inputs into rivers, filter sediments and pollutants, stabilise riverbanks, maintain shading and low temperatures, and provide inputs of terrestrial organic matter such as dead wood, leaves, seeds, and insects (336-341). In Malaysia for example, oil palm plantation streams with higher riparian foliage cover or forest quality were more shaded and cooler, and also had higher levels of leaf litter $(211,213)$. High tree cover in riparian areas is associated with high levels of dissolved oxygen in water (342), low levels of sediment (342) and sand (211), and lower levels of disease-causing bacteria (343).

Fish and stream macroinvertebrates in protected streams are typically more similar in composition to those found in pristine forests than unprotected streams in farmland $(210,344$, 345). For example, species that use leaf litter and coarse substrate for hiding and foraging were found to be missing from oil palm sites that did not have riparian reserves (345).

There is growing consensus that riparian buffers also support higher terrestrial species abundance, richness and diversity compared to nearby agricultural systems (e.g., 346, 347), and can, in some cases, support comparable diversity to riparian sites in continuous forests for a range of taxa, e.g. mammals (348); birds (349); leaf litter ants (350); butterflies

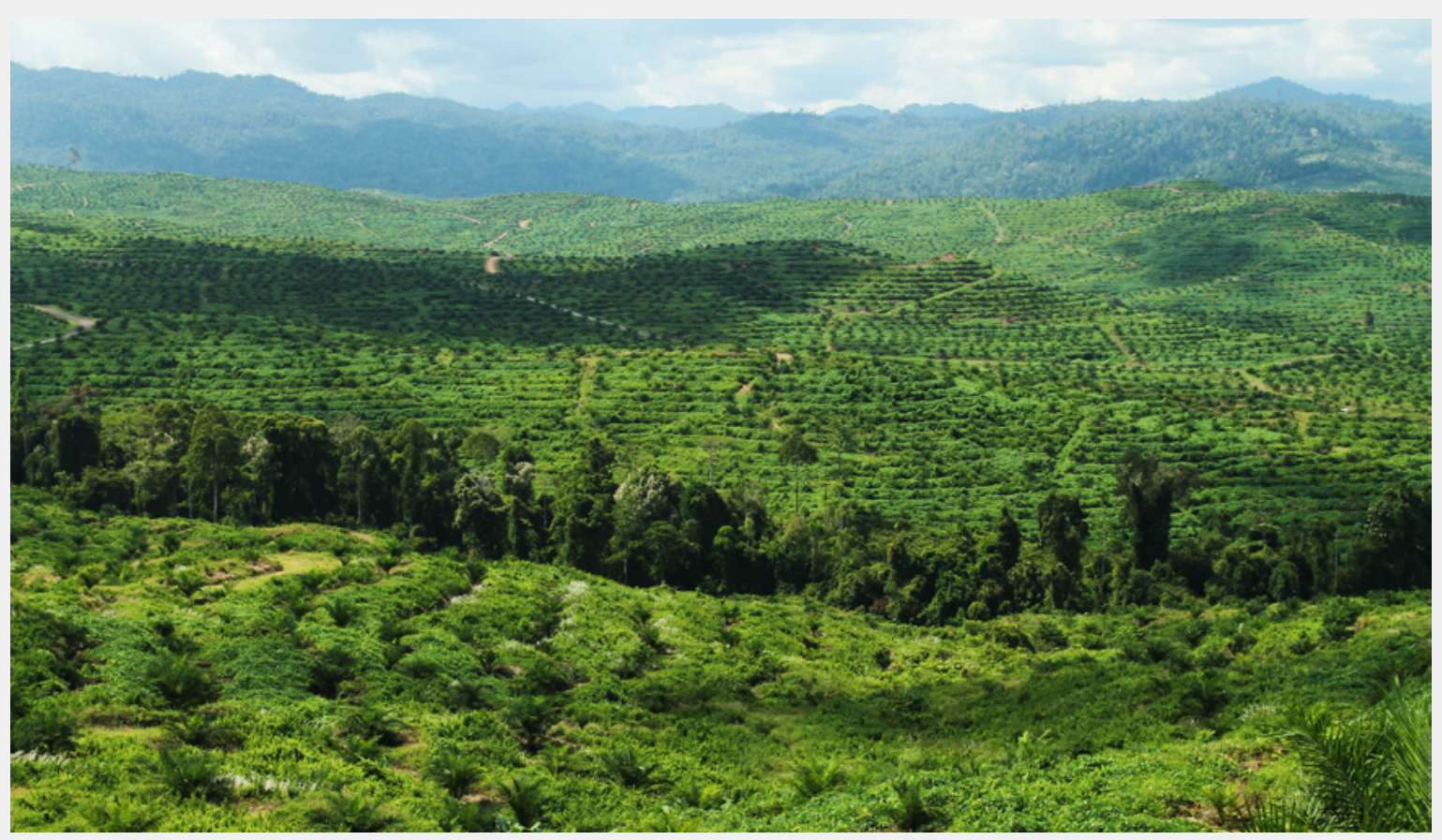

Figure 33. A riparian reserve in an oil palm landscape in Sabah, Malaysia. (O Matthew Struebig) 
(351); and dung beetles (352). Riparian reserve widths typical of many tropical countries (20-30 m on each bank) can support substantial levels of biodiversity. For example in Borneo, 20 m reserves support around $80 \%$ of the bird and dung beetle species found in comparable riverine areas in logged forests $(349,353)$.

Wider riparian reserves typically support more species (354-356). Unfortunately, few studies give explicit recommendations on the optimum width to maintain similar species diversity to rivers in forested areas. These width thresholds are likely to be taxon specific. A recent unpublished study of birds in oil palm demonstrated optimum riparian widths to be $>40 \mathrm{~m}$ on each river bank, but would need to be at least $100 \mathrm{~m}$ to support equivalent numbers of forest-dependent species and species of conservation concern to those found in continuous forest. Even small width increases of $10 \mathrm{~m}$ each side of the river can improve biodiversity levels found in riparian areas. Nevertheless, it is important to note that all studies to date have worked with short-term datasets, and the long-term value of riparian reserves for wildlife, hydrology and other ecosystem services is unknown.

Riparian reserves in oil palm areas have the potential to connect other high conservation value areas within farmland landscapes. However, the extent to which this connectivity function occurs likely varies by species and local context, and only a few studies have investigated these processes directly in the tropics. To do so rigorously requires information on movement patterns to establish whether wildlife is actively using riparian areas to commute and disperse, or merely as temporary or static purposes. A recent study in oil palm in Sabah showed potential for riparian reserves to serve as movement corridors for insects, and they may be particularly important for forest specialist species that could not cross the agricultural matrix (357). However, connectivity can also come at a price, particularly if riparian reserves facilitate the spread of pests or invasive species (358).

As areas of natural habitat within the oil palm matrix, riparian reserves could potentially contribute to pollination, pest control, and decomposition services that may improve agricultural yields and lower production costs. However, they also have the potential to cause disservices to agriculture by harbouring pests, predators of livestock, or removing large areas of land from production (359). Anecdotally, it is widely believed in the oil palm industry that riparian buffers can harbour high populations of pests such as rhinoceros beetles (Oryctes rhinoceros), wild pigs, and rats (authors' personal observations). However, studies to date suggest limited, or mostly neutral, effects on ecosystem services. For example, 30-50 m wide riparian reserves in Malaysia did not increase the density of defoliating insect pests, but nor was it likely they provided a pest control service (360). However, there is also no evidence for any link between the presence of forest remnants, including riparian forests, and reductions in oil palm yield (361). Riparian reserves could therefore contribute significantly to estate-wide carbon assessments (e.g., using the High Carbon Stock approach) (268), but a lack of data on carbon stocks in riparian areas, prevents the potential roles of riparian reserves in reducing emissions from being fully quantified.

\section{Fragmentation and connectivity loss. More} recently, new efforts in the industry are focusing on addressing fragmentation effects from forest loss, through the incorporation of patch and landscape criteria when identifying areas important for conservation within oil palm developments. The High Carbon Stock approach, for instance, provides detailed guidelines on how to identify high carbon stock forests, based on vegetation structure, forest patch size, and patch location in the landscape. Loss of ecological connectivity is one of the aspects that many initiatives require producers to account for within their impact assessments. Yet, only the High Carbon Stock approach provides any concrete guidelines to address this issue within plantation design.

\section{Conversion of non-forest ecosystems. Industry}

initiatives are less explicit with regards to the protection of non-forest ecosystems. Conservation of non-forest ecosystems is particularly relevant, because pressures on ecosystems such as savannahs and wetlands, may increase with the introduction of carbon and forest-focus environmental strategies through displacement of demand to these ecosystems $(362,363)$. Most sustainability initiatives considered here do not explicitly address the protection of these ecosystems. A notable exception is the International Sustainability and Carbon Certification standard, which contains guidelines towards the protection of grasslands and wetlands. Others, like the Roundtable on Sustainable Palm Oil and many corporate commitments, do not contain clear guidelines for the conservation of 
these ecosystems directly, but still address this issue through the implementation of the High Conservation Value approach. This approach contains specific methodologies designed to identify non-forest High Conservation Value areas.

Other threats to biodiversity. While considerable effort has gone into halting forest loss in the industry, initiatives also address other threats to biodiversity from oil palm development to various degrees. Some aspects directly connected to agricultural production such as water pollution or pesticide use are addressed through guidance to producers within many certification systems and often through regulatory frameworks in producing countries (364). Aspects related to human-animal interaction, like human-wildlife conflict and illegal hunting, have been addressed through the production of specific methodological frameworks by conservation organizations (365) or through safeguards that prohibit or regulate hunting within plantations (e.g., 366), but on-the-ground implementation is often poor $(111,367,368)$. On the other hand, initiatives do not provide concrete mechanisms to address off-site impacts related to indirect land use changes, increase pressure due to new infrastructure (e.g. roads) or human migration for labour, and changes in ecological processes such as local hydrological and climate regulation processes.

\subsubsection{Complementarity between environmental governance initiatives}

Most of the sustainability initiatives in the sector complement each other (364): they have different conservation scopes (as shown in the previous section), are applied at different scales and target different stakeholders and markets. In other words, these conservation interventions together cover a broader scope than any one of them does individually.

\section{Upscaling sustainability: from plantation to landscapes. Sustainability initiatives have typically addressed only conservation within plantation or smallholder boundaries and immediate surroundings, and over relatively short time scales. This approach}

is practical because it aligns with land areas under management control of oil palm producers, but may not produce maximum conservation benefits due to spillover effects of conservation efforts. Especially within vast oil palm plantations typical in Southeast Asia, conservation efforts could be strengthened by consideration of conservation in the context of the broader landscape. For instance, recent work suggests that High Conservation Value areas are more beneficial for species movement when the surrounding landscape has intermediate levels of forest cover (369). Long-term effects are also likely to be important in developing oil palm landscapes. The impacts of climate change, for instance, may cause vegetation trajectories to shift (186) and increase the risk of extinction for species in fragmented landscapes (370). Environmental governance initiatives are increasingly addressing landscape-level dynamics. The High Conservation Value approach, for instance, has now been applied at a nation-wide scale in Gabon (371) to inform oil palm planning within the country. Data from individual High Conservation Value assessments could also inform national planning when analysed together and provide insights about species presence, ecosystem services and social and cultural values found in areas where oil palm is expanding. The Roundtable on Sustainable Palm Oil's RSPO Next and the work by the Palm Oil Innovation Group (372) have also developed additional indicators and criteria that include landscape considerations to support actions by Roundtable on Sustainable Palm Oil certified producers that aim to go beyond current certification standards. The recent emergence of landscape and jurisdictional approaches, which operate across large spatial scales (e.g. a district or a state) in contrast to single oil palm landholdings, may also contribute to addressing these scale aspects (373).

Targeting different stakeholders. There appears to be a good degree of complementarity between initiatives with regards to stakeholders and the supply chain. While the majority of initiatives are designed to influence oil palm growers, there is also much focus on sustainability across the supply chain in the industry, including processing facilities, trading companies and retailers. Efforts have also addressed 
enhancing sustainability of smallholder producers, in particular those that are independent. Smallholder producers can provide more biodiversity-friendly plantations and can benefit significantly from oil palm development (374). However, smallholders are certified at lower rates than large-scale growers (42), because of the social, economic, cultural and environmental complexities (375). Specifically, while certification standards have developed specific guidelines to certify individual and groups of independent smallholders, empirical evidence suggests that smallholders often lack the information, access to capital and support, and degree of organization that certification demands (376). While reducing these barriers to entry may ensure that more smallholders can enter into certification programs, landscape approaches can also support and enhance sustainability efforts that target smaller producers. Synergies and complementarities of these initiatives might be a key intervention for landscapes where multiple smallholders, taken together, represent a large portion of land.

\section{Industry acceptance of leading initiatives.}

Understanding how initiatives are articulated is not straightforward (Figure 34), because of the recent and rapid emergence of multiple approaches from different interest groups. The cornerstone of most initiatives in the industry, however, is compliance with national environmental laws, the use of environmental impact assessments, the High Conservation Value approach, and more recently the High Carbon Stock approach. As such, strengthening the stringency, scope, enforcement, implementation, and uptake of these instruments could significantly influence the effectiveness of these initiatives at supporting biodiversity conservation.

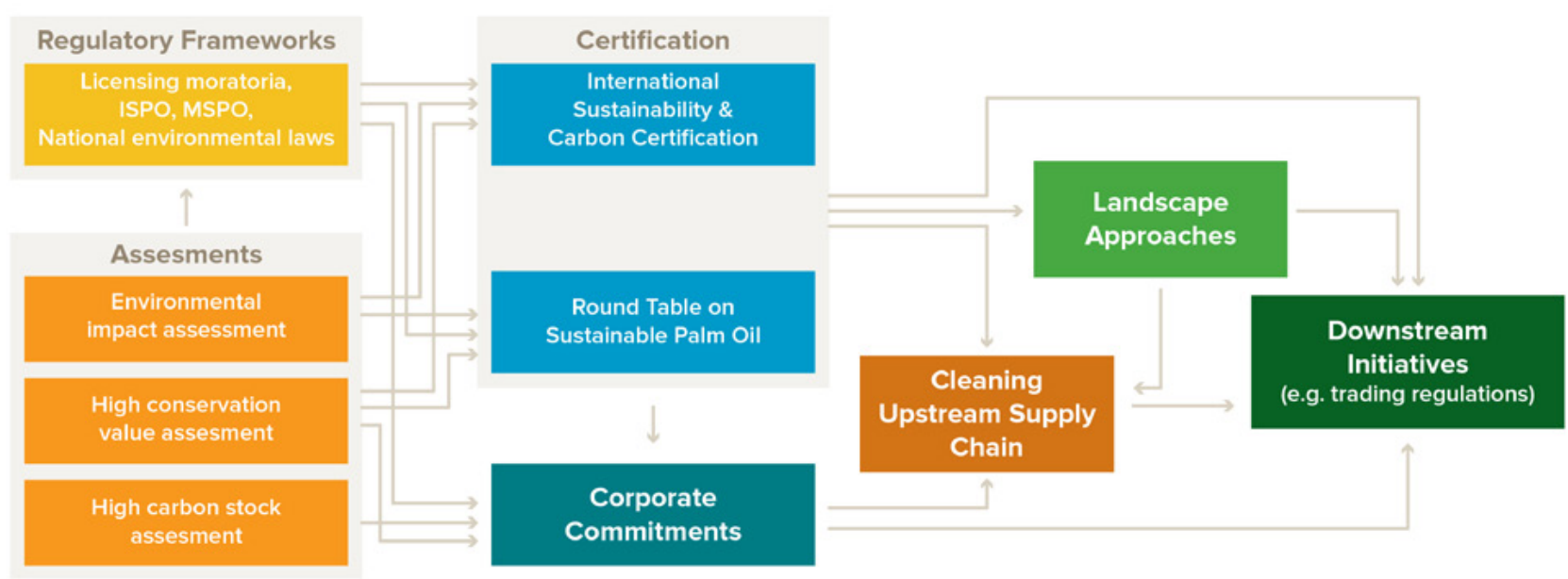

Figure 34. Schematic representation of selected interactions between different sustainability tools and initiatives in the oil palm industry. Arrows depict relationships where a tool/initiative is explicitly used by another initiative to achieve its sustainability objectives. Please note that not all existing relationships, initiatives or tools are represented. Rather this figure aims to illustrate some of the articulation complexities in the environmental governance of the oil palm sector.

Because of the parallel emergence of multiple initiatives, and the fact that a stakeholder may be involved in many of them, sustainability initiatives are highly complementary. Some of the most progressive company pledges usually include commitments to the use of the Roundtable on Sustainable Palm Oil standard, the use of the High Conservation Value and High Carbon Stock approaches, the compliance with government regulations, and the full avoidance of development in peatland areas, and ensure that these apply to the full supply chains. Despite the high complementarity of current sustainability initiatives, a thorough analysis of their collective conservation scope is needed. For instance, can these initiatives address underlying causes of deforestation and habitat degradation (e.g., inadequate and corrupt land governance)? If not, what other initiatives should be in place to address these issues? How should they be articulated? Currently, these questions remain unanswered. 


\subsection{Are environmental governance initiatives effective?}

The effectiveness of environmental governance initiatives to reduce biodiversity loss from palm oil production is lauded by many, but also highly contested. Here, we summarize current understandings of their effectiveness in producing beneficial conservation outcomes and discuss challenges to implementation.

\subsubsection{What are the impacts of environmental governance initiatives on biodiversity conservation?}

Our understanding of the effectiveness of sustainability initiatives in the industry is quite limited. This stems from the relatively new nature of many of these policies, the long time lags between implementation and impact, the continuous evolution of the governance landscape, continuous changes in technology and markets, and the difficulty of robustly evaluating the impacts of multiple interactive policy interventions (377-379). Most research has focused on the impacts of certification by the Roundtable on Sustainable Palm Oil, with just a few studies focusing on corporate commitments and licensing moratoria. Researchers have used models to project the likely future impact of voluntary commitments and stateled policies. No information is currently available on the impact of jurisdictional approaches or state-led certification systems on biodiversity conservation.

\section{Roundtable on Sustainable Palm Oil}

Certification. Even though adoption of Roundtable on Sustainable Palm Oil certification is increasing (380) (Figure 35), and investigation on its impacts on the ground is still ongoing (e.g., 381, 382), several examinations of its outcomes suggest limited conservation improvements. Between 2009 and 2015, Roundtable on Sustainable Palm Oil certification in Indonesia significantly reduced deforestation within large-scale plantations (382). However, most of these certified plantations were developed prior to year 2000, and contain very little natural forest area (382). In contrast, certification

\section{Certified Area by Region Total: 3,236,429 ha as at 30 June 2017}

Total Certified Area as at 30 June 2016

Total Certified Area as at 30 June 2017

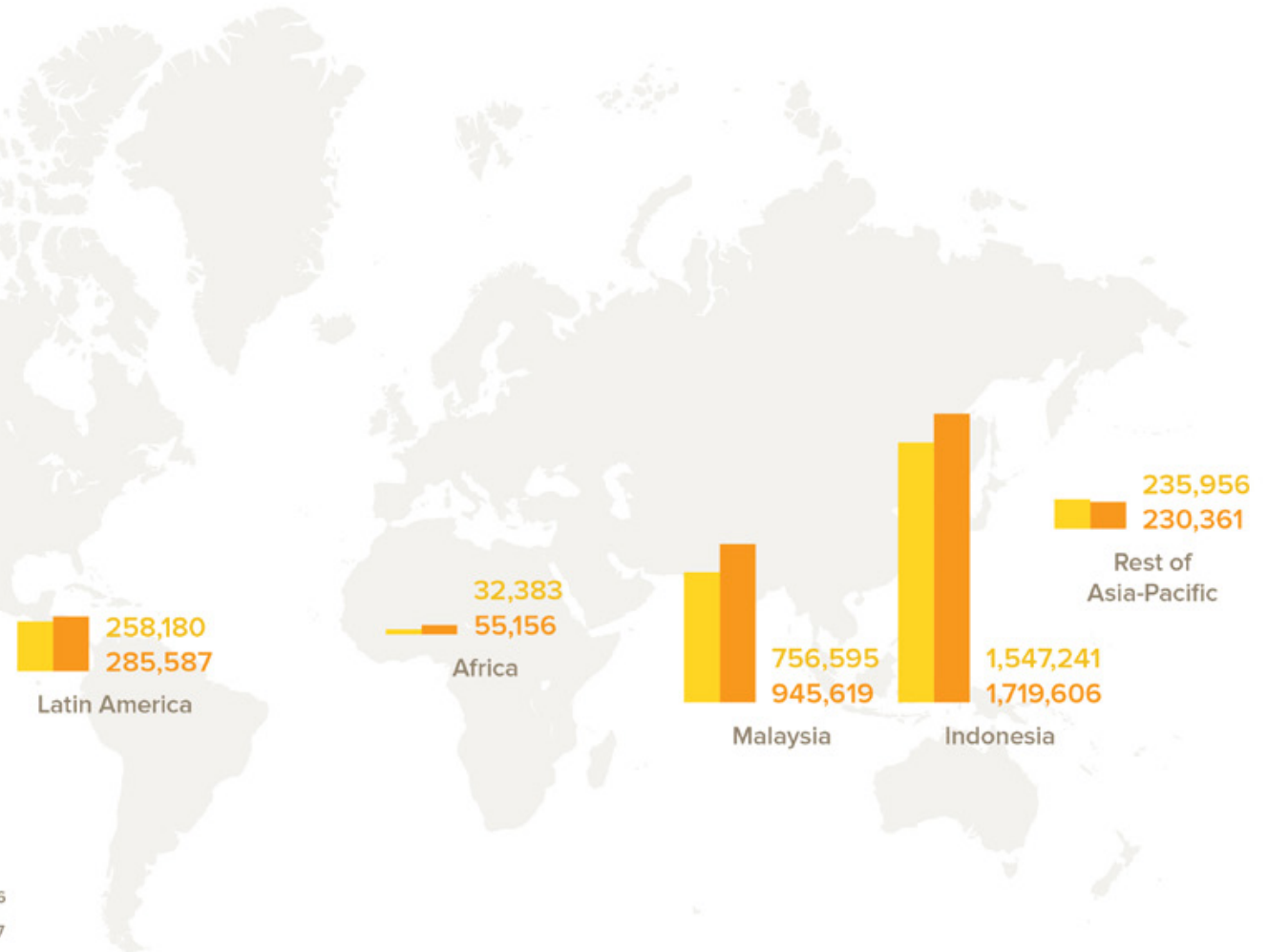

Figure 35. Roundtable on Sustainable Palm Oil Certification-certified area by region in 2017 (380). 
is seemingly unable to address deforestation along forest frontiers where smaller, non-certified plantations are being developed, as was shown in a study on Borneo (140). Moreover, certification did not have a significant impact on the clearing of peatland or lower canopy cover forests (382). An assessment of High Conservation Value areas within Roundtable on Sustainable Palm Oil member plantations in Borneo found that just $21 \%$ are forested (369). It is unclear whether this is because these areas are important non-forest habitats, because they had been degraded prior to plantation development, because they have been degraded during the plantation development (despite Roundtable on Sustainable Palm Oil membership), or because they were identified for reasons other than biodiversity (e.g., social or ecosystem service values). Whatever the case, the benefit of these areas for conservation has been often questioned (73).

Certified plantations in Indonesia have fewer fires than non-certified areas (382-384). However, differences in the behaviour of companies that choose to pursue sustainability certification, rather than certification itself, may drive these lower fire rates (382). While some posit that smallholder oil palm is more biodiversity-friendly than industrialscale plantings (385), and that the largest gains for biodiversity conservation can be made by supporting smallholders (386), conservation outcomes related to smallholder certification remain largely undocumented. Further, the relatively low certification rates for smallholders in Indonesia and Malaysia may limit the ability of certification to significantly affect conservation in and around smallholder landholdings (42).

Few studies have examined the direct effect of certification on species, with most focusing on ecosystem level impacts. Roundtable on Sustainable Palm Oil certification appears to have few benefits for orangutan populations in Sumatra, because of a lack of rigor in the standard itself, the nonintegration of the standard within the local sociopolitical-legal Indonesian context, the lack of external control systems (387), and insufficient financial compensation (96, 388). On Borneo, Roundtable on Sustainable Palm Oil-certified concessions had lower - although still substantial - absolute losses of orangutans compared to concessions not certified under the standard (140).

\section{Because Roundtable on Sustainable Palm Oil} certification has been adopted mainly by wellestablished large-scale producers located on lands deforested long ago, certification has resulted in few additional benefits above and beyond business as usual. Studies have also reported cases where operations from Roundtable on Sustainable Palm Oil certified companies were still involved in the trade of palm oil from mills which purchased produce from illegal plantations (16). In addition, in its current form the principles and criteria used by the Roundtable on Sustainable Palm Oil have been criticized for not being comprehensive enough in many environmental and social aspects, among other reasons because they do not tackle the underlining local factors of decision making (73). This said, the Roundtable on Sustainable Palm Oil is a relatively new organization that over time has increased its oversight and enforcement (389). Recent development such as the introduction of a New Planting Procedure in 2011, the High Conservation Value Resource Network Assessor Licensing Scheme, and a future revision of the Principles and Criteria may increase its effectiveness. However, the overall impact of the Roundtable on reducing deforestation in palm oil producing countries largely rests on the degree of adoption of the standard by oil palm growers. If adoption remains static or declines, the Roundtable won't be able to address forest loss associated to oil palm development (42).

Corporate commitments. Analysis of the effectiveness of "no-deforestation" commitments in the palm oil sector is limited to prospective modelling. This is largely due to the diversity of actors making these pledges, variable scope and implementation timelines, difficulties inherent in tracing commitments along supply chains, and their recent introduction as policy instruments (390). One projection suggests that implementation of no deforestation commitments for all large-scale producers in Indonesia could lead to a $25 \%$ reduction in cumulative deforestation 
through to 2030 (286). The issue is complex (391), however, including its terminology (e.g., no zero net deforestation versus no zero gross deforestation (392)). By contrast, analysis of the actual impacts of "no-deforestation" commitments in the cattle and soybean sectors in Brazil suggest that these commitments change behaviour, but they do not lead to reduced deforestation, due to displacement of deforestation to actors who have not made such commitments $(247,393)$. This was also indicated in the 2017 cross-commodity survey discussed in Section 3.3.2. Most companies have deforestationfree commitments, especially those in the oil palm sector (Figure 36) (394). However, there are no consistent statistics to inform how corporate commitments are impacting the overall area of production or rate of deforestation and uptake of oil sourced in compliance with these policies, or on the rate or effectiveness at which with these policies are translated into implementation. Of the 448 companies across different sectors with such commitments in 2017, the study found that only $51 \%$ of these commitments were being consistently tracked and that one in five commitments has become dormant (281).

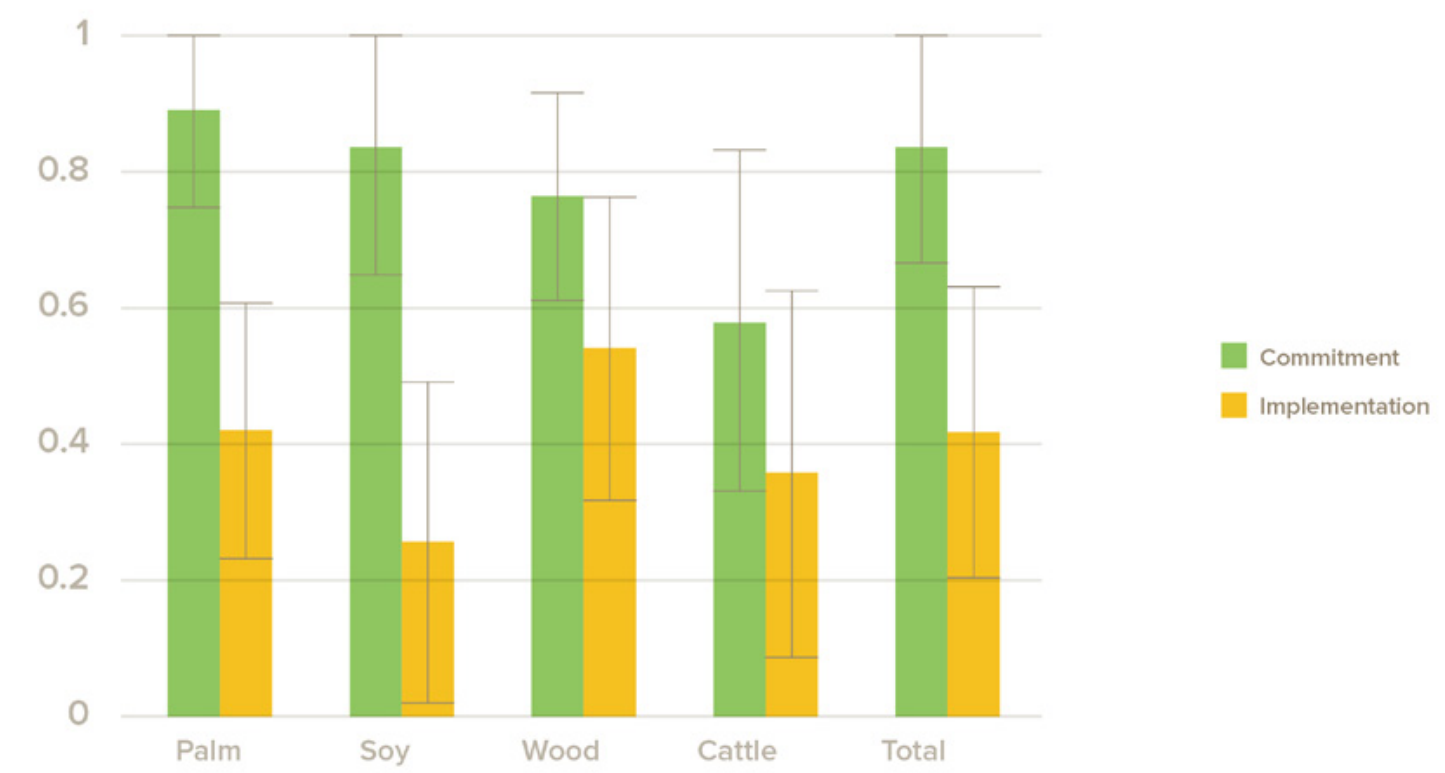

Figure 36. Zero deforestation performance by commodity (395). Vertical axes indicates the overall zero deforestation score for each commodity.

State-led policies. The Indonesian Forest Moratorium implemented in May 2011 aimed to protect primary forests and peatlands from encroachment by industrial commodity concessions and to reduce deforestation in these areas. One Indonesia-wide study investigated the potential impact of the moratorium on deforestation in Indonesia, and found a 1-2.7\% reduction in deforestation would have occurred had the moratorium been implemented from 2000-2010 (396). Protected areas, if well-managed and located in the most important sites, can also be effective at conserving biodiversity in landscapes with active oil palm expansion (397).

Another study, however, found no positive impacts from the moratorium because forest loss within moratorium areas continued to increase in 2015 in all areas except Sumatra (398). This suggests that the moratorium had limited effect on forest protection. Kalimantan recorded the highest forest loss within the moratorium area in 2015 (69,000 ha), followed by Sumatra (39,000 ha) and Papua (25,000 ha) (398).

The effectiveness of other initiatives such as the Indonesian Sustainable Palm Oil (ISPO) and the Malaysian Sustainable Palm Oil (MSPO) certification systems has not been assessed. Information on the progress, members, certification assessment results or complaints is difficult to find. As of 2017, only 12 percent of the 11.9 million hectares of oil palm plantations in Indonesia were Indonesian Sustainable Palm Oil certified (399). 


\section{Box 20.}

\section{Do undeveloped patches in oil palm plantations support biodiversity conservation?}

Forest set asides are areas within oil palm plantations that are left uncleared and not developed for oil palm (Figure

37). They may provide habitat and connectivity for terrestrial species, and when they are adjacent to streams or wetlands, they can also protect aquatic ecosystem biodiversity. Set asides are frequently identified through High Conservation Value or High Carbon Stock Approach assessments, but may also be designated in accordance with national laws and regulations (e.g., protection of riparian buffers or steep slopes).

Although few data exist to assess the value of forest patches in oil palm plantations, the number of species retained in these patches likely depends on patch size, such that larger patches harbour more species. For example, in Borneo, forest patches with a core area (i.e., minus a 100-meter buffer) greater than 200 hectares retained $60-70 \%$ of the tree species richness found in continuous forests and sustain populations of dipterocarpaceae, the dominant family of mainly lowland rainforest trees in the region (334). On the other hand, patches of less than 100 hectares were unable to support threatened birds (400), while fragments smaller than 200 hectares do not support many more species than surrounding plantations (401). In general, such small forest patches are particularly sensitive to edge effects (e.g., higher temperatures and lower humidity) and are more vulnerable to natural events like fires or storms, and to human activities such as hunting or illegal logging (402). As a result, small set asides are often degraded or encroached, further minimizing their ecological function.

Recent review studies have shown however that habitat fragmentation per se does not necessarily have negative impacts (403). Small forest patches may thus still be valuable. They can provide connectivity benefits for individuals and populations and support critical ecosystem functions (e.g., seed dispersal). Patches are particularly useful for individuals of certain species (e.g., orangutans, civets and macaques) that can move within planted oil palm, but require 'stepping stones' for dispersal between larger forested areas (404,

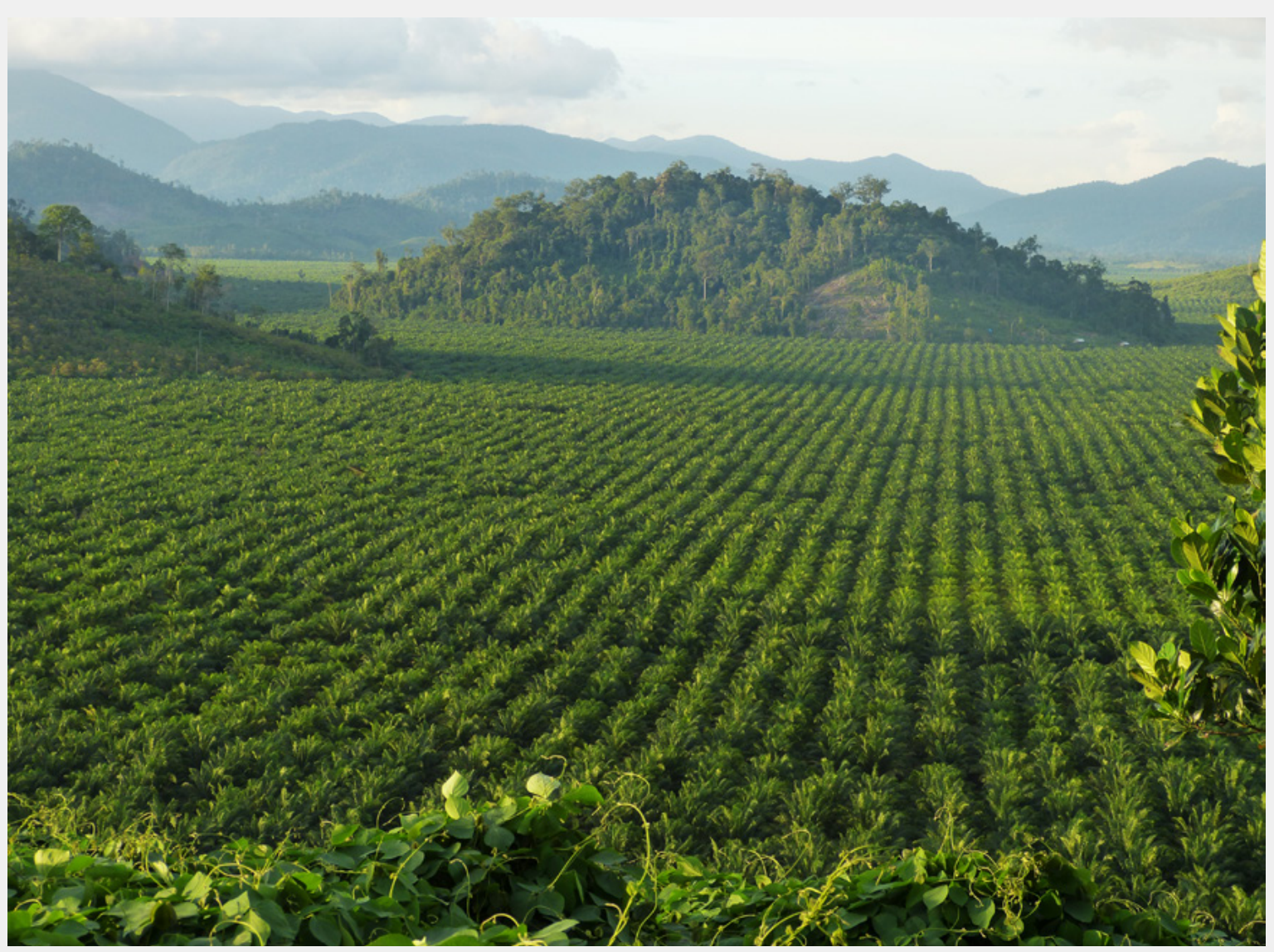

Figure 37. Forest set asides in an oil palm plantation in West Kalimantan. (@ Douglas Sheil) 
405). Genetic data from fragments in Malaysian oil palm demonstrate that many bat species are clearly capable of dispersal (406). Other species are unlikely to disperse into oil palm habitats, and require full connectivity (i.e., an uninterrupted forested corridor) for successful dispersal (407).

A distributed network of small patches is also more likely to capture the full diversity of species present in a concession when the spatial turnover of species is high, such as for small mammals (106).

Notably, lands previously planted with oil palm have the capacity to recover and support additional biodiversity. One case study in Sabah, Malaysia found that after 17 years of post-oil palm regrowth, a set-aside supported almost $50 \%$ of natural forest carbon and was more used by elephants (408). Thus, even after full plantation development, conservation set-asides may be restored to support connectivity or biodiversity protection.

Maintenance, restoration, and monitoring of set-asides will likely fall upon estate managers or smallholder producers associations, and may incur costs including the opportunity cost of planting as well as the cost of maintenance. Since set-asides support ecosystem services such as pest control and water regulation (229), they may provide financial cobenefits to palm oil producers that may offset such costs.
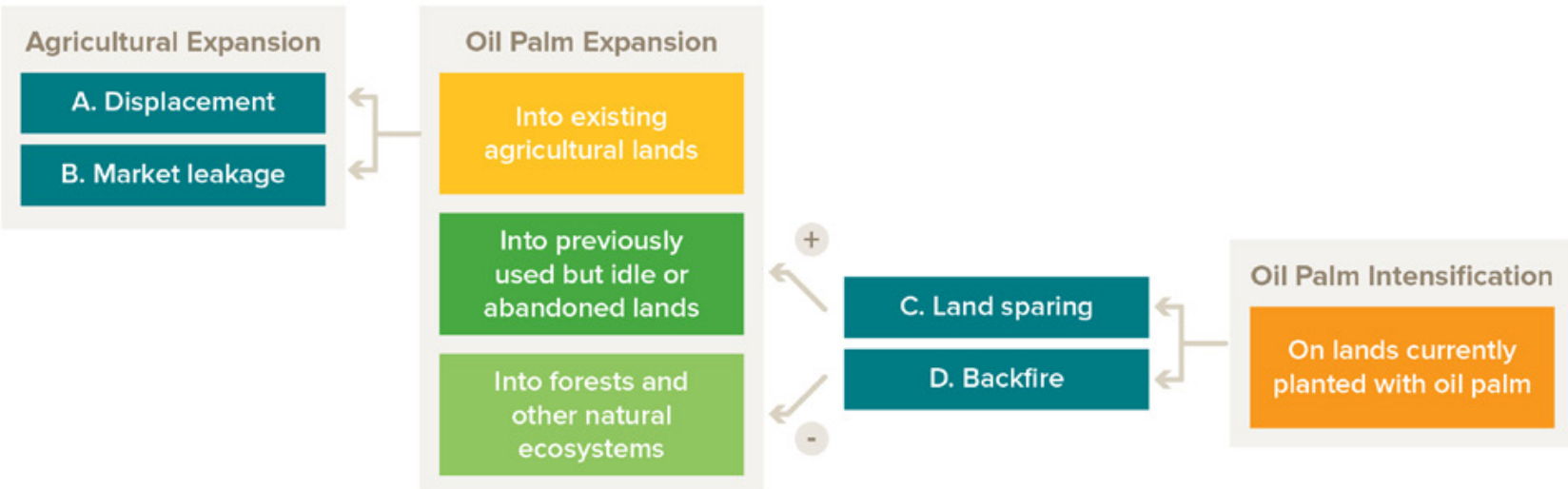

Figure 38. Possible unintended consequences ( $A, B, C$ and $D$ ) of different oil palm development trajectories, and thus the initiatives and policies that shape these trajectories. Please note that oil palm intensification strategies may increase (+) or decrease (-) oil palm expansion on other land uses. Adapted from (331).

\subsubsection{Unintended consequences of initiatives and pledges}

Sustainability initiatives in the palm oil sector may face several "spillover" effects that may lead to additional negative or positive impacts on conservation outcomes beyond their intended objective. These include leakage of land use change, displacement of land use, and adverse effects due to intensification.

Increases in future oil palm production will occur through either expansion or intensification (i.e., increasing yields on existing oil palm lands). If oil palm expands into agricultural lands instead of forests, displaced land uses may expand into other areas including frontier forest regions (A in Figure 38). In certain scenarios, reduced local production of a commodity crop may lead to a global price increase for that crop or a substitute, which could stimulate additional agricultural expansion (B in Figure 38). This "leakage" effect could occur due to reduced supply of palm oil because of policy interventions, or could be due to replacement of a commodity crop such as rubber with oil palm. Intensification is thought to spare land at a global level (C in Figure 38) (409). However, if intensification generates higher profits, it may also generate a paradoxical "rebound effect" or increase in expansion beyond what was expected in the absence of intensification (D Figure 38). Land sparing approaches (see Box 21 in Chapter 4), including initiatives that promote closing yield gaps $(410,411)$, could result in this backfire effect. Whether land will be spared for conservation will largely depend on the strength and effectiveness of environmental governance in the industry (412). Unintended consequences, may also arise when a company with a "no deforestation" 
commitment relinquishes concessions in as-yetunconverted forest, which may be inherited by competing companies without such commitments - a redistribution of responsibility for deforestation. Conversely, positive effects may be observed when neighbouring oil palm producers learn from one another (413), interventions such as certification may result in adoption of improved environmental management practices among non-participant producers, a positive spill-over effect.

\subsubsection{Challenges to implementation}

The palm oil industry has been widely criticized for not performing according to agreed principles and criteria or for not following local laws, but in many cases the on-the-ground conditions and challenges are such that even the most willing companies struggle to abide.

\section{Limited demand for more sustainable palm}

oil. While civil society organization are driving manufacturers and retailers in the European Union and the United States to source more sustainable palm oil, currently limited demand for such products in major consuming countries may limit the uptake of sustainability initiatives such as certification. In 2017, it is estimated that only a fifth of global palm oil was certified, of which only half was sold as certified (380). Most of this certified palm oil is sold to European or North American markets, which accounted for only $16 \%$ of global palm oil domestic supply in 2014 (414). In other words, while certification aims to "transform the markets to make sustainable palm oil the norm" (275), demand for sustainability certification appears currently limited. In addition, financial benefits of more sustainable production may not be reaching all producers (73). Global corporate commitments may pave the way to the uptake of more sustainable palm oil in other markets through the transnational operations of committed companies. Specifically, if these multinational companies commit to the use of certified palm oil in their products, its demand may transcend beyond the European and North American markets and into other globally important markets such as China and India. Increasing the demand for sustainably produced palm oil in domestic markets in producing countries (e.g., in Indonesia and Malaysia) is also a challenge that remains to be addressed. However, restrictions on the importation of palm oil in western markets may undermine these processes.

\section{Barriers to the implementation of "no deforestation" commitments. . While "no} deforestation" commitments are easy for companies to make, putting them into practice has proven challenging (e.g., 16). Implementation problems are rooted in the difficulty of tracing palm oil back to the location of production, defining what is meant by zero-deforestation, and verifying that production is indeed deforestation-free. In addition, such commitments can be seen as top-down impositions and in conflict with development agendas by producing countries. Addressing this requires further changes in supplier behaviour in order to materialize the potential benefits of such commitments in the industry. Bottom-up initiatives, including participatory landscape approaches, may support the implementation of these commitments, but pilot projects are needed to explore these synergies.

Traceability of supply chains. Many of the stricter commitments and initiatives originate from downstream actors in the supply chain, such as manufacturers, retailers, and traders (415) or from the largest palm oil producers in the industry (287). These companies are faced with the challenge of tracing sources of palm oil that they use through their supply chains, even if they originate from farms and plantations outside of their direct control. Thus, the majority of initiatives strive to develop ways to trace fresh fruit bunches from estates and smallholder farms, crude palm oil produced from mills, and crude palm oil traded in national and international markets. Until recently, most companies could not trace their supply back to mills, let alone plantations. Even in regions, where considerable efforts have been made to trace palm oil and fresh fruit bunches, "illegal" palm oil still manages to penetrate the supply chain of companies with commitments to certification and "no deforestation" $(16,416)$. Because of the costs and seemingly unfeasibility of fully tracing upstream production of fresh fruit bunches, it is perhaps 
necessary to explore alternative cost-effective approaches to the "cleaning" of supply chains. Landscape and jurisdictional approaches may represent one of such alternatives.

\section{Harmonization of regulatory and voluntary \\ initiatives. Lack of complementarity, and even} antagonism, between government and voluntary policies can undermine overall sustainability and conservation efforts in the industry (417). For example, Indonesia requires that companies use $100 \%$ of their arable leased land area, including forests, for plantation activities (418-420). Yet, many large, palm oil companies participate in voluntary schemes that require protection of High Conservation Value or High Carbon Stock set-asides within plantations. Such situations create incompatible choices for a company between complying with national laws and abiding by voluntary sustainability commitments. In many instances, companies have relinquished some of these areas, handing them back to the government, and thus opening an opportunity for other companies - oil palm or other non-forests uses such as mining - that do not abide by sustainability standards to develop them (72). This lack of legal protection for set-aside areas may be addressed through new national regulations for the definition and identification of high conservation value areas (421), a process that started in 2016 and includes discussions on how to articulate this with the High Conservation Value approach used by the Roundtable on Sustainable Oil Palm (422).

In Malaysia, palm oil concession boundaries may be considered private data by the Malaysian state. Yet, in 2013, the Roundtable on Sustainable Palm Oil passed a measure that required all oil palm growers to provide boundaries of their landholdings to the public (423). While such transparency policies are crucial to track compliance, this rule represented a legal conflict for roundtable members with plantations in Malaysia. Despite years of negotiation, the Malaysian government has refused to change their rules. To ensure that Malaysian companies could remain part of the Roundtable without blatant violation of government regulations, the Roundtable decided not to enforce this transparency requirement for Malaysian grower members (outside of Sabah, given its recent development jurisdictional approach).

Resolving conflicts and ensuring coherence between government regulations and voluntary policies that promote good land use practices across all stakeholders, is required to better support biodiversity conservation (320). Initiatives such as the Jurisdictional Approach pledged by the Bornean Malaysian state of Sabah may serve as initial test case to align government regulations with voluntary policies.

\section{Monitoring, reporting and verification of} progress. Finally, strengthening the monitoring, reporting, and verifying (MRV) process to assess the implementation and effectiveness of sustainability initiatives is an important priority. Without effective management and monitoring of areas set aside for conservation, such areas may degrade over time. It appears, however, that monitoring, reporting, and verifying of corporate commitments remains inconsistent, in part because pledges are made outside of a pre-existing framework such as thirdparty certification systems. Guidance for such monitoring, reporting, and verifying efforts is being developed by a range of organizations, including CERES (424), CDP (425), and the Accountability Framework (426). In addition, SMART, a partnership between civil society organizations provides an on the ground monitoring tool (427), Moreover, externally produced rankings and scorecards such as the Sustainable Policy Transparency Toolkit (287), and those by Greenpeace (428) and WWF (429), are currently used to assess companies in relation to monitoring, reporting, and verification. These rankings depend on corporate reporting and transparency (although corporate sustainability commitments may not always translate into effective implementation on the ground). Certification initiatives have consolidated frameworks to conduct monitoring, reporting, and verification, which are facilitating the assessments of their effectiveness on the ground (e.g., 382). 


\subsection{Knowledge gaps}

The governance landscape of the oil palm sector will keep evolving rapidly, as pressures from consumers and non-governmental organizations on the industry continue. Many stakeholders are working on solutions to the sustainability issues of this sector. Yet, the issues are complex and context-dependent, and unlikely to be solved with silver bullets. Changes in the discourses in consuming and producing countries call for further research to understand the actual benefits and impact of policies such as the banning of palm oil and the implementation of landscapes approaches. Building on the experiences so far in the oil palm industry, in other industries and from global programmes such as the Reducing Emissions from Deforestation and Forest Degradation initiative, will be key to the future development and implementation of sustainability actions in the oil palm sector. Furthermore, the impacts and benefits from development and the implementation of governance initiatives in the industry are not limited to biodiversity but also affect social and economic contexts: e.g., the livelihood and welfare of local communities, the rights of vulnerable groups, tenure systems in forested landscapes, income of local and regional governments, and global food prices. Understanding the trade-offs and impacts across stakeholders and scales is, thus, fundamental. The following studies may contribute to understand some of these issues:

- A comprehensive and systematic analysis of the scope and stringency of governance initiatives in the oil palm sector. Such analyses should consider how initiatives address, individually and together, conservation concerns in oil palm landscapes in each context;

- Development of frameworks to monitor and evaluate the effectiveness of governance initiatives on the ground;

- Analyses to understand the effectiveness of governance initiatives for conservation, including accounting for recent changes in their frameworks and implementation;

- A comparative synthesis analysis on the feasibility and effectiveness of the multiple certification standards that are available to companies, in order to identify strengths, weaknesses and synergies;

- Broad analyses on additionality, synergies, antagonistic and confounding effects from the existing governance initiatives in the industry, which account for the diversity of local and regional contexts;

- Synthesis studies on how governance initiatives in the sector have impacted social and political aspects in producing regions (e.g. land tenure), to identify trade-offs for conservation; and

- Studies on the feasibility and potential impacts of landscape approaches in oil palm producing regions. 


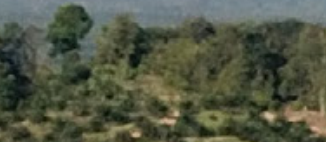

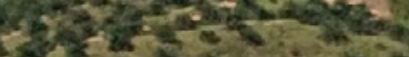

$8+20+2,5$ is

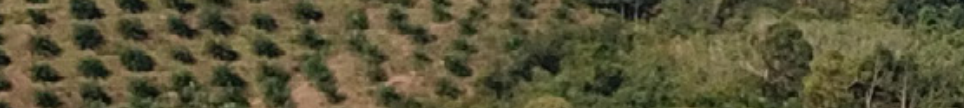

3.5.

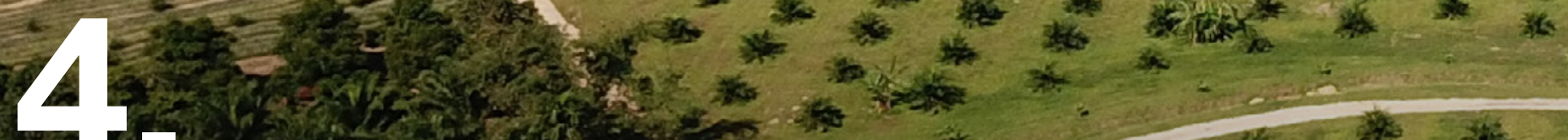

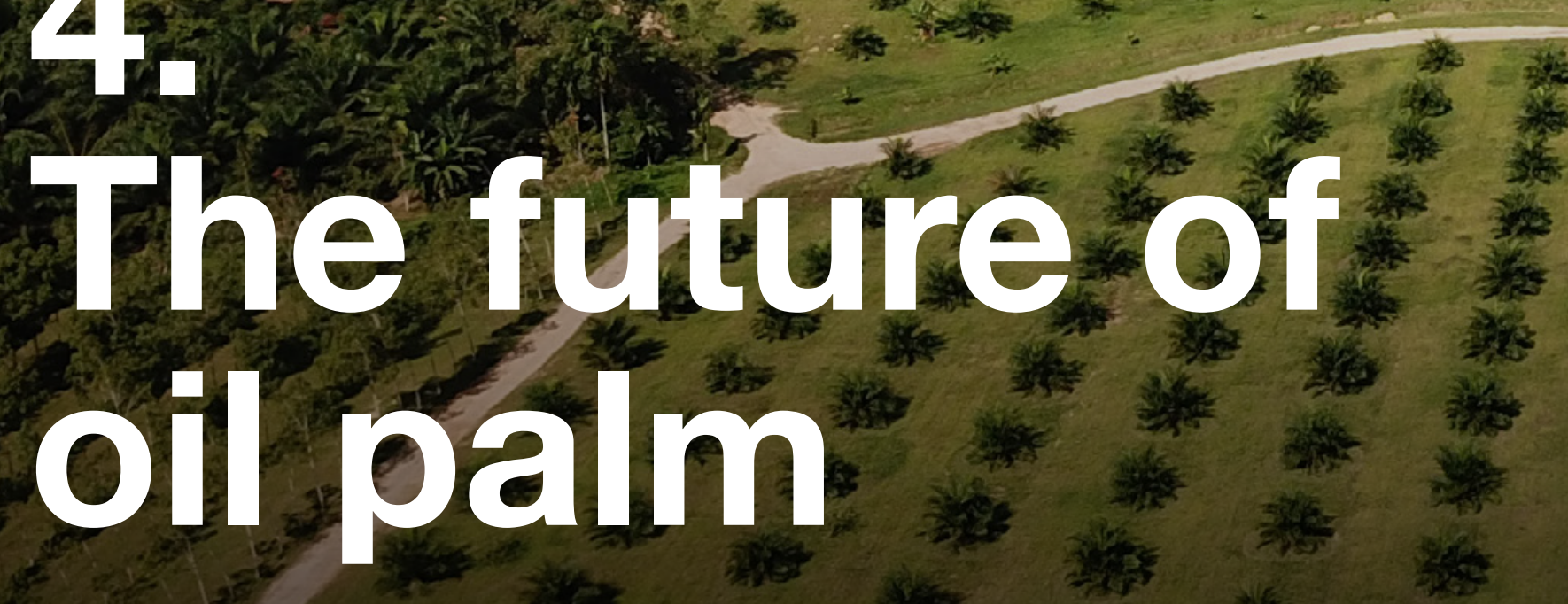


- Palm oil demand has grown by 4.8\% per year between 2001 and 2013 but is expected to slow to $1.7 \%$ per year until 2050 . There is much uncertainty about the extent to which palm oil will continue to be used as biofuel.

- Yield increases can meet some of the growing demand, but these will also make palm oil more competitive compared to other vegetable oil crops, and further boost the palm oil industry. It is unclear how the switch between vegetable oil crops could affect global biodiversity.

- If oil palm expands into biophysically suitable areas, some 270 million hectares of biodiversity hotspots could be threatened, and 39\%, 64\%, and 54\% respectively of all threatened amphibians, birds and mammals affected. Other factors, such as availability of labour, quality of local infrastructure, and political stability will likely play a key role in determining whether oil palm will expand in certain parts of the tropics or not. This is especially relevant in the African and American tropics where the biophysical potential for oil palm to expand is greatest. 


\subsection{What is the future demand for palm oil?}

The global need for vegetable oil is soaring. It is the fastest growing commodity today (9): demand for edible vegetable oil has been projected to be double in 2050 of what it was in 2008 (430). In 2015, it was estimated that a total of 175 million tonnes was needed globally, while a total of 220 million tonnes is projected to be needed to supply the planet in 2050 (Figure 39). Meeting this demand will require growth of $3.6 \%$ per year over the entire period.

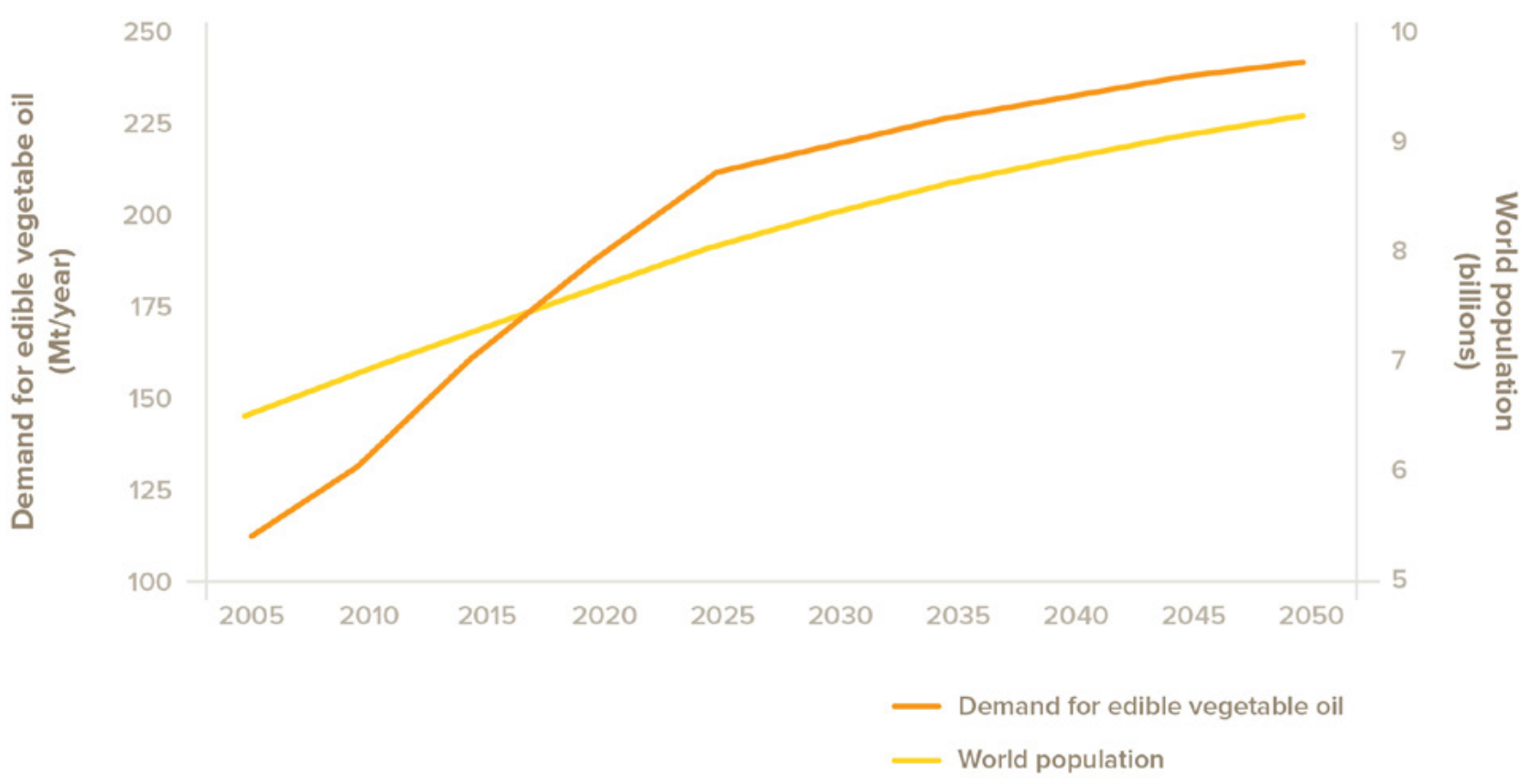

Figure 39. Palm oil. World population growth and demand for edible vegetable oil (430).

Total demand for vegetable oil, including biofuel, in 2050 is projected to be about 310 million tonnes, up from about 165 million tonnes in 2013 (9). This would require an annual growth rate of $1.7 \%$ - a bit more than one third of the $4.8 \%$ growth rate from 2001 to 2013 (9), indicating that recent growth rates will not be replicated in future decades (Figure 40). The main exception to this trend would be sub-Saharan Africa, where both population and incomes are rising rapidly and vegetable oil consumption per capita is still very low (9). The key uncertainty in this is the extent to which growth in supply can be met by increasing yields and to what extent there would be an increase in planted area. An additional uncertainty is the extent to which synthetic oils would replace palm oil for non-food products (19).

Palm oil consumption is especially rising in countries with an expanding middle class, its associated urbanisation and demand for packaged food. Cheap vegetable oil therefore has a huge market to tap into, and indeed, oil palm is currently the major vegetable oil exchanged in the international market (433). The extent to which palm oil will be used as biofuel is unclear. There is currently significant resistance from non-governmental organizations and governments in the European Union to the use of palm oil as a biofuel, in part because $\mathrm{CO}_{2}$-emissions from biofuel production and use can be significantly higher than that of mineral oils (434-436). This relates to oil palm-driven deforestation and associated peatland development, which release significant greenhouse gas emissions. It has been argued, however, that if oil palm is developed on low carbon stock lands, it has lower carbon emissions than, for example, European rape seed or canola (437) (Figure 40), although this also depends on the extent to which oil crops displace other crops into high carbon environments. 


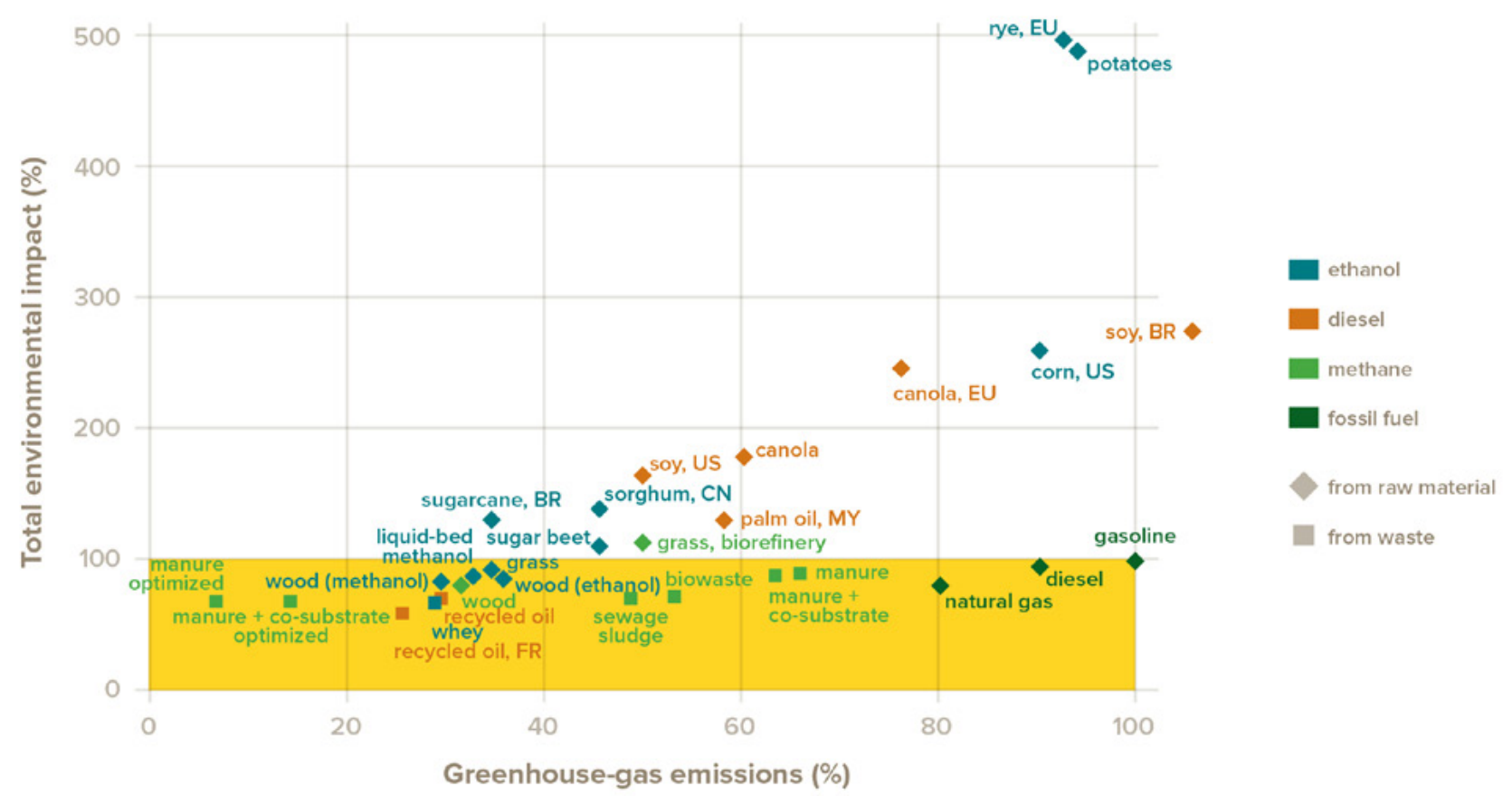

Figure 40. Greenhouse emissions are plotted against overall environmental impacts of 29 transport fuels, scaled relative to gasoline. Environmental impact is calculated by the ecological scarcity method which weights environmental impacts - e.g., biodiversity loss, smoke and haze pollution - by applying "eco-factors", derived from environmental law or corresponding political targets. The origin of biofuels produced outside Switzerland is indicated by country code: Brazil (BR), China (CN), European Union (EU), France (FR), and Malaysia (MY). Fuels in the shaded part of the graph are considered less disadvantageous than gasoline in both their overall environmental impacts and greenhouse-gas emissions (431, 432).

\subsection{What is the potential impact of oil palm expansion in forest frontiers?}

How will the increased global demand for palm oil be met over coming decades, and what is the potential impact of different scenarios on biodiversity? Supplying this demand will probably be achieved through a combination of approaches, including increasing the yield in existing production areas, and especially in smallholder settings (9), planting in new ecosystems such as savannas, and opening up new frontiers in Africa and the Americas.

\subsubsection{Increasing yield}

Higher yields should mean less land needed for the production of the same amount of palm oil; the sparing option along the land sharing - land sparing continuum (Box 21). Increasing yields is a combination of increasing oil palm productivity, reducing diseases, changing palm composition and content, changing oil palm tree architecture, preventing post-harvest losses, and breeding for an expanded cultivation range (20). Theoretically, higher yields could mean a reduced incentive to convert natural ecosystems. The situation, however, might not be so simple.

Globally the average yield for industrial-scale oil palm is about 3,700 kilograms of oil per hectare per year - football field. Small holders produce less, between 200 and 2,000 kilograms per hectare. Most planters could produce more oil through supporting smallholders to improve their current yields, more intensive management, and the use of higher-yielding varieties (229). Although it may be theoretically possible for oil palm to produce five times the current average of palm oil per hectare (439), under ideal growing conditions 10,500 kilograms currently appears to be more realistic (Figure 41).

Higher yields, however, do not necessarily result in less land being used for palm oil. When higher yields mean higher profits, palm oil production becomes more attractive for investors. A recent study showed that doubling current production yields in Indonesia 


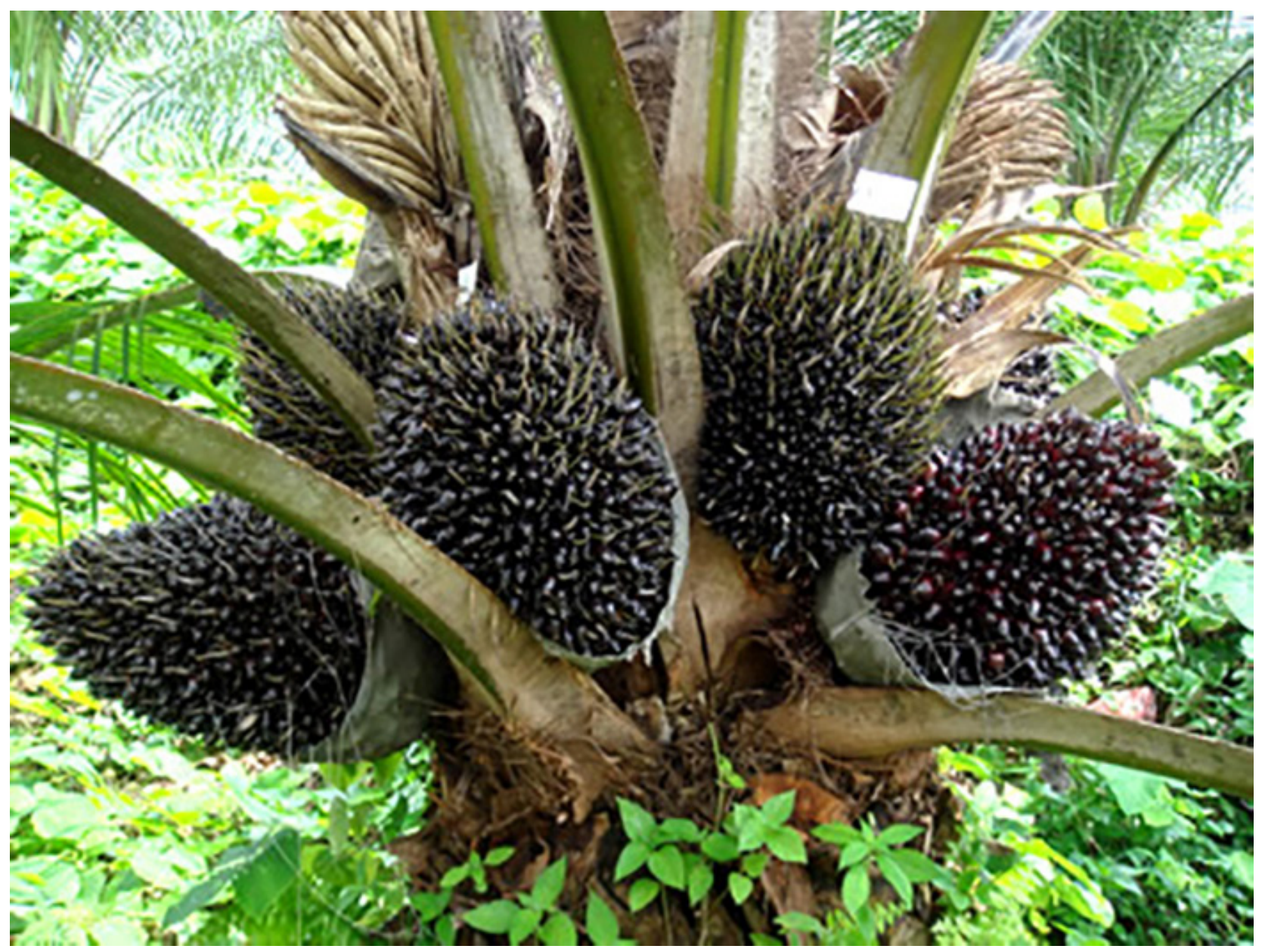

Figure 41. New oil palm varieties such as this Australia-grown variety produce increasingly high yields, up to 10,500 kilograms of oil per hectare (438).

and Malaysia - the two main palm oil producing countries - would likely do three things (121):

- $\quad$ The global price of palm oil would drop by $4.3 \%$ (and that of other vegetable oils by $2.5 \%$ ), potentially resulting in cheaper end products.

- Approximately 400,000 ha of agricultural land would be taken out of production. Higher profits in palm oil would mean that the production of other oils, like maize, sunflower, soy, and rapeseed would become less competitive. Countries like India, Brazil and Canada would most likely lose production of their vegetable oils.
Therefore, improving oil palm yield will only generate biodiversity conservation gains if strong governance systems and public policies are in place to protect and restore forests; to prevent further expansion that may be incentivised through increases in yield (85, 440).

While it is theoretically possible to produce more palm oil on less land, policy and market conditions mean that increasing yield is not necessarily an easy win for biodiversity. It is evident that attempting to predict the biodiversity outcomes of increasing oil palm yield, or replacing oil palm with other oil crops, is extremely difficult.

- Higher yields and higher profits would attract more people to grow oil palm, and the area allocated to palm oil production would likely increase, potentially threatening highly biodiverse rainforest. 
Box 21.

\section{Land sparing, land sharing or something in between?}

The land sparing-sharing framework provides a way of thinking about some of the hard choices that face conservation decision-makers when trying to address land use and food production. The framework describes a continuum of strategies from land sparing (minimizing the area occupied by agriculture by increasing yields, alongside conserving native vegetation) to land sharing (extensifying farmland to make it more wildlife-friendly, often at the cost of lower yields and greater agricultural land take). By collecting and analyzing data on how species' densities respond to increasing yields, it is possible to estimate the populationlevel consequences for each species of land sparing, land sharing and intermediate strategies.

One study (400) measured bird abundance in oil palm, forest fragments in oil palm, and contiguous forest in Sabah, Borneo and found that globally threatened or nearthreatened species had 60-fold lower abundance in forest fragments than in contiguous forest, and 200-fold lower abundance in oil palm. Another study (125) compared forests, large oil palm plantations, and mosaic farmlands in Ghana in which small-scale oil palm agroforestry were a substantial component. While small-scale mosaic farming had higher species richness of birds and trees than oil palm plantations, it was a relatively poor habitat for the majority of species originally present in the area. Most forest species were absent, or present only at low densities. Because a proportion of the mosaic was left fallow in any one year, it was also considerably lower-yielding than permanent oil palm plantations.

Both studies concluded that from a conservation and food production perspective land sparing is a more promising strategy than land sharing or intermediate strategies. This was also found in a study in Central Kalimantan which found that species and forest types sensitive to agricultural disturbance could benefit most if land in agricultural zones is spared and prioritized for conservation. Conversely, land sharing strategies favour the more widespread and common species, particularly if the area of wildlife-friendly agriculture is increased (441).

These and other studies make it clear that further expansion of oil palm into native vegetation (forest or non-forest) would cause considerable damage to biodiversity. There may be opportunities for improving the wildlife value of oil palm plantations without reducing yields, such as by retaining epiphytes (264), but these seem likely to be compatible with relatively high yields (so would not conflict with land sparing) and also likely to do little for the most sensitive species which are at most risk of global extinction.

The sparing-sharing studies done to date suggest that meeting growing vegetable oil demand will have less impact on biodiversity if it comes from higher-yielding oil palm cultivation. This does not that mean conservation organisations should lobby for rollouts of agricultural technology to increase yields. The large companies have the means to do this already. There is instead a greater need for land-use planning and environmental protection to constrain companies to produce from existing oil palm area. Companies that want to increase production then have no choice but to increase yields. The situation is more complex for smallholders, who often do not have the resources to easily increase yields, and where consideration of social justice is critical. Here, interventions such as certification and strategic delivery of infrastructure, technology and knowledge (412) may be appropriate, so as to make the choice of increasing yields more attractive and feasible for smallholders than clearing more land.

\subsubsection{Oil palm expansion and its potential impacts on biodiversity}

To understand potential biodiversity impacts of future oil palm expansion, it is possible to model the unregulated future expansion of oil palm (e.g. 2020s) into suitable yet unplanted lands (see Appendix 6).

Globally, a total of 577 million ha of land is potentially suitable for future oil palm cultivation (Appendix 6). This approach does not consider other factors that determine oil palm suitability: distance to markets, distance to mills, infrastructure, labour availability, access to finance, regulation, etc. (442). 

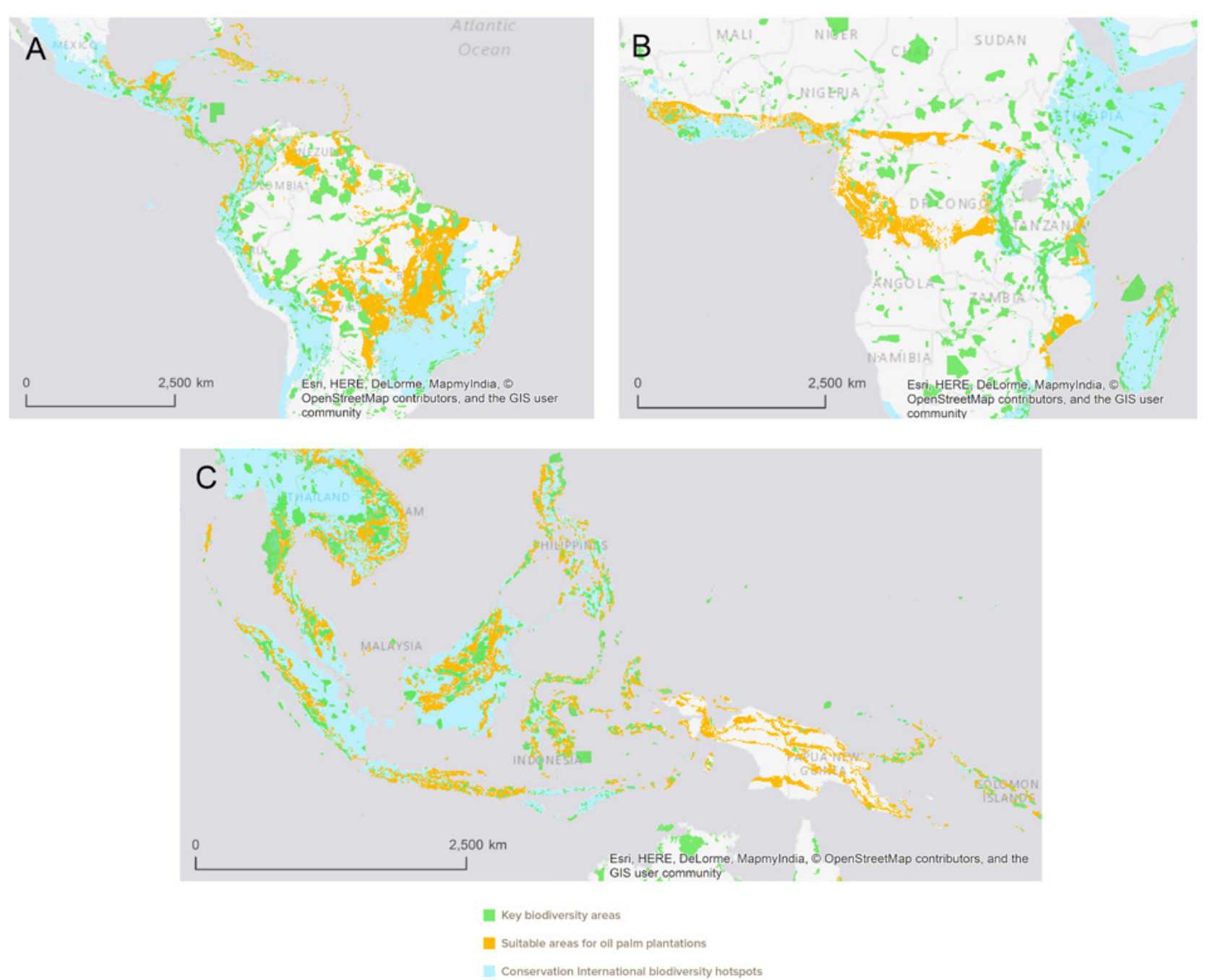

Figure 42. Map of tropical regions of (A) America, (B) Africa and (C) Asia-Pacific, showing biophysical suitability areas for oil palm (class 'Good' and above) (443), Key Biodiversity Areas (444) and biodiversity hotspots (445).

Overlaying the potential future oil palm distribution with the known ranges of threatened amphibian, bird and mammal species (446), as well as with biodiversity hotspots (447) and Key Biodiversity Areas (444) suggests that land areas suitable for oil palm cultivation overlap significantly with areas of biodiverse landscapes, including around 270 million hectares of biodiversity hotspots ( $11 \%$ of the total hotspot area) and about 62 million hectares (3.5\%) of terrestrial Key Biodiversity Areas (KBAs) (Figure 42, see Appendix 6). Oil palm suitable areas also overlap with the ranges of about $48 \%$ of all threatened amphibian, bird and mammals species (Table 4). If expansion would be realised in the future, it could result in further declines in their populations (104).

We recognize that an expansion of oil palm over the full 577 million hectares of suitable land is highly unlikely given the projected demands for vegetable oil (Box 22). It will be crucial to determine where in the potential expansion area biodiversity and socioeconomic impacts would be lowest. Impacts could potentially be reduced by diverting future palm oil expansion into less biologically sensitive areas. For example, there may be up to 31 million ha of potential future oil palm areas located outside KBAs and biodiversity hotspots, and outside the range of any threatened amphibian, bird and mammal species (Figure 42). However, even here, there are other social, economic and cultural factors that will determine the feasibility of palm oil development on these lands (see Sections 4.1 and 4.3). 
Table 4. Projected number of threatened species (446) and the extent of their ranges that could be affected by potential future oil palm expansion. The numbers in the right column show the overlap between combined ranges of threatened species and potential oil palm expansion, with the percentages in parentheses indicating the proportion of this overlap in relation to the combined range of the threatened species. For example, $1 \%$ of the combined ranges of all threatened amphibians overlap with potential oil palm and are therefore 'affected'.

\begin{tabular}{lll}
\hline Taxon & $\begin{array}{l}\text { Total number of threatened species } \\
\text { potentially affected (percentage of all } \\
\text { threatened species) }\end{array}$ & $\begin{array}{l}\text { Extent of the combined ranges of all threatened } \\
\text { species potentially affected (percentage of total } \\
\text { threatened species range) }\end{array}$ \\
\hline Amphibians & $2,067(39 \%)$ & $5,095,700$ ha (1\%) \\
\hline Birds & $735(64 \%)$ & $455,029,700$ ha (6\%) \\
\hline Mammals & $1,158(54 \%)$ & $530,966,600$ ha $(10 \%)$ \\
\hline
\end{tabular}

Box 22.

\section{Oil palm will not be grown everywhere where it can grow}

\begin{abstract}
A number of studies, including the present one, have modelled where oil palm expansion could potentially occur given the biophysical properties of oil palm and global soil and climate conditions (448-450). One study reported that up to 1.37 billion hectares of land globally are suitable for oil palm cultivation, and that almost $50 \%$ of the area of Brazil or some 400 million hectares is to some extent suitable for oil palm planting $(451,452)$. Given the current 18.7 million hectares of industrial-scale oil palm plus several
\end{abstract}

million hectares of smallholder lands, an increase to 1.37 billion hectares would entail a 60-fold increase in oil palm production. Such figures are not realistic given the predicted demand for vegetable oils (see section 4.1). Furthermore, there are many social, economic, financial and political constraints to oil development that make it unlikely that oil palm will be grown wherever it can grow. Such caveats are important to keep in mind when studies model the potential expansion area of oil palm.

\subsubsection{Oil palm expansion into savanna and shrubland}

The impacts of palm oil on tropical forests are relatively well studied (see section 2.2.1). Perhaps less understood are the potential impacts of palm oil expansion to other natural ecosystems, such as tropical savannas and shrublands (362, 453-456). These ecosystems account for up to $20 \%$ of the land suitable for palm oil worldwide, though suitability may be limited by climatic or soil conditions characteristic of grasslands, such as lower rainfall, longer dry periods, and less fertility (443). Their conversion may increase in the near future due to the focus on conservation of forest ecosystems and areas with high carbon values (see section 3.3.1).

While less biodiverse than tropical forest ecosystems,

tropical savannahs and shrublands do also hold numerous unique and threatened species (453, $455)$, and so such conversion would likely result in substantial biodiversity loss. Part of the problem is the lack of differentiation between natural savannahs, natural shrublands, and open degraded land covers (e.g. pasture land, early secondary vegetation) within the frameworks of current sustainability initiatives in the sector. The High Conservation Value (HCV) approach, for example, could provide protection to tropical savanna and shrublands based on merits for biodiversity, critical habitat, or integral landscapes, but more tools are needed to assist in the classification of these habitats based on anthropogenic gradients. This distinction is important because it can prevent unintended consequences from policies that emphasize expansion of oil palm in open lands (Box 23). 
In Colombia, for example, the Llanos ecosystem in the eastern lowlands of Orinoco has large expanses of natural savannas and also areas of man-made pasture lands (i.e. open degraded areas, Figure 43), both of which are highly suitable for oil palm (457). Low environmental-impact oil palm development could be achieved by targeting pasture land areas, without significant impacts to forest, savannahs and existing food production systems in the country (456). However, distinguishing between the natural and man-made open areas of this region can be difficult due to a long history of cattle grazing dating back to the colonial period (458). Additionally, the Llanos savanna has been targeted by the country's government as the next agricultural frontier in the region. Of the $7,278,964$ hectares of the national territory deemed suitable for socio-economic and rural development and zoned for agricultural development, $76 \%$ (5,548,018 ha) are situated in the Llanos region (459). The impacts of a potential expansion of oil palm and other agro-industries on the ecology and conservation in this tropical savanna region remain poorly understood (460).
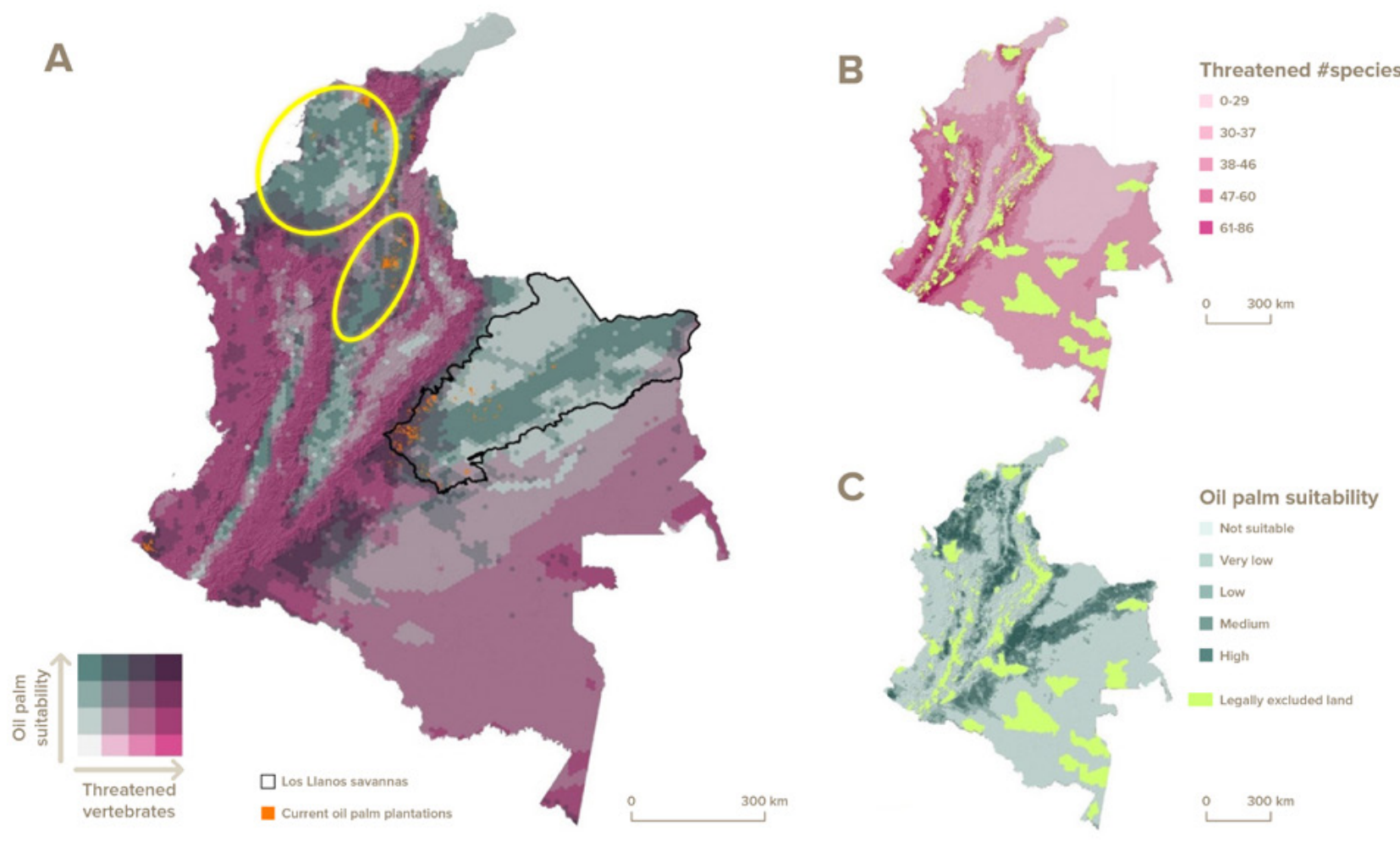

Figure 43. A) Overlay map of concentration of threatened vertebrates (IUCN categories: CR, EN, VU, and NT) and oil palm suitability in Colombia. In orange oil palm plantations in 2014. The Los Llanos natural savanna is outlined in black contour, while regions with large open degraded areas are circled in yellow. B) Concentration of threatened vertebrates and lands legally line for oil palm development (input for panel A). C) Oil palm suitability and lands legally excluded for oil palm development (input for panel A). Adapted from (457).

\section{Box 23.}

\section{When savannas matter more than carbon}

Concern over carbon emissions and 'no deforestation' pledges have focused some new palm oil development on non-forested ecosystems. Such open lands may be characterized by low above ground carbon stocks and generally low biodiversity value, but this does not necessarily mean that all of their conservation values are low. Savannas and other grasslands can include unique and threatened habitats and endemic plants and animals (461), as well as significant stores of below ground carbon (462). These habitats also play important ecological roles and are part of traditional land used by rural populations. 
A potential consequence of 'no deforestation' pledges is therefore that palm oil and other crops could be pushed into savannas and other non-forest habitats.

In Gabon, forests remain plentiful while savannas cover less than $9 \%$ of the country. These restricted areas of savanna can be subdivided into nine distinct types each with its own species some of which are threatened $(461,463)$. Rather than converting these special non-forest habitats to plantations it would arguably yield better biodiversity outcomes if plantations were developed in areas of regrowth and secondary degraded forest - which cover about 3.7 million hectares and are judged to have relatively limited conservation values. Mono-specific regrowth of pioneer species Musanga cecropioides $\mathrm{R}$. Br. are of low value in Gabon, but yet assimilated as High Carbon Stock and prone for protection after 5 years due to its fast growth. We note, however, that such secondary forests can be important for local subsistence, biodiversity, carbon stocks and that High Conservation Value assessment must be carried out independently of the type of habitat - to find out if there is any socio-economic dimension in these depleted habitats (464).

\subsection{Growth of the oil palm sector in Africa}

Africa is palm oil's ancestral home, but the continent currently produces less than $5 \%$ of global output. Africans currently consume $10 \%$ of the world's palm oil. Current production does not even meet present demand, and rapid urbanization on the continent will increase demand (9). Large areas of the continent have conditions that are highly suitable for growing oil palm (see section 4.2.2) and some think that Africa is about to experience a rapid expansion of oil palm production (465). However, major palm oil development in Africa is likely limited by large ecological, social and economic constraints.

\section{More than 50 million hectares in Central Africa} are perceived as being agronomically suitable for oil palm development (Figure 44). However, it has been suggested that not even a tenth of this area could be developed in a responsible and sustainable way, as a result of social (land already used by local communities for different types of production, potential conflicts with communities), technical (absence of adequate infrastructure, such as roads, mills or export facilities), and ecological (solar radiation, rainfall, temperature) constraints and limitations (466, 467). Already, average yields in Africa have proven lower than expected - sometimes half of that in Southeast Asia $(466,468)$. This appears to be due to water deficits, different soil composition, and limited sunlight, because of excessive cloud cover (411), and the use of unselected plant materials (466).
At the present time, African palm oil is further constrained by poor infrastructure and communication systems, a lack of labour and potential conflict with local communities over land ownership, although this could change with the current pace of development in most countries (469). In many parts of Francophone Africa, all land officially belongs to the state, however, there are obviously customary claims to many of these lands (470), which can results in social conflicts around oil palm plantations when not taken into consideration by the grower (471), as in the example of the Herakles Plantations in Cameroon (21). We note, however, that African countries are very diverse and that there is significant potential for radical transformation in many African economies in the coming decades. Tarred roads, ports and stable governments, as well as a wave of new investment, could transform the potential of several key agricultural powers in Africa.

Many African farmers grow oil palm as a cash crop and produce "red oil" that is locally consumed (472). In most African countries where palm oil could be produced, the price of the oil is highly volatile and season-dependent: prices drop when palms are producing more fruits and increasing three to five fold (for red oil production) when fruits are rarer (473, 474). This high volatility in prices results in uneven supply of fresh fruit bunches to palm oil mills (when the fresh fruit bunches are rare, they tend to be transformed to red oil and not sold to large palm oil mills). As a result, mills need to rely more on their own production; collaboration with large producers owning their own mills and small growers appears 
thus more challenging than in South-East Asia where fresh fruit bunches prices are more stable. The lack of a "culture" to grow oil palm as a commodity as opposed to a "cash crop" makes it difficult for many governments to develop national transformation plans and for major investing firms to assess development scenario (474).

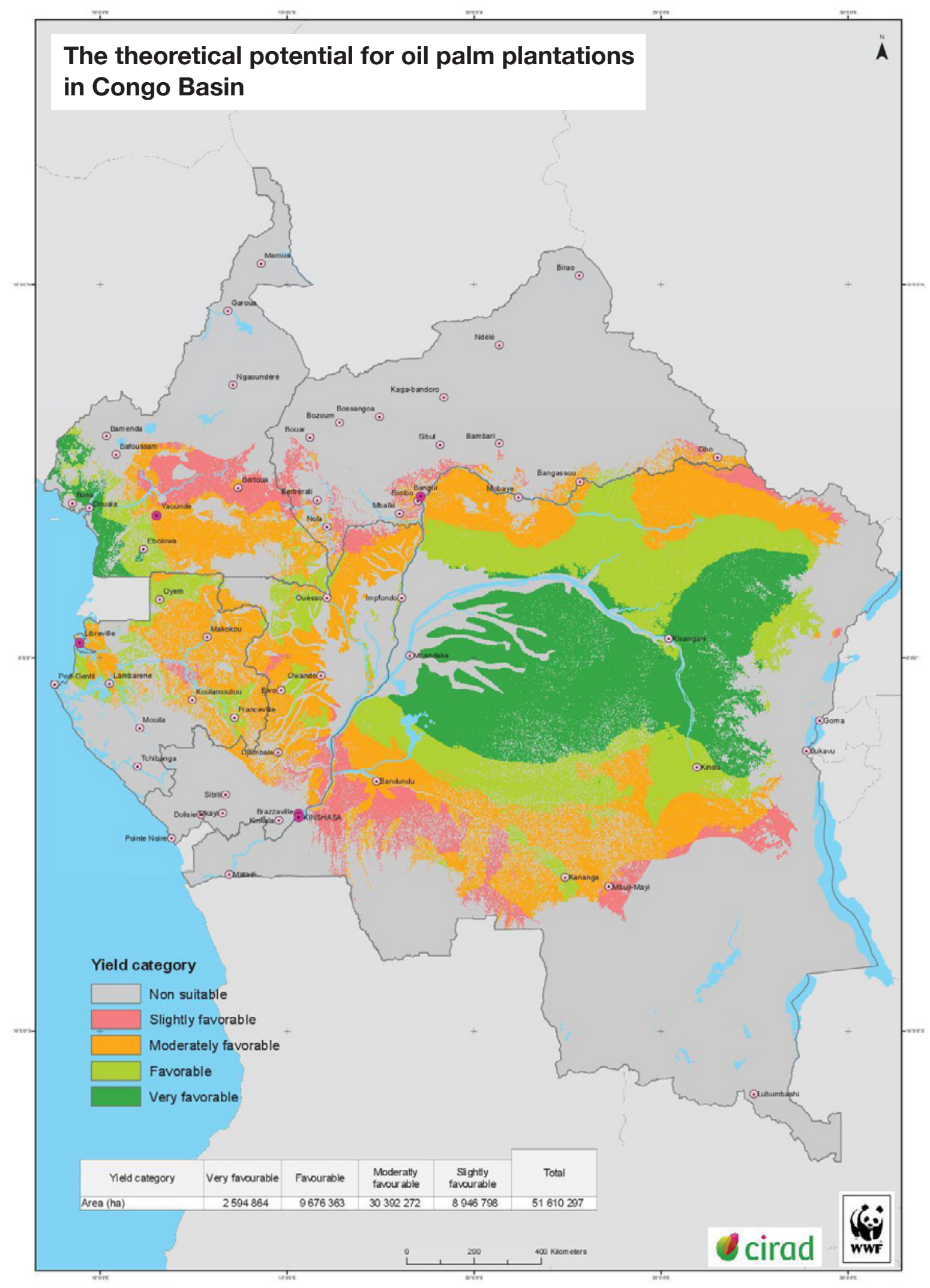

Figure 44. Theoretical potential for oil palm plantations in Central Africa (based on environmental and social modelling) (466). 
With urbanization, the market for refined palm oil will expand faster (Figure 45). This expansion will shift the advantage from small, semi-mechanized mills to larger industrial mills to meet quality standards, but with innovative business models, even the larger mills can be supplied by smallholders. We note that crude palm oil (red oil) produced by artisanal and small mills has a different market and use compared to that produced by industrial mills, with artisanal mills almost exclusively supplying the domestic market with red palm oil used extensively in local dishes. In most cases, this red oil cannot be replaced with refined palm oil. Crude palm oil produced in industrial mills is almost exclusively supplied to refineries and only sold on the local market as refined oil. Whereas artisanal red oil and industrial crude palm oil are unlikely to compete, the two mill categories will compete for the fresh fruit bunches from independent smallholders. The current emphasis on investment in large plantations is likely to remain challenging, given the complexities of African land markets and land rights (9). African oil palm expansion will therefore require improvements in the local supply chains of smallholders and small-scale processors with the injection of outside capital, technology, and market expertise through private investors. If the focus is on increasing the productivity of existing producers, whose yields are only a fraction of potential yields, there is scope for meeting market demand, both regional and global, without expanding land area and by relying on smallholders (9). The fragmented nature of the current production in most parts of the African continent and the trend toward urbanization is an opportunity to improve the current land tenure system, to develop innovative approaches like jurisdictional land use planning or active collaboration between small communities and large companies. Considering that most of the threats to forests and wildlife in Africa are driven by poverty and lack of economic opportunity, palm oil may offer a potential revenue source that help balance development and conservation objectives. This would require resolution of land rights issues to prevent land grabs and resulting conflict and displacement of environmentally harmful activities (475)

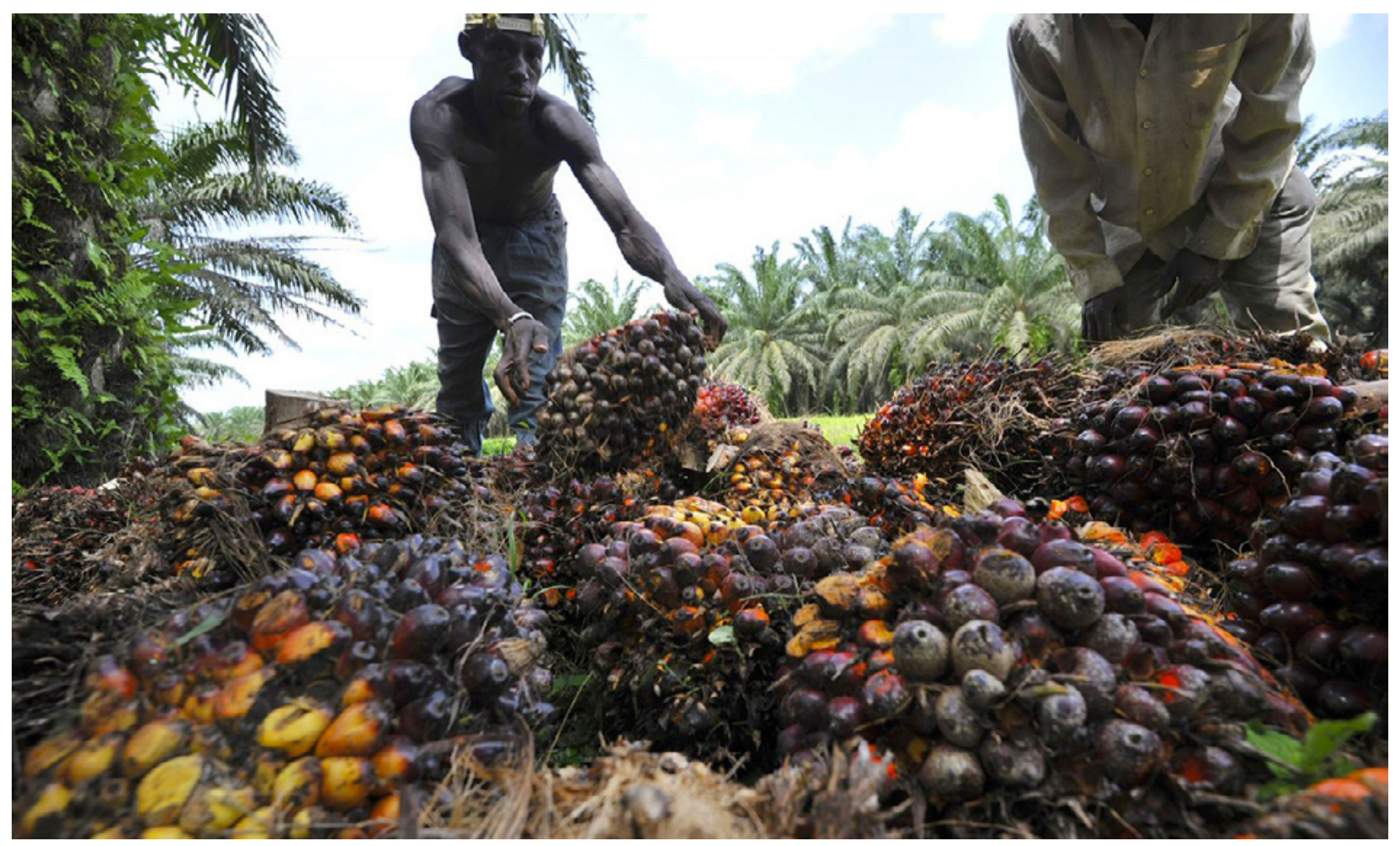

Figure 45. Africa: harvesting of fresh fruit bunches (476). 


\subsection{Growth of the oil palm sector in Americas}

The first plantations in the Latin America and Caribbean region date from the 1950s, yet the current harvested area does not exceed 800,000 hectares (equivalent to just $15 \%$ of the area harvested in Indonesia), and the region contributes only $6 \%$ of the total global production (2). In Latin America palm oil is not used as cooking oil, as consumers prefer clearer oils such as those coming from sunflower, rapeseed or soy (imported mostly from Argentina, Brazil, or North America). As such, producers in the region focus mostly on the food industry, cosmetic and chemical industries, biofuels and exports. The main export destinations are other countries in the Latin America and Caribbean region, particularly Mexico, as well as the United States of America and Europe. The average plantation size in the region is much smaller than those in Indonesia and Malaysia, with medium- and smallholders cultivating the majority of the total area planted in some countries (e.g. 73\% of planted area in Ecuador belongs to plantations smaller than 200 ha, 477). Despite this, countries like Guatemala, Nicaragua and Honduras register the highest yields per area globally. The largest producers in the continent, Colombia and Ecuador, have recently battled widespread outbreaks of bud-rot disease, which in some cases has decimated extensive planted areas (478). Bud-rot disease, or Pudrición de Cogollo as it is known locally, has affected to a lesser extent Nicaragua, Costa Rica, Panama, and Peru as well. In response to these outbreaks and widespread loss of palms, many companies in the afflicted areas are replanting with $E$. oleifera $\times E$. guineensis hybrid palms, the result of crossing flowers of the American oil palm with pollen from the African oil palm. These hybrids are more resistant to bud-rot disease and can reduce costs. However, as hybrids they are sterile, and pollination must be done manually, increasing the costs of production (hybrid palm fruits also require different machinery for extracting oil than E. guineensis, which will also increase production costs). Pollination costs in Colombia, for instance, can be as high as 500 USD per hectare/year (479). This does create more labour demand on hybrid plantations, especially for women. Cultivating hybrid palm is feasible for some larger producers, but not for smallholders. Hybrid palms produce more fresh fruit bunches per harvest but they are smaller and contain less oil per bunch. The oil produced has a high oleic content, however, and is considered of higher quality than traditional E. guineensis oil. Another advantage of these hybrid palms is that they grow more slowly, and thus can be harvested with greater ease for a longer period of time before growing tall enough to complicate harvest.

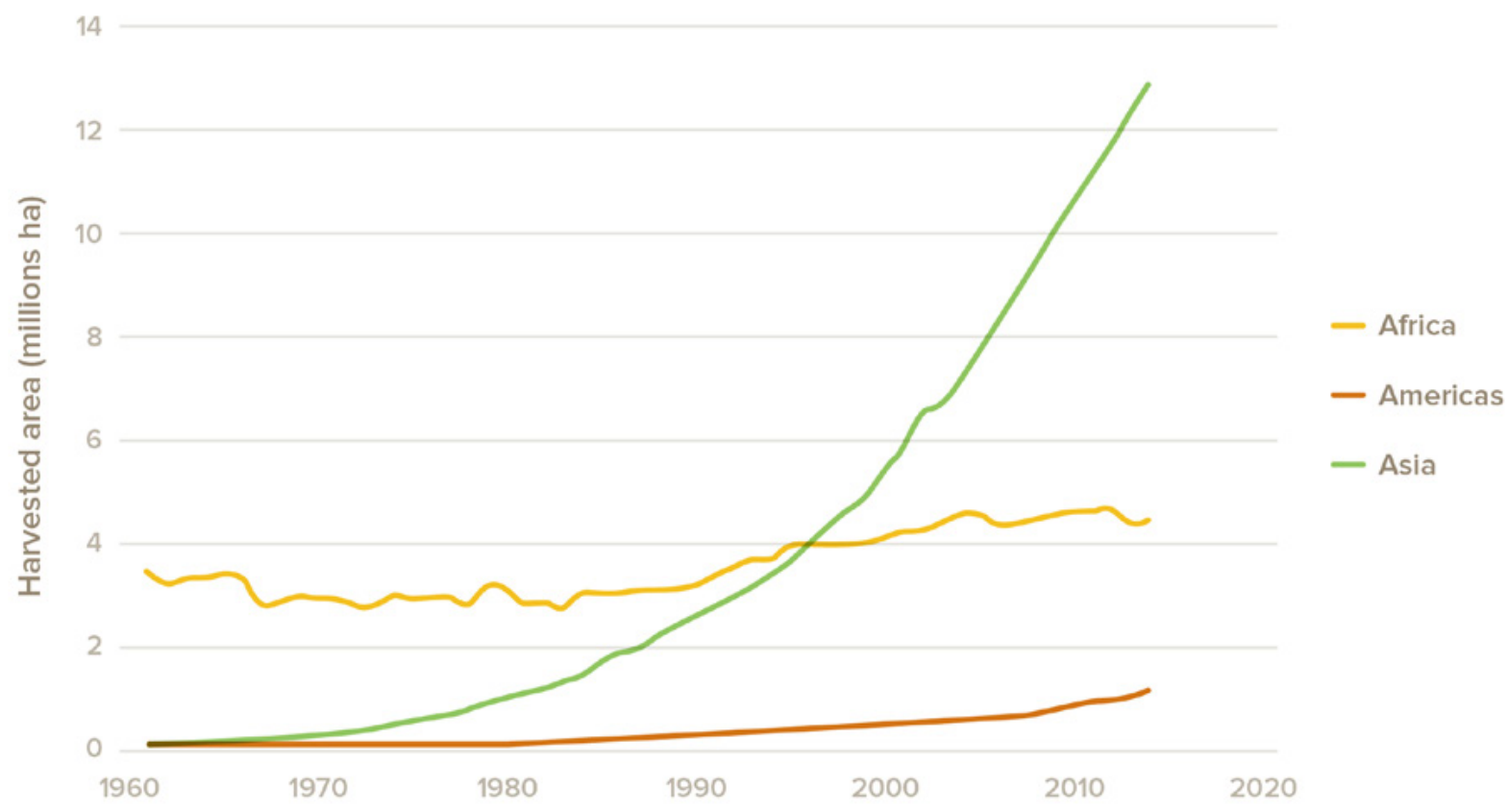

Figure 46. Increase in oil palm harvested area in Africa, the Americas and Asia, between 1960 and 2020 (2). 
The establishment of oil palm in Central and South America was aided by food security policies in the region (480), and the idea of self-sufficient production of vegetable oil remains one of the main motivations behind Latin American governments' interest in this crop, breaking from the export production model typically associated with palm oil and other commodities. The planted oil palm area grew steadily until the 2000s (Figure 46), but never at the high rates observed in Indonesia and Malaysia (2). For many countries like Brazil, Peru and Mexico oil palm is a relatively new crop, and thus much effort has gone into kick-starting their sectors. Other countries like Colombia, Ecuador, and Honduras are trying to consolidate their lead as largest producers in the region. To support these developments, many countries have created national biodiesel markets through the introduction of blending policies in fuels. This is most significant in Colombia, where about $37 \%$ palm oil produced goes toward meeting the national B9 biodiesel-blending mandate $(481,482)$.

The environmental impacts of oil palm expansion in Latin America are understudied. Up to $79 \%$ of expansion of oil palm has occurred on degraded lands (16), and in Colombia, $80 \%$ of new plantations in the 2000s were established on pasture lands (454). There is evidence that biodiversity loss can be minimized when oil palm plantations replace these pasture lands (120; Box 8 of this report). Forest loss for conversion to oil palm in the Latin America and Caribbean region is less chronic than it has been in Southeast Asia, with a few exceptions of acute deforestation in the Peruvian Amazon (27). Beyond environmental concerns, the expansion of oil palm in the region has been associated to social impacts, in particular with isolated cases of land grabbing in Colombia and Honduras $(483,484)$.

The future expansion of oil palm in Latin America is very uncertain because of the many competitive challenges the sector faces, in particular overall lower yields than in South East Asia (with local exceptions), weak demand from national markets (with the exception of Colombia), high labour costs, and high investments costs, including land purchase costs. Although the importance of these factors varies from country to country, in general the expansion of the oil palm industry in Latin America depends heavily on economic incentives and policies, and the access to international markets. The dominance of cattle pastures in production landscapes of Latin America, and the industry lessons learned from deforestation in Southeast Asia, suggest that future expansion in the Latin America and Caribbean region could be positioned to avoid major impacts on the environment. The Colombian oil palm sector has recently pledged zero deforestation in the palm oil supply chain by 2020 (321). This could eventually give Colombian palm oil a competitive edge in the market and push other countries in Latin America to take similar steps.

\subsection{What are the knowledge gaps?}

Despite the likely expansion of oil palm in especially in the African and American tropics, significant uncertainty remains regarding the extent to which oil palm development will expand into all areas which are biophysically suitable and socio-economically feasible. To better understand the constraints on oil palm expansion, and thus to more accurately forecast future biodiversity impacts, the following issues need to be addressed:

- Modelling of past oil palm expansion using spatial data in addition to biophysical and socio-economic data (e.g., infrastructure, labour availability (domestic and opportunities for labour import from other countries), political stability, presence of competing crops) to better understand what the key constraints are to expansion, and thus to more accurately model future expansion;

- Field-based research to characterize the biodiversity value of traditional oil palm production systems in Africa;

- Research on the feasibility, efficiency and productivity of small scale oil production systems (micromills), and the conservation benefits of such systems. 


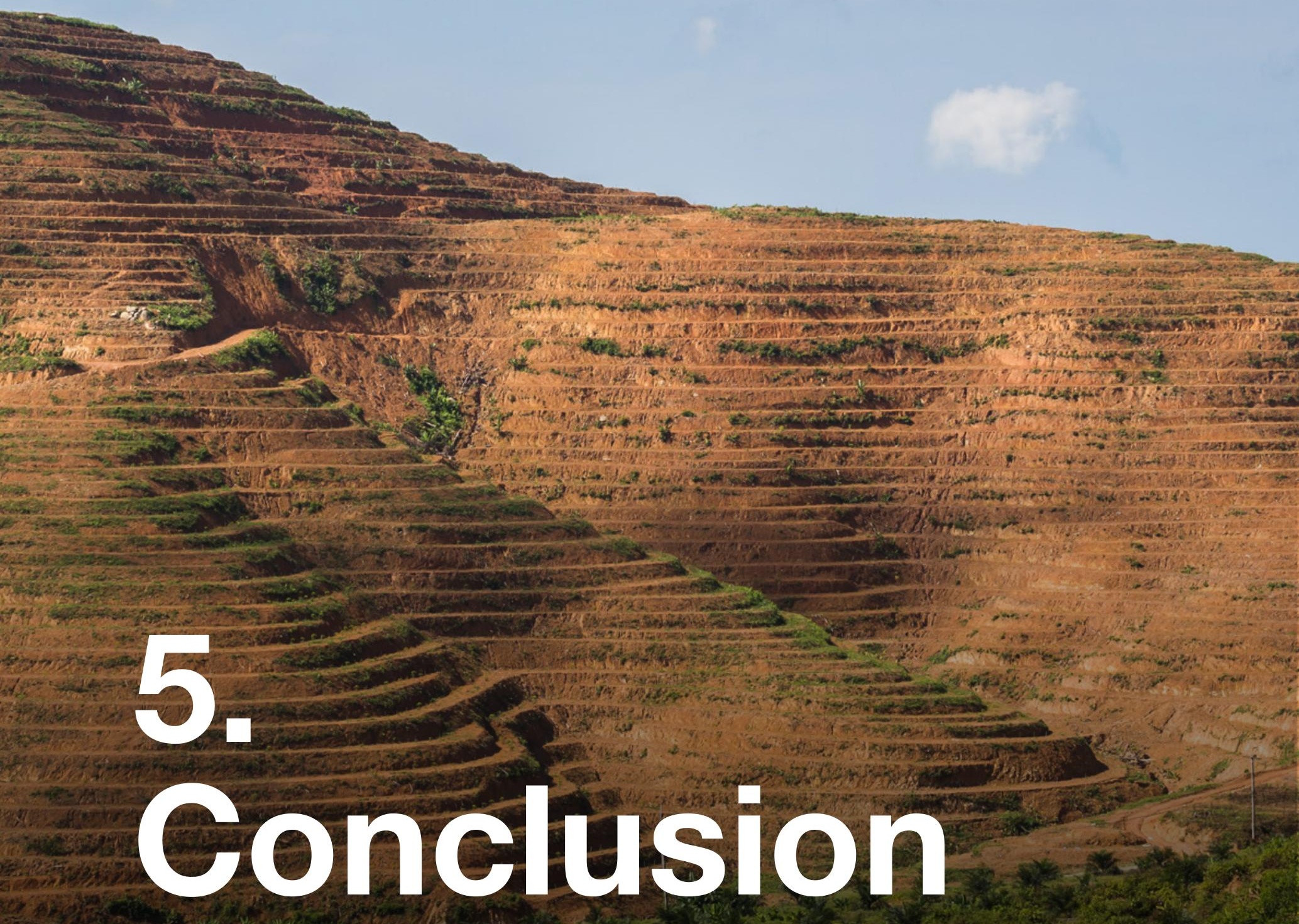


Between 1980 and 2000, two crops, soy and oil palm, became among the most important crops in world agriculture because of their contributions to food, feed, and fuel supplies (9). Whereas, in 1938, oil palm contributed less than $3 \%$ to global vegetable oil production, with most oil coming from cottonseed, ground nuts and linseed (485), eight decades later, soy bean and oil palm produced over $60 \%$ of the world's vegetable oils (2).

It is clear from the current analysis that the biodiversity impacts of the growing palm oil production have been significant. Given human population growth and increasing consumption, especially in lower and middle-income countries, the demand for vegetable oils will grow further. How this demand will be met is not fully clear, but palm oil will likely be a significant component of the total vegetable oil supply, because of its comparatively high yields and popularity in tropical producing countries. The extent to which this will have further negative consequences for tropical biodiversity will depend on whether improvements in the production of palm oil occur. Currently most palm oil is produced with minimal consideration of environmental and biodiversity impacts. Certified palm oil has so far only been proven to have marginally fewer negative impacts on biodiversity than the crop in general. The initiative is still new, however, and the Roundtable on Sustainable Palm Oil and other certification schemes remain ambitious to improve practices of its members. A greater demand for sustainably produced palm oil should put pressure on producers to improve practices. With most palm oil being supplied to India, China, and Indonesia, consumer awareness in these countries needs to be raised to ensure that this demand will materialize.

While certification of sustainable palm oil has the potential the improve practices on the ground, by far the biggest gains for biodiversity in an oil palm context are through avoiding further deforestation. In many places where oil palm generates poor yields - such as flood plains and other frequently flooded areas -- this would also makes economic sense (486, 487). Jurisdictional approaches that focus on improved land use planning for oil palm development and the identification and better management of protected areas and forest set asides, could have both environmental and socio-economic benefits (488), avoiding societal costs from, for example, flooding (489), temperature rises caused by deforestation $(186,490)$ and land use conflicts (71), and ensuring that connected forest areas are maintained in which threatened wildlife can survive.

Many in the conservation community dislike oil palm cultivation because of its negative biodiversity impacts (491), even though this is a feature of many agricultural commodities. This situation analysis of oil palm and biodiversity shows that the relationship between the two is complicated. A ban on palm oil, as for example called for by some, could have overall negative biodiversity impacts, if, for example, demand for vegetable oil was then satisfied by conversion of biodiverse ecosystems for cultivation of alternatives more land-hungry than oil palm, such as soy. Similarly, yield increases in palm oil could mean that the same amount of oil is produced on less land, thus benefiting biodiversity, but it could also make palm oil even more competitive compared to other crops, increasing palm oil expansion at the expense of other lower yield crops. This would demand stricter control on expansion than currently seems possible. The palm oil debate is not simple.

We recognize that in this report we address only some aspects of the palm oil discussion - biodiversity and the environment. The current study did not touch much on the social, cultural and economic aspects of the palm oil industry. An improved understanding is needed on how biodiversity impacts compare with socio-cultural and economic impacts. Do win-wins and loss-losses exist, where either both biodiversity and people benefit or suffer? This requires further study, and potentially lays out an agenda for the IUCN Oil Palm Task Force. To be meaningful as a conservation community, but also a community that stands for good and responsible land use solutions, we somehow need to find effective answers within the complex context of production of palm and other oils, the need to feed and fuel people, the need to alleviate poverty, and a range of other sustainability objectives. We hope that this Situation Analysis can 
contribute to finding workable solutions that benefit the planet. For this we invite the readers of this study to contribute to integrated solutions with a strong view on biodiversity, and the broader sustainability context.

Conservation efforts are gaining momentum in the global palm oil sector, but there is still much ground to be covered in the transition to sustainable production. Part of the challenge to sustainability is that socio-ecological outcomes are increasingly telecoupled: pressures for local land use change are driven by actors and processes beyond sites of production and are therefore unresponsive to traditional boundaries of governance. However, these same globalizing forces are also creating new governance tools for conservation, such as certification programmes. These programs express consumer leverage in the market for sustainably sourced products and aim to expand shared-value along the supply chain by incorporating more stakeholders in the decision-making processes around palm oil production, processing, trade, and consumption.

Key to the future success of more responsible palm oil production programs will require:

1. Stronger government commitment in producing countries towards environmentally and socially responsible and just land use planning and land use, with a focus on halting deforestation and in line with their (international) commitments, including moratoria. This can be supported through partnerships between governments, civil society organizations, non-governmental organizations, producers, buyers and investors and banks;

2. Scientists to create an improved evidencebase of in-situ certification effectiveness to continuously refine criteria to be more vigorous and effective in meeting environmental (and social) goals among highly variable production systems and groups of stakeholders;
3. The private sector to create more added value from certification by ensuring that producers deliver maximum gains to conservation (i.e. by preventing plantations expanding into forest frontiers), but also benefit financially through improved operation effectiveness and decreased costs, increased market share, and shareholder profit; certification needs to make business sense;

4. The private sector, non-governmental sector, governments and consumers to increase the adoption of standardized best practice (certified or otherwise well verified) across production zones, regardless of market or end use (i.e. export vs. domestic consumption);

5. The private sector, non-governmental sector, governments and consumers to increase consumption/demand of certified palm oil in underperforming markets (i.e. Indonesia China and India) to make sustainably certified palm oil the norm;

6. Stronger government commitment in consuming countries to exclude imports of irresponsible palm oil (e.g., by establishing a legal framework, public procurement with certified palm oil, etc) and support to producing countries to comply with these norms;

7. Stronger commitment and action of all supply chain actors and financial institutions to exclude irresponsible palm oil trade, consumption \& financing from their business;

8. Private sector and government to make available green finance to further help protect and restore biodiversity in palm oil landscapes.

In addition to these recommendations, our report identifies a need to strength the supply-side mandatory certification schemes - Indonesian Sustainable Palm Oil and Malaysian Sustainable Palm Oil, for example, through establishing 
creative positive feedbacks with the Roundtable on Sustainable Palm Oil. This represents the best hope for avoiding leakage and other unintended impacts (especially given our findings that expansion in Africa and Latin America may be slow, and thus Indonesia and Malaysia retain the majority of production for the foreseeable future). Strengthening transparency may be key here, with the requirement from the Malaysian and Indonesian governments to the Roundtable on Sustainable Palm Oil to keep spatial data on oil palm secret being particularly worrying. Reversing this kind of downward transparency spiral will be essential, while reform of perverse legislation would also be important. Indonesia is showing the way forward with a recently announced 2-year moratorium on new oil palm licenses, providing an opportunity to review current legislation and any potential negative social, economic and environmental impacts this has (492).
The IUCN Oil Palm Task Force will take on board the lessons learned from the current study and seek to follow up on the recommendations for filling knowledge gaps. This report has gone through an extensive external review process involving 43 reviewers, and we have attempted as much as possible to incorporate reviewers' comments and suggestions into this final version. We hope the extensive review has benefitted the (objectivity and) scientific rigor of this report. We believe this approach also provides the Task Force with a future niche in the complex arena of oil palm sustainability, providing the IUCN with a balanced and factual basis for providing input into policy discussions concerning and involving the palm oil, and ultimately other vegetable oil industries. 


\section{References}

1. A. Cosiaux, L. M. Gardiner, T. L. P. Couvreur, Elaeis guineensis. The IUCN Red List of Threatened Species 2016: e.T13416970A13416973. http://dx.doi.org/10.2305/IUCN.UK.2016-3.RLTS.T13416970A13416973.en. Downloaded on 19 December 2017 (2016).

2. FAOSTAT, Food and agriculture data. http://www.fao.org/faostat/en/\#home (Food and Agriculture Organization of the United Nations, 2017).

3. Global Invasive Species Database (GISD), Species profile Elaeis guineensis. Available from: http://www.iucngisd.org/gisd/species. php?sc=377 [Accessed 27 February 2018] (IUCN, 2015).

4. M. Basri Wahid, S. N. A. Abdullah, I. E. Henson, Oil Palm--Achievements and Potential. Plant Production Science 8, 288-297 (2005). https://doi.org/10.1626/pps.8.288.

5. J. A. Duke, Handbook of Energy Crops (Center for New Crops and Plant Products. Purdue University West Lafayette, IN, 1983).

6. J. P. Baskett, Myanmar Oil Palm Plantations. A Productivity \& Sustainability Review. Report no. 28 of the Tanintharyi Conservation Programme, a joint initiative of Fauna \& Flora International and the Myanmar Forest Department. (Fauna \& Flora International, Cambridge, UK, 2016).

7. WTO, World Trade Organization. Country Trade Profiles. http://stat.wto.org/CountryProfile/WSDBCountryPFHome. aspx? Language=E (2018).

8. WTEx, World's Top Exports. http://www.worldstopexports.com/worlds-top-oil-exports-country/. (2018).

9. D. Byerlee, W. P. Falcon, R. L. Naylor, The Tropical Oil Crop Revolution: Food, Feed, Fuel, and Forests. (Oxford University Press, Oxford, UK, 2017).

10. T. M. Teo, Effectiveness of the oil palm pollinating weevil, Elaeidobius kamerunicus, in Malaysia. Utar Agriculture Science Journal 1, 40-43 (2015).

11. R. H. V. Corley, P. B. H. Tinker, The Oil Palm (World Agriculture Series). (Blackwell Publishing Limited, Oxford, UK, 2003).

12. T. Fairhurst, D. McLaughlin, Sustainable Oil Palm Development on Degraded Land in Kalimantan (Tropical Crop Consultants Limited, United Kingdom and WWF, United States of America, 2009).

13. J. Rich, A Workman Is Worthy of His Meat: Food and Colonialism in the Gabon Estuary. (University of Nebraska Press, Lincoln, NE, 2007).

14. A. Kassim, Recent Trends in Transnational Population Inflows into Malaysia: Policy, Issues and Challenges. Malaysian Journal of Economic Studies 51, 9-28 (2014).

15. S. Sanderson, in The Oil Palm Complex: Smallholders, Agribusiness and the State in Indonesia and Malaysia, R. Cramb, J. F. McCarthy, Eds. (NUS Press, Singapore, 2016), pp. 378-408.

16. Eyes on the Forest, No one is safe. Illegal Indonesian palm oil spreads through global supply chains despite global sustainability commitments and certification (Riau, Indonesia, 2016).

17. N. Hinrichsen, Commercially available alternatives to palm oil. Lipid Technology 28, 65-67 (2016). https://doi.org/10.1002/ lite.201600018.

18. F. Santamauro, F. M. Whiffin, R. J. Scott, C. J. Chuck, Low-cost lipid production by an oleaginous yeast cultured in non-sterile conditions using model waste resources. Biotechnology for Biofuels 7, 34 (March 04, 2014). https://doi.org/10.1186/1754-6834-734

19. C. Fry, Slipping away from palm oil. Engineering \& Technology 6, 68-71 (2011). https://doi.org/10.1049/et.2011.0112.

20. E. Barcelos et al., Oil palm natural diversity and the potential for yield improvement. Frontiers in Plant Science 6, 1-16 (2015). https:// doi.org/10.3389/fpls.2015.00190.

21. D. Hoyle, P. Levang, Oil Palm Development in Cameroon (WWF \& IRD/CIFOR, Yaoundé, Cameroon, 2012).

22. W. Yan, A makeover for the world's most hated crop. Nature 543, 306-308 (2017). https://doi.org/10.1038/543306a.

23. USDA-FAS, Production, Supply and Distribution Online. (United States Department of Agriculture-Foreign Agricultural Service, Washington, DC, 2017).

24. P. R. Furumo, T. M. Aide, Characterizing commercial oil palm expansion in Latin America: land use change and trade. Environmental Research Letters 12, 024008 (2017). https://doi.org/10.1088/1748-9326/aa5892.

25. D. L. A. Gaveau et al., Overlapping Land Claims Limit the Use of Satellites to Monitor No-Deforestation Commitments and NoBurning Compliance. Conservation Letters 10, 257-264 (2017). https://doi.org/10.1111/conl.12256.

26. RSPO Smallholders Task Force, Smallholders. Retrieved from http://www.rspo.org/en/definition (2012).

27. A. Baudoin, P.-M. Bosc, C. Bessou, P. Levang, Review of the diversity of palm oil production systems in Indonesia: Case study of two provinces: Riau and Jambi. (Center for International Forestry Research (CIFOR), Bogor, Indonesia, 2017).

28. Hardman Agribusiness, Palm Oil. http://www.hardmanagribusiness.com/sector-focus/palm-oil/. (2017).

29. J. S. H. Lee et al., Environmental Impacts of Large-Scale Oil Palm Enterprises Exceed that of Smallholdings in Indonesia. Conservation Letters 7, 25-33 (2014). https://doi.org/10.1111/conl.12039.

30. I. Jelsma, G. C. Schoneveld, A. Zoomers, A. C. M. van Westen, Unpacking Indonesia's independent oil palm smallholders: An 
actor-disaggregated approach to identifying environmental and social performance challenges. Land Use Policy 69, 281-297 (2017/12/01/, 2017). https://doi.org/10.1016/j.landusepol.2017.08.012.

31. J. S. H. Lee, L. Rist, K. Obidzinski, J. Ghazoul, L. P. Koh, No farmer left behind in sustainable biofuel production. Biological Conservation 144, 2512-2516 (2011/10/01/, 2011). https://doi.org/10.1016/j.biocon.2011.07.006.

32. A. Casson, The hesitant boom: Indonesia's oil palm sub-sector in an era of economic crisis and political change. CIFOR Occasional Paper No. 29 (Center for International Forestry Research, Bogor, Indonesia, 2000).

33. NEPCon, Malaysia Sarawak Palm Oil Risk Profile. https://www.nepcon.org/sourcinghub/palm-oil/palm-oil-malaysia-sarawak (Nature Economy and People Connected, 2018).

34. B. Azhar et al., The conservation value of oil palm plantation estates, smallholdings and logged peat swamp forest for birds. Forest Ecology and Management 262, 2306-2315 (2011/12/15/, 2011). https://doi.org/10.1016/j.foreco.2011.08.026.

35. T. Anderson, Oil Palm and small farmers in Papua New Guinea. Report for the Centre for Environmental Law and Community Rights on the economic prospects for small farmers in PNG's oil palm industry (University of Sydney, Sydney, Australia, 2006).

36. E. Ngom, paper presented at the Oil Palm in Cameroon. Communication at the South-South Exchange. 21-27 September 2011, Bogor, Indonesia, 2011.

37. NEPCon, Ghana Palm Oil Risk Profile. https://www.nepcon.org/sourcinghub/palm-oil/palm-oil-ghana (Nature Economy and People Connected, 2018).

38. J. Chamberlin, It's Small World After All: Defining Smallholder Agriculture in Ghana (International Food Policy Research Institute, Washington, DC, 2008).

39. R. N. Nkongho, L. Feintrenie, P. Levang, Strengths and weaknesses of the smallholder oil palm sector in Cameroon. Oilseeds and fats, Crops and Lipids (2014), vol. 21, pp. D208.

40. V. Gutiérrez-Vélez, H. et al., High-yield oil palm expansion spares land at the expense of forests in the Peruvian Amazon. Environmental Research Letters 6, 044029 (2011). https://doi.org/10.1088/1748-9326/6/4/044029.

41. D. Robinson, Smallholder Oil Palm growers in Latin America. Smallholder Acceleration and REDD+ Programme (SHARP) Workshop (Brazil, 2014).

42. R. Garrett, D. , K. Carlson, M. , X. Rueda, P. Noojipady, Assessing the potential additionality of certification by the Round table on Responsible Soybeans and the Roundtable on Sustainable Palm Oil. Environmental Research Letters 11, 045003 (2016).

43. IPOB, Indonesian palm oil in numbers (Indonesian Palm Oil Board, Jakarta, Indonesia, 2007).

44. A. K. A. Rahman, R. A. Faizah, M. Shariff, M. A. Simeh, The Malaysian Palm Oil Supply Chain: The Role of the Independent Smallholders. Oil Palm Industry Economic Journal 8, 17-27 (2008).

45. S. Somnuek, M. M. A. Slingerland, C. M. Grünbühel, The introduction of oil palm in Northeast Thailand: A new cash crop for smallholders? Asia Pacific Viewpoint 57, 76-90 (2016). https://doi.org/10.1111/apv.12114

46. Daemeter Consulting, Indonesian Oil Palm Smallholder Farmers: A Typology of Organizational Models, Needs, and Investment Opportunities (Daemeter Consulting, Bogor, Indonesia, 2015).

47. Daemeter, Indonesian Oil Palm Smallholder Farmers: Sustainability Challenges and Recommendations for the Design of Smallholder Support Programs (Daemeter, Bogor, Indonesia, 2016).

48. A. H. Iyabano, L. Feintrenie, M. I. Ludovic, A. Tahani, paper presented at the Conference on International Research on Food Security, Natural Resource Management and Rural Development, Prague, Czech Republic, 2014.

49. I. Jelsma, G. C. Schoneveld, Mewujudkan petani kecil sawit mandiri yang lebih produktif dan berkelanjutan di Indonesia: Pandangan dari pengembangan tipologi petani kecil. (2016), pp. 20p.

50. J. McCarthy, Z. Zen, Regulating the oil palm boom: Assessing the effectiveness of environmental governance approaches to agroindustrial pollution in Indonesia. Law \& Policy 32, 153-179 (Jan, 2010). https://doi.org/10.1111/j.1467-9930.2009.00312.x.

51. H. Purnomo et al., Fire economy and actor network of forest and land fires in Indonesia. Forest Policy and Economics 78, 21-31 (2017). https://doi.org/10.1016/j.forpol.2017.01.001.

52. C. Araujo, C. A. Bonjean, J.-L. Combes, P. Combes Motel, E. J. Reis, Property rights and deforestation in the Brazilian Amazon. Ecological Economics 68, 2461-2468 (2009/06/15/, 2009). https://doi.org/10.1016/j.ecolecon.2008.12.015.

53. J. A. Puppim de Oliveira, Property rights, land conflicts and deforestation in the Eastern Amazon. Forest Policy and Economics 10, 303-315 (2008/04/01/, 2008). https://doi.org/10.1016/j.forpol.2007.11.008.

54. C. Kubitza, V. V. Krishna, K. Urban, Z. Alamsyah, M. Qaim, Land Property Rights, Agricultural Intensification, and Deforestation in Indonesia. Ecological Economics 147, 312-321 (2018/05/01/, 2018). https://doi.org/10.1016/j.ecolecon.2018.01.021.

55. B. E. Robinson, M. B. Holland, L. Naughton-Treves, Does secure land tenure save forests? A meta-analysis of the relationship between land tenure and tropical deforestation. Global Environmental Change 29, 281-293 (2014/11/01/, 2014). https://doi. org/10.1016/j.gloenvcha.2013.05.012.

56. J. Busch, K. Ferretti-Gallon, What Drives Deforestation and What Stops It? A Meta-Analysis. Review of Environmental Economics and Policy 11, 3-23 (2017). https://doi.org/10.1093/reep/rew013.

57. V. V. Krishna, C. Kubitza, U. Pascual, M. Qaim, Land markets, Property rights, and Deforestation: Insights from Indonesia. World Development 99, 335-349 (2017/11/01/, 2017). https://doi.org/10.1016/j.worlddev.2017.05.018.

58. T. Griffiths, Closing the Gap: rights-based solutions for tackling deforestation (Forest Peoples Programme, Moreton-in-Marsh, UK, 2018).

59. T. Santika et al., Community forest management in Indonesia: Avoided deforestation in the context of anthropogenic and climate 
complexities. Global Environmental Change 46 60-71 (2017). https://doi.org/10.1016/j.gloenvcha.2017.08.002.

60. E. Ostrom, H. Nagendra, Insights on linking forests, trees, and people from the air, on the ground, and in the laboratory. Proceedings of the National Academy of Sciences of the United States of America 103, 19224-19231 (Dec 19, 2006). https://doi.org/10.1073/ pnas.0607962103.

61. M. Ojanen et al., What are the environmental impacts of property rights regimes in forests, fisheries and rangelands? Environmental Evidence 6, 12 (2017/05/25, 2017). https://doi.org/10.1186/s13750-017-0090-2.

62. X. Arnauld de Sartre et al., Sustainable development policies and the spread of land-sharing practices - A statistical assessment in a frontier region of the Brazilian Amazon. Journal of Rural Studies 48, 65-76 (2016/12/01/, 2016). https://doi.org/10.1016/j. jrurstud.2016.09.009.

63. R. B. Davenport et al., Adaptive Forest Governance in Northwestern Mato Grosso, Brazil: Pilot project outcomes across agrarian reform landscapes. Environmental Policy and Governance 27, 453-471 (2017). https://doi.org/10.1002/eet.1772.

64. J. Agyeman, D. Schlosberg, L. Craven, C. Matthews, Trends and Directions in Environmental Justice: From Inequity to Everyday Life, Community, and Just Sustainabilities. Annual Review of Environment and Resources 41, 321-340 (2016). https://doi.org/10.1146/ annurev-environ-110615-090052.

65. M. Colchester, Palm Oil and Indigenous Peoples of South East Asia: land acquisition, human rights violations and indigenous peoples on the palm oil frontier (Forest Peoples Programme and International Land Coalition, Moreton-in-Marsh and Rome, 2010).

66. L. A. Wily, 'The Law is to Blame': The Vulnerable Status of Common Property Rights in Sub-Saharan Africa. Development and Change 42, 733-757 (2011). https://doi.org/10.1111/j.1467-7660.2011.01712.x.

67. M. Colchester, S. Chao, Eds., Conflict or Consent? The oil palm sector at a crossroads, (Forest Peoples Programme, TUKIndonesia, SawitWatch, Bogor, Indonesia, 2013).

68. V. Barreiro et al., The Cost of Conflict in Oil Palm in Indonesia (Daemeter Consulting, Bogor, Indonesia, 2016).

69. S. Budidarsono et al., The relevance of land and tree tenure reform in Indonesia: cost of unresolved land disputes and informal local solutions along four stages in the trajectory of spontaneous migrants. ICRAF Southeast Asia Working Paper 2, (2005).

70. M. Persch-Orth, E. Mwangi, Company-community conflict in Indonesia's industrial plantation sector. (Center for International Forestry Research (CIFOR), Bogor, Indonesia, 2016), pp. 8p.

71. N. K. Abram et al., Oil palm-community conflict mapping in Indonesia: A case for better community liaison in planning for development initiatives. Applied Geography 78, 33-44 (2017). https://doi.org/10.1016/j.apgeog.2016.10.005.

72. M. Colchester et al., HCV and the RSPO: report of an independent investigation into the effectiveness of the application of High Conservation Value zoning in palm oil development in Indonesia (Forest Peoples Programme, HuMA, SawitWatch and Wild Asia, Moreton-in-Marsh, UK, 2009).

73. D. Ruysschaert, The Impact of Global Palm Oil Certification on Transnational Governance, Human Livelihoods and Biodiversity Conservation. Policy Matters 21, 45-58 (2016). http://dx.doi.org/10.2305/IUCN.CH.2014.PolicyMatters-21.en.

74. J. Lyons-White et al., HCV Management and Monitoring: review of field-level barriers to effective HCV management and monitoring in RSPO-certified oil palm plantations (RSPO and HCVRN, Oxford, UK, 2017).

75. M. Colchester, N. Jiwan, P. Anderson, A. Darussamin, A. Kiky, Securing High Conservation Values in Central Kalimantan: Report of the Field Investigation in Central Kalimantan of the RSPO Ad Hoc Working Group on High Conservation Values in Indonesia (Roundtable on Sustainable Palm Oil, Kuala Lumpur, Malaysia, 2011).

76. M. Colchester et al., How can 'Zero Deforestation' policies accommodate the rights and livelihoods of local communities and indigenous peoples? Lessons from the field. Paper presented at the 2016 World Bank Conference on Land and Poverty (The World Bank, Washington DC, 2016).

77. High Carbon Stock, The HCS Approach Toolkit. http://highcarbonstock.org/the-hcs-approach-toolkit/ (2017).

78. HCV Resource Network, HCV-HCSA Assessment Manual (High Conservation Value Resource Network, Oxford, 2017).

79. P. Dauvergne, Shadows in the Forest: Japan and the politics of timber in Southeast Asia. (MIT Press, Cambridge, MA, USA, 1997).

80. E. Wakker, Greasy Palms: the social and ecological impacts of large-scale oil palm plantation development in Southeast Asia (Friends of the Earth, London, UK, 2004).

81. CBD, Convention on Biological Diversity. List of Parties. https://www.cbd.int/information/parties.shtml (2017).

82. CBD, Key Elements of the Strategic Plan 2011-2020, including Aichi Biodiversity Targets. https://www.cbd.int/sp/elements/default. shtml\#III (2017).

83. D. Ruysschaert, A. Darsoyo, R. Zen, G. Gea, I. Singleton, Palm-oil production on fallow land: technical, economic, biodiversity, climate, legal and policy implications (International Finance Corporate, PanEco, YEL and World Agroforestry Centre, Medan, Indonesia, 2011).

84. F. Danielsen et al., Biofuel Plantations on Forested Lands: Double Jeopardy for Biodiversity and Climate. Conservation Biology 23, 348-358 (Apr, 2009). https://doi.org/10.1111/j.1523-1739.2008.01096.x.

85. E. B. Fitzherbert et al., How will oil palm expansion affect biodiversity? Trends in Ecology \& Evolution 23, 538-545 (Oct, 2008$).$ https://doi.org/10.1016/j.tree.2008.06.012.

86. L. P. Koh, D. S. Wilcove, Is oil palm agriculture really destroying tropical biodiversity? Conservation Letters 1, 60-64 (March 2008, 2008). https://doi.org/10.1111/j.1755-263X.2008.00011.X.

87. E. Meijaard, D. Sheil, Oil palm and biodiversity. Encyclopedia of Biodiversity 5, 600-612 (2013). 612 (2013). https://doi.org/10.1016/ B978-0-12-384719-5.00340-3. 
88. P. Potapov et al., The last frontiers of wilderness: Tracking loss of intact forest landscapes from 2000 to 2013. Science Advances 3 (2017). https://doi.org/10.1126/sciadv.1600821.

89. S. U. Okoro, U. Schickhoff, J. Böhner, U. A. Schneide, A novel approach in monitoring land-cover change in the tropics: Oil palm cultivation in the Niger Delta, Nigeria. Die Erde. Journal of the Geographical Society of Berlin 147, 40-52 (2016).

90. R. D. Garrett, K. M. Carlson, X. Rueda, P. Noojipady, Assessing the potential additionality of certification by the Round Table on Responsible Soybeans and the Roundtable on Sustainable Palm Oil. Environmental Research Letters 11, 045003 (2016). https://doi. org/10.1088/1748-9326/11/4/045003.

91. CIFOR, Atlas of Deforestation and Industrial Plantations in Borneo https://www.cifor.org/map/atlas/ (2017).

92. D. L. A. Gaveau et al., Rapid conversions and avoided deforestation: examining four decades of industrial plantation expansion in Borneo. Scientific Reports 6, 32017 (2016). https://doi.org/10.1038/srep32017.

93. D. L. A. Gaveau, What a difference 4 decades make: Deforestation in Borneo since 1973. (Center for International Forestry Research (CIFOR), Bogor, Indonesia, 2017).

94. L. Cotula, Land rights and investment treaties: exploring the interface (International Institute for Environment and Development, London, 2015).

95. H. L. Tata et al., Will funding to Reduce Emissions from Deforestation and (forest) Degradation (REDD+) stop conversion of peat swamps to oil palm in orangutan habitat in Tripa in Aceh, Indonesia? Mitigation and Adaptation Strategies for Global Change 19, 693-713 (August 01, 2014).

96. D. Ruysschaert, D. Salles, Towards global voluntary standards: Questioning the effectiveness in attaining conservation goals: The case of the Roundtable on Sustainable Palm Oil (RSPO). Ecological Economics 107, 438-446 (2014/11/01/, 2014). https://doi. org/10.1016/j.ecolecon.2014.09.016.

97. H. N. Jong, These 3 companies owe Indonesia millions of dollars for damaging the environment. Why haven't they paid? Mongabay 23 August 2017, https://news.mongabay.com/2017/2008/these-2013-companies-owe-indonesia-millions-of-dollars-for-damagingthe-environment-why-havent-they-paid/ (2017).

98. D. Ruysschaert, H. Rainer, in State of the Apes 2015. Industrial Agriculture and Ape Conservation, Arcus Foundation, Ed. (Cambridge University Press, Cambridge, UK, 2015), pp. 135-164.

99. I. Comte, F. Colin, J. L. Whalen, O. Grunberger, J.-P. Caliman, in Advances in Agronomy, D. L. Sparks, Ed. (Academic Press 2012), vol. 76, pp. 71-124.

100. A. J. Marshall, Are Montane Forests Demographic Sinks for Bornean White-bearded Gibbons Hylobates albibarbis? Biotropica 41, 257-267 (2009). https://doi.org/10.1111/j.1744-7429.2008.00461.x.

101. M. S. Luskin, W. R. Albert, M. W. Tobler, Sumatran tiger survival threatened by deforestation despite increasing densities in parks. Nature Communications 8, 1783 (2017/12/05, 2017). https://doi.org/10.1038/s41467-017-01656-4.

102. F. H. Sheldon, A. Styring, P. A. Hosner, Bird species richness in a Bornean exotic tree plantation: A long-term perspective. Biological Conservation 143, 399-407 (Feb, 2010). https://doi.org/10.1016/j.biocon.2009.11.004.

103. W. A. Foster et al., Establishing the evidence base for maintaining biodiversity and ecosystem function in the oil palm landscapes of South East Asia. Philosophical Transactions of the Royal Society B: Biological Sciences 366, 3277 (2011). https://doi.org/10.1098/ rstb.2011.0041.

104. S. Savilaakso et al., Systematic review of effects on biodiversity from oil palm production. Environmental Evidence 3, 4 (February 25, 2014). https://doi.org/10.1186/2047-2382-3-4.

105. T. Maddox, D. Priatna, E. Gemita, A. Salampessy, The conservation of tigers and other wildlife in oil palm plantations Jambi Province, Sumatra, Indonesia. ZSL Conservation Report No.7 (The Zoological Society of London, London, UK, 2007).

106. O. R. Wearn, C. Carbone, J. M. Rowcliffe, H. Bernard, R. M. Ewers, Grain-dependent responses of mammalian diversity to land use and the implications for conservation set-aside. Ecological Applications 26, 1409-1420 (2016). https://doi.org/10.1890/15-1363.

107. L. H. Liow, N. S. Sodhi, T. Elmqvist, Bee diversity along a disturbance gradient in tropical lowland forests of south-east Asia. Journal of Applied Ecology 38, 180-192 (Feb, 2001). https://doi.org/10.1046/j.1365-2664.2001.00582.x.

108. L. López-Ricaurte, D. P. Edwards, N. Romero-Rodríguez, J. J. Gilroy, Impacts of oil palm expansion on avian biodiversity in a Neotropical natural savanna. Biological Conservation 213, 225-233 (2017/09/01/, 2017). https://doi.org/10.1016/j. biocon.2017.07.009.

109. A. C. Mendes-Oliveira et al., Oil palm monoculture induces drastic erosion of an Amazonian forest mammal fauna. PLoS ONE 12, e0187650 (2017). https://doi.org/10.1371/journal.pone.0187650.

110. O. R. Wearn et al., Mammalian species abundance across a gradient of tropical land-use intensity: A hierarchical multi-species modelling approach. Biological Conservation 212, 162-171 (2017/08/01/, 2017). https://doi.org/10.1016/j.biocon.2017.05.007.

111. J. T. Davis et al., It's not just conflict that motivates killing of orangutans. PLOS ONE 8, e75373 (2013). https://doi.org/10.1371/ journal.pone.0075373.

112. N. K. Abram et al., Mapping perceptions of species' threats and population trends to inform conservation efforts: the Bornean orangutan case study. Diversity and Distributions 21, 487-499 (2015). https://doi.org/10.1111/ddi.12286.

113. R. Clements et al., Trio under threat: can we secure the future of rhinos, elephants and tigers in Malaysia? Biodivers Conserv 19, 1115-1136 (April 01, 2010). https://doi.org/10.1007/s10531-009-9775-3.

114. J. G. Estes et al., Quantity and Configuration of Available Elephant Habitat and Related Conservation Concerns in the Lower Kinabatangan Floodplain of Sabah, Malaysia. PLoS ONE 7, e44601 (2012). https://doi.org/10.1371/journal.pone.0044601. 
115. A. S. L. Rodrigues et al., Spatially Explicit Trends in the Global Conservation Status of Vertebrates. PLoS ONE 9, e113934 (2014). https://doi.org/10.1371/journal.pone.0113934.

116. E. Meijaard, J. P. d'Huart, W. L. R. Oliver, in Handbook of the Mammals of the World. Vol 2. Hoofed Mammals, D. E. Wilson, R. A. Mittermeier, Eds. (Lynx Edicions, Barcelona, Spain, 2011), pp. 248-291.

117. P. J. Piper, R. J. Rabett, Hunting in a Tropical Rainforest: Evidence from the Terminal Pleistocene at Lobang Hangus, Niah Caves, Sarawak. International Journal of Osteoarchaeology 19, 551-565 (Jul-Aug, 2009). https://doi.org/10.1002/oa.1046.

118. J. O. Caldecott, R. A. Blouch, A. A. MacDonald, in Pigs, peccaries, and hippos. Status survey and conservation action plan. Available online at: https://portals.iucn.org/library/node/6805. , W. L. R. Oliver, Ed. (IUCN/SSC Pigs and Peccaries Specialist group and IUCN/SSC Hippos Specialist Group, Gland, Switzerland, 1993), pp. 136 - 145.

119. K. Ickes, Hyper-abundance of native wild pigs (Sus scrofa) in a lowland dipterocarp rain forest of Peninsular Malaysia. Biotropica 33 , 682-690 (December, 2001). https://doi.org/10.1646/0006-3606(2001)033[0682:HAONWP]2.0.CO;2

120. R. Lohe, Bearded pigs on the Malayan Peninsular - a travel report. Suiform Soundings 14, 21-23 (2015).

121. L. R. Carrasco, C. Larrosa, E. J. Milner-Gulland, D. P. Edwards, A double-edged sword for tropical forests. Science 346, 38-40 (October 3, 2014, 2014). https://doi.org/10.1126/science.1256685.

122. M. S. Yahya et al., Switching from monoculture to polyculture farming benefits birds in oil palm production landscapes: Evidence from mist netting data. Ecology and Evolution 7, 6314-6325 (2017). https://doi.org/10.1002/ece3.3205.

123. B. Azhar, C. L. Puan, M. Zakaria, N. Hassan, M. Arif, Effects of monoculture and polyculture practices in oil palm smallholdings on tropical farmland birds. Basic and Applied Ecology 15, 336-346 (2014/06/01/, 2014). https://doi.org/10.1016/j.baae.2014.06.001.

124. B. Phalan, A. Balmford, R. E. Green, J. P. W. Scharlemann, Minimising the harm to biodiversity of producing more food globally. Food Policy 36, S62-S71 (Jan, 2011). https://doi.org/10.1016/j.foodpol.2010.11.008.

125. B. Phalan, M. Onial, A. Balmford, R. E. Green, Reconciling Food Production and Biodiversity Conservation: Land Sharing and Land Sparing Compared. Science 333, 1289-1291 (Sep 2, 2011). https://doi.org/10.1017/S0030605313001270.

126. M. Ancrenaz et al., Of pongo, palms, and perceptions - A multidisciplinary assessment of orangutans in an oil palm context. Oryx 49, 465-472 (2015). https://doi.org/10.1017/S0030605313001270.

127. I. Singleton, S. A. Wich, M. Nowak, G. Usher, S. S. Utami-Atmoko, Pongo abelii. The IUCN Red List of Threatened Species 2017 , e.T121097935A115575085 (2017).

128. M. Ancrenaz et al., Pongo pygmaeus. The IUCN Red List of Threatened Species 2016, e.T17975A17966347 (2016).

129. M. G. Nowak, P. Rianti, S. A. Wich, E. Meijaard, G. Fredriksson, Pongo tapanuliensis. The IUCN Red List of Threatened Species 2017, e.T120588639A120588662 (2017).

130. T. Santika et al., First integrative trend analysis for a great ape species in Borneo. Scientific Reports 7, 4839 (2017/07/07, 2017).

131. S. A. Wich et al., Hunting of Sumatran orang-utans and its importance in determining distribution and density. Biological Conservation 146, 163-169 (Feb, 2012). https://doi.org/10.1016/j.biocon.2011.12.006.

132. S. A. Wich et al., Understanding the Impacts of Land-Use Policies on a Threatened Species: Is There a Future for the Bornean Orang-utan? PLoS ONE 7, e49142 (2012). https://doi.org/10.1371/journal.pone.0049142.

133. M. Ancrenaz, E. Meijaard, S. A. Wich, J. Simery, Palm oil paradox. Sustainable solutions to save the great apes (UNEP/GRASP, Nairobi, Kenya, 2016).

134. E. Meijaard et al., Quantifying killing of orangutans and human-orangutan conflict in Kalimantan, Indonesia PLoS ONE 6, e27491 (2011). https://doi.org/10.1371/journal.pone.0027491.

135. E. Meijaard et al., Declining orangutan encounter rates from Wallace to the present suggest the species was once more abundant. PlosONE 5, e12042 (2010). https://doi.org/10.1371/journal.pone.0012042.

136. A. Nater et al., Morphometric, Behavioral, and Genomic Evidence for a New Orangutan Species. Current Biology, (2017). https:// doi.org/10.1016/j.cub.2017.09.047.

137. H. D. Rijksen, E. Meijaard, Our vanishing relative. The status of wild orang-utans at the close of the twentieth century. (Kluwer Academic Publishers, Dordrecht, The Netherlands, 1999), pp. 480.

138. B. Goossens et al., Genetic signature of anthropogenic population collapse in orang-utans - art. no. e25. Plos Biology 4, 285-291 (Feb, 2006). https://doi.org/10.1371/journal.pbio.0040025.

139. S. A. Abood, J. S. H. Lee, Z. Burivalova, J. Garcia-Ulloa, L. P. Koh, Relative Contributions of the Logging, Fiber, Oil Palm, and Mining Industries to Forest Loss in Indonesia. Conservation Letters 8, 58-67 (2015). https://doi.org/10.1111/conl.12103.

140. E. Meijaard, C. Morgans, Husnayaen, N. K. Abram, M. Ancrenaz, An impact analysis of RSPO certification on Borneo forest cover and orangutan populations (Borneo Futures, Brunei Darussalam, 2017).

141. H. N. Jong, Debates heat up as Indonesian palm oil moratorium is about to be signed. Mongabay 13 March 2018, (2018).

142. E. Meijaard et al., A case study of oil-palm contributing to biodiversity conservation. International Journal of Natural Resource Ecology and Management 4, 179-187 (2016).

143. R. Shine, T. Madsen, Prey abundance and predator reproduction: Rats and pythons on a tropical Australian floodplain. Ecology 78, 1078-1086 (1997). https://doi.org/10.1890/0012-9658(1997)078[1078:PAAPRR]2.0.CO;2.

144. D. J. McCauley, F. Keesing, T. P. Young, B. F. Allan, R. M. Pringle, Indirect effects of large herbivores on snakes in an African savanna. Ecology 87, 2657-2663 (2006). https://doi.org/10.1890/0012-9658(2006)87[2657:ieolho]2.0.co;2.

145. P. Caley, Population Dynamics of Feral Pigs (Sus Scrofa) in a Tropical Riverine Habitat Complex. Wildlife Research 20, 625-636 (1993). https://doi.org/10.1071/WR9930625. 
146. H. Tristiani, O. Murakami, Rates of population increase in the ricefield rat (Rattus argentiventer) as a function of food supply: an enclosure study in Jatisari, West Java. Journal of Zoology 259, 239-244 (2003). https://doi.org/10.1017/s0952836902003163.

147. R. B. Stuebing, J. Gasis, A survey of small mammals within a tree plantation in Malaysia. Journal of Tropical Ecology 5, 203-214 (1989). https://doi.org/10.1017/S0266467400003485

148. C. L. Puan, A. W. Goldizen, M. Zakaria, M. N. Hafidzi, G. S. Baxter, Relationships among rat numbers, abundance of oil palm fruit and damage levels to fruit in an oil palm plantation. Integrative Zoology 6, 130-139 (2011). https://doi.org/10.1111/j.17494877.2010.00231.x.

149. R. Shine, Ambariyanto, P. S. Harlow, Mumpuni, Reticulated pythons in Sumatra: Biology, harvesting and sustainability. Biological Conservation 87, 349-357 (1999). https://doi.org/10.1016/S0006-3207(98)00068-8.

150. D. J. D. Natusch et al., Sustainable Management of the Trade in Reticulated Python Skins in Indonesia and Malaysia. A report under the 'Python Conservation Partnership' programme of research. Occasional Paper of the IUCN Species Survival Commission No. 61 (Gland, Switzerland, 2016).

151. R. Shine, Ambariyanto, P. S. Harlow, Mumpuni, Ecological attributes of two commercially-harvested python species in northern Sumatra. Journal of Herpetology 33, 249-257 (1999). https://doi.org/10.2307/1565722.

152. G. C. Akani, N. Ebere, L. Luiselli, E. A. Eniang, Community structure and ecology of snakes in fields of oil palm trees (Elaeis guineensis) in the Niger Delta, southern Nigeria. African Journal of Ecology 46, 500-506 (Dec, 2008). https://doi.org/10.1111/j.13652028.2007.00885.x.

153. J. D. Lynch, The role of plantations of the Africa palm (Elaeis guineensis Jacq.) in the conservation of snakes in Colombia. Caldasia 37, 169-182 (2015). http://dx.doi.org/10.15446/caldasia.v37n1.50992

154. World Bank, Indonesia country data https://data.worldbank.org/country/indonesia (The World Bank, Jakarta, Indonesia, 2015).

155. H. Sinaga, Employment and Income of Workers on Indonesian Oil Palm Plantations: Food Crisis at the Micro Level. Future of Food: Journal on Food, Agriculture \& Society 1, 64-77 (2013).

156. M. N. Hafidzi, M. K. Saayon, Status of rat infestation and recent control strategies in oil palm plantations in Peninsular Malaysia. Journal of Tropical Agricultural Science 24, 109-114 (2001).

157. K. Nossal et al., Trade In Python Skins: Impact on Livelihoods in Malaysia (International Trade Centre, Geneva, Switzerland, 2016).

158. B. Azhar et al., The influence of agricultural system, stand structural complexity and landscape context on foraging birds in oil palm landscapes. Ibis 155, 297-312 (2013). https://doi.org/10.1111/ibi.12025.

159. K. A. Tohiran et al., Targeted cattle grazing as an alternative to herbicides for controlling weeds in bird-friendly oil palm plantations. Agronomy for Sustainable Development 37, 62 (November 09, 2017). https://doi.org/10.1007/s13593-017-0471-5.

160. B. Azhar, D. B. Lindenmayer, J. Wood, J. Fischer, M. Zakaria, Ecological impacts of oil palm agriculture on forest mammals in plantation estates and smallholdings. Biodivers Conserv 23, 1175-1191 (2014/05/01, 2014). https://doi.org/10.1007/s10531-0140656-z.

161. S. N. Shuhada, S. Salim, F. Nobilly, A. Zubaid, B. Azhar, Logged peat swamp forest supports greater macrofungal biodiversity than large-scale oil palm plantations and smallholdings. Ecology and Evolution 7, 7187-7200 (2017). https://doi.org/10.1002/ece3.3273.

162. WWF, Palm Oil Report Germany. Searching for Alternatives (WWF Deutschland, Ferlin, 2016).

163. C. Dislich et al., A review of the ecosystem functions in oil palm plantations, using forests as a reference system. Biological Reviews 92, 1539-1569 (2017). https://doi.org/10.1111/brv.12295.

164. J. M. Guinotte, V. J. Fabry, Ocean acidification and its potential effects on marine ecosystems. Annals of the New York Academy of Sciences 1134, 320-342 (2008). https://doi.org/10.1196/annals.1439.013.

165. K. J. Kroeker et al., Impacts of ocean acidification on marine organisms: quantifying sensitivities and interaction with warming. Global change biology 19, 1884-1896 (2013). https://doi.org/10.1111/gcb.12179.

166. J.-P. Gattuso et al., Contrasting futures for ocean and society from different anthropogenic CO2 emissions scenarios. Science $\mathbf{3 4 9}$, aac4722 (2015). https://doi.org/10.1126/science.aac4722.

167. M. O. Clarkson et al., Ocean acidification and the Permo-Triassic mass extinction. Science 348, 229-232 (2015). https://doi. org/10.1126/science.aaa0193.

168. A. Hooijer et al., Subsidence and carbon loss in drained tropical peatlands. Biogeosciences 9, 1053-1071 (2012). https://doi. org/10.5194/bg-9-1053-2012.

169. L. S. Wijedasa et al., Denial of long-term issues with agriculture on tropical peatlands will have devastating consequences. Global Change Biology, n/a-n/a (2016). https://doi.org/10.1111/gcb.13516.

170. S. C. Davis et al., Management swing potential for bioenergy crops. Gcb Bioenergy 5, 623-638 (2013). https://doi.org/10.1111/ gcbb. 12042

171. T. Silalertruksa, S. H. Gheewala, Environmental sustainability assessment of palm biodiesel production in Thailand. Energy 43, 306314 (2012/07/01/, 2012). https://doi.org/10.1016/j.energy.2012.04.025.

172. D. Murdiyarso, M. Van Noordwijk, U. Wasrin, T. Tomich, A. Gillison, Environmental benefits and sustainable land-use options in the Jambi transect, Sumatra. Journal of Vegetation Science 13, 429-438 (2002). https://doi.org/10.1658/1100-9233(2002)013[0429:EB ASLU]2.0.CO;2

173. G. Myhre et al., in Climate Change 2013: The physical science basis. Contribution of Working Group I to the fifth assessment report of the Intergovernmental Panel on Climate Change., T. Stocker et al., Eds. (Cambridge University Press, Cambridge, UK, 2013), pp. $659-740$. 
174. S. Oktarita, K. Hergoualc'h, S. Anwar, L. V. Verchot, Substantial N2O emissions from peat decomposition and N fertilization in an oil palm plantation exacerbated by hotspots. Environmental Research Letters 12, 104007 (2017). https://doi.org/10.1088/1748-9326/ aa80f1.

175. H. Stichnothe, F. Schuchardt, Life cycle assessment of two palm oil production systems. Biomass and bioenergy 35, 3976-3984 (2011). https://doi.org/10.1016/j.biombioe.2011.06.001.

176. L. Reijnders, M. Huijbregts, Palm oil and the emission of carbon-based greenhouse gases. Journal of cleaner production 16, $477-$ 482 (2008). https://doi.org/10.1016/j.jclepro.2006.07.054.

177. S. S. Harsono, P. Grundmann, S. Soebronto, Anaerobic treatment of palm oil mill effluents: potential contribution to net energy yield and reduction of greenhouse gas emissions from biodiesel production. Journal of Cleaner Production 64, 619-627 (2014/02/01/, 2014). https://doi.org/10.1016/j.jclepro.2013.07.056.

178. P. Crippa et al., Population exposure to hazardous air quality due to the 2015 fires in Equatorial Asia. Scientific reports 6, 37074 (2016). https://doi.org/10.1038/srep37074.

179. J. Nichol, Bioclimatic impacts of the 1994 smoke haze event in Southeast Asia. Atmospheric Environment 31, 1209-1219 (1997). https://doi.org/10.1016/S1352-2310(96)00260-9.

180. Y.-H. Lee, B. Paul, Z. G. Davies, M. J. Struebig, Smoke pollution disrupted biodiversity during the 2015 El Niño fires in Southeast Asia. Environmental Research Letters, (2017). https://doi.org/10.1088/1748-9326/aa87ed.

181. S. R. Hardwick et al., The relationship between leaf area index and microclimate in tropical forest and oil palm plantation: Forest disturbance drives changes in microclimate. Agricultural and Forest Meteorology 201, 187-195 (2015/02/15/, 2015). https://doi. org/10.1016/j.agrformet.2014.11.010.

182. G. B. Bonan, Forests and Climate Change: Forcings, Feedbacks, and the Climate Benefits of Forests. Science 320, 1444-1449 (June 13, 2008, 2008). https://doi.org/10.1126/science.1155121.

183. D. Ellison et al., Trees, forests and water: Cool insights for a hot world. Global Environmental Change 43, 51-61 (2017). https://doi. org/10.1016/j.gloenvcha.2017.01.002.

184. D. V. Spracklen, S. R. Arnold, C. M. Taylor, Observations of increased tropical rainfall preceded by air passage over forests. Nature 489, 282-286 (Sep 13, 2012). https://doi.org/10.1038/nature11390.

185. R. Mahmood et al., Land cover changes and their biogeophysical effects on climate. International Journal of Climatology 34, 929953 (2014). https://doi.org/10.1002/joc.3736.

186. C. A. McAlpine et al., Forest loss and Borneo's climate. Environmental Research Letters, (2018). https://doi.org/10.1088/1748-9326/ aaa4ff.

187. A. Guenther et al., A Global-model of natural volatile organic-compound emissions. Journal of Geophysical Research-Atmospheres 100, 8873-8892 (May, 1995). https://doi.org/10.1029/94JD02950.

188. N. Unger, Human land-use-driven reduction of forest volatiles cools global climate. Nature Climate Change 4, 907 (08/24/online, 2014). https://doi.org/10.1038/nclimate2347.

189. C. Hewitt et al., Nitrogen management is essential to prevent tropical oil palm plantations from causing ground-level ozone pollution. Proceedings of the National Academy of Sciences 106, 18447-18451 (2009). https://doi.org/10.1073/pnas.0907541106.

190. J. Lelieveld et al., Atmospheric oxidation capacity sustained by a tropical forest. Nature 452, 737 (2008). https://doi.org/10.1038/ nature06870

191. S. J. Silva et al., Impacts of current and projected oil palm plantation expansion on air quality over Southeast Asia. Atmospheric Chemistry and Physics 16, 10621-10635 (2016). https://doi.org/10.5194/acp-16-10621-2016, 2016.

192. P. Misztal et al., Direct ecosystem fluxes of volatile organic compounds from oil palms in South-East Asia. Atmospheric Chemistry and Physics 11, 8995 (2011).

193. A. Guenther et al., The Model of Emissions of Gases and Aerosols from Nature version 2.1 (MEGAN2. 1): an extended and updated framework for modeling biogenic emissions. (2012).

194. S. Maxwell, R. Fuller, T. Brooks, J. Watson, Biodiversity: The ravages of guns, nets and bulldozers. Nature 536, 143 (2016). https:// doi.org/10.1038/536143a.

195. J. J. Wiens, Climate-related local extinctions are already widespread among plant and animal species. PLOS Biology 14, e2001104 (2016). https://doi.org/10.1371/journal.pbio.2001104.

196. A. E. Cahill et al., How does climate change cause extinction? Proceedings of the Royal Society B: Biological Sciences 280, 1-10 (2013). https://doi.org/10.1098/rspb.2012.1890.

197. IPCC, The physical science basis. Contribution of working group I to the fifth assessment report of the intergovernmental panel on climate change. K., Tignor, M., Allen, SK, Boschung, J., Nauels, A., Xia, Y., Bex, V., Midgley, PM, Eds, 1535 (2013).

198. M. B. Davis, R. G. Shaw, Range shifts and adaptive responses to Quaternary climate change. Science 292, 673-679 (2001). https:// doi.org/10.1126/science.292.5517.673.

199. K. E. Trenberth, Changes in precipitation with climate change. Climate Research 47, 123-138 (2011).

200. B. Stevens, S. Bony, What are climate models missing? Science 340, 1053-1054 (2013). https://doi.org/10.1126/science.1237554.

201. I. Khaliq, C. Hof, R. Prinzinger, K. Böhning-Gaese, M. Pfenninger, Global variation in thermal tolerances and vulnerability of endotherms to climate change. Proceedings of the Royal Society of London B: Biological Sciences 281, 20141097 (2014). https:// doi.org/10.1098/rspb.2014.1097.

202. R. T. Corlett, D. A. Westcott, Will plant movements keep up with climate change? Trends in Ecology \& Evolution 28, $482-488$ (2013). 
https://doi.org/10.1016/j.tree.2013.04.003.

203. S. J. Wright, H. C. Muller-Landau, J. Schipper, The future of tropical species on a warmer planet. Conservation biology 23, 14181426 (2009). https://doi.org/10.1111/j.1523-1739.2009.01337.x.

204. R. K. Colwell, G. Brehm, C. L. Cardelús, A. C. Gilman, J. T. Longino, Global Warming, Elevational Range Shifts, and Lowland Biotic Attrition in the Wet Tropics. Science 322, 258-261 (October 10, 2008, 2008). https://doi.org/10.1126/science.1162547

205. C. D. Thomas, A. Franco, J. K. Hill, Range retractions and extinction in the face of climate warming. Trends in Ecology \& Evolution 21, $415-416$ (2006). https://doi.org/10.1016/j.tree.2006.05.012.

206. M. C. Urban, J. J. Tewksbury, K. S. Sheldon, On a collision course: competition and dispersal differences create no-analogue communities and cause extinctions during climate change. Proceedings of the Royal Society B: Biological Sciences 279, $2072-2080$ (2012). https://doi.org/10.1098/rspb.2011.2367.

207. R. Warren et al., Quantifying the benefit of early climate change mitigation in avoiding biodiversity loss. Nature Clim. Change advance online publication, (05/12/online, 2013). https://doi.org/10.1038/nclimate1887.

208. K. E. Selwood, M. A. McGeoch, R. Mac Nally, The effects of climate change and land-use change on demographic rates and population viability. Biological Reviews 90, 837-853 (2015). https://doi.org/10.1111/brv.12136.

209. C. S. Mantyka-Pringle et al., Climate change modifies risk of global biodiversity loss due to land-cover change. Biological Conservation 187, 103-111 (2015). https://doi.org/10.1016/j.biocon.2015.04.016.

210. S. H. Luke et al., The impacts of habitat disturbance on adult and larval dragonflies (Odonata) in rainforest streams in Sabah, Malaysian Borneo. Freshwater Biology 62, 491-506 (2017). https://doi.org/10.1111/fwb.12880.

211. S. H. Luke et al., The effects of catchment and riparian forest quality on stream environmental conditions across a tropical rainforest and oil palm landscape in Malaysian Borneo. Ecohydrology 10, e1827-n/a (2017). https://doi.org/10.1002/eco.1827.

212. P. Sulai et al., Effects of water quality in oil palm production landscapes on tropical waterbirds in Peninsular Malaysia. Ecol Res $\mathbf{3 0}$, 941-949 (2015/09/01, 2015). https://doi.org/10.1007/s11284-015-1297-8.

213. D. Chellaiah, C. M. Yule, Effect of riparian management on stream morphometry and water quality in oil palm plantations in Borneo. Limnologica - Ecology and Management of Inland Waters, (2017/12/06/, 2017). https://doi.org/10.1016/j.limno.2017.11.007

214. V. J. Tulloch et al., Improving conservation outcomes for coral reefs affected by future oil palm development in Papua New Guinea. Biological Conservation 203, 43-54 (2016). https://doi.org/10.1016/j.biocon.2016.08.013.

215. C. Bessou et al., Agroecological practices in oil palm plantations: examples from the field. Oilseeds and fats Crops and Lipids $\mathbf{2 4}$ D305 (2017). https://doi.org/10.1051/ocl/2017024.

216. L. Brussaard, in Soil ecology and ecosystem services, D. H. Wall et al., Eds. (Oxford University Press, Oxford, UK, 2012), pp. 45-58.

217. S. Salètes, F. Siregar, J. Caliman, T. Liwang, Ligno-cellulose composting: Case study on monitoring oil palm residuals. Compost Science \& Utilization 12, 372-382 (2004). https://doi.org/10.1080/1065657X.2004.10702207.

218. M. P. Carron et al., Temporal variability in soil quality after organic residue application in mature oil palm plantations. Soil Research 53, 205-215 (2015). https://doi.org/10.1071/SR14249.

219. D. T. Sabrina, M. M. Hanafi, A. A. Nor Azwady, T. M. M. Mahmud, Earthworm Populations and Cast Properties in the Soils of. Oil Palm Plantations. Malaysian Journal of Soil Science 13, 29-42 (2009).

220. S. K. Teng et al., Earthworm diversity and population density in the Kaki Bukit agroecosystem, Perlis, Peninsular Malaysia. Tropical Ecology 54, 291-299 (2013).

221. C. Fragoso, P. Lavelle, Earthworm communities of tropical rain forests. Soil Biology and Biochemistry 24, 1397-1408 (1992/12/01/, 1992). https://doi.org/10.1016/0038-0717(92)90124-G.

222. R. J. Blakemore et al., Taxonomic status and ecology of Oriental Pheretima darnleiensis (Fletcher, 1886) and other earthworms (Oligochaeta : Megascolecidae) from Mt Kinabalu, Borneo. Zootaxa 1613, 23-44 (2007).

223. R. J. Blakemore, Cosmopolitan Earthworms - an Eco-Taxonomic Guide to the Peregrine Species of the World. VIth Edition. (VermEcology, Yokohama/Zama, 2016).

224. R. J. Blakemore, Veni, Vidi, Vermi -II. Earthworms in organic fields restore SOM \& H2O and fix CO2. VermEcology Occasional Papers 2, 1-26 (2016).

225. A. Darmawan, T. Atmowidi, W. Manalu, B. Suryobroto, Land-use change on Mount Gede, Indonesia, reduced native earthworm populations and diversity. Australian Journal of Zoology 65, 217-225 (2017). https://doi.org/10.1071/ZO17028.

226. S. L. Lim, T. Y. Wu, C. Clarke, Treatment and Biotransformation of Highly Polluted Agro-industrial Wastewater from a Palm Oil Mill into Vermicompost Using Earthworms. Journal of Agricultural and Food Chemistry 62, 691-698 (2014/01/22, 2014). https://doi. org/10.1021/jf404265f.

227. R. J. Blakemore, Eco-Taxonomic Profile of an Iconic Vermicomposter - the 'African Nightcrawler' Earthworm, Eudrilus eugeniae (Kinberg, 1867). African Invertebrates 56, 527-548 (2015/12/01, 2015). https://doi.org/10.5733/afin.056.0302.

228. R. H. V. Corley, P. B. Tinker, The oil palm, Fifth edition. (Wiley Blackwell Publishing, Chichester, UK, 2016).

229. C. Bessou et al., Sustainable Palm Oil Production project synthesis: Understanding and anticipating global challenges. (Center for International Forestry Research (CIFOR), Bogor, Indonesia, 2017).

230. R. D. Zenni, S. R. Ziller, An overview of invasive plants in Brazil. Brazilian Journal of Botany 34, 431-446 (2011). https://doi. org/10.1590/S0100-84042011000300016

231. Pacific Island Ecosystems at Risk (PIER), Elaeis guineensis N. Jacquin, Arecaceae. http://www.hear.org/pier/species/elaeis_ guineensis.htm. (2013). 
232. A. S. Juraimi, M. Y. Rafii, S. A. Sheikh Awadz, M. P. Anwar, A. R. Anuar, Effect of cover crops on weed suppression in oil palm plantation. International Journal of Agriculture \& Biology 17, 251-260 (2015).

233. J. Yue et al., Pollination Activity of Elaeidobius kamerunicus (Coleoptera: Curculionoidea) on Oil Palm on Hainan Island. Florida Entomologist 98, 499-505 (2015/06/01, 2015). https://doi.org/10.1653/024.098.0217.

234. M. R. Meléndez, W. P. Ponce, Pollination in the oil palms Elaeis guineensis, E. oleifera and their hybrids (OxG), in tropical America. Pesquisa Agropecuária Tropical Goiânia 3, 46-48 (2016). http://dx.doi.org/10.1590/1983-40632016v4638196.

235. H. Wan, The introduction of barn owl (Tyto alba) to Sabah for rat control in oil palm plantations. Planter 76, 215-222 (2000).

236. J. P. Twining, H. Bernard, R. M. Ewers, Increasing land-use intensity reverses the relative occupancy of two quadrupedal scavengers. PLOS ONE 12, e0177143 (2017). https://doi.org/10.1371/journal.pone.0177143.

237. D. Tilman et al., Future threats to biodiversity and pathways to their prevention. Nature 546, 73 (2017). https://doi.org/10.1038/ nature22900.

238. S. L. Maxwell, R. A. Fuller, T. M. Brooks, J. E. M. Watson, The ravages of guns, nets and bulldozers. Nature 536, 143-145 (2016). https://doi.org/10.1038/536143a.

239. N. Hosonuma et al., An assessment of deforestation and forest degradation drivers in developing countries. Environmental Research Letters 7, 044009 (2012). https://doi.org/10.1088/1748-9326/7/4/044009.

240. B. Zimbres, C. A. Peres, R. B. Machado, Terrestrial mammal responses to habitat structure and quality of remnant riparian forests in an Amazonian cattle-ranching landscape. Biological Conservation 206, 283-292 (2017). https://doi.org/10.1016/j. biocon.2016.11.033.

241. J. J. Gilroy et al., Minimizing the biodiversity impact of Neotropical oil palm development. Global Change Biology 21, 1531-1540 (2015). https://doi.org/10.1111/gcb.12696.

242. D. J. Immerzeel, P. A. Verweij, F. van der Hilst, A. P. C. Faaij, Biodiversity impacts of bioenergy crop production: a state-of-the-art review. Global Change Biology Bioenergy 6, 183-209 (2014). https://doi.org/10.1111/gcbb.12067.

243. A. S. Di Giacomo, J. L. De Casenave, Use and importance of crop and field-margin habitats for birds in a neotropical agricultural ecosystem. The Condor 112, 283-293 (2010). https://doi.org/10.1525/cond.2010.090039.

244. A. P. Goijman, M. J. Conroy, J. N. Bernardos, M. E. Zaccagnini, Multi-Season Regional Analysis of Multi-Species Occupancy: Implications for Bird Conservation in Agricultural Lands in East-Central Argentina. PLOS ONE 10, e0130874 (2015). https://doi. org/10.1371/journal.pone.0130874.

245. H. K. Gibbs et al., Brazil's Soy Moratorium. Science 347, 377 (2015). https://doi.org/10.1126/science.aaa0181.

246. M. N. Macedo et al., Decoupling of deforestation and soy production in the southern Amazon during the late 2000s. Proceedings of the National Academy of Sciences 109, 1341 (2012). https://doi.org/10.1073/pnas.1111374109.

247. E. Barona, N. Ramankutty, G. Hyman, O. T. Coomes, The role of pasture and soybean in deforestation of the Brazilian Amazon. Environmental Research Letters 5, 024002 (2010). https://doi.org/10.1088/1748-9326/5/2/024002.

248. P. F. Donald, Biodiversity Impacts of Some Agricultural Commodity Production Systems. Conservation Biology 18, 17-38 (2004). https://doi.org/10.1111/j.1523-1739.2004.01803.x.

249. B. B. N. Strassburg et al., Moment of truth for the Cerrado hotspot. Nature Ecology \&Amp; Evolution 1, 0099 (03/23/online, 2017). https://doi.org/10.1038/s41559-017-0099.

250. S. Schlesinger, The whole Pantanal, not just the half. Soy, waterway and other threats to the integrity of the Pantanal (Ecosystem Alliance, 2014).

251. FAO, FAO Statistics Division. http://faostat3.fao.org/compare/E (2013).

252. W. E. Prabowo et al., Bird Responses to Lowland Rainforest Conversion in Sumatran Smallholder Landscapes, Indonesia. PLoS ONE 11, e0154876 (2016). https://doi.org/10.1371/journal.pone.0154876.

253. S. Aratrakorn, S. Thunhikorn, P. F. Donald, Changes in bird communities following conversion of lowland forest to oil palm and rubber plantations in southern Thailand. Bird Conservation International 16, 71-82 (2006). https://doi.org/10.1017/ S0959270906000062

254. G. Ortolani, Agroforestry: An increasingly popular solution for a hot, hungry world. Mongabay 26 October 2017, https://news. mongabay.com/2017/2010/agroforestry-an-increasingly-popular-solution-for-a-hot-hungry-world/ (2017).

255. S. A. Bhagwat, K. J. Willis, H. J. B. Birks, R. J. Whittaker, Agroforestry: a refuge for tropical biodiversity? Trends in Ecology \& Evolution 23, 261-267 (May, 2008). https://doi.org/10.1016/j.tree.2008.01.005.

256. C. A. Harvey, J. A. González Villalobos, Agroforestry systems conserve species-rich but modified assemblages of tropical birds and bats. Biodivers Conserv 16, 2257-2292 (July 01, 2007). https://doi.org/10.1007/s10531-007-9194-2.

257. FAO, State of the World's Forests 2016. Forests and agriculture: land-use challenges and opportunities (The Food and Agricultural Organization of the United Nations, Rome, Italy, 2016).

258. T. Aide, A. Hernández-Serna, M. Campos-Cerqueira, O. Acevedo-Charry, J. Deichmann, Species Richness (of Insects) Drives the Use of Acoustic Space in the Tropics. Remote Sensing 9, 1096 (2017). https://doi.org/10.3390/rs9111096.

259. D. J. Murphy, The future of oil palm as a major global crop: opportunities and challenges. Journal of Oil Palm Research 26, 1-24 (2014).

260. European Palm Oil Alliance, Palm Oil Production. http://www.palmoilandfood.eu/en/palm-oil-production (2016).

261. D. J. Murphy, Palm oil: scourge of the earth, or wonder crop? https://theconversation.com/palm-oil-scourge-of-the-earth-or-wondercrop-42165. The Conservation June 30, 2015. 
262. F. Normua, S. Higashi, L. Ambu, M. Mohamed, Notes on oil palm plantation use and seasonal spatial relationships of sun bears in Sabah, Malaysia. Ursus 15, 227-231 (2004/11/01, 2004). https://doi.org/10.2192/1537-6176(2004)015<0227:NOOPPU>2.0.CO;2.

263. R. Guharajan et al., Does the Vulnerable sun bear Helarctos malayanus damage crops and threaten people in oil palm plantations? Oryx, 1-9 (2017). https://doi.org/10.1017/S0030605317001089.

264. G. W. Prescott, D. P. Edwards, W. A. Foster, Retaining biodiversity in intensive farmland: epiphyte removal in oil palm plantations does not affect yield. Ecology and Evolution 5, 1944-1954 (2015). https://doi.org/10.1002/ece3.1462.

265. G. Beth et al., How to Identify Degraded Land for Sustainable Palm Oil in Indonesia (Working paper) (World Resource Institute, Washington, DC, 2012).

266. President Office Republic of Indonesia, Instruksi Presiden Republic Indonesia. Nomor 10 tahun 2011 (Jakarta, Indonesia, 2011).

267. HCV Resource Network, What are High Conservation Values? https://www.hcvnetwork.org/about-hcvf (2017).

268. N. J. Deere et al., High Carbon Stock forests provide co-benefits for tropical biodiversity. Journal of Applied Ecology 55, 997-1008 (2018). https://doi.org/10.1111/1365-2664.13023.

269. G. Rosoman, S. S. Sheun, C. Opal, P. Anderson, R. Trapshah, The HCS Approach Toolkit (HCS Approach Steering Group, Singapore, 2017).

270. IUCN, World Database on Key Biodiversity Areas. https://www.iucn.org/resources/conservation-tools/world-database-on-keybiodiversity-areas. (2016).

271. N. Dudley, E. Brown, M. Leighton, in Applications of Key Biodiversity Areas: End-user consultations, N. Dudley, J. L. Boucher, A. Cuttelod, T. M. Brooks, P. F. Langhammer, Eds. (IUCN, Gland, Switzerland, Cambridge, UK, 2014), pp. 49-51.

272. BBOP, Standard on Biodiversity Offsets. http://bbop.forest-trends.org/guidelines/Standard.pdf (Business and Biodiversity Offsets Programme (BBOP), Forest Trends, Washington D.C., USA, 2012).

273. D. Aiama et al., No Net Loss and Net Positive Impact Approaches for Biodiversity. Exploring the potential application of these approaches in the commercial agriculture and forestry sectors (IUCN, Gland, Switzerland, 2015).

274. RSPO, RSPO Remediation and Compensation Procedure. https://www.rspo.org/certification/remediation-and-compensation. (2017).

275. RSPO, Round Table on Sustainable Palm Oil. https://www.rspo.org/ (2017).

276. High Carbon Stock Approach, Announcement: RSPO and HCSA SG to formalise dialogue on 'No Deforestation' Guidelines for inclusion into RSPO Standards. http://highcarbonstock.org/announcement-rspo-and-hcs-approach-steering-group-to-formalisedialogue-on-no-deforestation-guidelines-for-inclusion-into-rspo-standards/ (2017).

277. ISCC, Providing sustainability solutions for fully traceable and deforestation free supply chains. https://www.iscc-system.org/ (International Sustainability \& Carbon Certification., 2017).

278. European Palm Oil Alliance, Certified sustainable palm oil. https://www.palmoilandfood.eu/en/certified-sustainable-palm-oil. (2018).

279. N. Deanna, J. Milder, Rainforest Alliance Impacts Report: Partnership, Learning and Change. https://issuu.com/rainforest-alliance/ docs/ra_impacts_2018_8061023f78aba4. Accessed 17-03-2018 (2018).

280. Greenpeace, Certifying Destruction. Why consumer companies need to go beyond the RSPO to stop forest destruction (Greenpeace International, Amsterdam, the Netherlands, 2013).

281. S. Donofrio, P. Rothrock, J. Leonard, Tracking Corporate Commitments to Deforestation-free Supply Chains, 2017 (Forest Trends, Washington, DC, 2017).

282. SPOTT, Palm oil: ESG policy transparency assessments. https://www.spott.org/palm-oil/. (2018).

283. Forest Trends, Supply Change: Tracking Corporate Commitments to Deforestation-free Supply Chains, 2017. http://forest-trends. org/releases/p/supply_change_2017 (2017).

284. E. Giuliani, L. Ciravegna, A. Vezzulli, B. Kilian, Decoupling Standards from Practice: The Impact of In-House Certifications on Coffee Farms' Environmental and Social Conduct. World Development 96, 294-314 (2017/08/01/, 2017).

285. Nestle, The Nestlé Supplier Code. https://www.nestle.com/asset-library/documents/library/documents/suppliers/supplier-codeenglish.pdf (2013).

286. A. Mosnier et al., Palm oil and likely futures: Assessing the potential impacts of zero deforestation commitments and a moratorium on large-scale oil palm plantations in Indonesia. (Center for International Forestry Research (CIFOR), Bogor, Indonesia, 2017).

287. SPOTT, Sustainability Policy Transparency Toolkit. https://www.spott.org/ (2017).

288. Chain Reaction Research, Indonesian Palm Oil's Stranded Assets: 10 Million Football Fields of Undevelopable Land (Aidenvironment, Climate Advisers, and Profundo, Washington, DC, 2017).

289. A. A. Villela, D. A. B. Jaccoud, L. P. Rosa, M. V. Freitas, Status and prospects of oil palm in the Brazilian Amazon. Biomass and Bioenergy 67, 270-278 (2014/08/01/, 2014).

290. E. Benami et al., Oil palm land conversion in Pará, Brazil, from 2006-2014: evaluating the 2010 Brazilian Sustainable Palm Oil Production Program. Environmental Research Letters 13, 034037 (2018).

291. ISPO, Indonesian Sustainable Palm Oil (ISPO). www.ispo-org.or.id/ (2017).

292. N. K. Hidayat, A. Offermans, P. Glasbergen, Sustainable palm oil as a public responsibility? On the governance capacity of Indonesian Standard for Sustainable Palm Oil (ISPO). Agriculture and Human Values 35, 223-242 (March 01, 2018). https://doi. org/10.1007/s10460-017-9816-6

293. R. Kusumaningtyas, External Concerns on the RSPO and ISPO Certification Schemes (Profundo Research \& Advice, 2018). 294. MSPO, Malaysian Sustainable Palm Oil Certification Scheme. https://www.mpocc.org.my/mspo-certification-scheme (2017). 
295. H. Sivanandam, MSPO certification mandatory by 2019. Star Online Saturday, 25 Feb 2017 (2017).

296. MSPO, MSPO Certified Areas \& Mills. As of November 2017. https://www.mpocc.org.my/facts-and-figures (2017).

297. A.-C. Disdier, S. Marette, G. Millet, Are consumers concerned about palm oil? Evidence from a lab experiment. Food Policy 43, 180189 (2013). https://doi.org/10.1016/j.foodpol.2013.09.003.

298. P. Schleifer, Y. Sun, Emerging markets and private governance: the political economy of sustainable palm oil in China and India. Review of International Political Economy, 1-25 (2018). https://doi.org/10.1080/09692290.2017.1418759.

299. X. Giam, L. Mani, L. P. Koh, H. T. Tan, Saving tropical forests by knowing what we consume. Conservation Letters 9 , 267-274 (2016). https://doi.org/10.1111/conl.12209.

300. E. K. Hansen et al., The Amsterdam Declaration in Support of a Fully Sustainable Palm Oil Supply Chain by 2020 (Amsterdam, The Netherlands, 2015).

301. L. Bell, "Unclear if France will revisit 'discriminatory' palm oil tax," Mongabay, 2016.

302. H. K. Gibbs et al., Carbon payback times for crop-based biofuel expansion in the tropics: the effects of changing yield and technology Environmental Research Letters 3, (2008). https://doi.org/10.1088/1748-9326/3/3/034001.

303. T. Searchinger et al., Use of US croplands for biofuels increases greenhouse gases through emissions from land-use change. Science 319, 1238-1240 (Feb 29, 2008). https://doi.org/10.1126/science.1151861

304. United States Environmental Protection Agency. (https://www.epa.gov/renewable-fuel-standard-program, 2017).

305. United States Environmental Protection Agency. (https://www.epa.gov/sites/production/files/2015-08/documents/420f11046.pdf, 2012).

306. S. Searle, An unexpected tax bill for imported palm oil biodiesel (The International Council on Clean Transportation, https://www. theicct.org/blogs/staff/unexpected-tax-bill-for-imported-palm-oil-biodiesel, 2016).

307. European Parliament, Council of the European Union. (http://eur-lex.europa.eu/legal-content/EN/TXT/ HTML/?uri=CELEX:32009L0028\&from=EN, 2009).

308. H. Valin et al., The land use change impact of biofuels consumed in the EU: Quantification of area and greenhouse gas impacts (Ecofys, IIASA, E4tech, Utrecht, Netherlands, 2015).

309. European Union External Action, EU's Renewable Energy Directive \& its impact on Palm Oil (Jakarta, Indonesia, 2018).

310. M. Erickson-Davis, "Norway bans government purchasing of palm oil biofuel," Mongabay, 2017.

311. H. N. Jong, "Outrage and conspiracy claims as Indonesia, Malaysia react to EU ban on palm oil in biofuels," Mongabay, 2018.

312. J. Ghazoul, Banning oil palm blocks good practices. PhysOrg October 13, 2017, https://phys.org/news/2017-2010-oil-palmblocks-good.html (2017).

313. N. B. Villoria, A. Golub, D. Byerlee, J. Stevenson, Will Yield Improvements on the Forest Frontier Reduce Greenhouse Gas Emissions? A Global Analysis of Oil Palm. American Journal of Agricultural Economics 95, 1301-1308 (October 1, 2013, 2013). https://doi.org/10.1093/ajae/aat034.

314. E. F. Lambin, P. Meyfroidt, Global land use change, economic globalization, and the looming land scarcity. Proceedings of the National Academy of Sciences USA 108, 3465-3472 (Mar 1, 2011). https://doi.org/10.1073/pnas.1100480108.

315. K. M. Carlson et al., Greenhouse gas emissions intensity of global croplands. Nature Climate Change 7, 63-68 (2017). https://doi. org/10.1038/nclimate3158.

316. A. Gohin, On the direct, indirect and induced impacts of public policies: The European biofuel case. (2017).

317. C. Meyer, D. Miller, Zero Deforestation Zones: The Case for Linking Deforestation-Free Supply Chain Initiatives and Jurisdictional REDD+. Journal of Sustainable Forestry 34, 559-580 (2015/08/18, 2015). https://doi.org/10.1080/10549811.2015.1036886.

318. J. Reed, J. Van Vianen, E. L. Deakin, J. Barlow, T. Sunderland, Integrated landscape approaches to managing social and environmental issues in the tropics: learning from the past to guide the future. Global Change Biology 22, 2540-2554 (2016). https:// doi.org/10.1111/gcb.13284.

319. G. Fishbein, D. Lee, Early Lessons from Jurisdictional REDD+ and Low Emissions Development Programs (The Nature Conservancy, Forest Carbon Partnership and the World Bank, Arlington, VA, 2015).

320. H. Jonas, N. K. Abram, M. Ancrenaz, Addressing the impact of large-scale oil palm plantations on orangutan conservation in Borneo: A spatial, legal and political economy analysis (International Institute for Environment and Development (IIED), London, UK, 2017).

321. Tropical Forest Alliance, Zero deforestation public-private alliance. TFA 2020 Colombia (TFA 2020, 2017).

322. MINAMBIENTE, Acuerdo de voluntades para la deforestación cero en la cadena de aceite de palma en Colombia. http://www. minambiente.gov.co/images/ACUERDO_DEFORESTACION_CEROCADENA_ACEITE_DE_PALMA_COLOMBIA_Version_para_ Suscripcion_28112017.pdf (Ministerio de Ambiente, Gobierno de Colombia. , 2017).

323. A. Fishman, E. Oliveira, L. Gamble, ackling Deforestation Through a Jurisdictional Approach: Lessons From the Field. https://www. tfa2020.org/wp-content/uploads/2017/11/wwf_jurisdictional_approaches_fullpaper_web_1.pdf (World Wildlife Fund (WWF), 2017).

324. WWF, Jurisdictional Approaches to Zero Deforestation Commodities. Discussion Paper. https://d2ouvy59p0dg6k.cloudfront.net/ downloads/wwf_jurisdictional_approaches_to_zdcs_nov_2016.pdf (World Wildlife Fund (WWF) 2016).

325. A. Susanti, Oil Palm Expansion in Riau Province, Indonesia: Serving people, planet and profit? Thesis for Utrecht University, Faculty of Geosciences, Department of Human Geography and Spatial Planning, International Development Studies Group (Eburon Academic Publishers, Delft, The Netherlands, 2016).

326. R. Carmenta, A. Zabala, W. Daeli, J. Phelps, Perceptions across scales of governance and the Indonesian peatland fires. Global 
Environmental Change 46, 50-59 (2017). https://doi.org/10.1016/j.gloenvcha.2017.08.001.

327. S. Sloan, D. P. Edwards, W. F. Laurance, Does Indonesia's REDD+ moratorium on new concessions spare imminently threatened forests? Conservation Letters 5, 222-231 (2012). https://doi.org/10.1111/j.1755-263X.2012.00233.x.

328. J. Ghazoul, Z. Burivalova, J. Garcia-Ulloa, L. A. King, Conceptualizing Forest Degradation. Trends in Ecology \& Evolution 30,622632 (2015/10/01/, 2015). https://doi.org/10.1016/j.tree.2015.08.001.

329. L. Gibson et al., Primary forests are irreplaceable for sustaining tropical biodiversity. Nature, doi:10.1038/nature10425 (2011). https:// doi.org/10.1038/nature10425.

330. D. H. Dent, S. J. Wright, The future of tropical species in secondary forests: A quantitative review. Biological Conservation 142 , 2833-2843 (Dec, 2009). https://doi.org/10.1016/j.biocon.2009.05.035.

331. P. Meyfroidt et al., Multiple pathways of commodity crop expansion in tropical forest landscapes. Environmental Research Letters $\mathbf{9}$, 074012 (2014). https://doi.org/10.1088/1748-9326/9/7/074012.

332. Wilmar, No deforestation, no peat, no exploitation policy. http://www.wilmar-international.com/sustainability/wp-content/ uploads/2012/11/No-Deforestation-No-Peat-No-Exploitation-Policy.pdf Accessed 04.04.2018 (Wilmar International, Kuala Lumpur, Malaysia, 2013).

333. H. Barclay et al., RSPO Manual on Best Management Practices (BMPs) for the Management and Rehabilitation of Riparian Reserves (RSPO, 2016).

334. J. M. Lucey et al., Reframing the evidence base for policy-relevance to increase impact: a case study on forest fragmentation in the oil palm sector. Journal of Applied Ecology 54, 731-736 (2017). https://doi.org/10.1111/1365-2664.12845.

335. RERTA, Riparian Ecosystem Restoration in Tropical Agriculture Programme.. http://oilpalmbiodiversity.com/. (2018).

336. L. L. Osborne, D. A. Kovacic, Riparian vegetated buffer strips in water-quality restoration and stream management. Freshwater Biology 29, 243-258 (1993). https://doi.org/10.1111/j.1365-2427.1993.tb00761.x.

337. E. Tabacchi et al., Impacts of riparian vegetation on hydrological processes. Hydrological Processes 14, 2959-2976 (2000). https:// doi.org/10.1002/1099-1085(200011/12)14:16/17<2959::AID-HYP129>3.0.CO;2-B.

338. J. D. Allan, Landscapes and riverscapes: the influence of land use on stream ecosystems. Annual Review of Ecology Evolution and Systematics 35, 257-284 (2004). https://doi.org/10.1146/annurev.ecolsys.35.120202.110122.

339. M. G. Dosskey et al., The Role of Riparian Vegetation in Protecting and Improving Chemical Water Quality in Streams1. JAWRA Journal of the American Water Resources Association 46, 261-277 (2010). https://doi.org/10.1111/j.1752-1688.2010.00419.x.

340. K. M. Carlson et al., Influence of watershed-climate interactions on stream temperature, sediment yield, and metabolism along a land use intensity gradient in Indonesian Borneo. Journal of Geophysical Research: Biogeosciences, 2013JG002516 (2014). https://doi. org/10.1002/2013JG002516.

341. K. M. Carlson et al., Consistent results in stream hydrology across multiple watersheds: A reply to Chew and Goh. Journal of Geophysical Research: Biogeosciences 120, 812-817 (2015). https://doi.org/10.1002/2014JG002834.

342. T. Heartsill-Scalley, T. M. Aide, Riparian vegetation and stream condition in a tropical agriculture-secondary forest mosaic. Ecological Applications 13, 225-234 (2003). https://doi.org/10.1890/1051-0761(2003)013[0225:RVASCl]2.0.CO;2.

343. G. Ragosta et al., Risk factors for elevated Enterococcus concentrations in a rural tropical island watershed. Journal of Environmental Management 92, 1910-1915 (2011/08/01/, 2011). https://doi.org/10.1016/j.jenvman.2011.02.017.

344. C. M. Lorion, B. P. Kennedy, Riparian forest buffers mitigate the effects of deforestation on fish assemblages in tropical headwater streams. Ecological Applications 19, 468-479 (2009). https://doi.org/10.1890/08-0050.1.

345. X. Giam et al., Mitigating the impact of oil-palm monoculture on freshwater fishes in Southeast Asia. Conservation Biology 29, 13571367 (2015). https://doi.org/10.1111/cobi.12483.

346. S. M. Almeida et al., The effects of oil palm plantations on the functional diversity of Amazonian birds. Journal of Tropical Ecology $\mathbf{3 2}$, 510-525 (2016). https://doi.org/10.1017/S0266467416000377

347. E. de la Peña-Cuéllar, J. Benítez-Malvido, L. D. Avila-Cabadilla, M. Martínez-Ramos, A. Estrada, Structure and diversity of phyllostomid bat assemblages on riparian corridors in a human-dominated tropical landscape. Ecology and Evolution 5, 903-913 (2015). https://doi.org/10.1002/ece3.1375.

348. A. Medina, C. A. Harvey, D. S. Merlo, S. Vílchez, B. Hernández, Bat Diversity and Movement in an Agricultural Landscape in Matiguás, Nicaragua. Biotropica 39, 120-128 (2007). https://doi.org/10.1111/j.1744-7429.2006.00240.x.

349. S. V. Mendoza et al., Consistency in bird use of tree cover across tropical agricultural landscapes. Ecological Applications 24, 158168 (2014).

350. C. L. Gray, O. T. Lewis, A. Y. C. Chung, T. M. Fayle, Riparian reserves within oil palm plantations conserve logged forest leaf litter ant communities and maintain associated scavenging rates. Journal of Applied Ecology 52, 31-40 (2015). https://doi.org/10.1111/13652664.12371.

351. C. A. Harvey et al., Patterns of animal diversity in different forms of tree cover in agricultural landscapes. Ecological Applications $\mathbf{1 6}$, 1986-1999 (2006). https://doi.org/10.1890/1051-0761(2006)016[1986:POADID]2.0.CO;2.

352. C. L. Gray, E. M. Slade, D. J. Mann, O. T. Lewis, Do riparian reserves support dung beetle biodiversity and ecosystem services in oil palm-dominated tropical landscapes? Ecology and Evolution 4, 1049-1060 (2014).

353. C. L. Gray, B. I. Simmons, T. M. Fayle, D. J. Mann, E. M. Slade, Are riparian forest reserves sources of invertebrate biodiversity spillover and associated ecosystem functions in oil palm landscapes? Biological Conservation 194, 176-183 (2//, 2016). https://doi. org/10.1101/204347. 
354. B. Yaap, A. Magrach, G. R. Clements, Large Mammal Use of Linear Remnant Forests in an Industrial Pulpwood Plantation in Sumatra, Indonesia. Tropical Conservation Science 9, 194008291668352 (2016). https://doi.org/10.1177/1940082916683523.

355. A. C. Lees, C. A. Peres, Conservation value of remnant riparian forest corridors of varying quality for Amazonian birds and mammals. Conservation Biology 22, 439-449 (Apr, 2008). https://doi.org/10.1111/j.1523-1739.2007.00870.x.

356. A. F. Keir, R. G. Pearson, R. A. Congdon, Determinants of bird assemblage composition in riparian vegetation on sugarcane farms in the Queensland Wet Tropics. Pacific Conservation Biology 21, 60-73 (2015). https://doi.org/10.1071/PC14904.

357. R. E. J. Gray, E. Slade, O. Lewis, Riparian reserves in oil palm plantations may provide movement corridors for invertebrates. bioRxiv, (2017). https://doi.org/10.1101/204990.

358. Ş. Procheș et al., Landscape Corridors: Possible Dangers? Science 310, 779 (2005). https://doi.org/10.1126/science.310.5749.779

359. A. G. Power, Ecosystem services and agriculture: tradeoffs and synergies. Philosophical Transactions of the Royal Society B: Biological Sciences 365, 2959 (2010). https://doi.org/10.1098/rstb.2010.0143.

360. C. L. Gray, O. T. Lewis, Do riparian forest fragments provide ecosystem services or disservices in surrounding oil palm plantations? Basic and Applied Ecology 15, 693-700 (2014/12/01/, 2014). https://doi.org/10.1016/j.baae.2014.09.009.

361. F. A. Edwards, D. P. Edwards, S. Sloan, K. C. Hamer, Sustainable Management in Crop Monocultures: The Impact of Retaining Forest on Oil Palm Yield. PLoS ONE 9, e91695 (2014). https://doi.org/10.1371/journal.pone.0091695.

362. J. W. Veldman et al., Where Tree Planting and Forest Expansion are Bad for Biodiversity and Ecosystem Services. BioScience 65, 1011-1018 (2015). https://doi.org/10.1093/biosci/biv118.

363. C. A. Harvey, B. Dickson, C. Kormos, Opportunities for achieving biodiversity conservation through REDD. Conservation Letters $\mathbf{3}$, 53-61 (2010). https://doi.org/10.1111/j.1755-263X.2009.00086.X.

364. J. Garcia-Ulloa, Improving Conservation Perspectives of Land-Use Change Policies in the Tropics (Doctoral dissertation) (ETH Zürich, Switzerland, 2016).

365. E. H. Yuwono et al., Guidelines for the Better Management Practices on Avoidance, Mitigation and Management of HumanOrangutan Conflict in and around Oil Palm Plantations. (WWF-Indonesia, Jakarta, Indonesia, 2007), pp. 54.

366. Rainforest Alliance, Sustainable Agriculture Standard for farms and producer groups involved in crop and cattle production. Version 1.2. (Rainforest Alliance, 2017).

367. M. S. Luskin, E. D. Christina, L. C. Kelley, M. D. Potts, Modern Hunting Practices and Wild Meat Trade in the Oil Palm PlantationDominated Landscapes of Sumatra, Indonesia. Hum Ecol, 1-11 (2013/08/08, 2013). https://doi.org/10.1007/s10745-013-9606-8.

368. B. Azhar et al., Contribution of illegal hunting, culling of pest species, road accidents and feral dogs to biodiversity loss in established oil-palm landscapes. Wildlife Research 40, 1-9 (2013/03/19, 2012). https://doi.org/10.1071/WR12036.

369. S. A. Scriven et al., The Impact of RSPO Membership on Avoiding Biodiversity Losses in Oil Palm Landscapes (Socially and Environmentally Sustainable Oil Palm Research (SEnSOR) Programme, 2017).

370. N. E. Heller, E. S. Zavaleta, Biodiversity management in the face of climate change: A review of 22 years of recommendations. Biological Conservation 142, 14-32 (2009/01/01/, 2009). https://doi.org/10.1016/j.biocon.2008.10.006.

371. K. G. Austin et al., An assessment of high carbon stock and high conservation value approaches to sustainable oil palm cultivation in Gabon. Environmental Research Letters 12, 014005 (2017). https://doi.org/10.1088/1748-9326/aa5437.

372. POIG, Palm Oil Innovation Group. http://poig.org/ Accessed 25.03.2018 (2018).

373. Daemeter, Jurisdictional Approaches to Reducing Palm Oil Driven Deforestation in Indonesia: A Scoping Study of Design Considerations and Geographic Priorities (Daemeter, Bogor, Indonesia, 2016).

374. B. Azhar, N. Saadun, M. Prideaux, D. B. Lindenmayer, The global palm oil sector must change to save biodiversity and improve food security in the tropics. Journal of Environmental Management 203, 457-466 (2017/12/01/, 2017). https://doi.org/10.1016/j. jenvman.2017.08.021.

375. F. M. Mohd Noor, A. Gassner, A. Terheggen, P. Dobie, Beyond sustainability criteria and principles in palm oil production: addressing consumer concerns through insetting. Ecology and Society 22, (2017). https://doi.org/10.5751/ES-09172-220205.

376. C. Brandi et al., Sustainability Standards for Palm Oil: Challenges for Smallholder Certification Under the RSPO. The Journal of Environment \& Development 24, 292-314 (2015/09/01, 2015). https://doi.org/10.1177/1070496515593775.

377. E. F. Lambin et al., Effectiveness and synergies of policy instruments for land use governance in tropical regions. Global Environmental Change (Springer, 2014), vol. 28, pp. 129-140.

378. A. Blackman, L. Goff, M. R. Planter, Does Eco-certification Stem Tropical Deforestation? (Resources for the Future, Washington, DC, 2015).

379. J. C. Milder, D. Newsom, E. F. Lambin, X. Rueda, in Certification and Biodiversity - How Voluntary Certification Standards impact biodiversity and human livelihoods. Policy Matters, Issue 21, P. Castka et al., Eds. (CEESP and IUCN, Gland, Switzerland, 2016).

380. RSPO, Impact Report 2017 (RSPO Roundtable on Sustainable Palm Oil, Kuala Lumpur, Malaysia, 2017).

381. SEnSOR Project, Testing the impact of sustainable palm oil certification with world-leading science. http://www.sensorproject.net/ (Socially and Environmentally Sustainable Oil Palm Research, 2018).

382. K. M. Carlson et al., Effect of oil palm sustainability certification on deforestation and fire in Indonesia. Proceedings of the National Academy of Sciences 115, 121-126 (2018). https://doi.org/10.1073/pnas.1704728114.

383. M. E. Cattau, M. E. Marlier, R. DeFries, Effectiveness of Roundtable on Sustainable Palm Oil (RSPO) for reducing fires on oil palm concessions in Indonesia from 2012 to 2015. Environmental Research Letters 11, 105007 (2016). https://doi.org/10.1088/17489326/11/10/105007. 
384. P. Noojipady et al., Managing fire risk during drought: the influence of certification and El Niño on fire-driven forest conversion for oil palm in Southeast Asia. Earth System Dynamics; Gottingen 8, 749-771 (2017). https://doi.org/10.5194/esd-8-749-2017.

385. B. Azhar, N. Saadun, M. Prideaux, D. B. Lindenmayer, The global palm oil sector must change to save biodiversity and improve food security in the tropics. Journal of Environmental Management 203, 457-466 (2017). https://doi.org/10.1016/j.jenvman.2017.08.021.

386. D. Ruysschaert, D. A., Z. R., G. Gea, I. Singleton, Developing palm-oil production on degraded land (Foundation PanEco, YEL, World Agroforestry Centre, Medan, Indonesia, 2011).

387. EIA, Who watches the watchmen? Auditors and the breakdown of oversight in the RSPO (Environmental Investigation Agency (EIA), London, UK, 2015).

388. D. Ruysschaert, D. Salles, The strategies and effectiveness of conservation NGOs in the global voluntary standards: The case of the roundtable on sustainable palm-oil. Conservation and Society 14, 73-85 (2016). https://doi.org/10.1007/978-3-319-60579-1_5.

389. G. D. Paoli, B. Yaap, P. L. Wells, A. Sileuw, CSR, oil palm and the RSPO: Translating boardroom philosophy into conservation action on the ground. Tropical Conservation Science 34, 438-446 (2010). https://doi.org/10.1177/194008291000300408.

390. E. F. Lambin et al., The role of supply-chain initiatives in reducing deforestation. Nat Clim Change, (In Press). https://doi.org/10.1038/ s41558-017-0061-1.

391. P. Pacheco, Zero deforestation in Indonesia: Pledges, politics and palm oil. Forest News $\mathbf{7}$ January 2016, https://forestsnews.cifor. org/39085/zero-deforestation-in-indonesia-pledges-politics-and-palm-oil?fnl=en (2016).

392. L. Dattaro, The long road to 'zero deforestation' ... whatever that means. Forest News 23 September 2015, https://forestsnews. cifor.org/33778/zero-deforestation-special-are-we-getting-any-closer?fnl=en (2015).

393. H. K. Gibbs et al., Did Ranchers and Slaughterhouses Respond to Zero-Deforestation Agreements in the Brazilian Amazon? Conservation Letters 9, 32-42 (2015). https://doi.org/10.1111/conl.12175.

394. C. Tayleur et al., Global Coverage of Agricultural Sustainability Standards, and Their Role in Conserving Biodiversity. Conservation Letters 10, 610-618 (2017). https://doi.org/10.1111/conl.12314.

395. G. C. Schoneveld, P. Pacheco, M.-G. Picketty, I. Drigo, P. Cerutti, Zero deforestation commodities and the dynamics of regime complexity. IASC 2017, July 12, 2017, Utrecht, the Netherlands. https://goo.gl/wAChf1 (2017).

396. J. Busch et al., Reductions in emissions from deforestation from Indonesia's moratorium on new oil palm, timber, and logging concessions. Proceedings of the National Academy of Sciences 112, 1328-1333 (2015). https://doi.org/10.1073/pnas.1412514112.

397. T. Santika, E. Meijaard, K. A. Wilson, Designing multifunctional landscapes for forest conservation. Environmental Research Letters 10, 114012 (2015). https://doi.org/10.1088/1748-9326/10/11/114012.

398. A. Wijaya, 6 Years After Moratorium, Satellite Data Shows Indonesia's Tropical Forests Remain Threatened. http://www.wri.org/ blog/2017/05/6-years-after-moratorium-satellite-data-shows-indonesia\%E2\%80\%99s-tropical-forests-remain (2017).

399. S. Ribka, Only 12\% of Indonesia's oil palm plantations ISPO certified. The Jakarta Post 11 April 2017, (2017).

400. D. P. Edwards et al., Wildlife-friendly oil palm plantations fail to protect biodiversity effectively. Conservation Letters 3, 236-242 (Aug, 2010). https://doi.org/10.1111/j.1755-263X.2010.00107.x.

401. J. M. Lucey et al., Tropical forest fragments contribute to species richness in adjacent oil palm plantations. Biological Conservation 169, 268-276 (2014). https://doi.org/10.1016/j.biocon.2013.11.014.

402. W. F. Laurance et al., Ecosystem decay of Amazonian forest fragments: a 22-year investigation. Conservation Biology 16, 605-618 (2002). https://doi.org/10.1046/j.1523-1739.2002.01025.x.

403. L. Fahrig, Ecological Responses to Habitat Fragmentation Per Se. Annual Review of Ecology, Evolution, and Systematics 48, 1-23 (2017). https://doi.org/10.1146/annurev-ecolsys-110316-022612.

404. A. B. Davies, M. Ancrenaz, F. Oram, G. P. Asner, Canopy structure drives orangutan habitat selection in disturbed Bornean forests. Proceedings of the National Academy of Sciences 114, 8307-8312 (2017). https://doi.org/10.1073/pnas.1706780114.

405. H. Bernard, E. L. Baking, A. J. Giordano, O. R. Wearn, A. H. Ahmad, Terrestrial Mammal Species Richness and Composition in Three Small Forest Patches within an Oil Palm Landscape in Sabah, Malaysian Borneo. Mammal Study 39, 141-154 (2014/09/01, 2014). https://doi.org/10.3106/041.039.0303.

406. M. J. Struebig et al., Parallel declines in species and genetic diversity in tropical forest fragments. Ecology Letters 14, 582-590 (2011). https://doi.org/10.1111/j.1461-0248.2011.01623.x.

407. S. A. Scriven, C. M. Beale, S. Benedick, J. K. Hill, Barriers to dispersal of rain forest butterflies in tropical agricultural landscapes. Biotropica 49, 206-216 (2017). https://doi.org/10.1111/btp.12397.

408. L. J. Evans, G. P. Asner, B. Goossens, Protected area management priorities crucial for the future of Bornean elephants. Biological Conservation, (in press). https://doi.org/10.1016/j.biocon.2018.03.015.

409. J. A. Burney, S. J. Davis, D. B. Lobell, Greenhouse gas mitigation by agriculutral intensification. P Natl Acad Sci USA 107, 1205212057 (2010). https://doi.org/10.1073/pnas.0914216107.

410. R. Singh et al., The oil palm SHELL gene controls oil yield and encodes a homologue of SEEDSTICK. Nature 500, 340-344 (08/15/ print, 2013). https://doi.org/10.1038/nature12356.

411. L. S. Woittiez, M. T. van Wijk, M. Slingerland, M. van Noordwijk, K. E. Giller, Yield gaps in oil palm: A quantitative review of contributing factors. European Journal of Agronomy 83, 57-77 (2017/02/01/, 2017). https://doi.org/10.1016/j.eja.2016.11.002.

412. B. Phalan et al., How can higher-yield farming help to spare nature? Science 351, 450 (2016). https://doi.org/10.1126/science. aad0055.

413. T. Conley, C. Udry, Social learning through networks: The adoption of new agricultural technologies in Ghana. Am J Agr Econ 83, 
668-673 (2001).

414. FAO, FAOSTAT Online Statistical Service (Food and Agriculture Oranization (FAO), 2017).

415. B. McCarthy, Supply Change: Tracking Corporate Commitments to Deforestation-free Supply Chains, 2016 (Forest Trends' Ecosystem Marketplace, Washington, DC, 2016).

416. Chain Reaction Research, Unsustainable Palm Oil Faces Increasing Market Access Risks: NDPE Sourcing Policies Cover 74 Percent of Southeast Asia's Refining Capacity. https://chainreactionresearch.files.wordpress.com/2017/11/unsustainable-palm-oil-facesincreasing-market-access-risks-final-2.pdf (2017).

417. E. F. Lambin, P. Meyfroidt, Global land use change, economic globalization, and the looming land scarcity. Proceedings of the National Academy of Sciences 108, 3465-3472 (March 1, 2011, 2011). https://doi.org/10.1073/pnas.1100480108.

418. Republic of Indonesia. (Jakarta, Indonesia, 2004).

419. Republic of Indonesia, Law of the Republic of Indonesia No. 39 Year 2014 about Plantations (Jakarta, Indonesia, 2014).

420. S. Osman, H. U. Kueh, Land Administration, Land Management and Spatial Information in Sarawak, Malaysia. (Land and Survey Department, Sarawak, Malaysia, Kuching, Malaysia, 2010).

421. UNDP, FoKSBI Technical Inter-Ministerial Taskforce Agrees to Improve Regulations Related to Conservation Value Areas. http://www. undp.org/content/gcp/en/home/presscenter/articles/2016/05/03/inpop-technical-inter-ministerial-taskforce-agrees-to-improveregulations-related-to-conservation-value-areas.html. Accessed 17.04.2018 (2016).

422. HCV Taskforce, Preparation of technical guidelines high conservation value as essential ecosystem. Minutes meeting 15.11.2016. Retrieved from: http://www.foksbi.id/en/archive/view/12-04-2016-hcv-taskforce-november. Accessed 17.04.2018 (2016).

423. RSPO, Resolution 6g. Proposed Resolution to be adopted at the 10th General Assembly of the Roundtable on Sustainable Palm Oil (RSPO). 14th of November 2013. Title: Transparency in plantation concession boundaries. http://www.rspo.org/file/resolutions/ GA10-Resolution6g.pdf (2013).

424. Ceres, Sustainability is the bottom line. https://www.ceres.org/ (2017).

425. CDP, CDP Disclosure Insight Action. https://www.cdp.net/en (2017).

426. A. Framework, The Accountability Framework. Delivering on ethical supply chain commitments. https://accountability-framework. org/ (2017).

427. SMART, Spatial Monitoring and Reporting Tool. Measure, Evaluate and Improve the Effectiveness of your Wildlife Law Enforcement Patrols and Site-Based Conservation Activities. http://smartconservationtools.org/ (2018).

428. I. Schlegel, Palm Oil Scorecard: Are Brands Doing Enough for Indonesia's Rainforests? https://goo.gl/MXPHYy (2016).

429. WWF, Palm Oil Buyers Scorecard 2016. http://palmoilscorecard.panda.org/. (2016).

430. R. H. V. Corley, How much palm oil do we need? Environmental Science \& Policy 12, 134-139 (Apr, 2009).

431. J. P. W. Scharlemann, W. F. Laurance, How Green Are Biofuels? Animal Science Blogs 28 February 2008, (2008).

432. R. Zah et al., Ökobilanz Von Energieprodukten: Ökologische Bewertung Von Biotreibstoffen (EMPA, Abteilung Technologie und Gesellschaft, St. Gallen, Switzerland, 2007).

433. J.-M. Roda, in Huiles végétales: Enjeux, marchés et controverses, A. Rival, Ed. (Le Club Démeter, Paris 2018), pp. 109-122. 434. J. P. W. Scharlemann, W. F. Laurance, How Green Are Biofuels? Science 319, 43 (2008). https://doi.org/10.1126/science.1153103.

435. L. Reijnders, M. A. J. Huijbregts, Palm oil and the emission of carbon-based greenhouse gases. Journal of Cleaner Production 16, 477-482 (2006). https://doi.org/10.1016/j.jclepro.2006.07.054.

436. H. Valin et al., The land use change impact of biofuels consumed in the EU. Quantification of area and greenhouse gas impacts (ECOFYS Netherlands B.V., Utrecht, the Netherlands, 2015).

437. T. Thamsiriroj, J. D. Murphy, Is it better to import palm oil from Thailand to produce biodiesel in Ireland than to produce biodiesel from indigenous Irish rape seed? Applied Energy 86, 595-604 (2009/05/01/, 2009). https://doi.org/10.1016/j.apenergy.2008.07.010.

438. Palm Plantations of Australia, Oil palm Trees. Oil Palm Comparison. http://www.palmplantations.com.au/oil-palm-trees.htm (2017).

439. R. H. V. Corley, in International Conference on Oil and Kernel Production in Oil Palm-A Global Perspective. Kuala Lumpur: Palm Oil Research Institute of Malaysia N. Rajanaidu, I. E. Henson, B. S. Jalani, Eds. (1998), pp. 256-269.

440. D. Byerlee, J. Stevenson, N. Villoria, Does intensification slow crop land expansion or encourage deforestation? Global Food Security 3, 92-98 (2014). https://doi.org/10.1016/j.gfs.2014.04.001.

441. E. A. Law et al., Better land-use allocation outperforms land sparing and land sharing approaches to conservation in Central Kalimantan, Indonesia. Biological Conservation 186, 276-286 (2015). https://doi.org/10.1016/j.biocon.2015.03.004.

442. E. Dinerstein et al., Guiding Agricultural Expansion to Spare Tropical Forests. Conservation Letters 8, 262-271 (2015). https://doi. org/10.1111/conl.12149.

443. G. Fischer et al., Global Agro-ecological Zones (GAEZ v3.0)- Model Documentation (IIASA and FAO, Laxenburg, Austria and Rome, Italy., 2012).

444. Birdlife International, Key Biodiversity Areas (KBAs). https://www.birdlife.org/key-biodiversity-areas (2017).

445. Critical Ecosystem Partnership Fund (CEPF), Biodiversity Hotspots. http://www.cepf.net/resources/hotspots/Pages/default.aspx (2017).

446. IUCN, 2017 IUCN Red List of Threatened Species. www.iucnredlist.org WWW document (2017).

447. R. A. Mittermeier et al., Hotspots Revisited. Earth's Biologically Richest and Most Endangered Terrestrial Ecoregions. (The University of Chicago Press, Chicago, USA, 2004), pp. 329.

448. Serge A. Wich et al., Will Oil Palm's Homecoming Spell Doom for Africa's Great Apes? Current Biology 24, 1659-1663 (2014). 
https://doi.org/10.1016/j.cub.2014.05.077.

449. C. Stickler, M. Coe, D. Nepstad, G. Fiske, P. Lefebvre, Ready for REDD? A preliminary assessment of global forested land suitability for agriculture. http://whrc.org/BaliReports/assets/Bali_crop_suitability.pdf). (Woods Hole Research Center, Massachusetts, 2008).

450. H. van Velthuizen et al., Mapping biophysical factors that influence agricultural production and rural vulnerability (FAO and IIASA, Rome, Italy, 2007).

451. J. Pirker, A. Mosnier, Global oil palm suitability assessment. Interim Report 006 (International Institute for Applied Systems Analysis, Laxenburg, Austria, 2015).

452. J. Pirker, A. Mosnier, F. Kraxner, P. Havlík, M. Obersteiner, What are the limits to oil palm expansion? Global Environmental Change 40, 73-81 (2016). https://doi.org/10.1016/j.gloenvcha.2016.06.007.

453. W. J. Bond, C. L. Parr, Beyond the forest edge: Ecology, diversity and conservation of the grassy biomes. Biological Conservation 143, 2395-2404 (2010/10/01/, 2010). https://doi.org/10.1016/j.biocon.2009.12.012.

454. C. Castiblanco, A. Etter, T. M. Aide, Oil palm plantations in Colombia: a model of future expansion. Environmental Science \& Policy 27, 172-183 (2013/03/01/, 2013). https://doi.org/10.1016/j.envsci.2013.01.003.

455. J. M. C. Da Silva, Endemic bird species and conservation in the Cerrado Region, South America. Biodiversity \& Conservation 6 , 435-450 (1997/03/01, 1997). https://doi.org/10.1023/A:1018368809116.

456. J. Garcia-Ulloa, S. Sloan, P. Pacheco, J. Ghazoul, L. P. Koh, Lowering environmental costs of oil-palm expansion in Colombia. Conservation Letters 5, 366-375 (2012).

457. N. Ocampo-Peñuela, J. Garcia-Ulloa, J. Ghazoul, A. Etter, Quantifying impacts of oil palm expansion on Colombia's threatened biodiversity. Biological Conservation, (in review).

458. A. Etter, C. McAlpine, H. Possingham, Historical Patterns and Drivers of Landscape Change in Colombia Since 1500: A Regionalized Spatial Approach. Annals of the Association of American Geographers 98, 2-23 (2008).

459. CONPES, Areas de referencia como insumo para la identificacion de las zonas de interes de desarrollo rural, economico y social (ZIDRES) (Consejo Nacional de Politica Economica y Social. Departamento Nacional de Planeacion, Ministerio de Agricultura y Desarrollo Rural, Bogota D.C., 2018).

460. L. E. P. Vargas, W. Laurance, F. , G. R. Clements, W. Edwards, The Impacts of Oil Palm Agriculture on Colombia's Biodiversity: What We Know and Still Need to Know. Tropical Conservation Science 8, 828-845 (2015/09/01, 2015). https://doi. org/10.1177/194008291500800317

461. G. Walters, I. Parmentier, T. Stévart, Diversity and conservation value of Gabon's savanna and inselberg open vegetation: an initial gap analysis. Plant Ecology and Evolution 145, 46-54 (2012). https://doi.org/10.5091/plecevo.2012.606.

462. K. D. Kanniah, J. Beringer, in International Encyclopedia of Geography, D. Richardson et al., Eds. (Wiley and The American Association of Geographers 2017).

463. K. Jeffery et al., Fire management in a changing landscape: a case study from Lopé National Park, Gabon. PARKS 20, 35-48 (2014). http://hdl.handle.net/1893/21032.

464. R. L. Chazdon, F. G. Coe, Ethnobotany of Woody Species in Second-Growth, Old-Growth, and Selectively Logged Forests of Northeastern Costa Rica. Conservation Biology 13, 1312-1322 (1999). https://doi.org/10.1046/j.1523-1739.1999.98352.x

465. W. F. Laurance, J. Sayer, K. G. Cassman, Agricultural expansion and its impacts on tropical nature. Trends in Ecology \& Evolution 29 , 107-116 (2014). https://doi.org/10.1016/j.tree.2013.12.001.

466. L. Feintrenie, L. Gazull, R. Goulaouic, L. Miaro III, Spatialized production models for sustainable palm oil in Central Africa: Choices and potentials. Presented at Scaling Up Responsible Land Governance. Annual World Bank Conference on Land and Poverty, Washington DC, March 14-18, 2016 (2016).

467. L. Gazull, R. Goulaouic, L. Feintrenie, Cartographie du potentiel de production durable de palmier à huile certifiable RSPO dans le bassin du Congo. Rapport final (CIRAD and WWF, 2015).

468. L. S. Woittiez, M. T. van Wijk, M. Slingerland, M. van Noordwijk, K. E. Giller, Yield gaps in oil palm: A quantitative review of contributing factors. European Journal of Agronomy 83, 57-77 (2017/02/01/, 2017). https://doi.org/10.1016/j.eja.2016.11.002.

469. The Economist, A green evolution. The Economist Mar 12th 2016, https://goo.gl/DfuKyV (2016).

470. P. E. Peters, Conflicts over land and threats to customary tenure in Africa. African Affairs 112, 543-562 (2013). https://doi. org/10.1093/afraf/adt047.

471. K. Deininger, D. Byerlee, The Rise of Large Farms in Land Abundant Countries: Do They Have a Future? World Development 40, 701-714 (2012/04/01/, 2012). https://doi.org/10.1016/j.worlddev.2011.04.030.

472. E. Cheyns, La consommation urbaine de l'huile de palme rouge en Côte d'Ivoire : quels marchés ? Oilseeds and fats Crops and Lipids 8, 641-645 (2001). https://doi.org/10.1051/ocl.2001.0641.

473. E. Cheyns, N. Bricas, A. Aka, Des circuits courts et des réseaux sociaux : la proximité pour qualifier un produit territorial, l'huile de palme rouge en Côte d'Ivoire. Les systèmes agroalimentaires localisés : produits, entreprises et dynamiques locales. 16 - 18 octobre 2002. Montpellier (CIRAD-TERA Colloque International sur les Systèmes Agroalimentaires Localisés (SYAL), Montpellier, France, 2003).

474. E. Cheyns, C. Lamine, N. Bricas, in Coordination et qualité dans les filières agricoles des pays du sud. Evaluer les forces et les faiblesses de différents modes de coordination pour le développement de démarches qualité dans les filières agricoles du Sud, J. Egg, P. Moustier, F. Tallec, Eds. (INRA, Paris 2006), pp. 69-89.

475. R. Evans, G. Griffiths, Palm oil land rights and ecosystem services in Gbarpolu County, Liberia. Walker Institute for Climate System 
Research. Research Note 3. June 2013 (University of Reading, 2013).

476. N. Ford, Gabon: The battle over palm oil. African Business, http://africanbusinessmagazine.com/region/west-africa/gabon-battlepalm-oil/ (2017).

477. FEDEPAL, personal communication.

478. G. A. Torres et al., Bud Rot Caused by Phytophthora palmivora: A Destructive Emerging Disease of Oil Palm. Phytopathology 106, 320-329 (2016/04/01, 2015). https://doi.org/10.1094/PHYTO-09-15-0243-RVW.

479. M. Mosquera et al., Costos de producción para el fruto de palma de aceite y el aceite de palma en 2015: estimación en un grupo de productores colombianos. Palmas 38, 11-27 (2017).

480. M. Ospina Bozzi, J. D. Ochoa, La Palma Africana En Colombia: Apuntes y Memorias Vol. 1. (Federacion Nacional de Cultivadores de Palma de Aceite (Fedepalma), Bogota, Colombia, 1998).

481. B. Rau, L. A. Gomez, Colombia. Biofuels Annual (Global Agricultural Information Network. USDA Foreign Agricultural Service, 2017).

482. United States Department of Agriculture, Colombia Palm Oil Production by Year. https://www.indexmundi.com/agriculture/?country= co\&commodity=palm-oil\&graph=production (2017).

483. K. Redford, Honduran Farmers to the World Bank Group: "See You in Court". Huffingtonpost, https://goo.gl/Bi3KAW, accessed 29.09.2017. (2017).

484. J. Grajales, State Involvement, Land Grabbing and Counter-Insurgency in Colombia. Development and Change 44, 211-232 (2013). https://doi.org/10.1111/dech.12019.

485. De Telegraaf, Kolonië. Palmoliecultuur Nederl. Indië. https://goo.gl/f9S8GU. De Telegraaf - Avondblad 5 November 1935, 11 (1935)

486. N. K. Abram, Trade-offs between ecosystem protection and oil palm development (Royal Institution of Chartered Surveyors, London, UK, 2016).

487. N. K. Abram et al., Synergies for Improving Oil Palm Production and Forest Conservation in Floodplain Landscapes. PLOS ONE 9, e95388 (2014). https://doi.org/10.1371/journal.pone.0095388.

488. O. Hospes, C. Kroeze, P. Oosterveer, G. Schouten, M. Slingerland, New generation of knowledge: Towards an inter- and transdisciplinary framework for sustainable pathways of palm oil production. NJAS - Wageningen Journal of Life Sciences 80, 75-84 (2017/03/01/, 2017). https://doi.org/10.1016/j.njas.2017.01.001.

489. J. A. Wells et al., Rising floodwaters: mapping impacts and perceptions of flooding in Borneo. Environmental Research Letters 11 , 064016 (2016). https://doi.org/10.1088/1748-9326/11/6/064016.

490. E. Meijaard et al., People's perceptions on the importance of forests on Borneo. PLoS ONE 8, e73008 (2013). https://doi. org/10.1371/journal.pone.0073008.

491. D. Ruysschaert, D. Salles, in The Anthropology of Conservation NGOs: Rethinking the Boundaries, P. B. Larsen, D. Brockington, Eds. (Springer International Publishing, Cham, 2018), pp. 121-149.

492. H. N. de Jong, Debates heat up as Indonesian palm oil moratorium is about to be signed. Mongabay 13 March 2018, (2017).

493. K. G. Austin et al., Shifting patterns of oil palm driven deforestation in Indonesia and implications for zero-deforestation commitments. Land Use Policy 69, 41-48 (2017/12/01/, 2017). https://doi.org/10.1016/j.landusepol.2017.08.036.

494. P. Gunarso, M. E. Hartoyo, F. Agus, T. J. Killeen, Oil Palm and Land Use Change In Indonesia, Malaysia and Papua New Guinea. Reports from the Technical Panels of the 2nd Greenhouse Gas Working Group of the Roundtable on Sustainable Palm Oil (RSPO) (2013).

495. V. Vijay, S. L. Pimm, C. N. Jenkins, S. J. Smith, The Impacts of Oil Palm on Recent Deforestation and Biodiversity Loss. PLoS ONE 11, e0159668 (2016). https://doi.org/10.1371/journal.pone.0159668.

496. P. Potapov et al., The last frontiers of wilderness: Tracking loss of intact forest landscapes from 2000 to 2013. Science advances $\mathbf{3}$, e1600821 (2017). https://doi.org/10.1126/sciadv.1600821

497. K. M. Carlson et al., Committed carbon emissions, deforestation, and community land conversion from oil palm plantation expansion in West Kalimantan, Indonesia. Proceedings of the National Academy of Sciences 109, 7559-7564 (May 8, 2012, 2012). https://doi. org/10.1073/pnas.1200452109

498. V. H. Gutierrez-Velez et al., High-yield oil palm expansion spares land at the expense of forests in the Peruvian Amazon. Environmental Research Letters 6, (Oct-Dec, 2011). https://doi.org/10.1088/1748-9326/6/4/044029.

499. A. Hooijer et al., Subsidence and carbon loss in drained tropical peatlands. Biogeosciences 9, 1053-1071 (2012). https://doi. org/10.5194/bg-9-1053-2012.

500. T. S. Hansen, Spatio-temporal aspects of land use and land cover changes in the Niah catchment, Sarawak, Malaysia. Singapore Journal of Tropical Geography 26, 170-190 (Jul, 2005). https://doi.org/10.1111/j.0129-7619.2005.00212.x.

501. I. Sujaul, B. Ismail, B. G. Muhammad, E. T. Mohd, A. Sahibin, Assessment of land use and land cover changes in the Tasik Chini Catchment area, Pahang, Malaysia using the GIS. Advances in Environmental Biology 4, 404-414 (2010).

502. J. Miettinen et al., Extent of industrial plantations on Southeast Asian peatlands in 2010 with analysis of historical expansion and future projections. GCB Bioenergy 4, 908-918 (2012). https://doi.org/10.1111/j.1757-1707.2012.01172.x.

503. K. M. Carlson et al., Carbon emissions from forest conversion by Kalimantan oil palm plantations. Nature Clim. Change 3, 283-287 (2013). https://doi.org/10.1038/nclimate1702.

504. V. H. Gutiérrez-Vélez, R. DeFries, Annual multi-resolution detection of land cover conversion to oil palm in the Peruvian Amazon. Remote Sensing of Environment 129, 154-167 (2013). https://doi.org/10.1016/j.rse.2012.10.033.

505. S. D. Tarigan, Sunarti, S. Widyaliza, Expansion of Oil Palm Plantations and Forest Cover Changes in Bungo and Merangin Districts, 
Jambi Province, Indonesia. Procedia Environmental Sciences 24, 199-205 (2015/01/01/, 2015). https://doi.org/10.1016/j. proenv.2015.03.026.

506. A. Wijaya et al., Assessment of Large Scale Land Cover Change Classifications and Drivers of Deforestation in Indonesia. Proceeding of the 36th International Symposium on Remote Sensing of Environment, 11-15 May 2015, Berlin, Germany (2015), pp. 557-562.

507. J. Miettinen, C. Shi, S. C. Liew, Land cover distribution in the peatlands of Peninsular Malaysia, Sumatra and Borneo in 2015 with changes since 1990. Global Ecology and Conservation 6, $67-78$ (2016/04/01/, 2016). https://doi.org/10.1016/j.gecco.2016.02.004.

508. D. R. Richards, D. A. Friess, Rates and drivers of mangrove deforestation in Southeast Asia, 2000-2012. Proceedings of the National Academy of Sciences, (December 28, 2015, 2015). https://doi.org/10.1073/pnas.1510272113.

509. K. Saswattecha, L. Hein, C. Kroeze, W. Jawjit, Effects of oil palm expansion through direct and indirect land use change in Tapi river basin, Thailand. International Journal of Biodiversity Science, Ecosystem Services \& Management 12, 291-313 (2016/10/01, 2016). https://doi.org/10.1080/21513732.2016.1193560.

510. S. Boeadi, R. Shine, M. A. Sugardjito, M. H. Sinaga, Biology of the commercially harvested rat snake (Ptyas mucosus) and cobra (Naja sputatrix) in Central Java. Mertensiella 9, 99-104 (1998).

511. V. Veach, E. Di Minin, F. M. Pouzols, A. Moilanen, Species richness as criterion for global conservation area placement leads to large losses in coverage of biodiversity. Diversity and Distributions 23, 715-726 (2017). https://doi.org/10.1111/ddi.12571. 


\section{Appendix 1. The IUCN Oil Palm Task Force}

The IUCN Oil Palm Task Force (OPTF) was established in 2016, following the IUCN resolution WCC-2016-Res-061-EN: 'Mitigating the impacts of oil palm expansion and operations on biodiversity' adopted at the IUCN World Conservation Congress in Hawai'i, in September 2016.

Table 5. List of IUCN Oil Palm Task Force members as of January 2018.

\begin{tabular}{ll}
\hline Name & Role in Task Force \\
\hline Abhilash, P.C. & Commission Member \\
Alban, Maria & Commission Member \\
Ancrenaz, Marc & Commission Member \\
Brooks, Thomas & Commission Member \\
Carbone, Giulia & Commission Member \\
Carlson, Kimberly & Commission Member \\
Clements, Thomas & Commission Member \\
Colchester, Marcus & Commission Member \\
Delabre, Izabela & Commission Member \\
Garcia Ulloa, John Alejandro & Commission Member \\
Gaveau, David & Commission Member \\
Hartman, Paul & Commission Member \\
Hoffmann, Rachel & Commission Member \\
Koh, Lian Pin & Commission Member \\
Macfarlane, Nicholas & Commission Member \\
Meijaard, Erik & Chair \\
Ng, Ginny & Commission Member \\
Opal, Charlotte & Commission Member \\
Over, Sarah & Support Staff \\
Sheil, Douglas & Commission Member \\
Stewart, Christopher & Commission Member \\
van den Hombergh, Heleen & Commission Member \\
Webber, Darrel & Commission Member \\
Wich, Serge & Commission Member \\
\hline & \\
\hline
\end{tabular}

In December 2017, the task force was composed of 24 members (Table 5). Erik Meijaard, a conservation scientist and practitioner with 25 years of experience working in the South-East Asian tropics, is the Task Force chair. Members of the OPTF have been selected to ensure that a balance of perspectives adequately informs the palm oil debate and facilitates interdisciplinary engagement. As the membership grows, there will be representation from other IUCN commissions, industries, NGOs and other actors from important oil palm regions (e.g., Latin America, Pacific, Africa, SE Asia), as well as experts and practitioners from biological as well as social sciences, economics, humanities and other fields.

Further information can be found here: https://www.iucn-optf.org/ 


\section{Appendix 2. Global mapping industrial-scale oil palm plantations}

\section{METHODS}

We developed a map showing the global extent of industrial oil palm plantations following a threesteps procedure. First, we identified the top 29 palm oil producer countries based on FAO statistics of harvested area. Second, we carried out a literature review of published studies that have mapped industrial oil palm plantations, and compiled this information into a Geographic Information System. Third, we complemented this analysis for 13 countries, where no maps were available. For these thirteen countries, we delineated the boundaries of industrial oil palm using cloud-free LANDSAT mosaics acquired in 2017, created in Google Earth Engine.
We declared an area planted (the land is either already planted or under development), the moment we observed large rectangular elements, long linear boundaries, and distinctive grid- or contour-planting patterns appear on our images. These planting patterns characterize industrial plantations. They are easily detected by the human eye, but are difficult to capture with computer codes. Therefore, we delineated the boundaries of the planted areas (or under development) using a visual, expert-based interpretation method. We also employed maps of oil-palm concessions that have entered the public sphere to distinguish young oil-palm from other types of industrial plantations.

Table 6. Estimated planted industrial-scale oil palm (in hectares) for 24 countries according to the FAO and according satellite analysis. FAO. Harvested area of year 2014. Based on FAOSTATS (2).

\begin{tabular}{|c|c|c|c|c|c|c|c|}
\hline \multirow{2}{*}{$\begin{array}{l}\text { Country } \\
\text { Indonesia }\end{array}$} & \multirow{2}{*}{$\begin{array}{l}\text { Harvested } \\
\text { area (FAO) }\end{array}$} & \multicolumn{2}{|c|}{ Planted area (satellite analysis) } & \multirow{2}{*}{$\begin{array}{c}\text { Year } \\
2016\end{array}$} & \multirow{2}{*}{$\begin{array}{l}\text { Satellite } \\
\text { LANDSAT }\end{array}$} & \multirow{2}{*}{$\begin{array}{l}\text { Peer- } \\
\text { reviewed } \\
\text { Yes }\end{array}$} & \multirow{2}{*}{$\begin{array}{l}\text { Source } \\
(92)\end{array}$} \\
\hline & & $11,129,434$ & Kalimantan: 5,056,865 & & & & \\
\hline & & & Sumatra: 5,859,904 & 2015 & LANDSAT & Yes & $(493)$ \\
\hline & & & Papua: 212,665 & 2015 & LANDSAT & Yes & $(493)$ \\
\hline \multirow[t]{3}{*}{ Malaysia } & $4,689,321$ & $6,033,868$ & Sabah:1,629,305 & 2016 & LANDSAT & Yes & $(92)$ \\
\hline & & & Sarawak:1,679,766 & 2016 & LANDSAT & Yes & (92) \\
\hline & & & Pen. Malaysia: 2,724,792 & 2010 & LANDSAT & No & $(494)$ \\
\hline \multirow[t]{2}{*}{ Nigeria } & $3,031,661$ & 123,898 & 69,188 & 2013 & GE (World View) & Yes & $(495)$ \\
\hline & & & 54,710 & 2017 & LANDSAT & No & Personal analysis \\
\hline \multirow[t]{2}{*}{ Thailand } & 684,198 & 65,918 & 21,624 & 2013 & GE (World View) & Yes & $(495)$ \\
\hline & & & 44,294 & 2017 & LANDSAT & No & Personal analysis \\
\hline \multirow[t]{2}{*}{ Ghana } & 349,040 & 38,105 & 16,060 & 2013 & GE (World View) & Yes & $(495)$ \\
\hline & & & 22,044 & 2017 & LANDSAT & No & Personal analysis \\
\hline \multirow[t]{2}{*}{ CA te d'Ivoire } & 273,709 & 98,036 & 21,175 & 2013 & GE (World View) & Yes & $(495)$ \\
\hline & & & 76,861 & 2017 & LANDSAT & No & Personal analysis \\
\hline \multirow[t]{2}{*}{ Ecuador } & 272,011 & 24,503 & 15,808 & 2014 & MODIS & Yes & (24) \\
\hline & & & 8,695 & 2013 & GE (World View) & Yes & $(495)$ \\
\hline
\end{tabular}




\begin{tabular}{|c|c|c|c|c|c|c|c|}
\hline \multirow{2}{*}{$\begin{array}{l}\text { Country } \\
\text { Colombia }\end{array}$} & \multirow{3}{*}{$\begin{array}{l}\text { Harvested } \\
\text { area (FAO) }\end{array}$} & \multicolumn{2}{|c|}{$\begin{array}{l}\text { Planted area (satellite } \\
\text { analysis) }\end{array}$} & \multirow{2}{*}{$\begin{array}{l}\text { Year } \\
2014\end{array}$} & \multirow{2}{*}{$\begin{array}{l}\text { Satellite } \\
\text { MODIS }\end{array}$} & \multirow{2}{*}{$\begin{array}{l}\begin{array}{l}\text { Peer- } \\
\text { reviewed }\end{array} \\
\text { Yes }\end{array}$} & Source \\
\hline & & 290,600 & 234,783 & & & & (24) \\
\hline & & & 55,817 & 2013 & GE (World View) & Yes & $(495)$ \\
\hline Democratic & 176,003 & 20,816 & 20,816 & 2013 & GE (World View) & Yes & $(495)$ \\
\hline \multicolumn{8}{|l|}{$\begin{array}{l}\text { Republic of } \\
\text { the Congo }\end{array}$} \\
\hline Papua New & 155,641 & 141,298 & 135,182 & 2014 & MODIS & No & $(494)$ \\
\hline Guinea & & & 6,116 & 2013 & GE (World View) & Yes & $(495)$ \\
\hline Cameroon & 138,000 & 86,933 & 86,933 & 2016 & LANDSAT & No & Personal digitizing \\
\hline \multirow[t]{2}{*}{ Honduras } & 130,000 & 64,084 & 49,247 & 2014 & & Yes & $(24)$ \\
\hline & & & 14,837 & 2013 & GE (World View) & Yes & $(495)$ \\
\hline \multirow[t]{2}{*}{ Brazil } & 126,559 & 114,188 & 69,721 & 2014 & & Yes & $(24)$ \\
\hline & & & 44,467 & 2013 & GE (World View) & Yes & $(495)$ \\
\hline \multirow[t]{2}{*}{ Guatemala } & 110,000 & 67,120 & 58,296 & 2014 & & Yes & (24) \\
\hline & & & 8,824 & 2013 & GE (World View) & Yes & $(495)$ \\
\hline \multirow[t]{2}{*}{ Costa Rica } & 77,750 & 37,653 & 31,866 & 2014 & & Yes & (24) \\
\hline & & & 5,788 & 2013 & GE (World View) & Yes & $(495)$ \\
\hline Philippines & 55,083 & 10,200 & 10,200 & 2013 & GE (World View) & Yes & $(495)$ \\
\hline \multirow[t]{2}{*}{ Mexico } & 50,868 & 15,082 & 12,399 & 2014 & & Yes & (24) \\
\hline & & & 2,683 & 2013 & GE (World View) & Yes & $(495)$ \\
\hline \multirow[t]{2}{*}{ Venezuela } & 40,198 & 27,298 & 22,599 & 2014 & & Yes & (24) \\
\hline & & & 4,699 & 2013 & GE (World View) & Yes & $(495)$ \\
\hline \multirow[t]{3}{*}{ Peru } & 37,567 & 53,795 & 23,249 & 2014 & & Yes & (24) \\
\hline & & & 15,435 & 2013 & GE (World View) & Yes & $(495)$ \\
\hline & & & 15,110 & 2017 & LANDSAT & No & Pernonal digitizing \\
\hline Benin & 35,788 & 24,449 & 24,449 & 2017 & LANDSAT & No & Personal digitizing \\
\hline Liberia & 17,439 & 88,283 & 88,283 & 2017 & LANDSAT & No & Personal digitizing \\
\hline Dominican & 17,154 & 11,220 & 6,051 & 2014 & MODIS & Yes & (24) \\
\hline Republic & & & 5,168 & 2013 & GE (World View) & Yes & $(495)$ \\
\hline $\begin{array}{l}\text { Solomon } \\
\text { Islands }\end{array}$ & 16,116 & 7,058 & 7,058 & 2017 & LANDSAT & No & Personal digitizing \\
\hline
\end{tabular}




\section{Appendix 3. How much global deforestation is really due to palm oil?}

\section{METHODS}

Literature search. We initially used Google Scholar to identify peer reviewed articles focused on deforestation attributed to oil palm across actors, geographic location, and time. Example search terms are presented in Table 7. We read the abstracts of the first fifty titles returned for each search term, and checked abstracts for relevance. Relevant papers were read in full. We identified additional potentially relevant papers from reference lists in these relevant papers.

Criteria for Inclusion. We selected peer-reviewed studies that reported land use or land cover change due to oil palm agriculture, or within governmentallocated oil palm plantation leases. We filtered by method used to quantify oil palm expansion and land cover change, such that only studies that relied on geospatial data (e.g., remote sensing) were included. Studies in languages other than English or that did not include both oil palm and forest cover data were excluded.

Data Collected. For each time-step in each article, we collected data on the total study area, initial and final forest area, area deforested due to oil palm, initial and final oil palm area, start and end year, actor responsible for oil palm expansion (i.e., smallholder versus industrial-scale company), methods (e.g., remote sensing), and geographic location. Where possible, we recorded forest cover quality (e.g., logged, intact) and ecosystem type (e.g., peat swamp forest, mangrove forest). We standardized all area metrics to hectares.

Definition of Forest. We relied on the forest classifications presented in the original studies. "Forest" is considered any intact, primary, logged, or secondary forest of any kind, including mangrove, peat swamp, lower montane, and lowland forest.
We excluded grasslands, savannas, and agroforests from our definition of forest, as this study focuses on natural forests.

Calculations. We calculated the percent of total deforestation in the study attributed to oil palm (i.e., deforestation from oil palm/total deforestation) as well as the percent of total oil palm expansion that cleared forest (i.e., oil palm expansion into forest/total oil palm expansion). For ease in comparison across studies, we annualized these percentages. All means and standard deviations were weighted by the study area.

\section{RESULTS}

Potentially Relevant Studies. We identified a total of 21 peer reviewed articles that met our screening criteria (Table 8). Nineteen of these studies applied remote sensing to detect land cover change from oil palm expansion. Of these, thirteen used Landsat, four used MODIS, and two used both LANDSAT and MODIS data. Two studies used government land use maps for their analysis.

Geographic Focus. While most studies ( $n=15)$ included Southeast Asia, all major oil palm growing regions of the world were included in our analysis (Table 8).

Temporal Distribution. Studies used for analysis measured land cover change and oil palm expansion from 1972 through 2015. The greatest density of data occurred in the 2000-2010 period. Articles included in our analysis were published from 20052017.

Forest-Oil Palm Land Cover Change. Overall, about $46 \pm 18 \%$ of oil palm expanded into forests, and about $23 \pm 22 \%$ of total deforestation in these studies was due to oil palm expansion. These rates differed by 
region (Table 9, Figure 47 and Figure 48). In Malaysia and Peru, a large portion of oil palm expansion cleared forest ( $67 \%$ and $44 \%$, respectively), and oil palm contributed substantially to overall deforestation (47\% and 53\%, respectively). In contrast, oil palm expansion in Mesoamerica and West Africa contributed very little (just 2-3\%) to overall forest loss. In Mesoamerica and South America, just 5-10\% of total oil palm developments were sourced from forests. In Indonesia, the main location of oil palm expansion for the last two decades, about $16 \%$ of all deforestation in studies considered here was due to oil palm expansion, while a mean of $39 \%$ of oil palm expansion was sourced from forests. These metrics do not include expansion into agroforests, which have been identified as a major source of expansion in previous studies. One global study focused on intact forests landscapes, and suggested that oil palm accounted for a negligible amount $(0.2 \%)$ of forest clearing in tropical regions $(496,497)$.

A few temporal trends in deforestation and oil palm expansion are apparent. In Indonesia, while the relative contribution of oil palm to deforestation grew rapidly and substantially from 2000 to 2015 , the proportion of oil palm expanding into forest in Sumatra declined. In Peru, a single study covering most of the country suggests an increasing amount of oil palm expansion, and a trend toward a greater proportion of forest loss due to oil palm (498). In contrast, Malaysia's oil palm expansion dynamics appear to be more stable over time. In terms of actors responsible for deforestation, only two studies (in Peru and Sumatra, Indonesia) clearly differentiated between smallholders and industrial scale oil palm, and both relied on proxies for such measurement $(498,499)$. In both cases, smallholder oil palm expansion largely occurred in non-forest areas, rather than forests.

\section{DISCUSSION}

Calculating the contribution of oil palm expansion to overall deforestation in the tropics is challenging for several reasons. First, most studies tend to collect data on the land cover types converted by oil palm, but not the broader role that oil palm plays in land cover change. For instance, eight studies mapped only land cover converted by oil palm expansion, and three focused only within oil palm concessions. By knowing the amount of forest converted to oil palm, in theory studies focusing on frontiers of oil palm expansion could be scaled to national levels through use of data on oil palm planted area. Unfortunately, our scaling attempts were severely hampered by the mismatch between statistical data on oil palm harvested area provided by the FAO and the area of oil palm mapped in these studies. Thus, we feel it would not be appropriate or accurate to conduct such scaling. Ten studies conducted wall to wall mapping as well as oil palm mapping, and these allowed us to estimate the contribution of oil palm to overall deforestation. Looking forward, there is a need for further research and time series analyses in West Africa, Mesoamerica, and South America. The role that smallholders and small producers play in deforestation, especially in Malaysia and Borneo, is largely unknown. 


\section{TABLES}

Table 7. Search terms used in literature search. Combinations of above terms were queried in Google Scholar [link: scholar.google.com] between 30 August 2017 and 16 September 2017.

\begin{tabular}{l}
\hline Search Term \\
\hline Land use change \\
Oil palm \\
oil palm" land use change Indonesia \\
"oil palm" land use change Malaysia \\
"oil palm" land use change Cameroon \\
"oil palm" land use change Ghana \\
"oil palm" land use change Dem. Republic of Congo \\
"oil palm" land use change Guatemala \\
"oil palm" land use change Peru \\
"oil palm" land use change Brazil \\
"oil palm" deforestation \\
"oil palm" smallholder \\
\hline
\end{tabular}

\section{Search Term}

Tropical deforestation palm oil

Gabon oil palm expansion

Cameroon oil palm expansion

Kalimantan oil palm deforestation

Borneo oil palm deforestation

Oil-palm forest

Peru forest palm oil

Cover change forest oil palm

Oil palm forest loss

Oil palm forest cover loss

Humid tropics forest oil palm

Table 8. Articles used in study.

\begin{tabular}{|c|c|c|c|c|c|c|c|c|}
\hline Author & Period & Region & $\begin{array}{l}\text { Study Area } \\
\text { (ha) }\end{array}$ & Forest Type & $\begin{array}{l}\text { Cover } \\
\text { Quality }\end{array}$ & $\begin{array}{l}\text { Resolu- } \\
\text { tion }\end{array}$ & Method & Actor \\
\hline (139) & $2000-2010$ & SE Asia & $56,659,954$ & $\begin{array}{l}\text { Peat swamp forest, } \\
\text { lowland forest, forest }\end{array}$ & $\begin{array}{l}\text { Intact or } \\
\text { logged }\end{array}$ & $250 \mathrm{~m}$ & Within concessions & Industrial \\
\hline$(500)$ & $1972-2002$ & SE Asia & 130,000 & Forest & Logged & $80 m$ & $\begin{array}{l}\text { Wall to wall with } \\
\text { mapped OP expansion }\end{array}$ & Industrial \\
\hline$(501)$ & 1984-2002 & SE Asia & 5,821 & Forest & Intact & NA & $\begin{array}{l}\text { Wall to wall with } \\
\text { mapped OP expansion }\end{array}$ & NA \\
\hline$(40)$ & $2000-2010$ & S America & $93,624,000$ & Forest & $\begin{array}{l}\text { Intact and } \\
\text { secondary }\end{array}$ & $250 \mathrm{~m}$ & Mapped OP expansion & $\begin{array}{l}\text { Industrial or } \\
\text { smallholders }\end{array}$ \\
\hline$(497)$ & $1989-2011$ & SE Asia & $1,203,800$ & Forest & $\begin{array}{l}\text { Intact, logged, } \\
\text { secondary }\end{array}$ & $30 \mathrm{~m}$ & $\begin{array}{l}\text { Wall to wall with } \\
\text { mapped OP expansion }\end{array}$ & Industrial \\
\hline$(502)$ & $2000-2010$ & SE Asia & $2,143,000$ & Peat swamp forest & Intact & $28.5 \mathrm{~m}$ & Mapped OP expansion & Industrial \\
\hline (503) & $1990-2010$ & SE Asia & 539,346 & $\begin{array}{l}\text { Peat swamp forest, } \\
\text { forest }\end{array}$ & $\begin{array}{l}\text { Intact, logged, } \\
\text { agroforest }\end{array}$ & $30 \mathrm{~m}$ & $\begin{array}{l}\text { Wall to wall with } \\
\text { mapped OP expansion }\end{array}$ & Industrial \\
\hline$(454)$ & $2002-2008$ & S America & $114,000,000$ & Forest & Intact & $30 \mathrm{~m}$ & Mapped OP expansion & NA \\
\hline$(504)$ & $2001-2010$ & S America & 215,700 & Forest & Intact & $\begin{array}{l}30 \mathrm{~m}, \\
250 \mathrm{~m}\end{array}$ & Mapped OP expansion & Industrial \\
\hline$(29)$ & $2000-2010$ & SE Asia & $3,508,938$ & $\begin{array}{l}\text { Peat swamp forest, } \\
\text { lowland forest, lower } \\
\text { montane forest, } \\
\text { mangrove }\end{array}$ & Intact & $250 \mathrm{~m}$ & Within concessions & $\begin{array}{l}\text { Industrial, } \\
\text { smallholders }\end{array}$ \\
\hline
\end{tabular}




\begin{tabular}{|c|c|c|c|c|c|c|c|c|}
\hline Author & Period & Region & $\begin{array}{l}\text { Study Area } \\
\text { (ha) }\end{array}$ & Forest Type & $\begin{array}{l}\text { Cover } \\
\text { Quality }\end{array}$ & $\begin{array}{l}\text { Resolu- } \\
\text { tion }\end{array}$ & Method & Actor \\
\hline$(505)$ & $1988-2013$ & SE Asia & 324,058 & Forest & Intact & $30 \mathrm{~m}$ & Within concessions & NA \\
\hline$(506)$ & $1990-2012$ & SE Asia & $11,300,600$ & Forest & Intact & $\begin{array}{l}30 \mathrm{~m} \\
250 \mathrm{~m}\end{array}$ & $\begin{array}{l}\text { Wall to wall with } \\
\text { mapped OP expansion }\end{array}$ & NA \\
\hline (92) & $1973-2015$ & SE Asia & $7,370,101,100$ & Forest & Logged & $30 \mathrm{~m}$ & $\begin{array}{l}\text { Wall to wall with } \\
\text { mapped OP expansion }\end{array}$ & Industrial \\
\hline$(507)$ & $1990-2015$ & SE Asia & $15,667,300$ & Peat swamp forest & Intact & $30 \mathrm{~m}$ & $\begin{array}{l}\text { Wall to wall with } \\
\text { mapped OP expansion }\end{array}$ & $\begin{array}{l}\text { Industrial, } \\
\text { smallholders }\end{array}$ \\
\hline (89) & $2005-2015$ & W Africa & $70,000,000$ & Forest & NA & $30 \mathrm{~m}$ & $\begin{array}{l}\text { Wall to wall with } \\
\text { mapped OP expansion }\end{array}$ & NA \\
\hline (508) & $2000-2012$ & SE Asia & $4,626,545$ & Mangrove & Intact & 0.9 ha & $\begin{array}{l}\text { Wall to wall with } \\
\text { mapped OP expansion }\end{array}$ & NA \\
\hline (509) & $2000-2009$ & SE Asia & $1,345,000$ & $\begin{array}{l}\text { Peat swamp forest, } \\
\text { forest, mangrove }\end{array}$ & Intact & $30 \mathrm{~m}$ & $\begin{array}{l}\text { Wall to wall with } \\
\text { mapped OP expansion }\end{array}$ & $\begin{array}{l}\text { Industrial, } \\
\text { smallholders }\end{array}$ \\
\hline (495) & $1989-2013$ & $\begin{array}{l}\text { Pan- } \\
\text { Tropics }\end{array}$ & 921,210 & Forest & Intact & $30 \mathrm{~m}$ & Mapped OP expansion & NA \\
\hline (493) & $1995-2015$ & SE Asia & $8,879,000$ & Forest & $\begin{array}{l}\text { Intact, } \\
\text { secondary }\end{array}$ & $250 \mathrm{~m}$ & Mapped OP expansion & Industrial \\
\hline (24) & $2001-2014$ & $\begin{array}{l}\text { Latin } \\
\text { America }\end{array}$ & 538,433 & Forest & Intact & $250 \mathrm{~m}$ & Mapped OP expansion & $\begin{array}{l}\text { Industrial, } \\
\text { smallholders }\end{array}$ \\
\hline (88) & $2000-2013$ & Global & $1,280,000,000$ & $\begin{array}{l}\text { Intact forest } \\
\text { landscape }\end{array}$ & Intact & $30 \mathrm{~m}$ & $\begin{array}{l}\text { Sample-based mapped } \\
\text { OP expansion }\end{array}$ & NA \\
\hline
\end{tabular}

Table 9. Global and regional deforestation from oil palm expansion. Southeast Asia excludes Indonesia and Malaysia, and South America excludes Peru. SD = standard deviation of the mean, weighted by study area.

\begin{tabular}{|c|c|c|c|c|}
\hline \multirow[t]{2}{*}{ Region } & \multicolumn{2}{|c|}{$\begin{array}{c}\text { Deforestation from Oil Palm } \\
\text { Expansion (\%) }\end{array}$} & \multicolumn{2}{|c|}{$\begin{array}{c}\text { Oil Palm Expansion into } \\
\text { Forest (\%) }\end{array}$} \\
\hline & mean & SD & mean & SD \\
\hline Indonesia & 16 & 18 & 38 & 8.8 \\
\hline Malaysia & 47 & 11 & 68 & 17 \\
\hline Peru & - & - & 44 & 36 \\
\hline West Africa & 3.2 & - & 6.1 & 4.6 \\
\hline Southeast Asia (excluding Indonesia and Malaysia) & 11 & 13 & 6.2 & 6.5 \\
\hline
\end{tabular}




\begin{tabular}{|c|c|c|c|c|}
\hline \multirow[t]{2}{*}{ Region } & \multicolumn{2}{|c|}{$\begin{array}{c}\text { Deforestation from Oil Palm } \\
\text { Expansion (\%) }\end{array}$} & \multicolumn{2}{|c|}{$\begin{array}{c}\text { Oil Palm Expansion into } \\
\text { Forest (\%) }\end{array}$} \\
\hline & mean & SD & mean & SD \\
\hline South America (excluding Peru) & - & - & 5.5 & 2.7 \\
\hline Central America & - & - & 5.6 & 8.5 \\
\hline Global & 0.20 & - & - & - \\
\hline
\end{tabular}

\section{FIGURES}

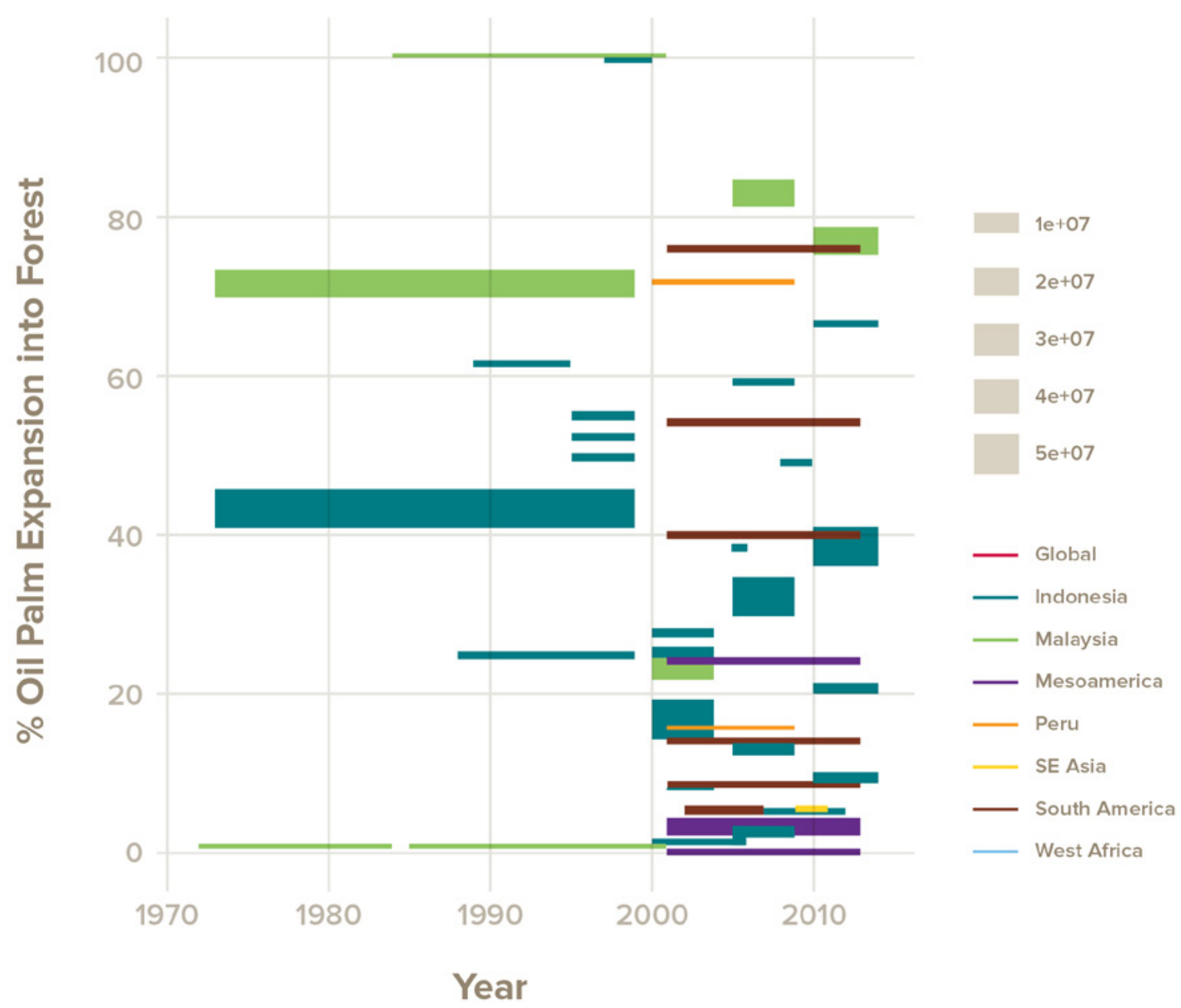

Figure 47. Percent of oil palm expansion into forest from 1972 to 2015 across regions and research investigations. Each bar represents the percentage of total oil palm expansion that was due to deforestation ( $y$ axis) across two points in time ( $x$ axis) derived from an individual study. The height of the bar represents the sampled study area (ha) with taller bars indicating larger study areas. 


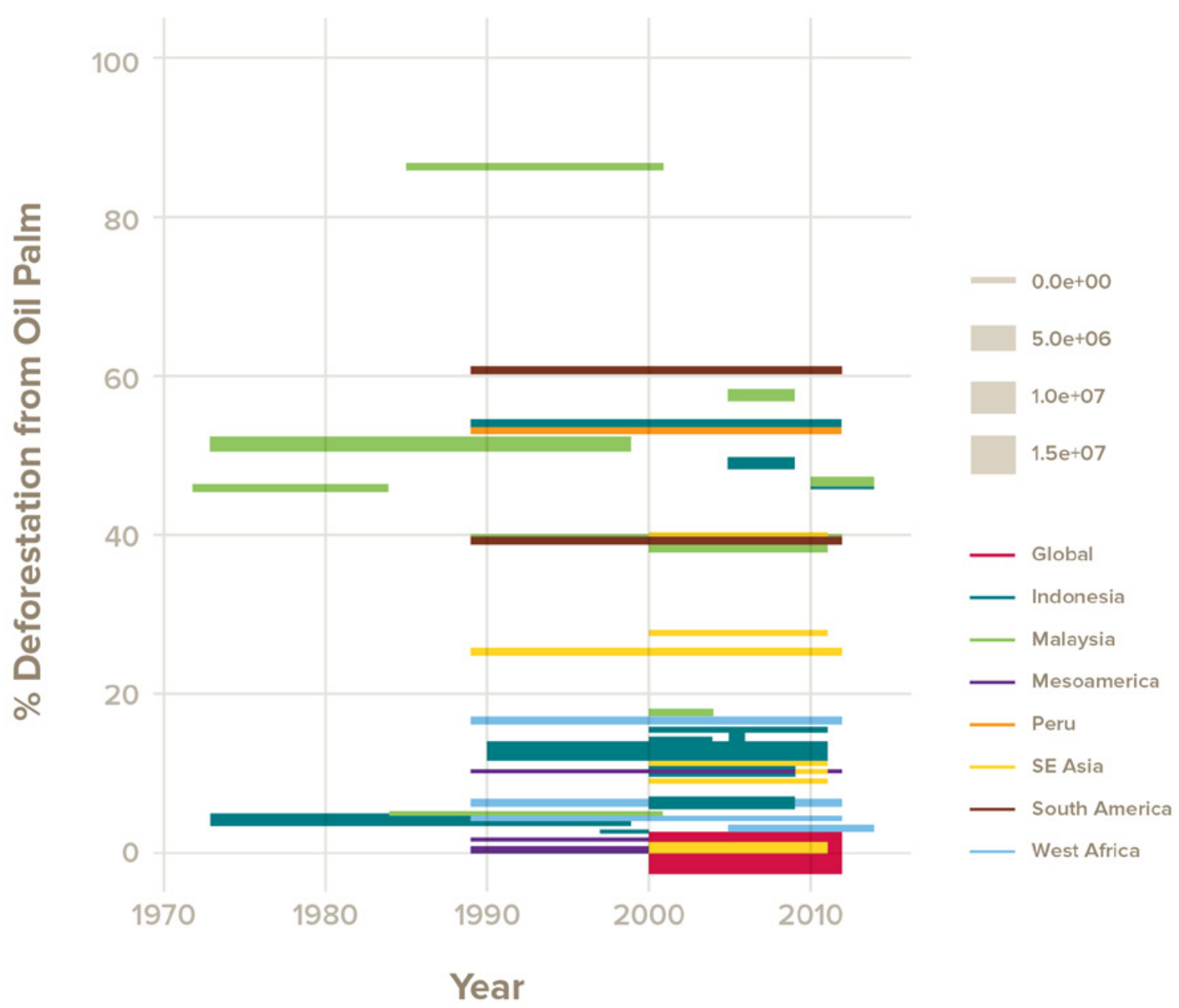

Figure 48. Percent of deforestation from oil palm from 1972 to 2015 across regions and research investigations. Each bar represents the percentage of total deforestation that was due to oil palm expansion ( $y$ axis) across two points in time ( $x$ axis) derived from an individual study. The height of the bar represents the sampled study area (ha) with taller bars indicating larger study areas. 


\section{Appendix 4. Snake species that benefit from oil palm}

Table 10. Southeast Asian snake species that thrive in oil palm plantations, their IUCN Red List status, major prey items, and utilisation for the leather industry.

\begin{tabular}{|c|c|c|c|c|c|}
\hline Species & $\begin{array}{l}\text { IUCN Red } \\
\text { list status }\end{array}$ & $\begin{array}{l}\text { Main prey } \\
\text { item }\end{array}$ & $\begin{array}{l}\text { Harvested } \\
\text { for skins }\end{array}$ & $\begin{array}{l}\text { Evidence for } \\
\text { increased density }\end{array}$ & Source \\
\hline $\begin{array}{l}\text { Radiated Rat Snake } \\
\text { (Coelognathus radiatus) }\end{array}$ & LC & Rodents & Yes & Yes & $\begin{array}{l}\text { IUCN SSC Boa and Python } \\
\text { Specialist Group }\end{array}$ \\
\hline $\begin{array}{l}\text { Monocled Cobra } \\
\text { (Naja kaouthia) }\end{array}$ & LC & $\begin{array}{l}\text { Rodents and } \\
\text { anurans }\end{array}$ & Yes & Yes & $\begin{array}{l}\text { IUCN SSC Boa and Python } \\
\text { Specialist Group }\end{array}$ \\
\hline $\begin{array}{l}\text { Sumatran Cobra } \\
\text { (Naja sumatrana) }\end{array}$ & LC & $\begin{array}{l}\text { Rodents and } \\
\text { anurans }\end{array}$ & Yes & Yes & $\begin{array}{l}\text { https://news.mongabay. } \\
\text { com/2016/10/indonesias- } \\
\text { oil-palm-plantations-are- } \\
\text { rife-with-spitting-cobras/ }\end{array}$ \\
\hline $\begin{array}{l}\text { Reticulated python } \\
\text { (Malayopython reticulatus) }\end{array}$ & NA & Rodents & Yes & Yes & $(149,157)$ \\
\hline $\begin{array}{l}\text { Oriental rats snake } \\
\text { (Ptyas mucosa) }\end{array}$ & NA & Rodents & Yes & Yes & $(510)$ \\
\hline $\begin{array}{l}\text { Sumatran Short-tailed Python } \\
\text { (Python curtus) }\end{array}$ & LC & Rodents & Yes & Yes & (151) \\
\hline $\begin{array}{l}\text { Borneo Short-tailed Python } \\
\text { (Python breitensteini) }\end{array}$ & LC & Rodents & Yes & Yes & $\begin{array}{l}\text { IUCN SSC Boa and Python } \\
\text { Specialist Group }\end{array}$ \\
\hline $\begin{array}{l}\text { Blood Python } \\
\text { (Python brongersmai) }\end{array}$ & LC & Rodents & Yes & Yes & (151) \\
\hline
\end{tabular}




\section{Appendix 5. Current practices to mitigate impacts to biodiversity?}

\section{What is the biodiversity conservation scope of current governance initiatives?}

\section{METHODS}

The analysis of the conservation scope of sustainability initiatives is based on the analysis presented by (364). This analysis uses an adapted version of programme theory evaluation methodology to understand the extent by which initiatives in the oil palm sector address the various threats to biodiversity linked to oil palm cultivation. The analysis focuses on evaluating ex ante the expected effects of these initiatives from a theoretical point of view. Evaluating empirically the outcomes and effectiveness of these initiatives is currently a difficult task, given that most initiatives are incipient or have evolved rapidly during the years.

\section{The Riau puzzle}

\section{METHODS}

Many cleared areas remain unused. While our analysis of time-series medium resolution (LANDSAT: $30 \mathrm{~m} \times 30 \mathrm{~m}$ ) imagery indicates that about 2.17 Mha of forest (or $75 \%$ of 1990 forest area) were cleared between 1990 and 2016 and industrial oil palm and pulpwood plantations comprised $0.71 \mathrm{Mha}$ and 0.40 Mha, respectively ( $0.17 \mathrm{Mha}$ and $0.28 \mathrm{Mha}$ on peat). The main cover (2.2 Mha; 1 Mha on peat) remained as neither forest nor plantation but cleared 'non-forest' land. These deforested and unplanted peatlands (1.48 Mha) are the lands requiring immediate restoration, because they burn repeatedly, for example they comprise 61 percent (0.24 Mha) of areas burned in 2013-2014. During the 2015 fires, when the Indonesian army sent troops to put out fires, that they were overwhelmed and lacked the capacity and manpower to control these vast areas. To determine the area of oil palm illegally planted, we classified our study region into 13 zones, where oil palm is either allowed or not. We did so by combining into one map: 1) national land use plans (SK.878/Menhut-II/2014); 2) legally-registered concessions maps (pulpwood: SK-IUPHK-HTI; oil-palm: HGU and SK-PKH) granted by national government; and 3) maps of remaining forest cover in 2014, water bodies, existing large-scale monoculture plantations (oil palm and pulpwood), and non-forest areas, all four land cover categories easily detected by medium resolution $(30 \mathrm{~m} \times 30 \mathrm{~m})$ Earth observation LANDSAT satellites. To determine the vegetation type in non-forest areas, where a mosaic of scrublands and smaller oil palm plantations are located, finer analysis of higher-resolution imagery is required. We quantified the proportion of unplanted lands present in non-forest areas by analysing a sample of highresolution ( $1 \mathrm{~m}$ ) image blocks ( $n=682$; mean size: 213 ha; total area: 144,960 ha) acquired in 2013 and 2014 (UAV for 2013; Digital Globe satellite imagery for 2014 available in Google Earth). 


\section{Appendix 6. Expansion into frontiers - a theoretical model of impacts to biodiversity -}

\section{Suitable oil palm lands}

Classification of land as suitable for oil palm was based on the Global Agro-Ecological Zones (GAEZ) database produced by the Food and Agriculture Organisation of the United Nations (FAO). This acted as a basis for a 'potential future oil palm' spatial layer which integrated soils and slope data for rain-fed conditions and commercial production systems, and discounted land likely to be unavailable for future oil palm expansion, such as urban areas, existing oil palm and other croplands, and protected areas. We recognize that this approach does not consider other factors that determine oil palm suitability: distance to markets, infrastructure, labour availability, access to finance, regulation, etc.

Crop suitability index (SI) reflects suitability levels and distributions within grid cells by classes based on SI values between 0 and 100. This dataset is the result of the calculation procedures of GAEZ Module $\mathrm{V}$ (Integration of climatic and edaphic evaluation) which executes the final step in the GAEZ crop suitability and land productivity assessment. It reads the land utilisation type (LUT) specific results of the agro-climatic evaluation for biomass and yield calculated in Module II/III for different soil classes and it uses the edaphic rating produced for each soil/slope combination in Module IV. The inventories of soil resources and terrain-slope conditions are integrated by ranking all soil types in each soil map unit with regard to occurrence in different slope classes. Considering simultaneously the slope class distribution of all grid cells belonging to a particular soil map unit results in an overall consistent distribution of soil-terrain slope combinations by individual soil association map units and 30 arc-sec grid cells, soil and slope rules are applied separately for rain-fed and irrigated conditions. A detailed description on structure and overview of GAEZ procedures in the GAEZ v.3.0 Global Agro Ecological
Zones - Model Documentation at http://typo3.fao. org/fileadmin/user_upload/gaez/docs/GAEZ_Model_ Documentation.pdf

For the purpose of this analysis, the following model parameters and assumptions were applied to the GAEZ product:

- Crop: oil palm

- Water supply: rain-fed

- Input level: high input level; focus on market oriented farming systems (commercial production). Production assumed to be based on improved or high yielding varieties, is fully mechanised with low labour intensity and uses optimum applications of nutrients and chemical pest, disease and weed control (FAO/IIASA, 2011-2012).

- Time: future period 2020s

- Scenario: CCCma CGCM2 B2

- $\mathrm{CO} 2$ Fertilization: without co2 fertilization

We consider oil palm suitable land to include 'Good' (class 6), 'High' (class 7) and 'Very High' (class 8) suitability categories. We exclude land use classes of 'Urban' and 'Cultivated land' based on ESA, 2010 (http://due.esrin.esa.int/page_globcover.php), and 'Protected Areas' based on World Database on Protected Areas (https://www.iucn.org/theme/ protected-areas/our-work/quality-and-effectiveness/ world-database-protected-areas-wdpa). We also excluded current oil palm planted areas (see Section 1.3.2).

This analysis does not consider socio-economic factors such as transport costs, labour availability, tenure systems and customary land ownership.

\section{Key Biodiversity Areas}

Data on Key Biodiversity Areas are based on the 
World Database on Key Biodiversity Areas (http:// www.keybiodiversityareas.org/home).

\section{Biodiversity hotspots}

Data on biodiversity hotspots are based on the Critical Ecosystem Partnership Fund (http://www. cepf.net/resources/hotspots/Pages/default.aspx).

\section{Threatened species}

Threatened species include species classified as Vulnerable (VU), Endangered (EN) or Critically Endangered (CR) based on the IUCN Red List of Threatened Species (http://www.iucnredlist.org/).

\section{Spatial analysis}

We overlaid the oil palm suitability layer with the threatened species layer, as well as with the biodiversity hotspot and KBA layers.

The analysis was based on the assumption that areas with high concentrations of threatened species of amphibians, birds and mammals are biologically valuable habitats. We did not consider land cover in our analysis.
The number of threatened species is just one convenient indicator of potential biodiversity impacts of oil palm expansion. We acknowledge arguments that this may be an oversimplification (e.g., 511) However, due to the global nature of this analysis, species richness was the most practical and spatially consistent option.

This analysis necessarily incorporated the inherent assumptions of the source data on which it was based. For example, the oil palm suitability layer was based on the GAEZ product, and incorporated its climate change scenario assumptions.

As a result of the above assumptions of the oil palm suitability dataset, the area estimated as available for oil palm expansion outside of KBAs, biodiversity hotspots and the ranges of threatened species (mammals, amphibians and birds) may be an overestimation.

Base map source (511): Esri, HERE, DeLorme, MapmyIndia, ( ) OpenStreetMap contributors, and then GIS user community. 


IUCN

INTERNATIONAL UNION

FOR CONSERVATION OF NATURE

WORLD HEADQUARTERS

Rue Mauverney 28

1196 Gland, Switzerland

mail@iucn.org

Tel +41229990000

Fax +41229990002

www.iucn.org 